\title{
5. RESULTS OF NUMERICAL EXPERIMENTS
}

For brevity all model results in this report will be taken from the solutions on the 5-km inner domain, which is the domain of primary interest. In most cases, statistics from coarser domains tend to be similar but somewhat smoother compared to those of the finest domain, when identical regions are compared. That type of inter-domain comparison is not presented here.

\subsection{Experiment 1: Control Experiment}

The Control Exp. used MM5 without the benefit of FDDA and is not expected to be accurate enough for use as the source of meteorological inputs for air-quality model applications. Its primary purpose is to reveal whether any aspects of the prognostic model simulation procedure, such as the initial and lateral boundary conditions, are seriously flawed and lead to large numerical errors. Thus, it serves as a preliminary diagnosis to determine how important the FDDA may be in the final numerical model solutions generated in subsequent experiments. Ideally, it is desirable that the control experiment be reasonably accurate, so that the dataassimilation terms remain small and the model solutions are continuously dominated by the natural physical and dynamical terms of the primitive equations. Examination of the results from this experiment and Experiment 2 (analysis nudging) in Sec. 5.1 allow identification of the most serious problems that may be associated with the numerical simulations of the 21-24 September 1997 SCOS episode. Once identified, it is then possible to design the most effective corrective approaches to attack specific problems. Some corrective procedures may be undertaken without recourse to FDDA, such as changes to the model's initial land-surface specifications or other parameters for which there may be insufficient observational information.

In this section, we will limit the model evaluation to a brief examination of statistical performance that will give a general idea of the simulation accuracy in the Control Experiment. Evaluations of the other experiments, presented in following sections, will include both statistical and visual examinations of model fields, as appropriate.

To begin the evaluations, Figures 28 presents the hour- by-hour evolution of domain-averaged surface-layer temperature in Exp. 1. The figure indicates that the model solution in the Control Exp. is consistently too cool at the surface by an average of $\sim 2-4 \mathrm{C}$, compared to the observations. The errors tend to be greatest in the late afternoon (about 2200 UTC) near the time of maximum heating and are smallest near sunrise (about 1300 UTC). Also, notice that Figure 28 reveals that both the model and observations show a steady trend toward warmer temperatures through the study period, especially over the final two days. This trend is consistent with the weakening of the sea breeze (and its cold advection of marine air) and the growth of easterly (offshore-directed) winds associated with the passage of the upper-level ridge near the middle of the period. The approach of the tropical cyclone during the latter half of the period helps account for the more significant rise of temperature during that phase of the episode. Easterly winds favor advection of hot air from the interior deserts into the LA Basin and other coastal regions, where most of the observing sites are located. Thus, even though temperatures in the desert do not change much through the episode, the coastal regions experience warming of $\sim 4 \mathrm{C}$ on average by the end of the period. Further statistical analysis of the model errors showed 
PLOT OF TEMP (C) VS. TIME, EXPNAM= SCOS97 5KM CNTL HRLYAVG

LAYER = sfc layer (40m) AGL, DOMAIN = $5 \mathrm{~km}$

DATE/TIME RANGE = 21 SEP 1997, 0000Z-24 SEP 1997, 23007 MODEL HOUR RANGE $=0.0-95.0 \mathrm{~h}$

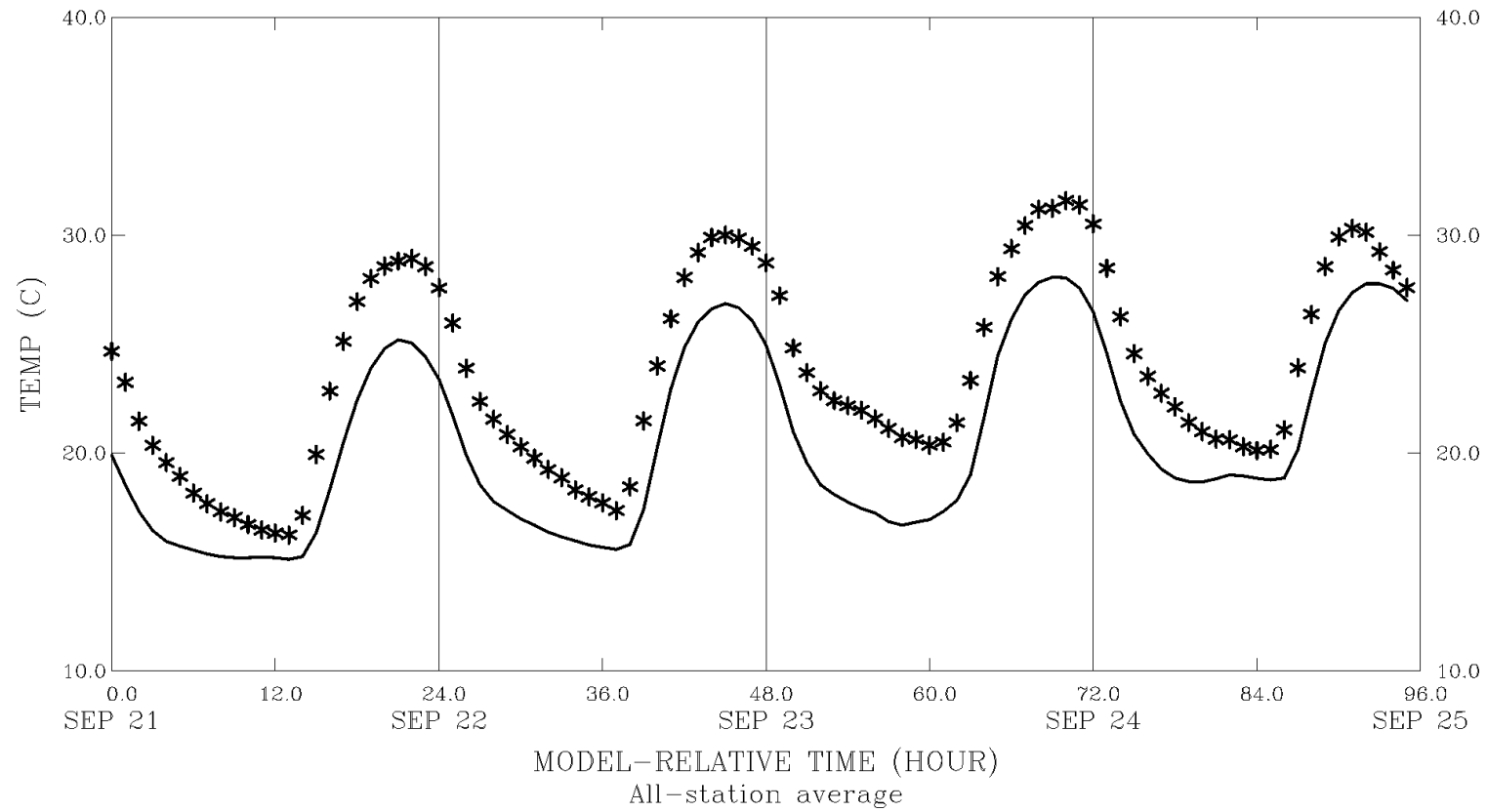

Figure 28. Evolution of domain-averaged surface-layer temperature (C) at $12 \mathrm{~m}$ AGL on the 5-km MM5 domain in the Control Experiment (Exp. 1) for 21-24 September 1997. Times shown on abscissa are forecast hours from the initial time, 0000 UTC, 21 September. Solid line is model-simulated mean, asterisks are hourly observed means. 
that Experiment 1 produced a case mean error for surface-layer temperatures of $-2.94 \mathrm{C}$ and a mean absolute error of $3.86 \mathrm{C}$ (Table 7). These errors are quite large compared to standard errors often deemed acceptable for air-quality applications ( $M E \leq 0.5 C$ and $M A E \leq 2.0 C$ ). Thus, thermal fields from Exp. 1 would be unacceptable without efforts to reduce existing errors.

Next, Figure 29 indicates that there is no large diurnal cycle in the domain-averaged surfacelayer mixing ratios, for either observations or the model solutions. The lack of a diurnal cycle is likely due to the dominance of observations in the regions directly affected by advection of moderately moist air from the ocean. However, the figure shows significant moistening in the surface mixing ratio during the last $12 \mathrm{~h}$ of the period, beginning $1200 \mathrm{UTC}, 24$ September. This moistening coincides with the arrival of tropical air from the south as the cyclone approaches the SoCAB. Also note that the greatest errors in surface mixing ratio $\left(\sim+3 \mathrm{~g} \mathrm{~kg}^{-1}\right)$ are at the initial time, when coarse-resolution NCEP global analyses are used to generate the MM5's initial conditions. Even without FDDA, the MM5 Control Exp. corrects for the excessively moist initial conditions during the first $12-18 \mathrm{~h}$, so that errors are considerably less through the rest of the simulation period. Overall, Table 7 shows that the mean error for the surface mixing ratio in the Control Exp. is only $+0.24 \mathrm{~g} \mathrm{~kg}^{-1}$, while the mean absolute error is $1.92 \mathrm{~g} \mathrm{~kg}^{-1}$.

Except perhaps for the boundary layer depth, the fields of greatest interest in air-quality related studies are generally the wind speed and direction. Without radiosonde temperature and moisture profiles during the daytime, it is difficult to obtain accurate measurements of the true convective boundary layer depth with which to validate model estimates. However, up to 27 radar wind profilers were operating during the SCOS-97 study, so it is possible to evaluate the accuracy of the wind fields both at the surface and aloft in considerable detail. Figures 30 and 31 present the hourly domain-averaged wind speed in the surface layer (12 m AGL) and in the region from 25 - $1500 \mathrm{~m}$ AGL for the Control Exp. This elevated layer is defined to encompass most of the region of prime interest for tracking pollutants, even though there are obvious difficulties in trying to define an arbitrary domain-wide layer to do so. In the LA-Basin and coastal regions, this zone includes the marine boundary layer, the convective boundary layer over land, and the stable zone aloft where most of the return offshore-directed circulation occurs. Farther inland, the daytime convective boundary layer over the deserts is expected to extend to 2500-3000 m AGL, but the region between 25-1500 m should be fairly representative of winds throughout the boundary layer because of its well-mixed character.

Figure 30 shows that observed winds in the surface layer (12 $\mathrm{m}$ AGL) tend to average between $\sim 2.5 \mathrm{~ms}^{-1}$ during the night to $\sim 3.5 \mathrm{~ms}^{-1}$ during the late afternoon. The figure also shows that the MM5 tends to predict wind speeds in Exp. 1 that are similar overall to the data, but the diurnal cycle of the speeds is not as clearly defined. There does tend to be a daily maximum near 0000 UTC in the model solutions, but it is generally a bit weaker than observed. Unexpectedly, on 23 September, the model simulates the highest average surface-layer speeds during the early morning at 1400 UTC (0700 PDT), although the observations do not confirm this event. A somewhat similar "unusual" peak occurs in the model on 24 September near 1800 UTC (1100 PDT). Further investigation revealed that these model winds are related to events occurring aloft. As might be expected, both the observed and model-simulated winds above the surface in the 25-1500 m layer are in general faster $\left(\sim 3-8 \mathrm{~ms}^{-1}\right)$ and have a greater diurnal range (Figure 31). The model follows the typical cycle in the boundary-layer and recirculation-layer winds 
Table 7. Statistical evaluation for Exp. 1 (Control Experiment) for the SCOS-97 episode of 21-24 September 1997. Statistics shown are mean errors (ME), mean absolute errors (MAE) and root mean square errors (RMS). Above the surface, statistics from individual MM5 calculation levels are merged into composite layers as weighted averages for the approximate boundary layer $(25-1500 \mathrm{~m})$, lower troposphere $(1500-5000 \mathrm{~m})$ and upper troposphere $(5000-10500 \mathrm{~m})^{*}$.

\begin{tabular}{|c|c|c|c|c|c|c|c|c|c|c|c|c|}
\hline \multirow[t]{2}{*}{$\begin{array}{c}\text { Verification } \\
\text { Layer (AGL) }\end{array}$} & \multicolumn{3}{|c|}{$\begin{array}{l}\text { Temperature } \\
\text { (C) }\end{array}$} & \multicolumn{3}{|c|}{$\begin{array}{c}\text { Mixing Ratio } \\
\text { (g/kg) }\end{array}$} & \multicolumn{3}{|c|}{$\begin{array}{c}\text { Wind Speed } \\
(\mathrm{m} / \mathrm{s})\end{array}$} & \multicolumn{3}{|c|}{$\begin{array}{l}\text { Wind Direct. } \\
\text { (degrees) }\end{array}$} \\
\hline & ME & MAE & RMS & ME & MAE & RMS & ME & MAE & RMS & ME & MAE & RMS \\
\hline $5000-10500 \mathrm{~m}$ & - & - & - & -- & -- & - & -2.92 & 3.17 & 3.17 & +24.8 & 35.0 & 35.0 \\
\hline $1500-5000 \mathrm{~m}$ & -- & -- & -- & -- & -- & -- & -1.90 & 2.83 & 3.29 & -15.8 & 37.9 & 44.4 \\
\hline $25-1500 \mathrm{~m}$ & -- & -- & -- & -- & -- & -- & +0.82 & 2.42 & 3.08 & -5.64 & 46.4 & 59.7 \\
\hline $12 \mathrm{~m} \mathrm{AGL}$ & -2.94 & 3.86 & 4.60 & +0.24 & 1.92 & 2.46 & +0.15 & 1.59 & 2.11 & -3.87 & 58.4 & 75.2 \\
\hline
\end{tabular}

* Note that no statistics appear for the temperature and mixing ratio above the surface because the 5-km model domain did not have supplemental upper-air measurement systems during SCOS-97 capable of taking observations for these variables more often than twice per day. Winds aloft are obtained from up to 27 radar wind profilers operated during the study period. 


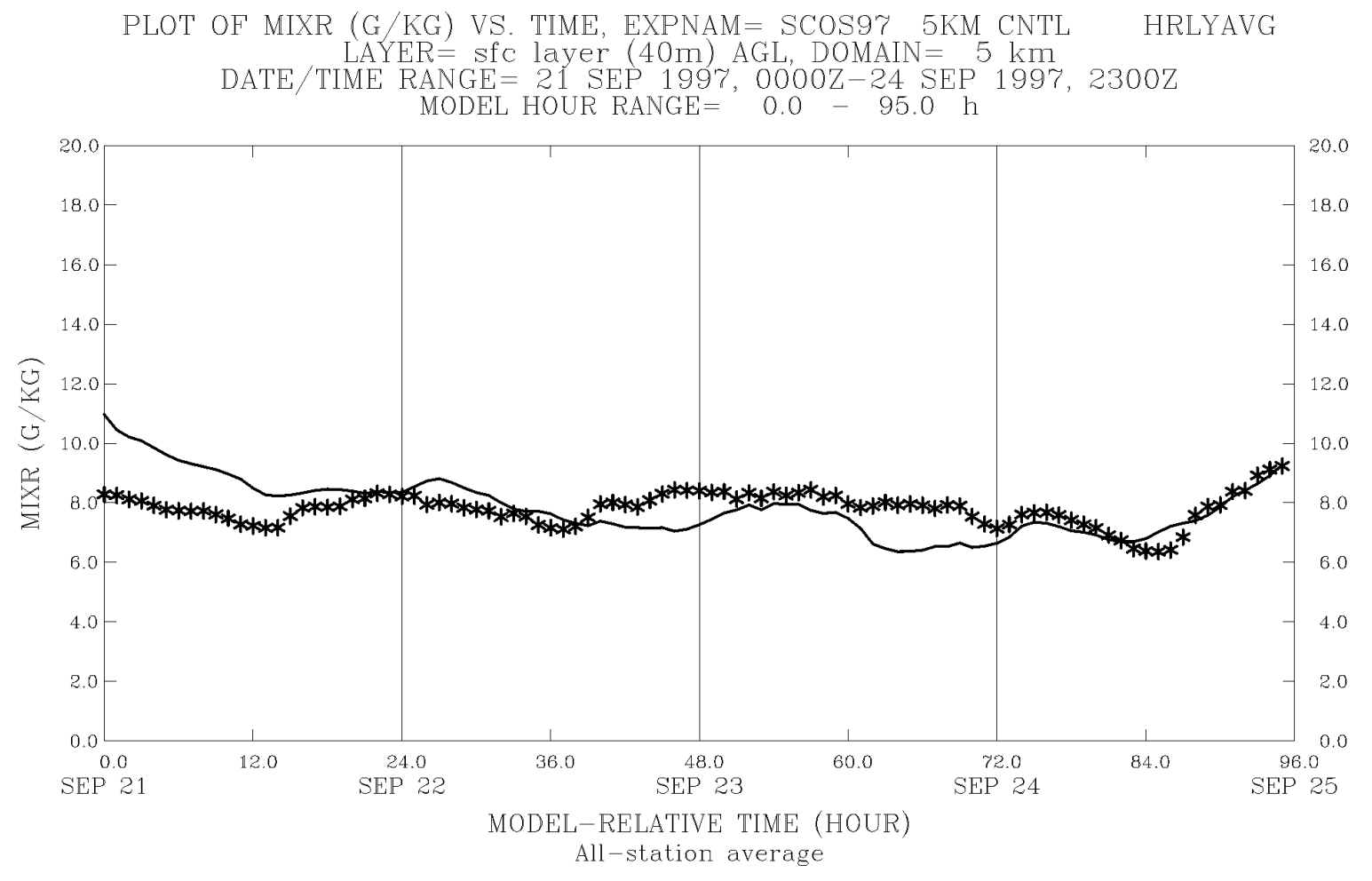

Figure 29. Evolution of domain-averaged surface-layer mixing ratio $\left(\mathrm{g} \mathrm{kg}^{-1}\right)$ at $12 \mathrm{~m} \mathrm{AGL} \mathrm{on}$ the 5-km MM5 domain in the Control Experiment (Exp. 1) for 21-24 September 1997. Times shown on abscissa are forecast hours from the initial time, 0000 UTC, 21 September. Solid line is model-simulated mean, asterisks are hourly observed means. 


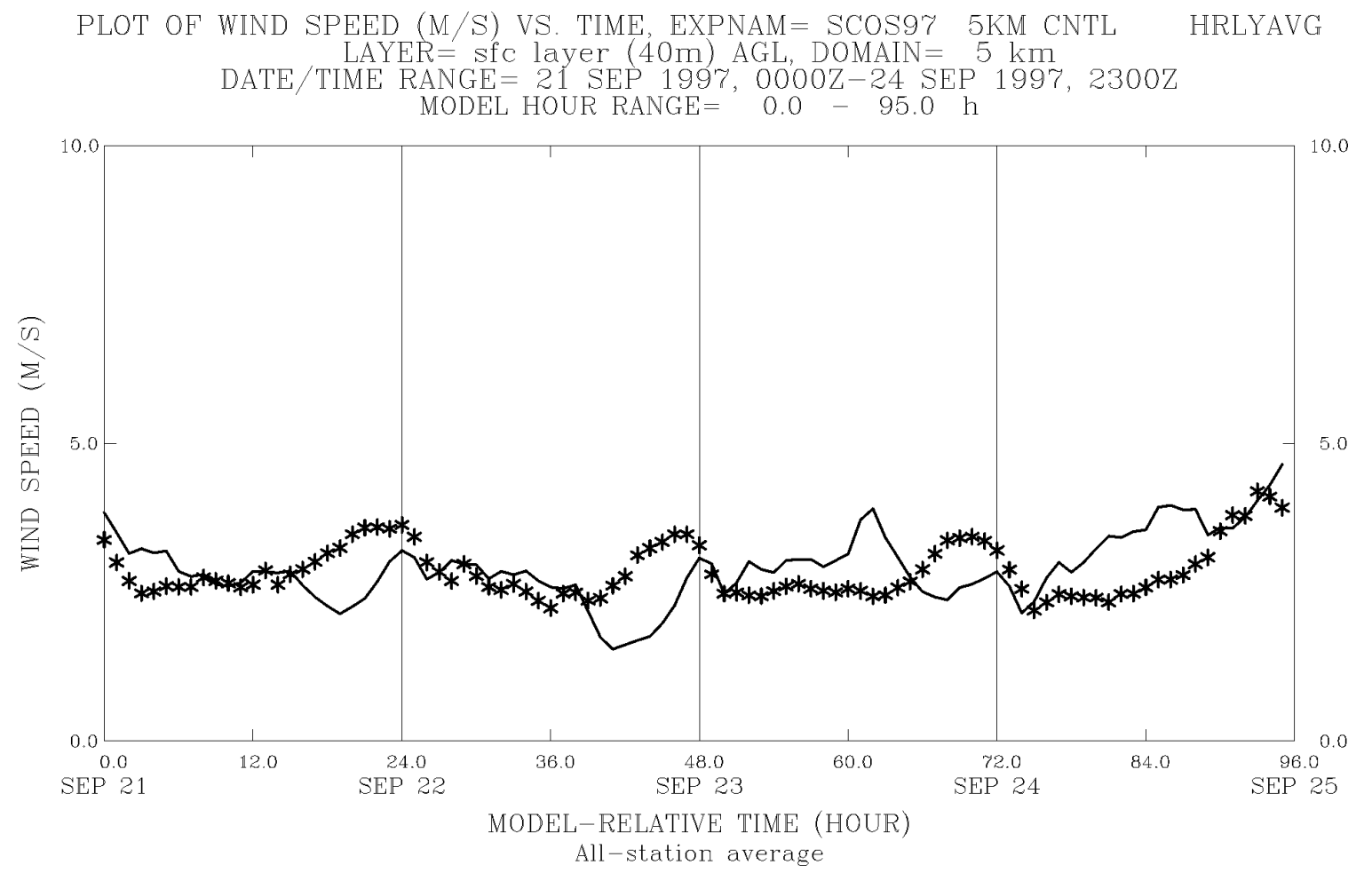

Figure 30. Evolution of domain-averaged surface-layer wind speed $\left(\mathrm{ms}^{-1}\right)$ at $12 \mathrm{~m} \mathrm{AGL} \mathrm{on}$ the 5-km MM5 domain in the Control Experiment (Exp. 1) for 21-24 September 1997. Times shown on abscissa are forecast hours from the initial time, 0000 UTC, 21 September. Solid line is model-simulated mean, asterisks are hourly observed means. 
PLOT OF WIND SPEED (M/S) VS. TIME, EXPNAM= SCOS97 5KM CNTL HRLYAVG

LAYER $=80-1500 \mathrm{~m}$ AGL, DOMAIN $=5 \mathrm{~km}$

DATE/TIME RANGE=21 SEP 1997, 0000Z-24, SEP 1997, 2300Z

MODEL HOUR RANGE $=0.0-95.0 \mathrm{~h}$

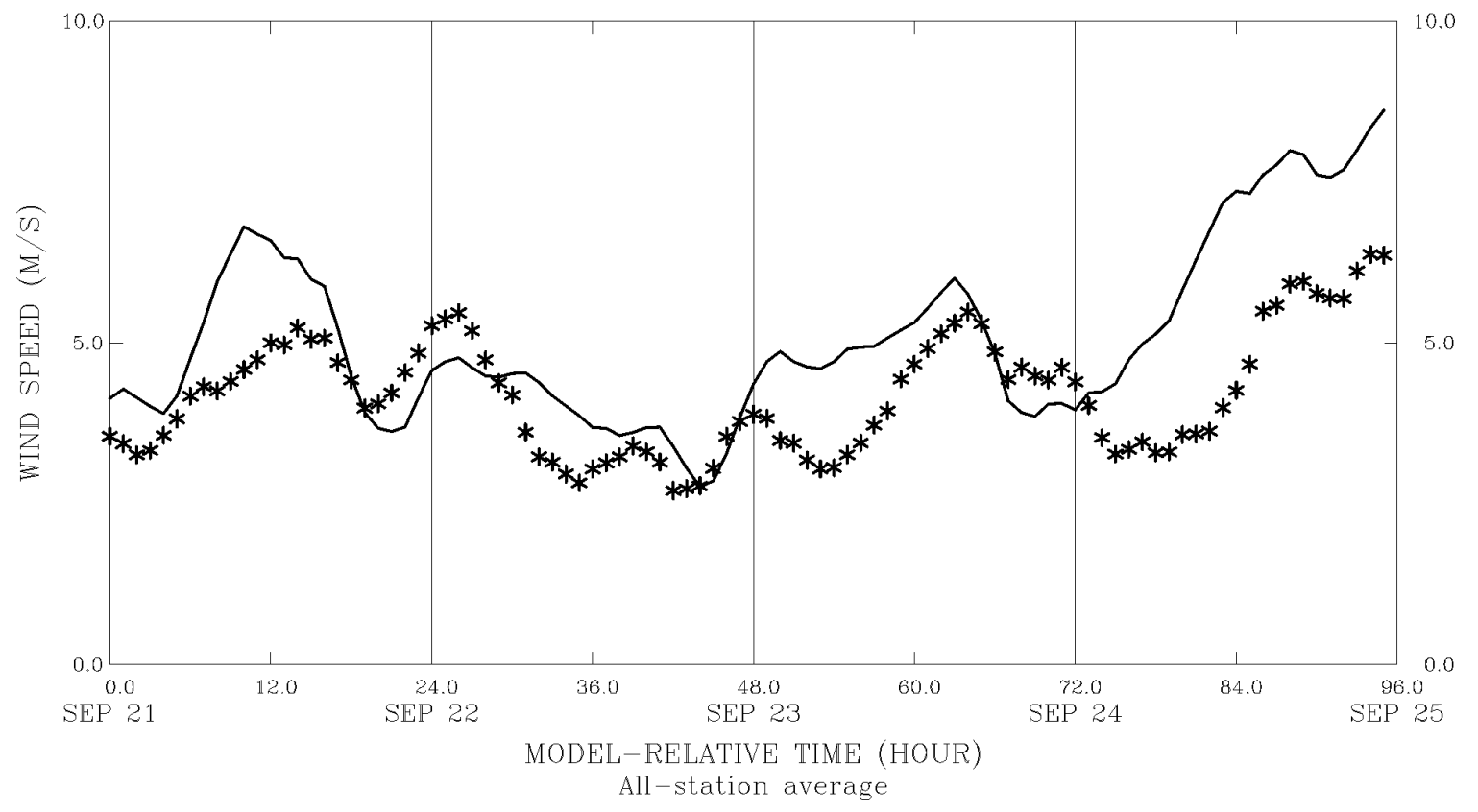

Figure 31. Evolution of domain-averaged wind speed $\left(\mathrm{ms}^{-1}\right)$ in the layers from $25-1500 \mathrm{~m}$ AGL on the 5-km MM5 domain in the Control Experiment (Exp. 1) for 21-24 September 1997. Times shown on abscissa are forecast hours from the initial time, 0000 UTC, 21 September. Solid line is model-simulated mean, asterisks are hourly observed means. 
reasonably well, producing minimums and maximums at nearly the right times throughout the episode. Closer examination of the observed winds averaged through these layers indicates that maximums occurred on each day near 1500-1700 UTC, with another series of maximums near 0000-0200 UTC. The maximums near 0000 UTC are clearly associated with the maximum in the thermodynamically driven sea breeze. The late-morning maximums are more difficult to understand, since they are out of phase with sea-breeze and low-level jet phenomena. On each day, Figure 31 indicates that the model also predicted peak winds at about the same times. So, the corresponding peak winds found in Figure 30 at the surface on 23 and 24 September are caused by mixing of momentum down to the surface more vigorously than occurred in the natural system. However, since most of the actual ozone transport occurs in the mixed layer above the surface layer, this flaw in the model-simulated surface wind field does not represent a serious problem. Also note that both Figures 30 and 31 indicate the greatest wind speeds $(\sim 5$ $\mathrm{ms}^{-1}$ at the surface and $\sim 8.5 \mathrm{~ms}^{-1}$ aloft) occur at the end of the episode due to the approach of the tropical cyclone.

A statistical summary for wind speed errors in the Control Exp. is given in Table 7 from the surface upward through the full troposphere. The mean error in the surface layer is only +0.15 $\mathrm{ms}^{-1}$, while the RMS error is $2.11 \mathrm{~ms}^{-1}$. Considering that this is a Control Exp. without the assistance of FDDA, the surface-layer wind speed statistics compare rather well with widely accepted standards for FDDA-assisted model wind fields used for air-quality studies ( $M E \leq 0.5 \mathrm{~ms}^{-1}$ and $R M S \leq 2.0 \mathrm{~ms}^{-1}$ ). In the 1500-m layer encompassing the boundary layer and recirculation layer, mean errors in Exp. 1 rise to $+0.82 \mathrm{~ms}^{-1}$ and the RMS error becomes 3.08 $\mathrm{ms}^{-1}$. The table also shows that mean errors continue to grow with height as the wind speeds gradually increase up to $10 \mathrm{~km}$ AGL, but the RMS error in this case remains near $3 \mathrm{~ms}^{-1}$ throughout the troposphere.

The final information provided here for the Control Exp. is for wind direction. Figure 32 shows the evolution of hourly domain-averaged wind directions through the episode in the surface layer. There is a strong diurnal signal in the direction, as expected. Winds in late afternoon at 0000 UTC are normally from the west-southwest ( 250 degrees) when the sea breeze is most intense and then shift to mostly southeasterly ( 140 degrees) by morning at 1200 UTC, when the land breeze and mountain (drainage) flows are dominant. This pattern is most evident on 21-22 September. During the second half of the episode, the afternoon wind directions gradually become less westerly as the tropical cyclone begins to influence the SoCAB, so that by 0000 UTC, 25 September, the domain-averaged direction is 200 degrees. However, as shown in Figure 26, there are very few wind observations at that time actually having directions close to 200 degrees. In fact, most are close to southeasterly ( 135 degrees), with some coastal winds persisting from west to northwesterly (270-315 degrees). Therefore, the domain-wide statistical average is somewhat misleading at this time. Examination of the model-simulated domainaveraged surface-layer winds in Figure 32 shows that the model responds reasonably well to the influences of diurnal forcing on the wind directions. It also captures the trend shifting to more southeasterly winds toward the end of the episode. In general, the greatest direction errors occur in the early morning hours near 1200 UTC, when the wind speeds are very light and variable. The statistics shown in Table 7 reveal that the average mean error at the surface for the entire episode is only -4 degrees. However, the RMS error is $\sim 75$ degrees, primarily because of the very light wind speeds in this case. Also, many wind observations occurring in very close 
PLOT OF WIND DIRECTION (DEG) VS. TIME, EXPNAM= SCOS97 5KM CNTL HRLYAVG

LAYER= sfe layer (40m) AGL, DOMAIN = $5 \mathrm{~km}$

DATE/TIME RANGE= 21 SEP 1997, 0000Z-24 SEP 1997, $2300 Z$ MODEL HOUR RANGE $=0.0-95.0 \mathrm{~h}$

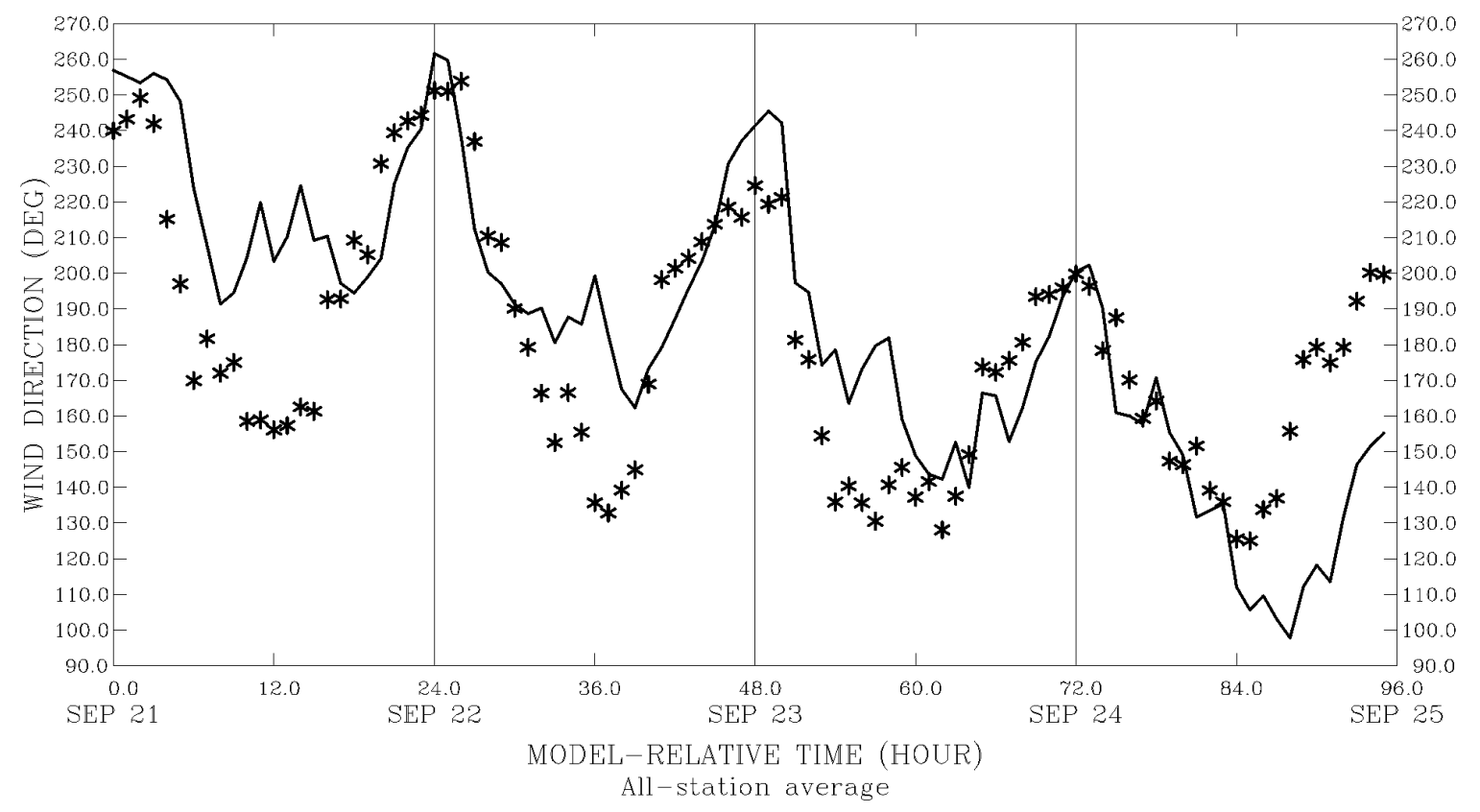

Figure 32. Evolution of domain-averaged surface-layer wind direction (deg.) at $12 \mathrm{~m} \mathrm{AGL}$ on the 5-km MM5 domain in the Control Experiment (Exp. 1) for 21-24 September 1997. Times shown on abscissa are forecast hours from the initial time, 0000 UTC, 21 September. Solid line is model-simulated mean, asterisks are hourly observed means. 
proximity often show very different directions at the same hour due to sub-grid-scale terrain forcing, buildings, trees and other vegetation, etc.. Thus, the SoCAB is a region prone to particularly difficult conditions for a model when winds are light.

Above the surface, between 25-1500 m AGL, Figure 33 indicates that the diurnal pattern in the wind is even more extreme, but smoother. The comparatively smooth evolution of wind direction in these levels is likely due to the gradually decreasing influence with height of trees, buildings, small hills and other microscale features of the surface topography. The close similarity between the modeled and observed directions, averaged over all model layers in this height zone, is evident immediately. However, closer inspection also shows that the asterisks (indicating observations) consistently lie above the solid curve (model solution). This means that the model is consistently producing wind directions that are rotated counter-clockwise (cyclonic) relative to the data. Table 7 quantifies this trend as a mean directional error of $\sim-6$ degrees between $25-1500 \mathrm{~m}$ AGL. Meanwhile, RMS error for direction in this layer is $\sim 60$ degrees, which is moderately less than at the surface. Farther aloft, the table indicates that RMS errors in Exp. 1 continue to decrease with height, while mean errors become much larger.

In summary for Exp. 1, the Control, wind speeds were simulated fairly well, with rather large RMS direction errors, especially during periods of light wind speeds. The domain-averaged mean wind directions, however, were in error by only 4-6 degrees in the lower parts of the atmosphere and captured the diurnal cycle rather well. Temperatures were consistently too cool by 2-4 C, but mixing ratio errors were generally small. Thus, overall, the Control Exp. was mostly successful because there were no major errors that would suggest serious deficiencies in the model initial conditions, physics or dynamics. However, the surface temperature errors suggest that the specification of one or more key parameters for the lower boundary could be deficient. Before proceeding to change any of the surface parameters, a preliminary dataassimilation experiment (Exp. 2) was conducted with only analysis nudging to further evaluate the significance of the results from the Control Experiment. 
PLOT OF WIND DIRECTION (DEG) VS. TIME, EXPNAM= SCOS9Y 5KM CNTL HRLYAVG LAYER $=80-1500 \mathrm{~m}$ AGL, DOMAIN $=5 \mathrm{~km}$

DATE/TIME RANGE=21 SEP 1997, 0000Z-24 SEP 1997, $2300 Z$ MODEL HOUR RANGE $=0.0-95.0 \mathrm{~h}$

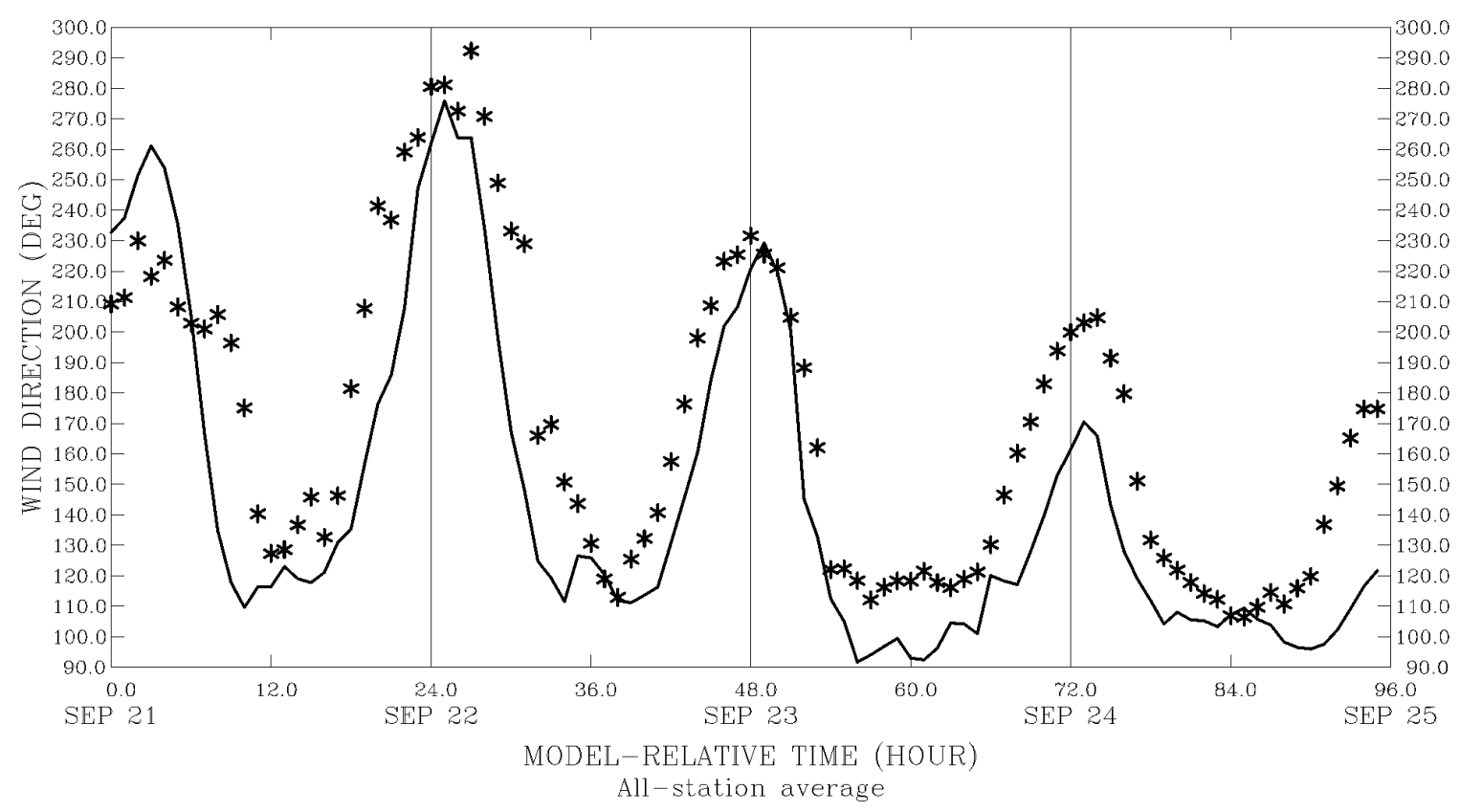

Figure 33. Evolution of domain-averaged wind direction (deg.) in the layers from 25-1500 m AGL on the 5-km MM5 domain in the Control Experiment (Exp. 1) for 21-24 September 1997. Times shown on abscissa are forecast hours from the initial time, 0000 UTC, 21 September. Solid line is model-simulated mean, asterisks are hourly observed means. 


\subsection{Experiment 2: Analysis Nudging with Standard Land/Sea Temperatures}

Examination of results from the Analysis-Nudging Exp. (Exp. 2) will begin with visual inspections of selected variable fields that describe the evolution of the model solutions. The majority of the visual fields shown in this report will be drawn from this experiment because they are representative of nearly all the experiments, due to the rather good performance of the MM5 in the Control Exp. discussed in Sec. 5.1. Therefore, variations among the experiments can best be discussed in terms of the statistical analyses of the results. Additional visual plots for the other experiments will be added as necessary to demonstrate specific changes related to the experiment design.

First, Figure 34 shows the surface-layer wind field at the initial time, 0000 UTC, 21 September 1997. Because all initial fields on the $5-\mathrm{km}$ domain are interpolated from the coarse-grid initialization performed on the $45-\mathrm{km}$ outermost domain, the winds shown in the figure are naturally quite smooth and lack the fine-scale detail associated with terrain and coastal forcing. However, they do contain the climatological northwesterly flow expected in the marine layer over the CA Bight and the westerly to southwesterly sea-breeze flow of $\sim 4 \mathrm{~ms}^{-1}$ over land in the coastal regions of the SoCAB. Farther inland over CA, the flow is northeasterly $\sim 2-3 \mathrm{~ms}^{-1}$ in the San Joaquin Valley and is mostly from the southwest at less than $2 \mathrm{~ms}^{-1}$ over the interior deserts.

In addition to plots of prognostic variable fields at the surface and on constant pressure levels aloft, the vertical structure in the solutions was examined along several convenient cross sections. Figures 35 and 36 show the locations of two cross sections that were of particular value, along with contours indicating the major terrain features in the domain. Figure 37 shows the initial vertical profile of potential temperature at 0000 UTC, 21 September along the northsouth cross section through Pt. Dume west of Los Angeles (Figure 35). This cross section lies well upstream (west) of the SoCAB and is oriented more or less perpendicular to the dominant low-level wind direction over the CA Bight. Aloft, it is roughly parallel to the dominant northerly upper-level flow during the first half of the episode (see Section 4). The shallow marine boundary layer in Figure 37 is capped by a strongly stable coastal inversion that slopes downward toward the shoreline. This shallow coastal marine layer is typical for CA Bight and Santa Barbara Channel in summer. Close to the coast, surface temperatures drop to $\sim 13 \mathrm{C}$ due to upwelling of deep ocean water caused by the prevailing winds. North of the Santa Inez and San Rafael Mountains in Figure 37, the boundary layer over the inland valleys is nearly $2000 \mathrm{~m}$ deep and much warmer $(\sim 33 \mathrm{C})$. On the south side of the mountain ranges, the marine air is advected over land where it warms rapidly. However, the stable mid-level inversion prevents the boundary layer from deepening significantly south of the San Rafael ridge. Figure $\mathbf{3 8}$ shows the corresponding initial north-south field of cloud liquid water, which indicates broken stratus and coastal fog with less than $0.5 \mathrm{~g} \mathrm{~kg}^{-1}$ of water content. Meanwhile, Figure 39 shows the east-west cross section of potential temperature just north of San Diego, which reflects much of the same structure as found in Figure 37. This second cross section better represents the southern air basins close to the Mexican border and the inland desert regions of southeastern CA. The figure shows that coastal temperatures are slightly warmer here ( 14 C) than near Pt. Dume due to the milder sea temperatures at this more southerly latitude. In Exps. 1 and 2, these initial 


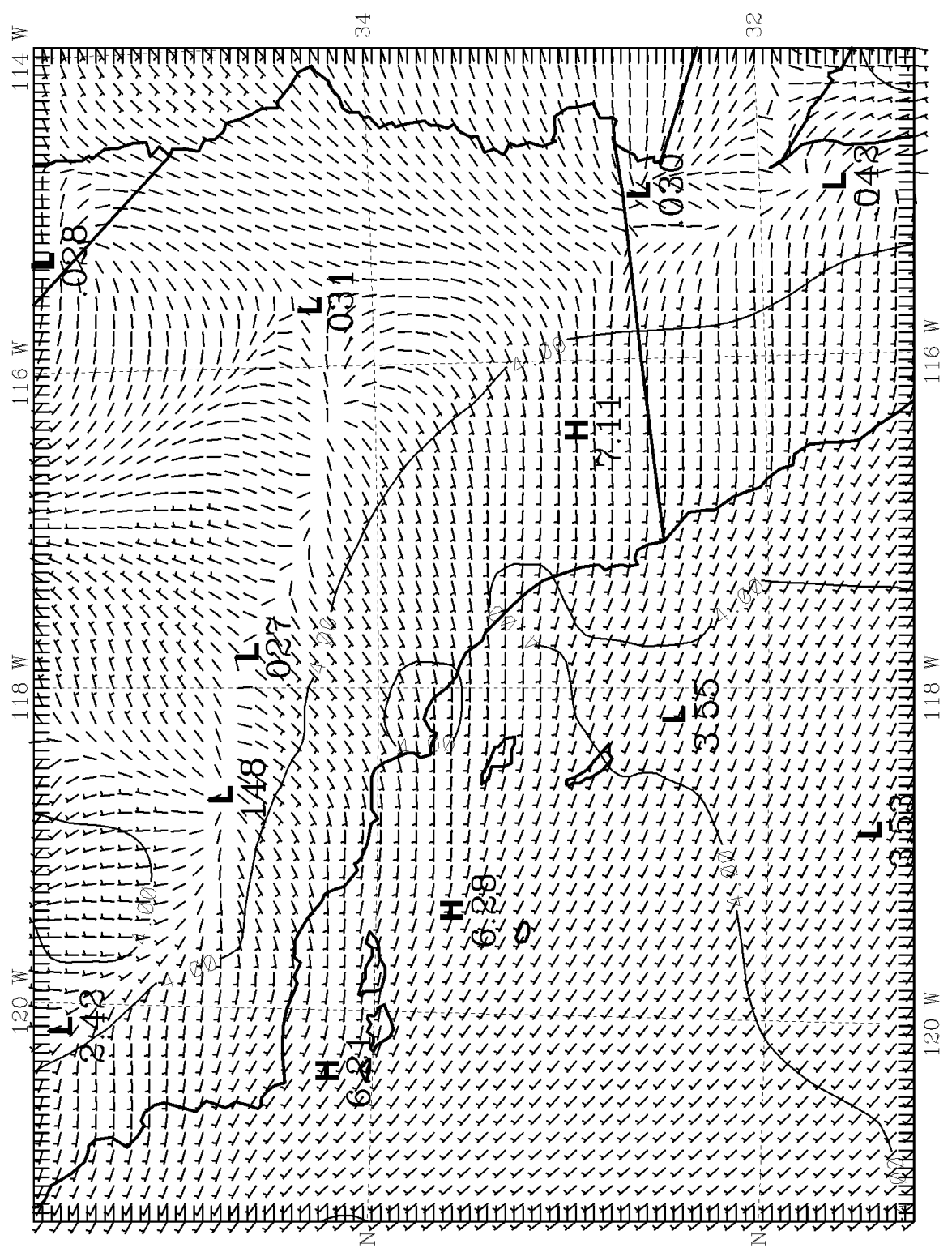




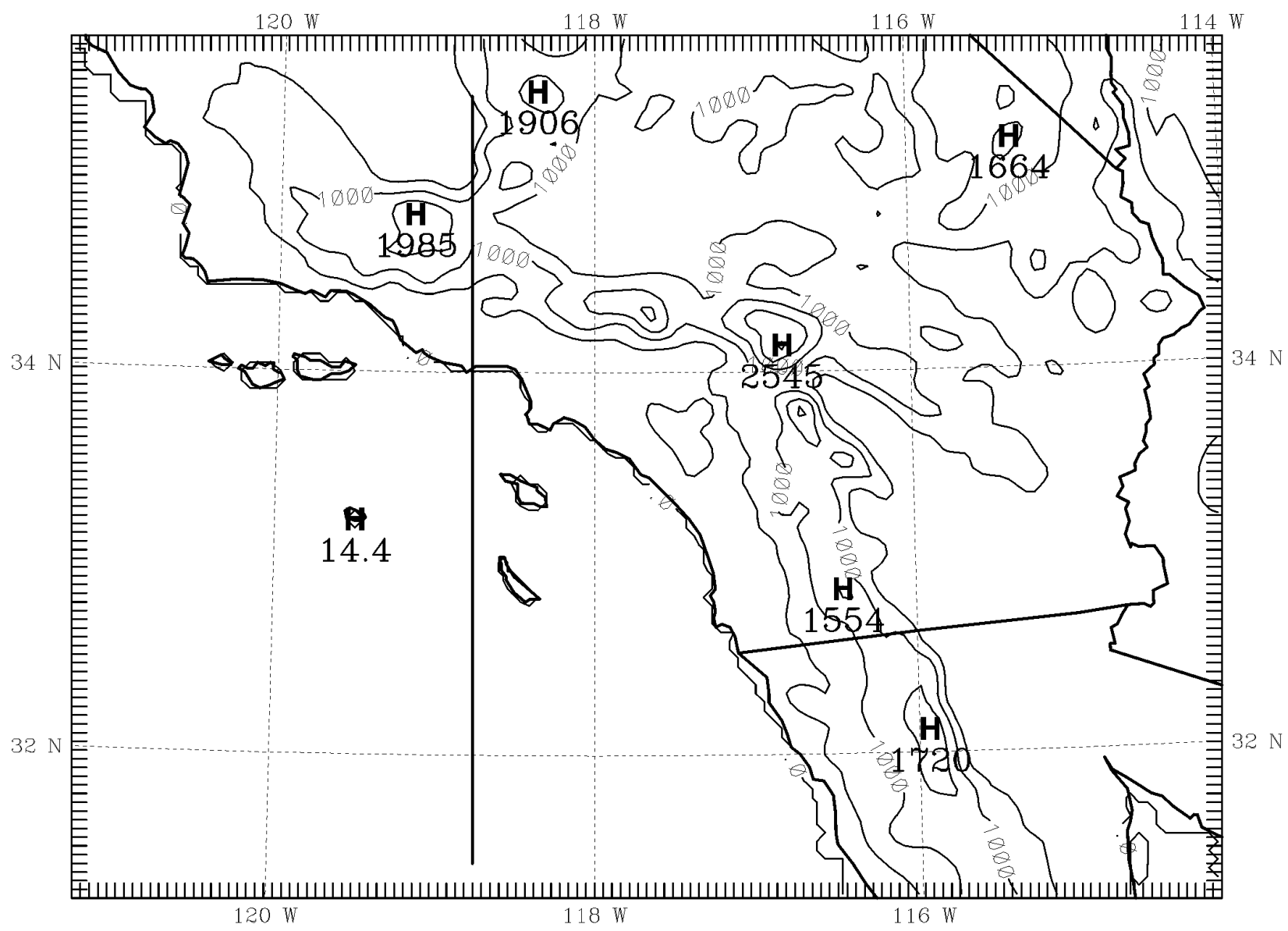

SCOS97 WITH PSU MODS $5 \mathrm{~km}$

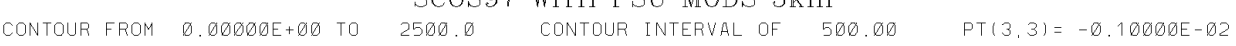

Figure 35. Terrain $(\mathrm{m})$ on the 5-km domain showing location of north-south cross section through Pt. Dume (bold line). Contour interval is $500 \mathrm{~m}$. 


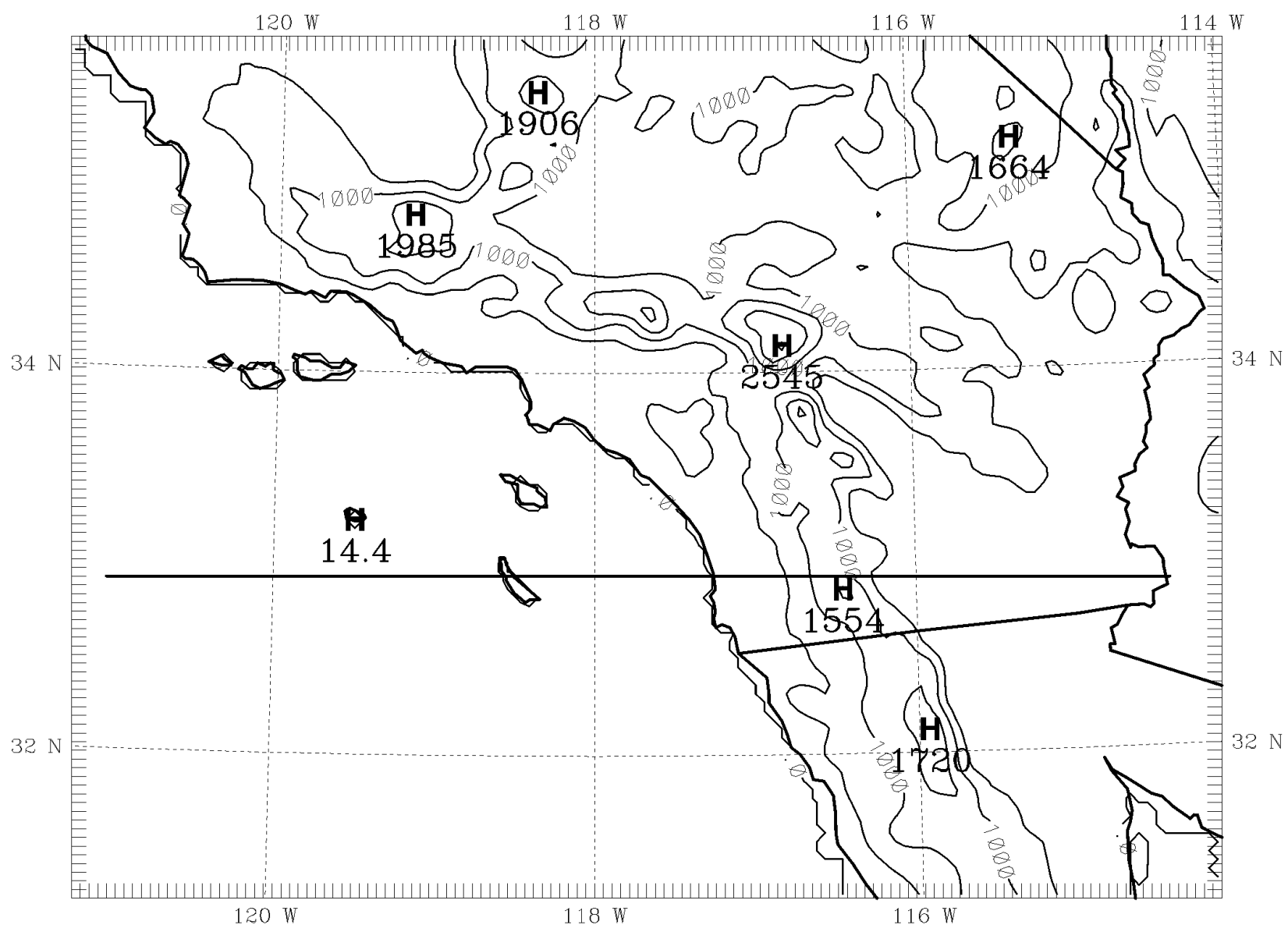

SCOS97 WITH PSU MODS $5 \mathrm{~km}$

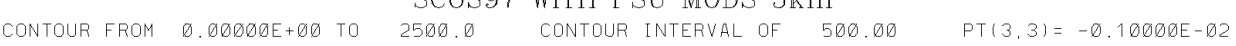

Figure 36. Terrain $(\mathrm{m})$ on the 5-km domain showing location of east-west cross section through San Clemente Island and just north of San Diego (bold line). Contour interval is $500 \mathrm{~m}$. 


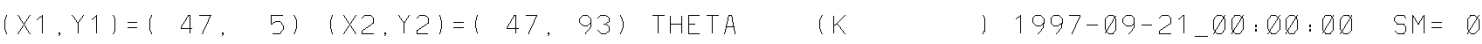

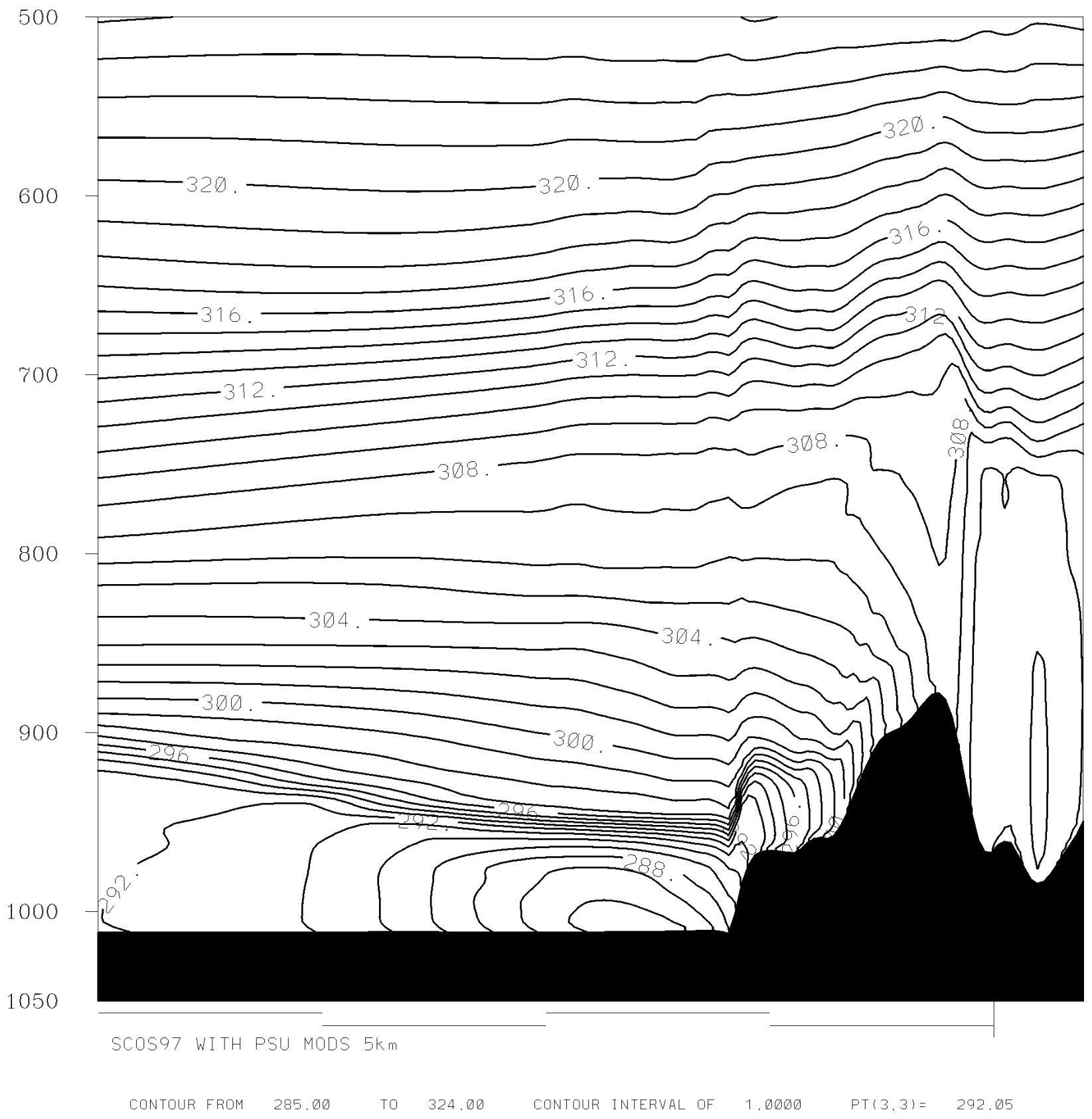

Figure 37. MM5 initial potential temperature, $\theta(\mathrm{K})$ on the 5-km domain plotted versus pressure in the plane of the Pt. Dume north-south cross section, valid for 0000 UTC, 21 September 1997, (+00 h) in Exp. 2. Isentrope interval is $1 \mathrm{~K}$. 


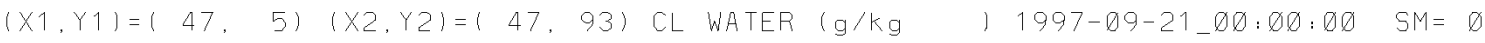

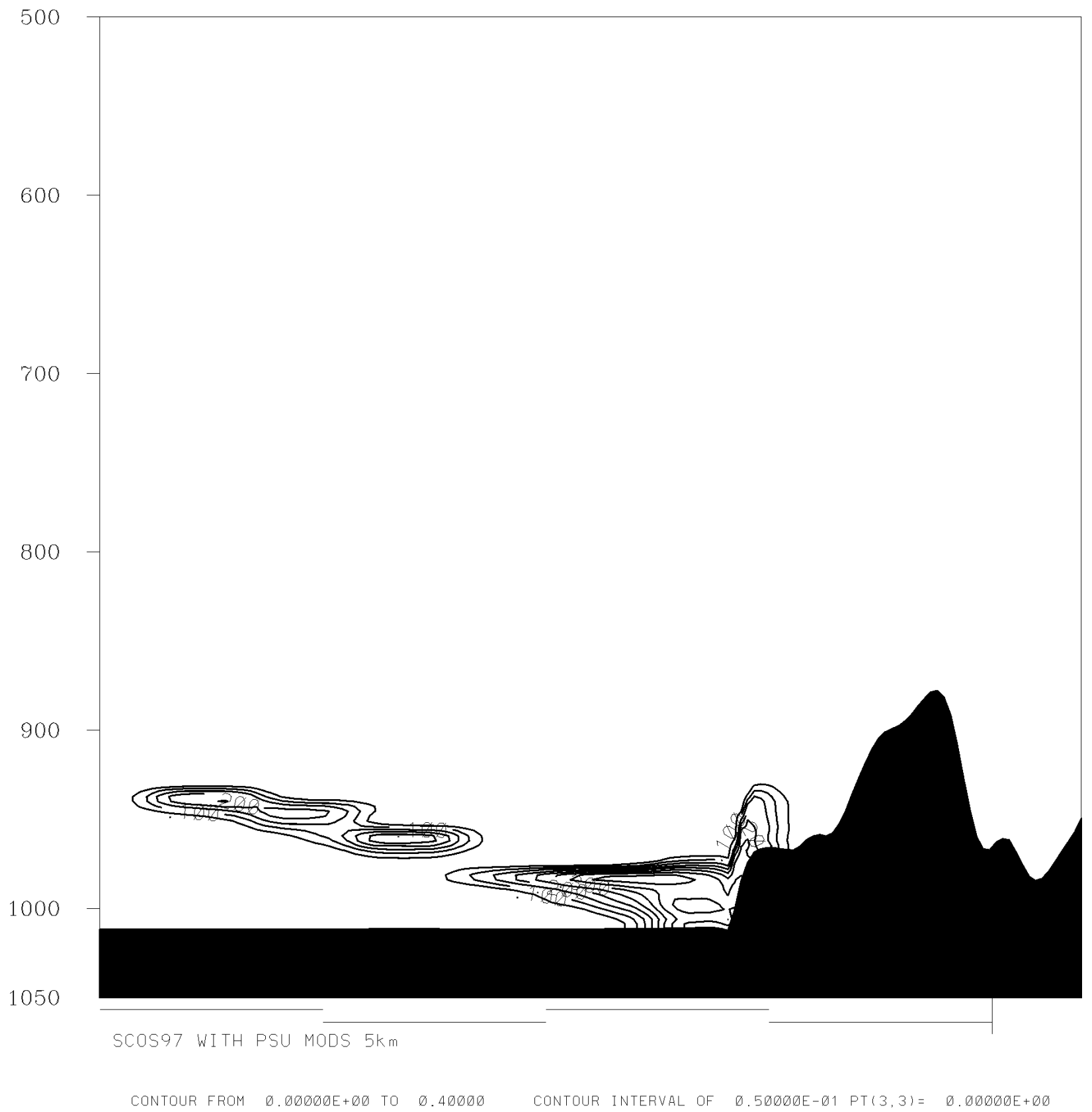

Figure 38. MM5 initial cloud liquid water mixing ratio, $q_{C}\left(\mathrm{~g} \mathrm{~kg}^{-1}\right)$ on the 5-km domain plotted versus pressure in the plane of the Pt. Dume north-south cross section, valid for 0000 UTC, 21 September 1997, (+00 h) in Exp. 2. Contour interval is $0.05 \mathrm{~g} \mathrm{~kg}^{-1}$. 


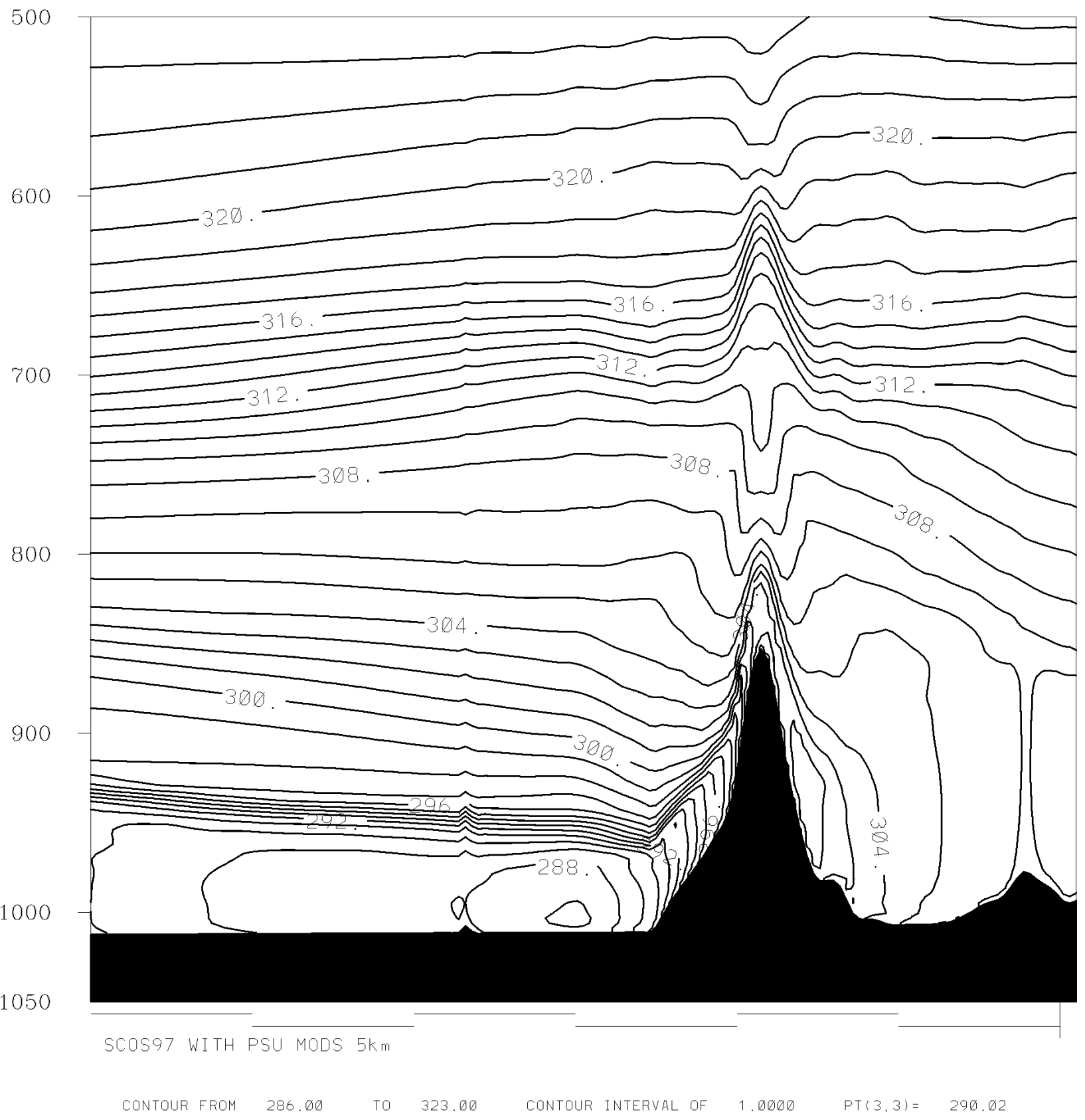

Figure 39. MM5 initial potential temperature, $\theta(\mathrm{K})$ on the 5-km domain plotted versus pressure in the plane of the San Diego east-west cross section, valid for 0000 UTC, 21 September 1997, (+00 h) in Exp. 2. Isentrope interval is $1 \mathrm{~K}$. 
temperatures in the marine boundary layer are consistent with the very cool sea-surface temperatures analyzed by NCEP and shown earlier in Figure 9a. However, Figure 9b based on NASA satellite data (also see Figure 8), shows warmer sea temperatures toward the south and thus suggest that the initial air temperatures in the marine layer in Figure 39 are probably too cool. The cloud liquid water field in this second east-west cross section also indicates broken low stratus over the ocean off San Diego, but no coastal fog (not shown). Thus, the initial vertical thermodynamic and moisture structure over the CA Bight is quite normal for this time of year, although the marine-layer air temperatures are probably too cold because of the excessively cool NCEP-derived water temperatures. Note that these same initial atmospheric conditions are used in all of the model experiments, although the ocean temperatures are changed for Exps. 2.54 (Section 3.2).

By the end of the first nocturnal period, the model simulations in all experiments developed finescale details that are typical for mesoscale model solutions. Figure 40 shows the surface-layer winds simulated in the Analysis-Nudging Exp. (Exp. 2) near sunrise at 1200 UTC, 21 September. The prevailing northwesterly flow over the Pacific Ocean persists through the night, but a low-level eddy has developed over the Santa Barbara Channel. This is a common mesoscale feature in the lee of Pt. Conception and the Santa Inez Mountains. Coastal regions from Pt. Dume to Baja CA show very light and variable winds in the basins west of the mountain chains (compare to Figure 15). Over the inland deserts winds are up to $5 \mathrm{~ms}^{-1}$ and have mostly northerly components. Wind speeds over the mountain peaks are as great as $8-10 \mathrm{~ms}^{-1}$. The corresponding early morning surface-temperature field in Figure 41 shows cold temperatures of 14-16 C in the LA Basin reflecting the cold offshore waters. Since the sea surface is so cold in Exp. 2, the winds immediately along the coastline in Figure $\mathbf{4 0}$ are mostly onshore (i.e., a sea breeze) at 1200 UTC, 21 September, rather than offshore as would be expected (a land breeze). Thus, the error in sea-surface temperatures caused by using the NCEP-analyzed fields in Exps. 1 and 2 not only leads to the surface thermal errors discussed above, but can even cause the wind direction near the coast to be reversed during the nocturnal period. This could have decidedly negative consequences for the nighttime transport of pollutants trapped in the LA Basin close to the surface in the stable nocturnal boundary layer.

The horizontal winds simulated in Exp. 2 above the SoCAB at $850-\mathrm{mb}$ for 1200 UTC, 21 September, are presented in Figure 42. Since this level lies above the terrain for all but the highest mountains, it shows that the model's mid-level flow is mostly from the northeast, which is consistent with the deep trough observed over the SoCAB during the early part of the episode (compare to Figure 11). Of special interest at $850 \mathrm{mb}$ are the two high speed jets with speeds up to $20 \mathrm{~ms}^{-1}$ flowing through passes in the mountain chains to the northwest and northeast of the LA Basin. These jet winds are generated as stable upper winds are directed more or less perpendicular to the terrain, leading to Bernoulli accelerations through the passes and mountaininduced gravity waves over the mountain ridges. The gravity waves (also called lee waves when generated by terrain) can propagate momentum vertically, both upwards and down to the surface. Descending air in a lee wave is warmed adiabatically in such cases, sometimes leading to Santa Ana winds in the LA Basin and surrounding areas of southern CA. However, in the case of 2124 September, the north-south cross section in Figure 43 shows that the stable inversion above the marine layer remained intact, despite the obvious gravity waves evident in the potential 


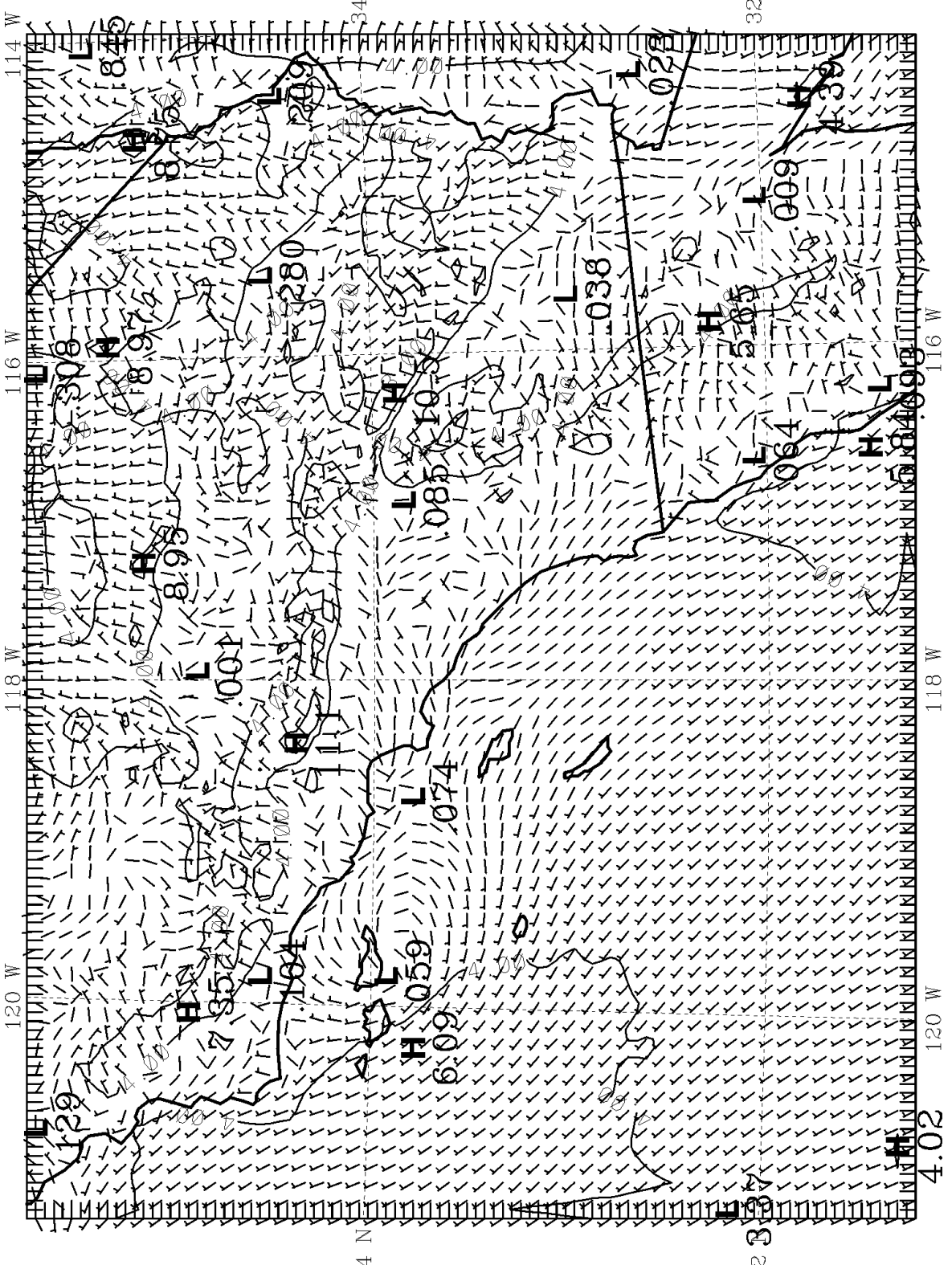

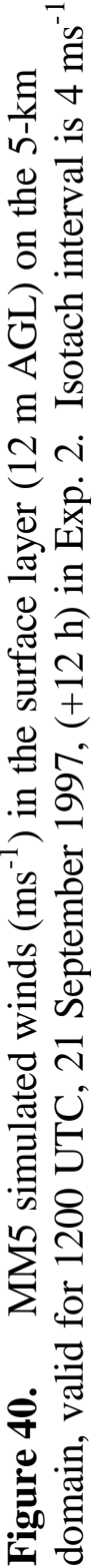




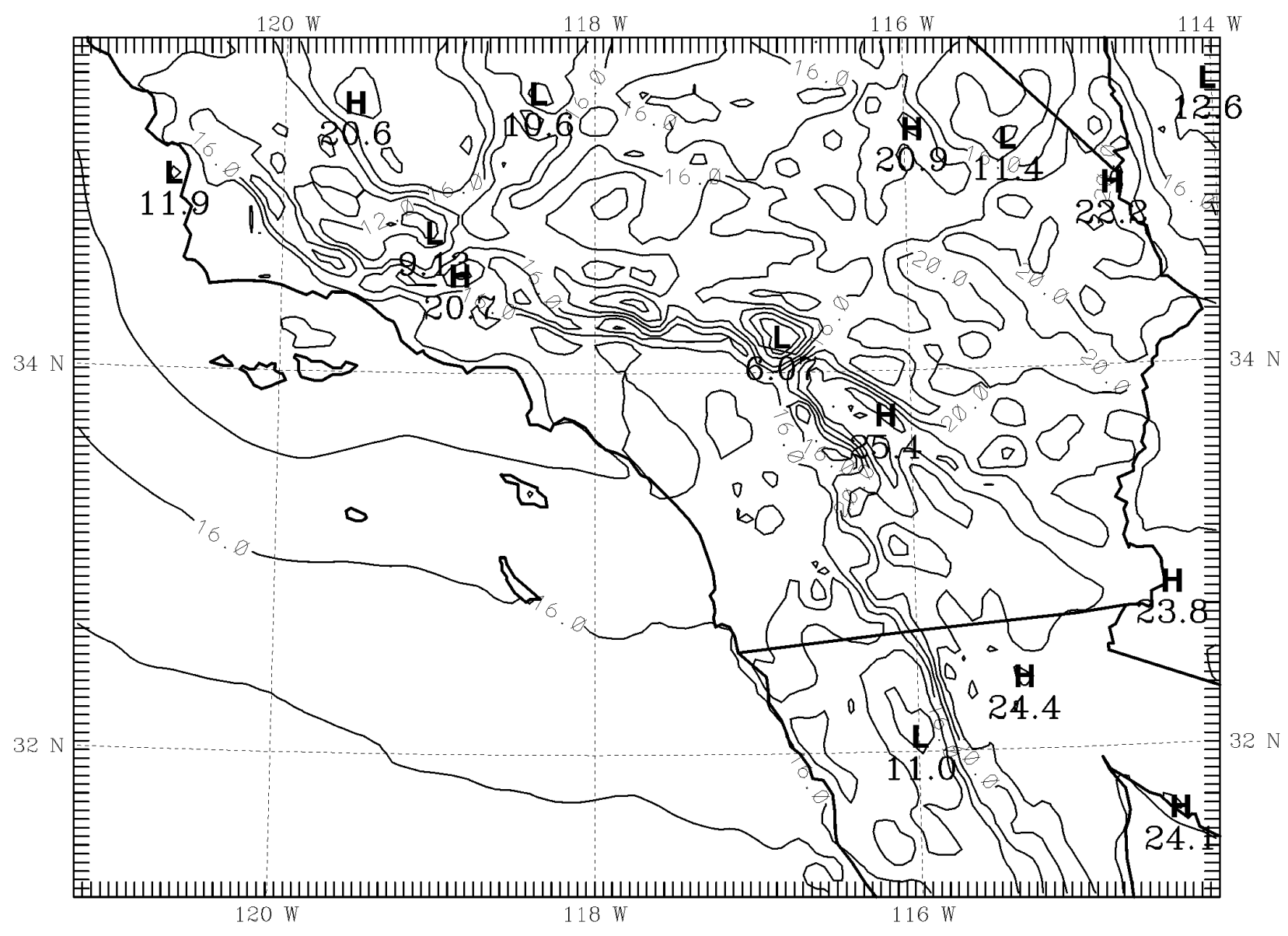

SCOS97 WITH PSU MODS $5 \mathrm{~km}$

Contour from 6.0000 to 24.000 contour Interval OF $2.0000 \quad$ PT(3.3) $=19.373$

Figure 41. MM5 simulated temperatures (C) in the surface layer (12 m AGL) on the 5-km domain, valid for 1200 UTC, 21 September 1997, (+12 h) in Exp. 2. Isotherm interval is 2 C. 


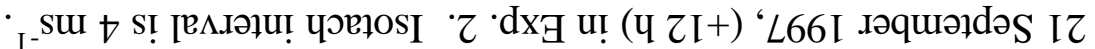

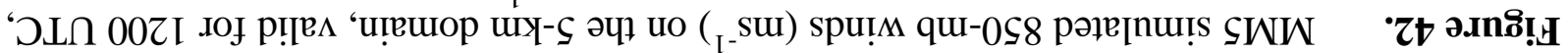

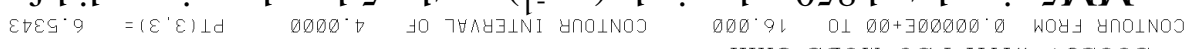

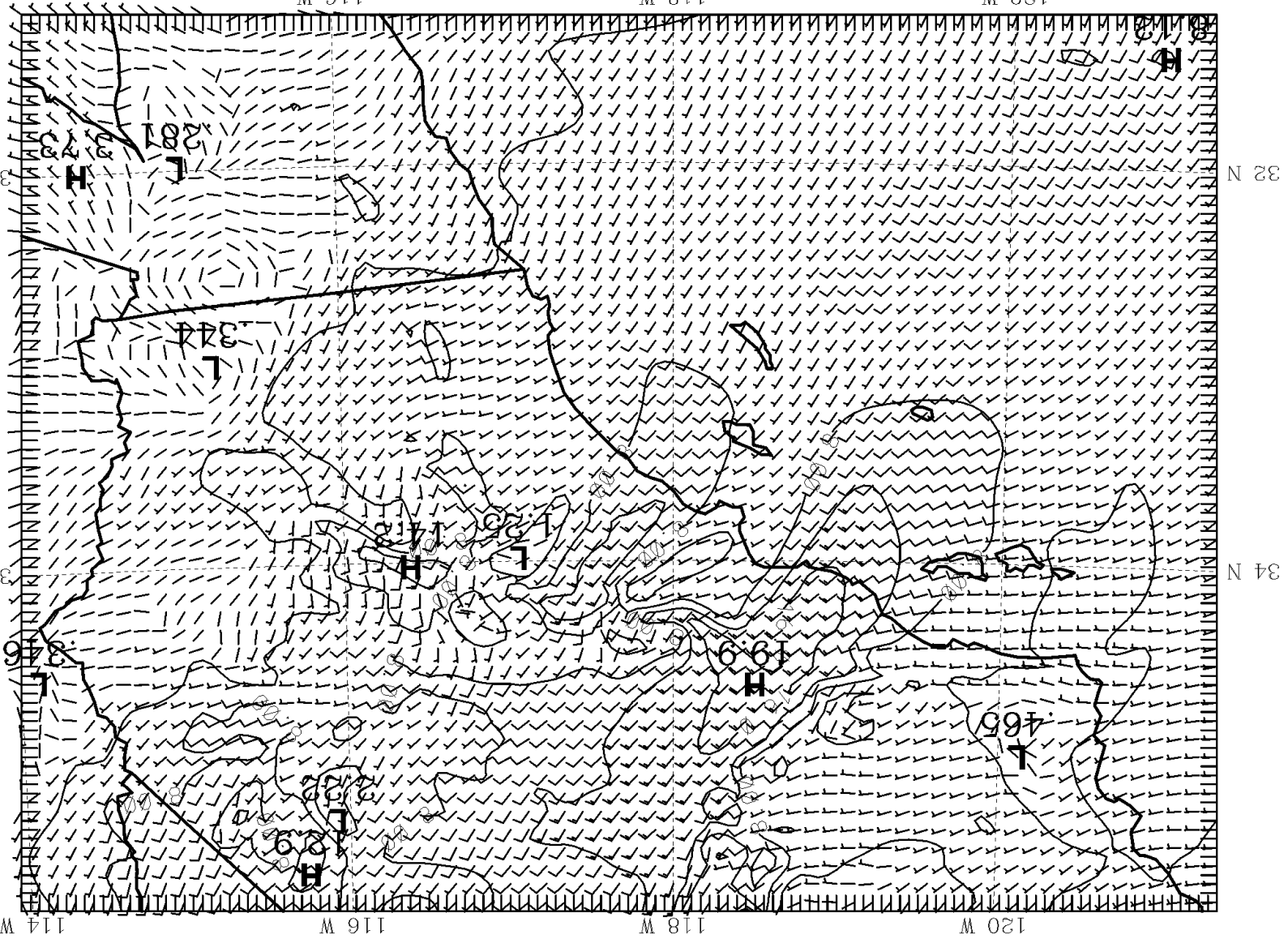




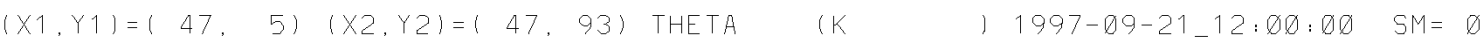

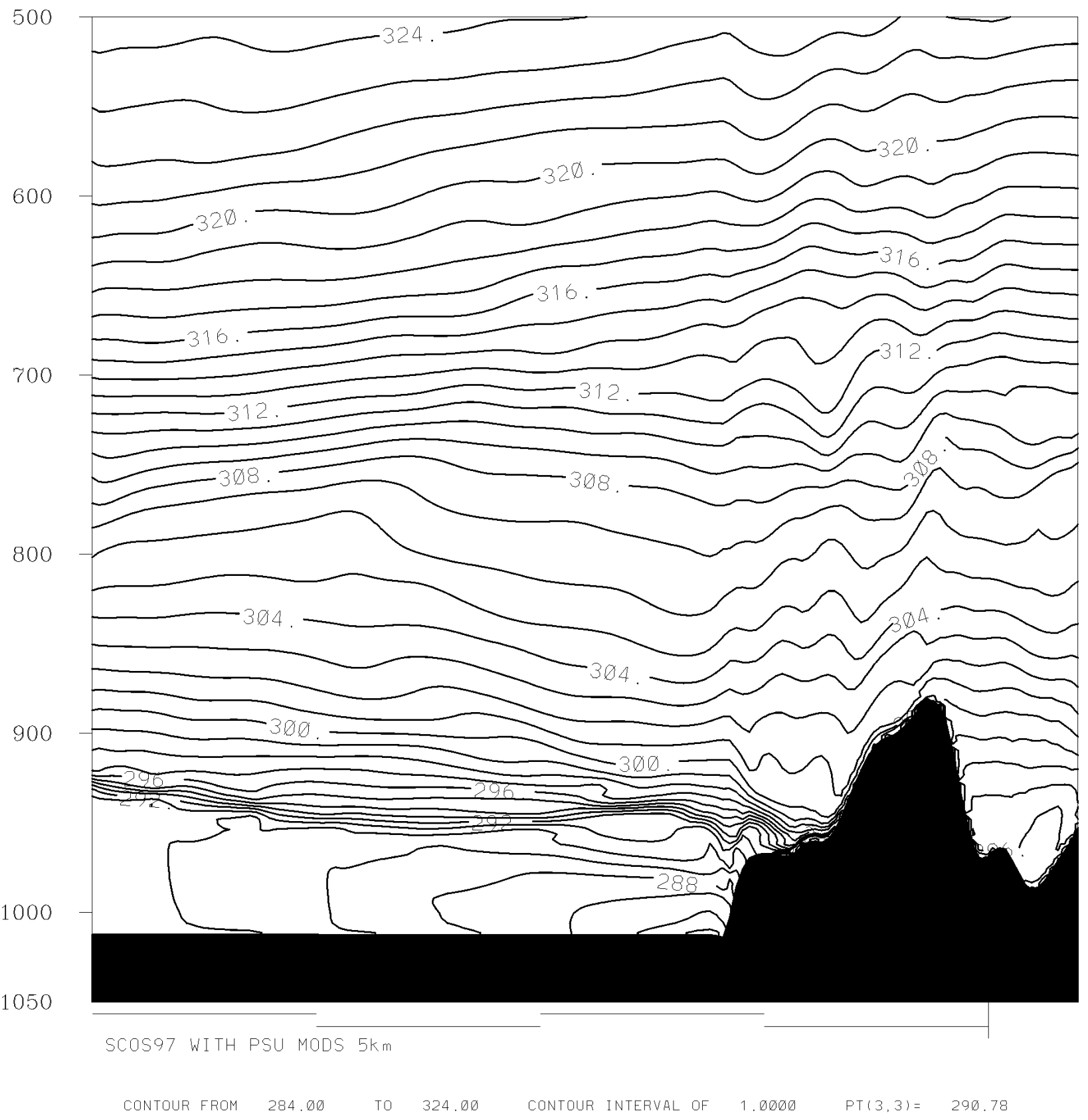

Figure 43. MM5 simulated potential temperature, $\theta(\mathrm{K})$ on the 5-km domain plotted versus pressure in the plane of the Pt. Dume north-south cross section, valid for 1200 UTC, 21 September 1997, (+12 h) in Exp. 2. Isentrope interval is $1 \mathrm{~K}$. 


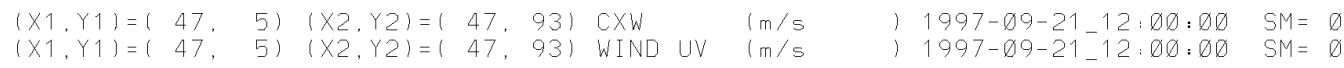

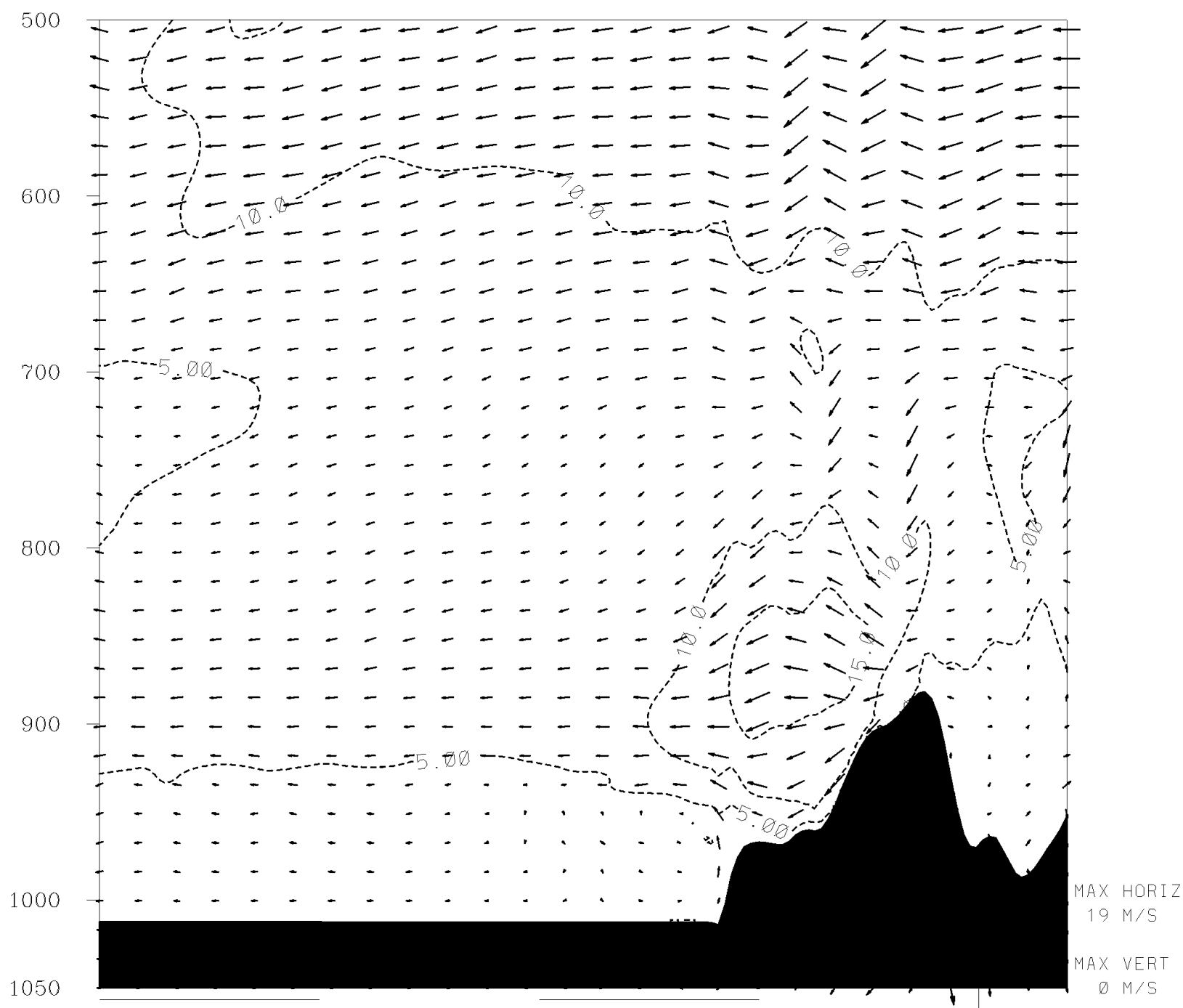

SCOS97 WITH PSU MODS $5 \mathrm{~km}$

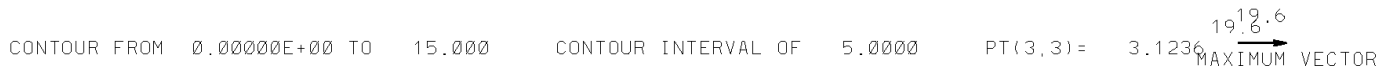

Figure 44. MM5 simulated winds $\left(\mathrm{ms}^{-1}\right)$ on the $5-\mathrm{km}$ domain plotted versus pressure in the plane of the Pt. Dume north-south cross section, valid for 1200 UTC, 21 September 1997, (+12 h) in Exp. 2. Isotach interval is $4 \mathrm{~ms}^{-1}$. 
temperature field to the lee (seaward) of the San Rafael Mountains. Therefore, the corresponding cross section for the winds (Figure 44) shows high-speed flow descending in the lee of the San Rafael mountains, but confined above the marine inversion (roughly outlined by the $5 \mathrm{~ms}^{-1}$ isotach. Also, note the narrow zone of rising air at the coastline below $950 \mathrm{mb}$ near Pt. Dume, where the marine air flowing onshore in the Santa Barbara eddy is forced upward by the terrain. No Santa Ana winds were observed in the LA Basin or other coastal areas during the 21-24 September episode, despite the modest rise of temperatures late in the period. Therefore, the three dimensional circulations shown in the model solutions at 1200 UTC, 21 September are very consistent with the expected flow and thermodynamic structure in this case prior to the passage of the upper-level ridge.

Following the daytime heating cycle, Figure 45 shows the surface-layer winds simulated over the 5-km domain in Exp. 2 at 0000 UTC, 22 September (+24 h, 1700 PDT). By this time, the sea breeze in the SoCAB is close to its maximum intensity, with onshore flow mostly from the west at $\sim 3-4 \mathrm{~ms}^{-1}$. Convergent winds are evident over the mountain ridges ringing the LA Basin and other coastal basins. Over the deserts of interior CA the simulated winds are light and variable due to the irregular heated terrain and large turbulent eddies in the deep convective boundary layer. The model's surface temperature field at the same time is shown in Figure 46. Although temperatures in the deserts are simulated up to $34 \mathrm{C}$, the model is several degrees cooler than peak observed temperatures of $37 \mathrm{C}$. In the LA Basin, the cool bias is generally 4-5 C, mostly due to advection from the model's excessively cold coastal waters.

Also at 0000 UTC, 22 September, the convective boundary layer development is of interest. Figure 47 shows the simulated mixed-layer depth at this time, shortly before the boundary layer collapses as sunset approaches. As expected the mixed layer in the LA Basin is only 250-500 $\mathrm{m}$ deep, while east of the mountains it reaches $\sim 2000-2500 \mathrm{~m}$ over the deserts. Above the ocean, the marine mixed layer is mostly less than $250 \mathrm{~m}$ in the coastal regions, gradually deepening to over $500 \mathrm{~m}$ toward the southwest corner of the domain. The extremely uneven patterns of the boundary layer depth simulated over the desert regions of southeastern CA is the result of deep turbulent eddies and local convergence cells generated by the irregular fine-scale terrain features of the 5-km domain. This interpretation is confirmed by the east-west cross section of simulated potential temperature at 0000 UTC, 22 September (Figure 48). East of the mountains, each minor terrain feature is associated with enhanced irregularity of the boundary-layer top (approximated over this region by the $307 \mathrm{~K}$ isentrope). West of the mountains, the shallow marine boundary layer slopes downward toward the shore (Figure 48), where it is especially low at this time of day due to the net mass divergence at the coast associated with the sea-breeze circulation. As the sea breeze flow heads inland and up the west slopes of the mountains defining the coastal air basins, the mixed layer warms rapidly due to strong surface sensible heat fluxes. However, despite the rapid heating of the marine air over land the mixed layer depth remains quite shallow until reaching the higher elevations near the mountain ridge. Finally, the cross section of cloud water in Figure 49 shows that the stratus and stratocumulus clouds over the CA Bight have mostly dissipated near the coast. The clearing is due to increased subsidence over the ocean generated in response to the vigorous sea breeze in the marine layer boundary and its elevated return (seaward-directed) circulation between 800-950 mb (Figure 50). 


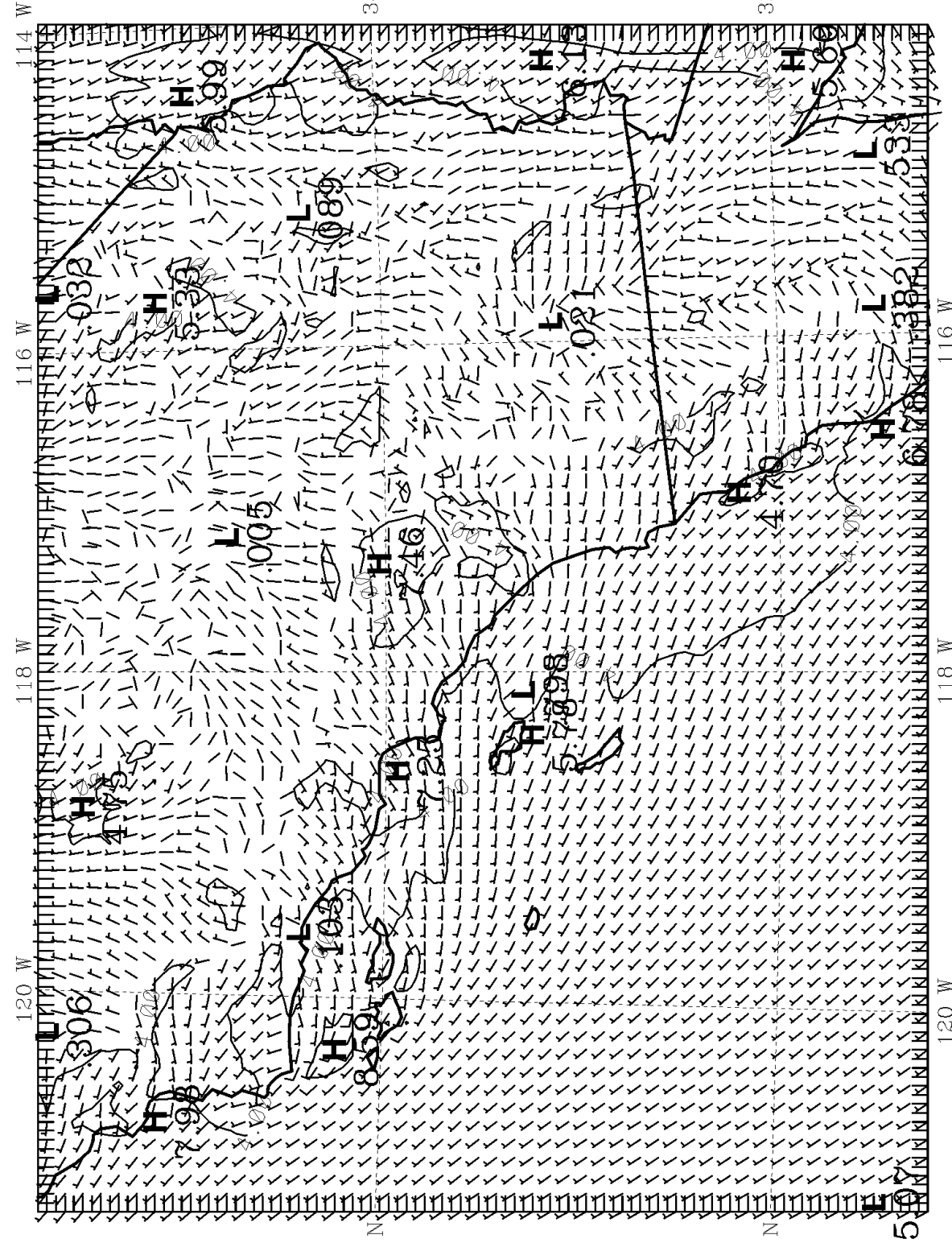




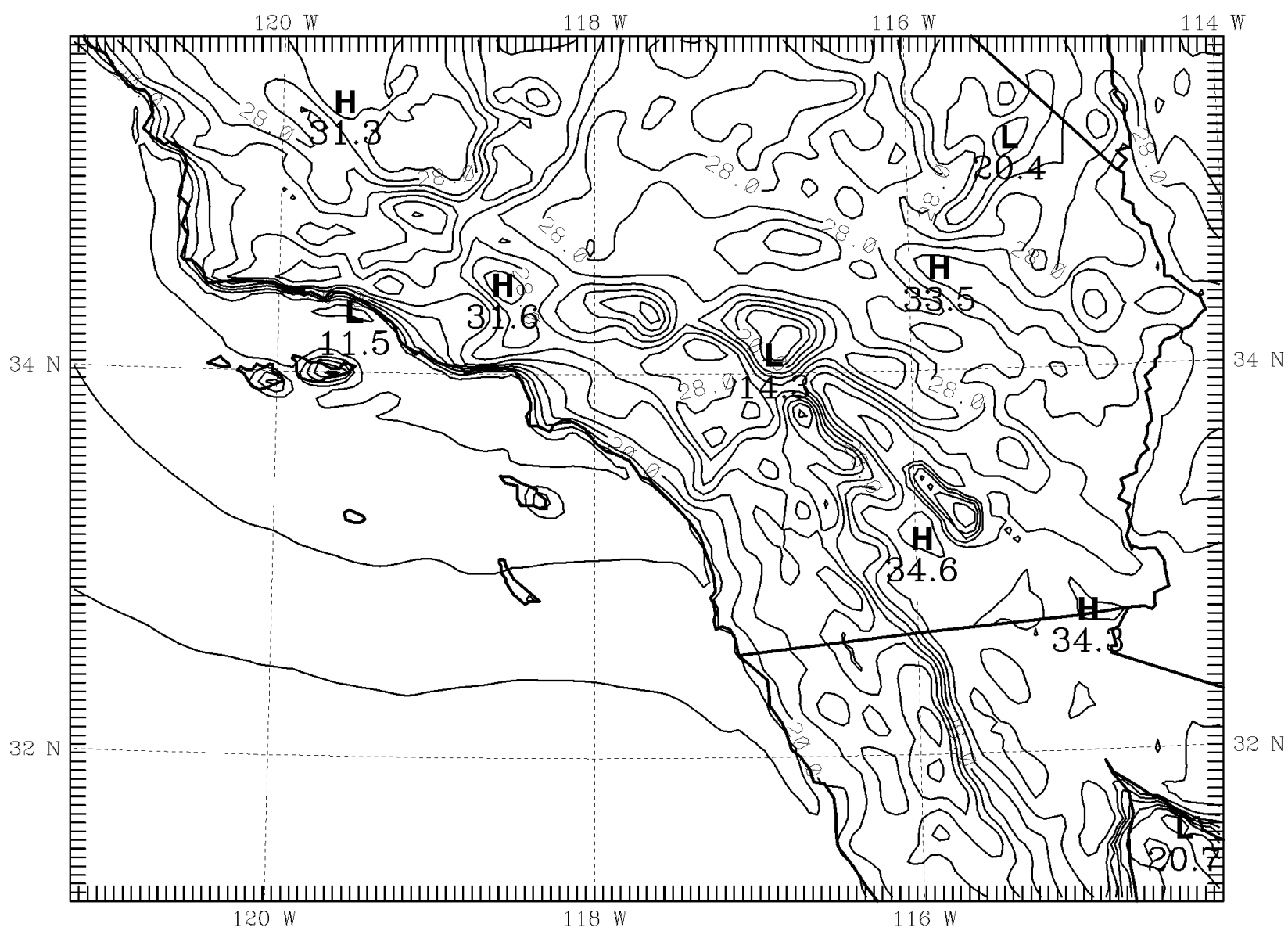

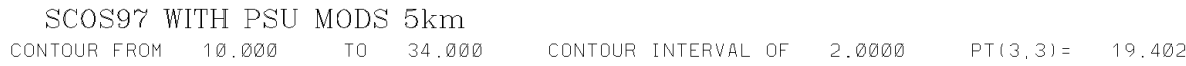

Figure 46. MM5 simulated temperatures (C) in the surface layer (12 m AGL) on the 5-km domain, valid for 0000 UTC, 22 September 1997, (+24 h) in Exp. 2. Isotherm interval is 2 C. 


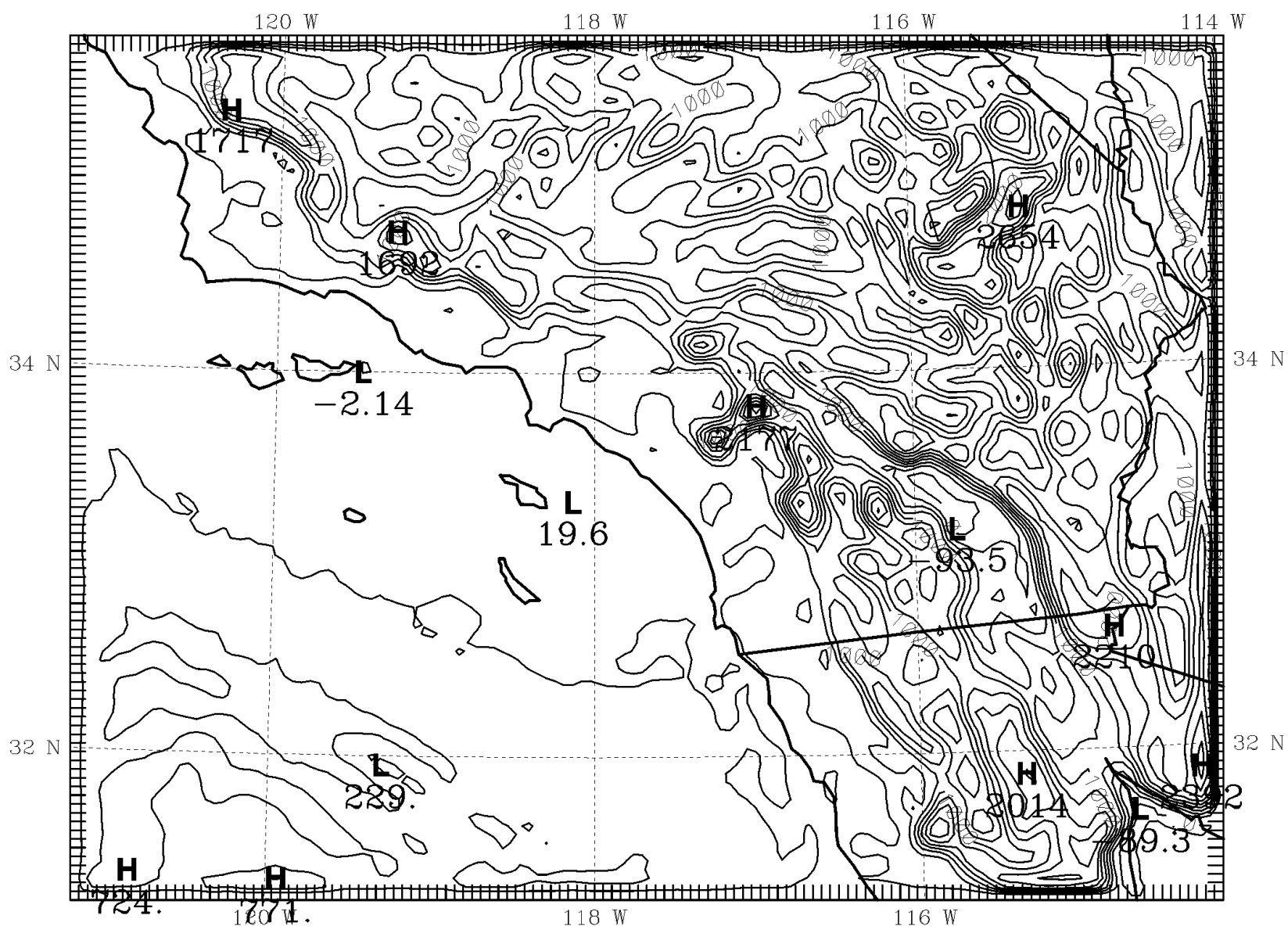

SCOS97 WITH PSU MODS $5 \mathrm{~km}$

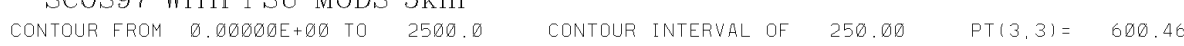

Figure 47. MM5 simulated mixed-layer depths $(\mathrm{m})$ on the 5-km domain, valid for 0000 UTC, 22 September 1997, (+24 h) in Exp. 2. Contour interval is $250 \mathrm{~m}$. 
$(X 1, Y 1)=(5.38)(X 2, Y 2)=(127.38)$ THETA $\left(K \quad, \quad 1997-\varnothing 9-22 \_\varnothing \emptyset: \varnothing \varnothing: \emptyset \varnothing \quad S M=\varnothing\right.$

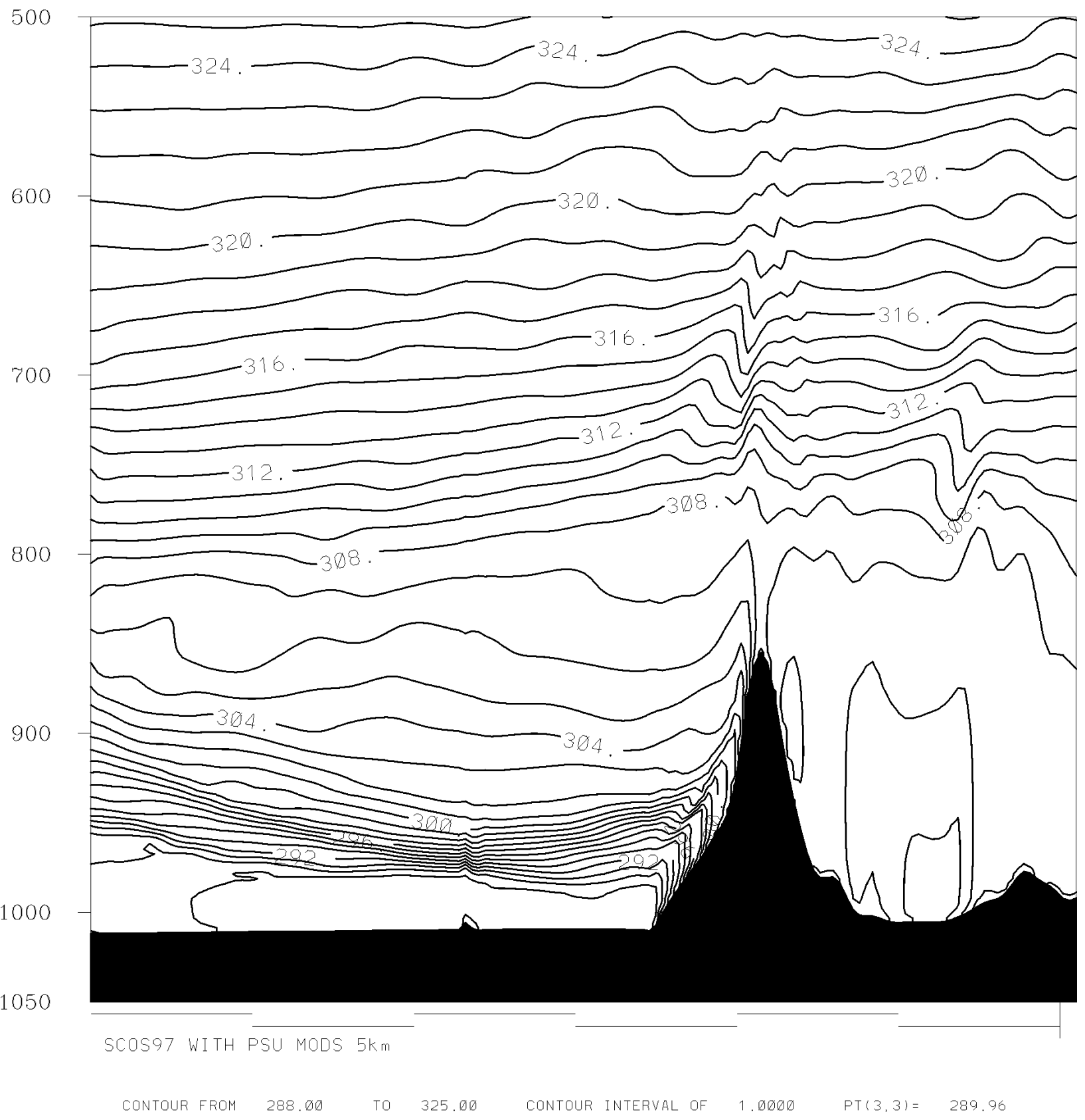

Figure 48. MM5 simulated potential temperature, $\theta(\mathrm{K})$ on the 5-km domain plotted versus pressure in the plane of the San Diego west-east cross section, valid for 0000 UTC, 22 September 1997, (+24 h) in Exp. 2. Isentrope interval is $1 \mathrm{~K}$. 


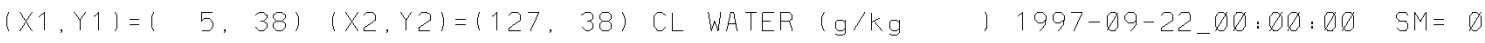

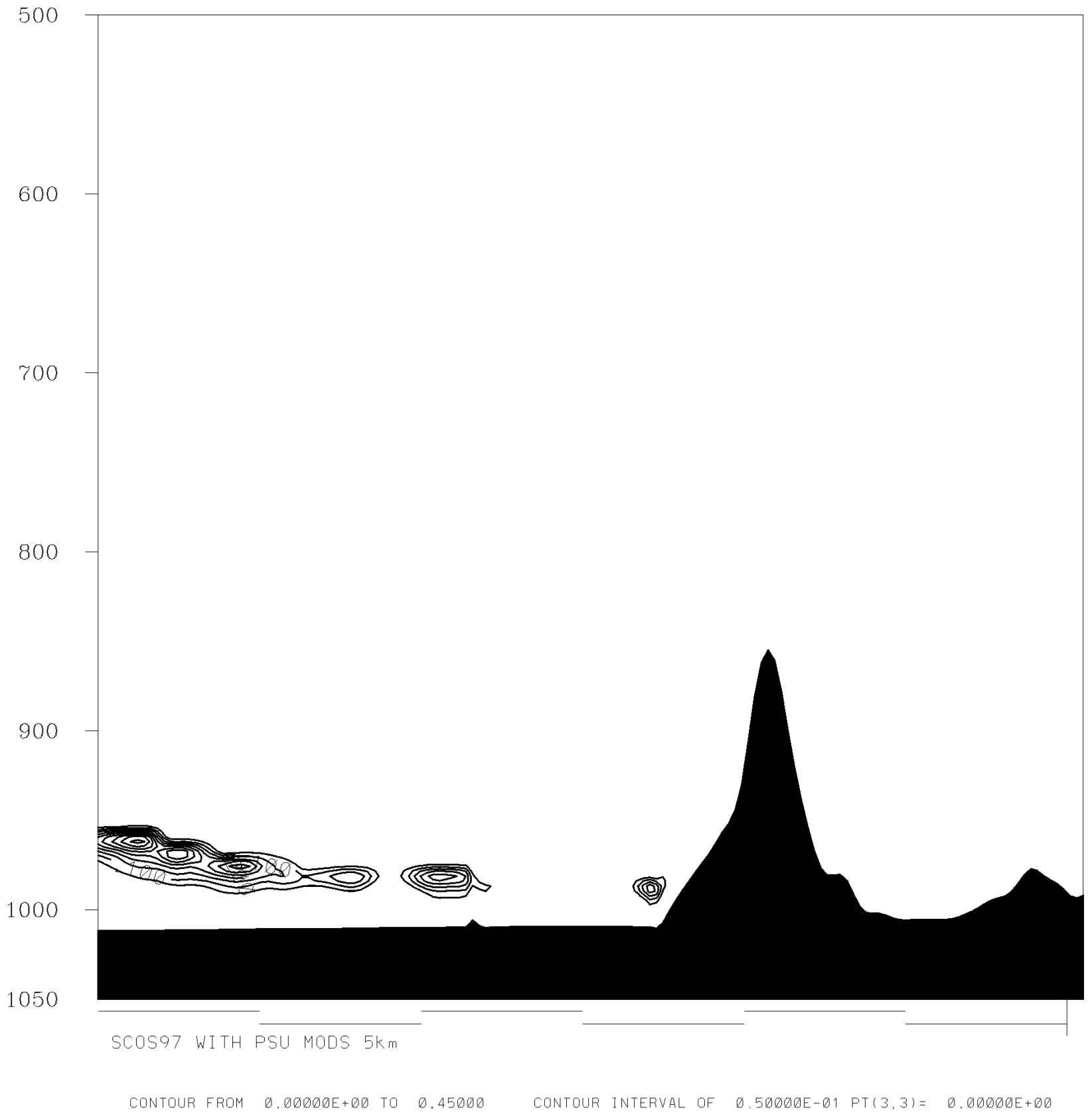

Figure 49. MM5 simulated cloud liquid water $\left(\mathrm{g} \mathrm{kg}^{-1}\right)$ on the 5-km domain plotted versus pressure in the plane of the San Diego west-east cross section, valid for 0000 UTC, 22 September 1997, (+24 h) in Exp. 2. Contour interval is $0.05 \mathrm{~g} \mathrm{~kg}^{-1}$. 


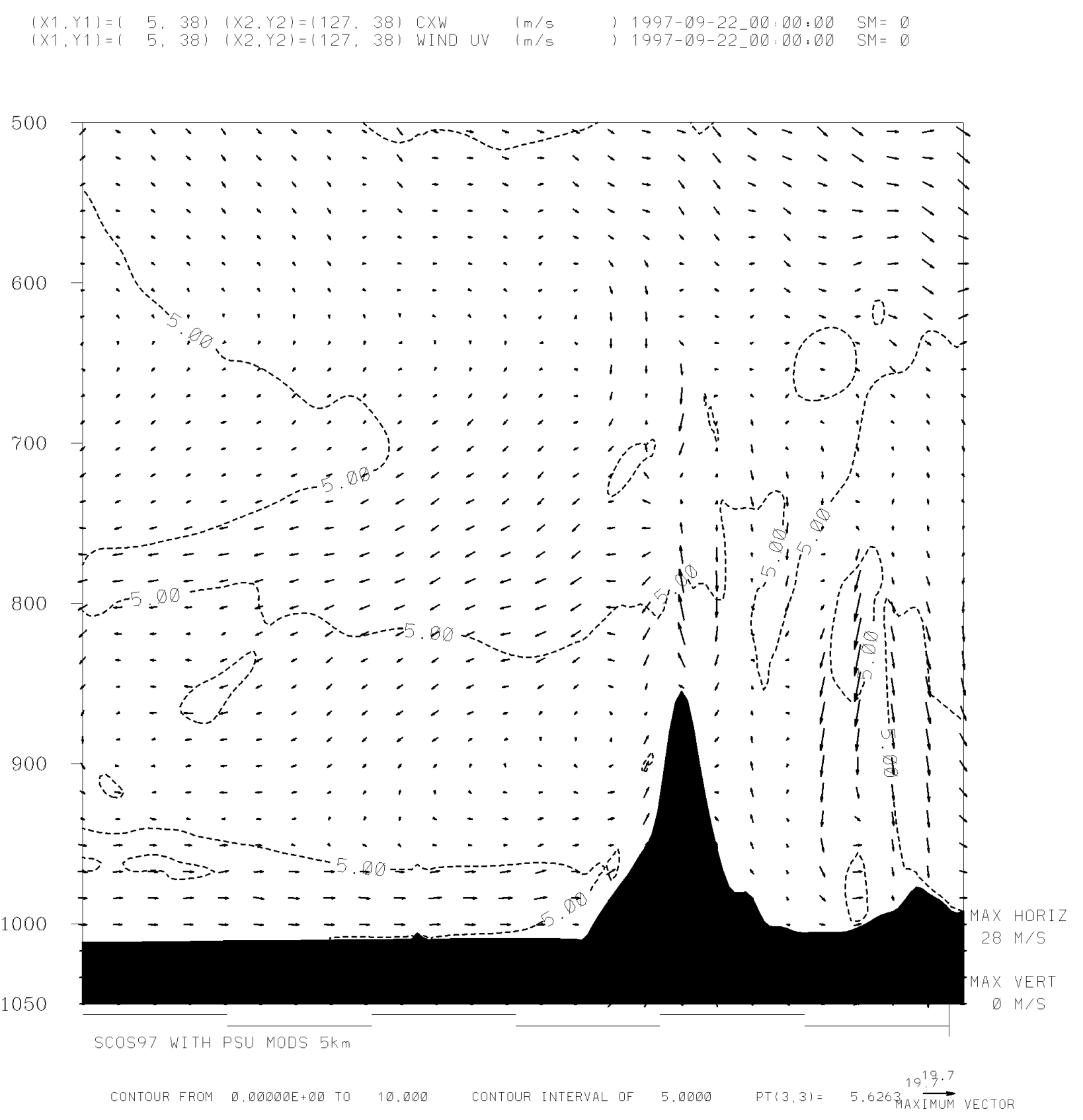

Figure 50. MM5 simulated winds $\left(\mathrm{ms}^{-1}\right)$ on the $5-\mathrm{km}$ domain plotted versus pressure in the plane of the San Diego west-east cross section, valid for 0000 UTC, 22 September 1997, (+24 h) in Exp. 2. Isotach interval is $5.0 \mathrm{~ms}^{-1}$. 
As discussed earlier, this diurnal cycle is repeated each day of the episode, except that it becomes weaker toward the end of the period as the upper ridge passes and the tropical storm approaches the SoCAB. Therefore, it is not especially important to show similar visual plots of the model simulations for each subsequent day. The gradual evolution of the case and the subtle differences between results from the different experiments is better revealed by the statistical evaluations.

The evolution of domain-averaged surface temperatures in Exp. 2, the Analysis Nudging Experiment, is given in Figure 51. Comparison with Figure 28 indicates no improvement in the simulated surface temperatures due to the addition of analysis nudging versus the Control Exp. 1. Comparison of Table 8 with Table 7 confirms this assessment, since the mean error at the surface for Exp. 2 is $-3.79 \mathrm{C}$, which is $0.85 \mathrm{C}$ colder (greater bias) than in Exp. 1. This result is not surprising since the analysis nudging approach does not assimilate the synoptic-scale temperature analyses below the 850 -mb level. Most of the change occurs in the form of cooler nocturnal temperatures during the last two days of the model simulation. The table also shows that the larger bias in Exp. 2 has resulted in greater MAEs and RMS errors, as well. Further comparison of Tables 7 and 8 shows that the surface mixing ratio bias has increased in Exp. 2 to $+0.83 \mathrm{~g} \mathrm{~kg}^{-1}$, although the MAE and RMS error for moisture is virtually unchanged.

Next, Figure 52 shows the domain-averaged surface-layer wind speeds for Exp. 2. Comparison with the corresponding surface-layer speed errors from Exp. 1 (Figure 30) indicates that introduction of analysis nudging has caused the model to more nearly replicate the diurnal cycles in the observed surface wind speed. This is interesting because no wind analyses are assimilated below $850 \mathrm{mb}$, so any impact at the surface represents a dynamical response to changes induced in the mid- and upper-level wind and mass fields. However, despite the more reasonable diurnal variation of the surface winds in Exp. 2, Table 8 reveals a moderate increase in the ME (bias) at the surface to $-0.40 \mathrm{~ms}$, while the RMS error decreased to $1.91 \mathrm{~ms}^{-1}$. Further inspection of the wind errors versus height indicates that the mixed result in the surface layer is not representative of the effect that analysis nudging has on the winds in Exp. 2. Comparison of Figures 53 and 31 shows that the wind speeds in the "boundary layer and recirculation" zone (25-1500 m AGL), where most of the pollutant mass is transported, are improved significantly. The mean speed errors have decreased from $+0.82 \mathrm{~ms}^{-1}$ to $+0.44 \mathrm{~ms}^{-1}$ in this zone, while the RMS error for speed has decreased from $3.08 \mathrm{~ms}^{-1}$ to $2.47 \mathrm{~ms}^{-1}$. Again, this layer gains little direct benefit from the analysis nudging, but is mostly affected indirectly through the dynamical adjustments induced farther aloft. Also, Table 8 reveals that the wind speed errors above $1500 \mathrm{~m}$, where the direct effect of analysis nudging occurs in Exp. 2, are substantially lower than in Exp. 1 (compare to Table 7). For example, the RMS errors for wind speed decrease between $\sim 25-45 \%$ in Exp. 2 in the mid- and upper-troposphere. Thus, the impact of the analysis nudging on winds is generally very positive. The misleading negative result in the surface layer is due to the extreme sensitivity of the surface winds to sub-grid scale surface irregularities (hills, trees, buildings, etc.). Errors in this layer are not particularly important because so little of the pollutant mass remains in that very thin layer.

Figures 54 and 55 show the corresponding evolution of wind direction in the surface layer and "boundary" layer for Exp. 2. These results can be compared to similar information 
Table 8. Statistical evaluation for Exp. 2 (Analysis-Nudging Experiment) for the SCOS-97 episode of 21-24 September 1997. Statistics shown are mean errors (ME), mean absolute errors (MAE) and root mean square errors (RMS). Above the surface, statistics from individual MM5 calculation levels are merged into composite layers as weighted averages for the approximate boundary layer $(25-1500 \mathrm{~m})$, lower troposphere $(1500-5000 \mathrm{~m})$ and upper troposphere $(5000-10500 \mathrm{~m}){ }^{*}$.

\begin{tabular}{|c|c|c|c|c|c|c|c|c|c|c|c|c|}
\hline \multirow[t]{2}{*}{$\begin{array}{c}\text { Verification } \\
\text { Layer (AGL) }\end{array}$} & \multicolumn{3}{|c|}{$\begin{array}{c}\text { Temperature } \\
\text { (C) }\end{array}$} & \multicolumn{3}{|c|}{$\begin{array}{c}\text { Mixing Ratio } \\
\text { (g/kg) }\end{array}$} & \multicolumn{3}{|c|}{$\begin{array}{c}\text { Wind Speed } \\
(\mathrm{m} / \mathrm{s})\end{array}$} & \multicolumn{3}{|c|}{$\begin{array}{l}\text { Wind Direct. } \\
\text { (degrees) }\end{array}$} \\
\hline & ME & MAE & RMS & ME & MAE & RMS & $\mathbf{M E}$ & MAE & RMS & $\mathbf{M E}$ & MAE & RMS \\
\hline $5000-10500 \mathrm{~m}$ & - & - & -- & -- & -- & - & -0.50 & 1.70 & 1.70 & -0.61 & 11.7 & 11.7 \\
\hline $1500-5000 \mathrm{~m}$ & -- & -- & -- & -- & -- & -- & -0.10 & 2.15 & 2.53 & +1.41 & 25.1 & 30.7 \\
\hline $25-1500 \mathrm{~m}$ & -- & -- & -- & - & -- & - & +0.44 & 1.92 & 2.47 & -1.27 & 41.0 & 54.5 \\
\hline $12 \mathrm{~m} \mathrm{AGL}$ & -3.79 & 4.36 & 5.14 & +0.83 & 1.97 & 2.47 & -0.40 & 1.44 & 1.91 & -3.17 & 56.4 & 73.1 \\
\hline
\end{tabular}

* Note that no statistics appear for the temperature and mixing ratio above the surface because the 5-km model domain did not have supplemental upper-air measurement systems during SCOS-97 capable of taking observations for these variables more often than twice per day. Winds aloft are obtained from up to 27 radar wind profilers operated during the study period. 

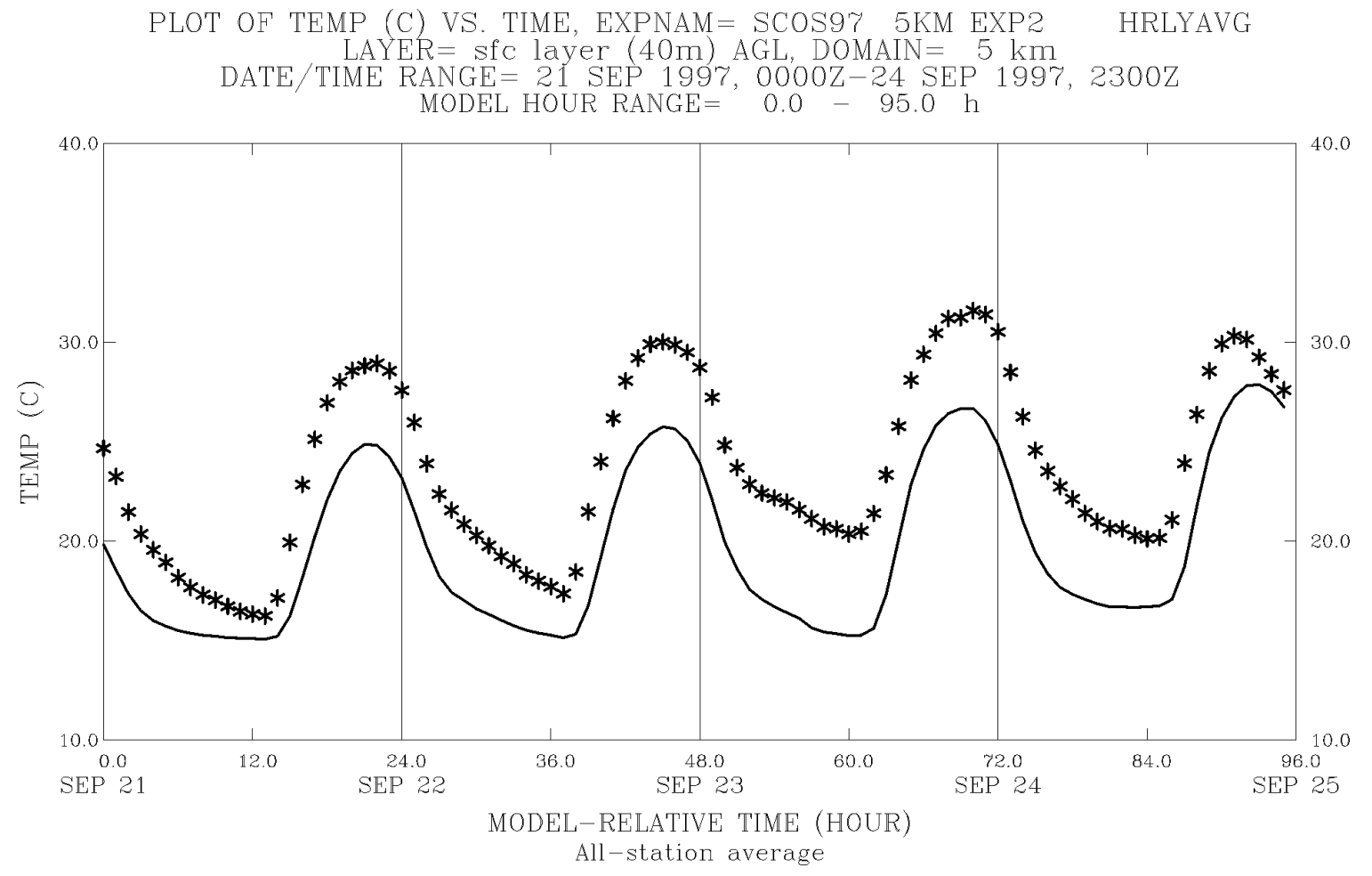

Figure 51. Evolution of domain-averaged surface-layer temperature (C) at $12 \mathrm{~m}$ AGL on the 5-km MM5 domain in the Analysis Nudging Experiment (Exp. 2) for 21-24 September 1997. Times shown on abscissa are forecast hours from the initial time, 0000 UTC, 21 September. Solid line is model-simulated mean, asterisks are hourly observed means. 

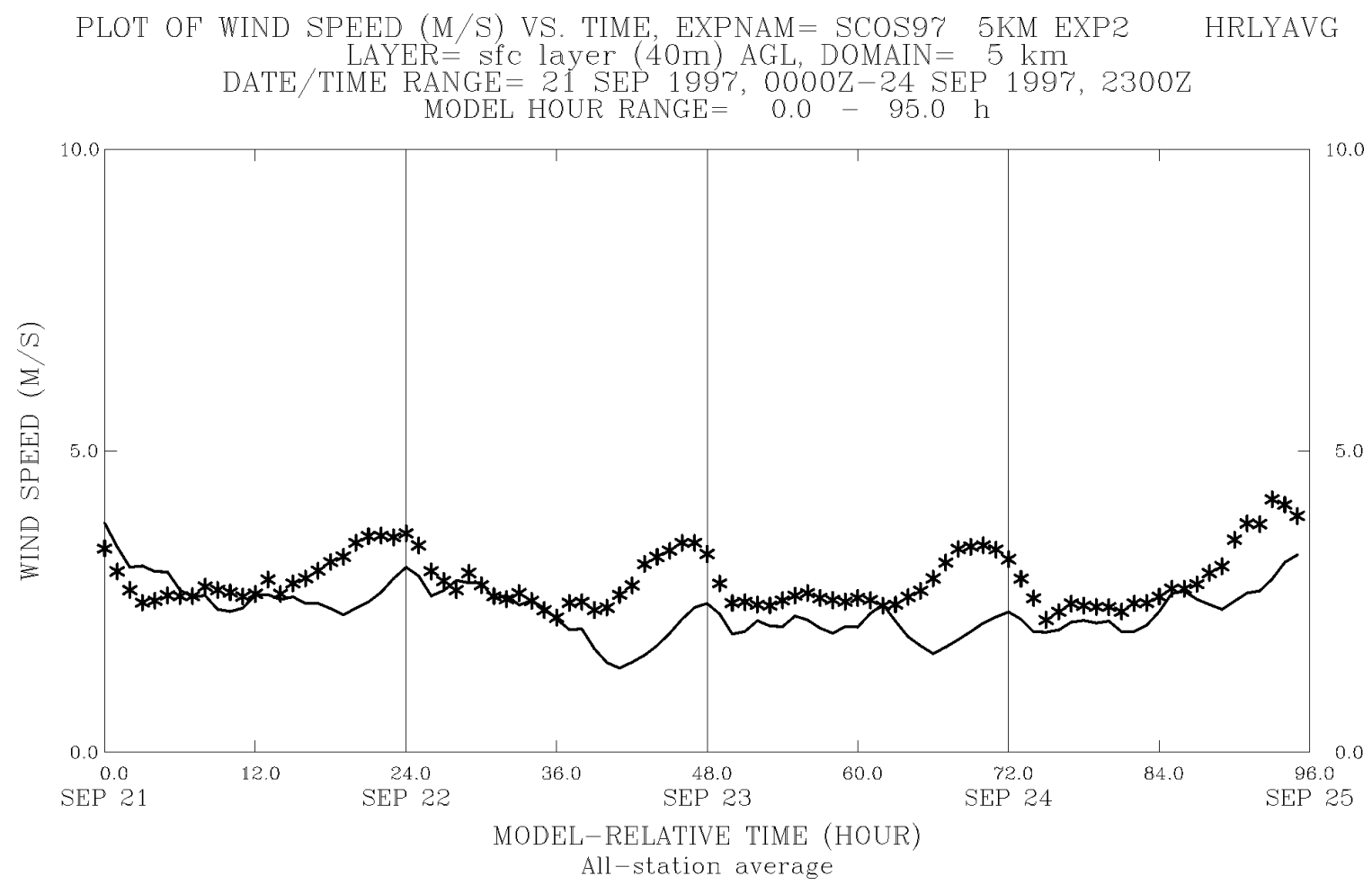

Figure 52. Evolution of domain-averaged surface-layer wind speed $\left(\mathrm{ms}^{-1}\right)$ at $12 \mathrm{~m}$ AGL on the 5-km MM5 domain in the Analysis Nudging Experiment (Exp. 2) for 21-24 September 1997. Times shown on abscissa are forecast hours from the initial time, 0000 UTC, 21 September. Solid line is model-simulated mean; asterisks are hourly observed means. 
PLOT OF WIND SPEED (M/S) VS. TIME, EXPNAM= SCOS97 5KM EXP2 HRLYAVG

LAYER $=80-1500 \mathrm{~m}$ AGL, DOMAIN $=5 \mathrm{~km}$

DATE/TIME RANGE=21 SEP 1997, 0000Z-24 SEP 1997, 23007

MODEL HOUR RANGE $=0.0-95.0 \mathrm{~h}$

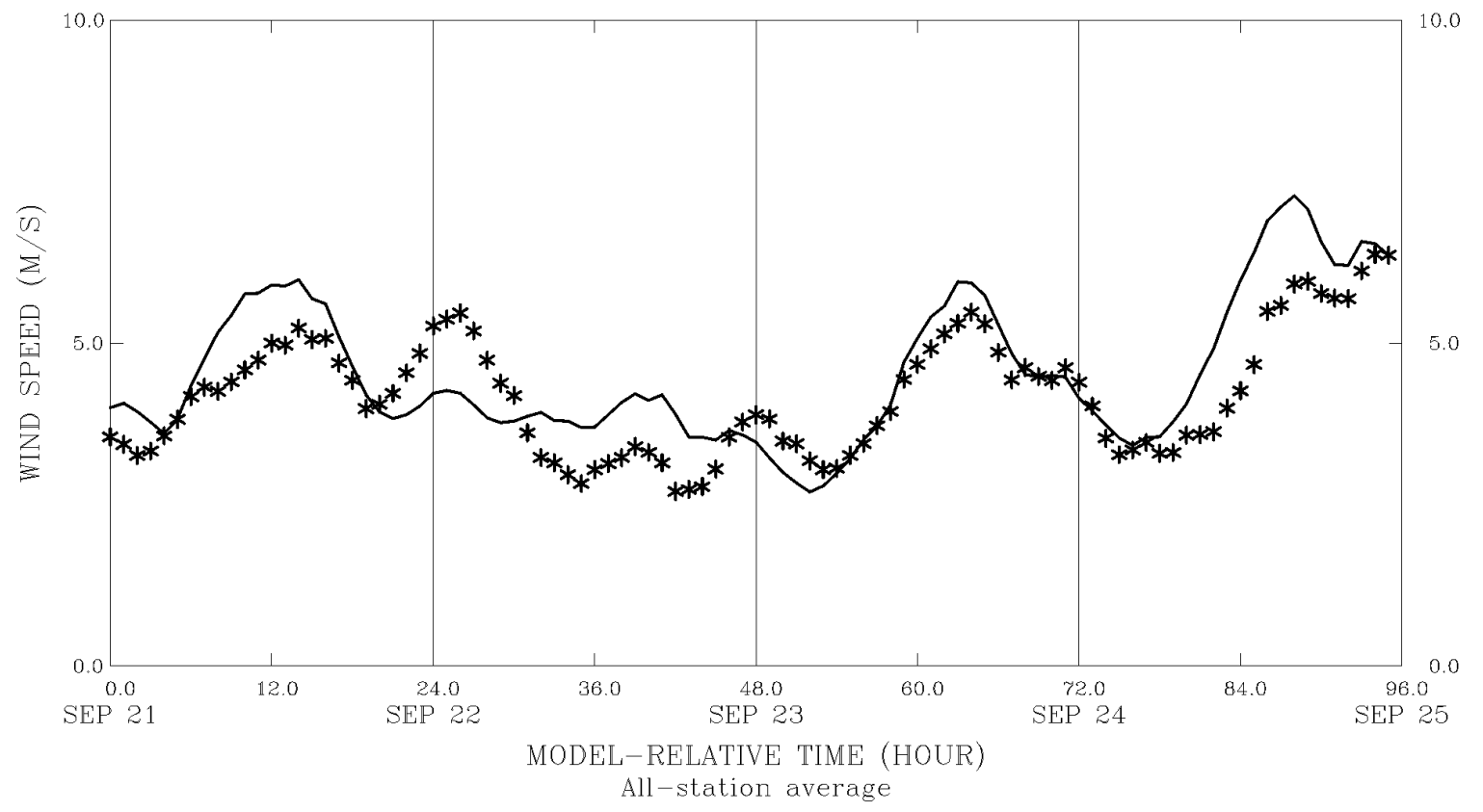

Figure 53. Evolution of domain-averaged wind speed $\left(\mathrm{ms}^{-1}\right)$ in the layers from $25-1500 \mathrm{~m}$ AGL on the 5-km MM5 domain in the Analysis Nudging Experiment (Exp. 2) for 21-24 September 1997. Times shown on abscissa are forecast hours from the initial time, 0000 UTC, 21 September. Solid line is model-simulated mean, asterisks are hourly observed means. 
PLOT OF WIND DIRECTION (DEG) VS. TIMF, FXPNAM= SCOS9Y 5KM EXP2 $\quad$ HRLYAVG

LAYER = sfe layer (40m) AGL, DOMAIN = $5 \mathrm{~km}$

$\mathrm{DATE} / \mathrm{TIME}$ RANGE $=21 \mathrm{SEP} 1997,0000 \mathrm{Z}-24 \mathrm{SEP} 1997,2300 \mathrm{Z}$ MODEL HOUR RANGE $=0.0-95.0 \mathrm{~h}$

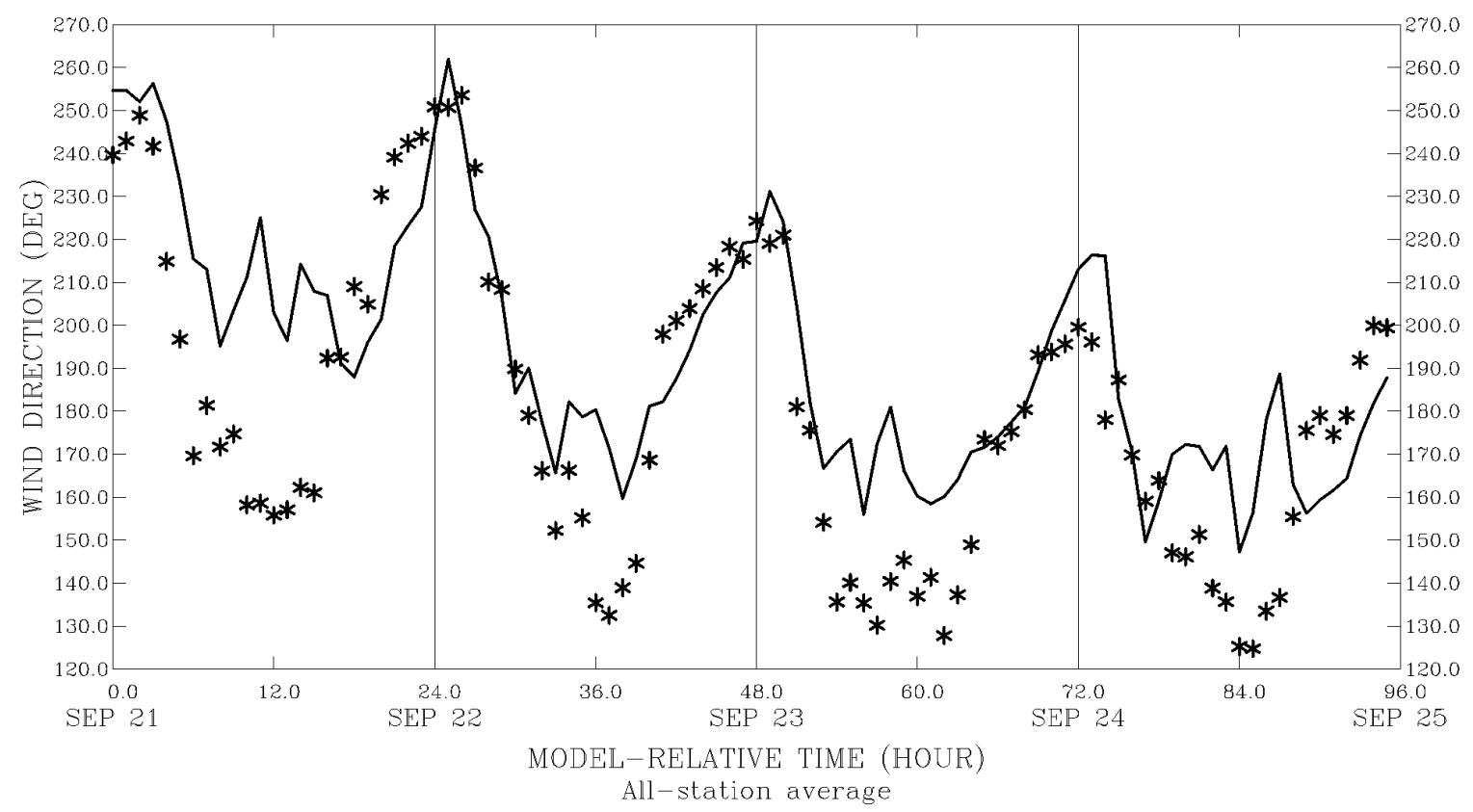

Figure 54. Evolution of domain-averaged surface-layer wind direction (deg.) at $12 \mathrm{~m} \mathrm{AGL}$ on the 5-km MM5 domain in the Analysis Nudging Experiment (Exp. 2) for 21-24 September 1997. Times shown on abscissa are forecast hours from the initial time, 0000 UTC, 21 September. Solid line is model-simulated mean, asterisks are hourly observed means. 


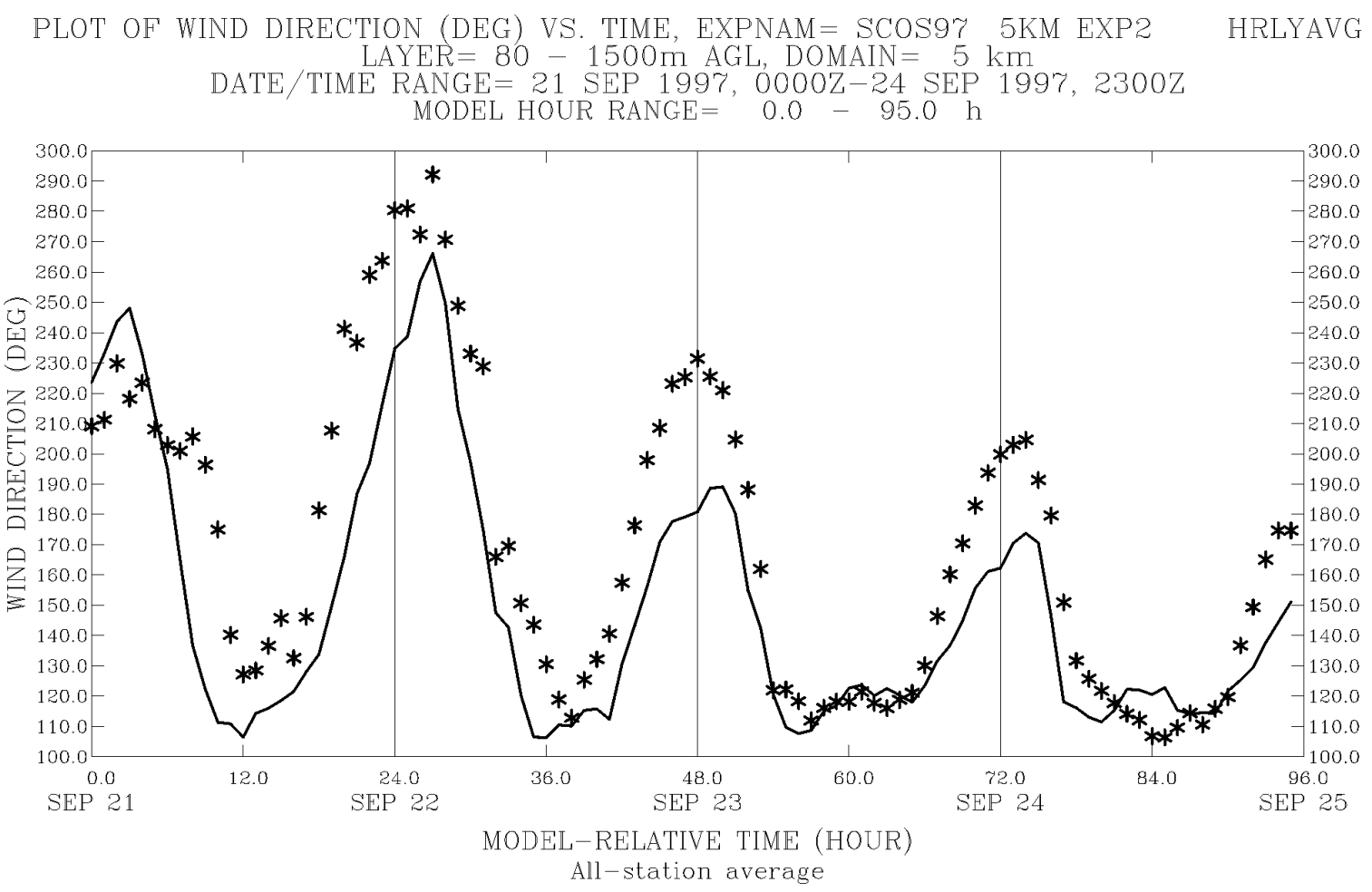

Figure 55. Evolution of domain-averaged wind direction (deg) in the layers from 25-1500 m AGL on the 5-km MM5 domain in the Analysis Nudging Experiment (Exp. 2) for 21-24 September 1997. Times shown on abscissa are forecast hours from the initial time, 0000 UTC, 21 September. Solid line is model-simulated mean, asterisks are hourly observed means. 
from Exp. 1 shown in Figures 32 and 33. With no direct assimilation of the synoptic-scale wind analyses in these layers, it is not surprising that comparison among these figures, and also in the statistical summaries of Tables 7 and 8 show no important reduction in the wind direction errors. However, in the mid- and upper-troposphere the tables reveal that the analysis nudging has induced an important reduction in the direction errors. In fact the mean errors in Table 8 show that direction bias has been practically eliminated above $1500 \mathrm{~m}$. Moreover, the RMS error for wind direction in these upper layers has been reduced by $\sim 33-67 \%$.

In summary, the introduction of analysis nudging in Exp. 2 produced very positive impacts on the wind speed and direction errors in the middle and upper troposphere (above $1500 \mathrm{~m} \mathrm{AGL),}$ where the synoptic-scale analyses could be assimilated directly. A similar reduction of temperature errors in the same layers cannot be verified directly because there are insufficient temperature data aloft in the SCOS-97 database to perform a meaningful statistical validation. However, application of analysis nudging in many other studies where data were more plentiful, both in CA (e.g., Seaman et al. 1995) and in other parts of the country, strongly suggest that the thermal field aloft has probably been affected favorably in this case as well. Importantly, the dynamical response to the upper-level wind and mass field nudging led to a dynamical response in the "boundary" layer that significantly reduced wind speed errors in that region and also led to small reductions in the direction errors. In the surface layer, however, the impact on temperature errors was somewhat negative (colder bias), while the effect on winds was inconclusive. Nevertheless, the overall impact of the analysis nudging was overwhelmingly positive.

\subsection{Experiment 2.5: Analysis Nudging with Refined Land/Sea Temperatures}

Assessment of results to this point led to the conclusion that the greatest remaining errors are related primarily to the very cold bias in the simulated surface-layer temperatures in Exps. 1 and 2. The cold bias, in turn, appears to be the result of two causes. First, satellite data from NASA's JPL suggest that NCEP analyses used originally contained excessively cold coastal seasurface temperatures. Second, the default method by which the MM5 preprocessors estimate deep soil temperature is likely to produce values that are too cold for this late September episode. The combination of these two errors in the lower-boundary conditions, both of which are specified at the episode initial time as constant fields, can be significant. Thus, a supplemental diagnostic Exp. 2.5 was designed (Section 3.2) in which the deep soil temperatures and seasurface temperatures were warmed by several degrees $C$. In the case of the former, the empirical change was based on the climatology of seasonal temperature cycles at depths of 0.5-1.0 m. In the case of the latter, NASA satellite measurements of sea-surface temperature based on AVHRR data were used to replace the NCEP analyses (Figure 9).

Since the only change introduced in Exp. 2.5 is through the lower boundary conditions for temperature, it is expected that the MM5 solutions will be affected primarily through the surfacelayer thermal simulations. (Recall that the initial atmospheric fields are not altered in any of the experiments discussed in this report.) Thus, any changes in the MM5's atmospheric simulations in Exp. 2.5 must occur through the direct impact of the surface fluxes of heat, moisture and momentum. Indirect effects on temperature above the surface should also be evident as a consequence of turbulent mixing of heat from the surface layer into the rest of the convective 
boundary layer. The change in turbulent transport of sensible heat also can result in changes to the boundary-layer depth, as well. Next, the thermal changes in the surface and boundary layers can have indirect minor impacts on the mid- and upper-tropospheric temperatures. Through dynamic adjustments, the winds at all layers can be affected by alterations in the mass field (thermal field), but the impact is likely to be minor. Finally, the FDDA (analysis nudging) used in Exp. 2 is also imposed in Exp. 2.5. Thus, any changes occurring in the model solutions above $1.5 \mathrm{~km}$ due to the different thermodynamic forcing will also result in somewhat different responses by the FDDA scheme, depending on the local model deviations in time and space from the assimilated fields.

To evaluate Exp. 2.5, we first examine the temperature fields at 1200 UTC, 21 September, at the $+12 \mathrm{~h}$ time of the simulation (Figures 56 and 57). Comparison of the surface-layer field in Figure 56 with the corresponding surface temperatures from Exp. 2 in Figure 41 reveals that temperatures over the ocean are 4-6 $\mathrm{C}$ warmer because of the warmer NASA sea-surface temperatures. This rapid adjustment of the air temperature, after only $12 \mathrm{~h}$, is expected because the warmer water generates larger positive surface sensible heat fluxes. The surface heat flux, in turn, destabilizes the marine boundary layer leading to enhanced turbulence production and rapid upward transport of heat through the layer. Comparison of Figures 57 and $\mathbf{4 3}$ confirms that the entire marine layer is 4-8 C warmer in Exp. 2.5, especially close to the coast at Pt. Dume. Meanwhile, it can be seen that the simulated temperatures over Los Angeles at dawn on 21 September are 20-21 C in Exp. 2.5, or about 6-7 C warmer than in Exp. 2. However, Figure 15 shows that the observed temperatures at this time in downtown Los Angeles were mostly about $18 \mathrm{C}$, so at least for this morning Exp. 2.5 appears to be 2-3 C too warm along the coast. Table 9 indicates that the domain-averaged surface-layer temperature bias for the entire episode is decreased greatly in Exp. 2.5 to only $-0.9 \mathrm{C}$, versus $-3.8 \mathrm{C}$ in Exp. 2. Because of the large drop in the mean error, the case-average MAE and RMS errors for the surface-layer temperatures also dropped substantially, to $2.8 \mathrm{C}$ and $3.5 \mathrm{C}$ respectively. The positive impact of the modified lower boundary conditions on the surface temperatures in Exp. 2.5 was favorable enough that the same conditions were adopted subsequently for Exps. 3 and 4 (also see Sec. 3.2).

At the end of the first daytime period, at 0000 UTC ( +24 h), 22 September, Figure 58 shows that the temperatures simulated in the LA Basin by Exp. 2.5 are $\sim 2-3 \mathrm{C}$ warmer than shown in Figure 46 for Exp. 2. Farther east over the CA deserts, Exp. 2.5 simulated temperatures that are generally warmer by 1-2 C. Figure 59, however, suggests that the warmer low-level temperatures in Exp. 2.5 have had little impact on the surface-layer wind pattern at $+24 \mathrm{~h}$ (compare with Figure 45). As expected, the warmer surface layer does lead to greater turbulent kinetic energy (not shown) and results in stronger vertical turbulent transport of thermal energy. The overall pattern of the boundary layer depth for Exp. 2.5 (Figure 60) appears similar to that in Exp. 2 (Figure 47), but careful examination shows maximum depths over the desert are 300 $500 \mathrm{~m}$ greater due to the enhanced surface heat fluxes. Finally, the east-west cross section of potential temperature for 0000 UTC $(+24 \mathrm{~h})$ shown in Figure 61 indicates that the mixed layer in the eastern desert is indeed several hundred meters deeper than in Exp. 2 (Figure 48). The deepening of the marine boundary layer also can be noticed in the same figure close to the coastline near San Diego, although the change is considerably less than over the desert. In this southern region of the 5-km MM5 domain, the warming of the sea-surface is considerably less $(\sim 3 \mathrm{C})$ than farther north near Pt. Dume, so the marine inversion is only slightly weaker in this 
Table 9. Statistical evaluation for Exp. 2.5 (Analysis-Nudging with Refined Land/Sea Temperatures) for the SCOS-97 episode of 21-24 September 1997. Statistics shown are mean errors (ME), mean absolute errors (MAE) and root mean square errors (RMS). Above the surface, statistics from individual MM5 calculation levels are merged into composite layers as weighted averages for the approximate boundary layer $(25-1500 \mathrm{~m})$, lower troposphere $(1500-5000 \mathrm{~m})$ and upper troposphere $(5000-10500 \mathrm{~m})^{*}$.

\begin{tabular}{|c|c|c|c|c|c|c|c|c|c|c|c|c|}
\hline \multirow[t]{2}{*}{$\begin{array}{c}\text { Verification } \\
\text { Layer (AGL) }\end{array}$} & \multicolumn{3}{|c|}{$\begin{array}{l}\text { Temperature } \\
\text { (C) }\end{array}$} & \multicolumn{3}{|c|}{$\begin{array}{c}\text { Mixing Ratio } \\
\text { (g/kg) }\end{array}$} & \multicolumn{3}{|c|}{$\begin{array}{c}\text { Wind Speed } \\
(\mathrm{m} / \mathrm{s})\end{array}$} & \multicolumn{3}{|c|}{$\begin{array}{l}\text { Wind Direct. } \\
\text { (degrees) }\end{array}$} \\
\hline & ME & MAE & RMS & ME & MAE & RMS & ME & MAE & RMS & ME & MAE & RMS \\
\hline $5000-10500 \mathrm{~m}$ & - & - & - & 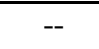 & - & - & -0.46 & 1.70 & 1.70 & -1.14 & 11.8 & 11.8 \\
\hline $1500-5000 \mathrm{~m}$ & -- & - & -- & -- & -- & - & -0.00 & 2.11 & 2.48 & +0.26 & 24.1 & 29.7 \\
\hline $25-1500 \mathrm{~m}$ & -- & -- & -- & -- & -- & -- & +0.24 & 1.79 & 2.27 & -3.79 & 41.0 & 54.2 \\
\hline $12 \mathrm{~m} \mathrm{AGL}$ & -0.92 & 2.79 & 3.50 & +2.96 & 3.18 & 3.86 & -0.32 & 1.41 & 1.88 & -0.40 & 58.6 & 75.4 \\
\hline
\end{tabular}

* Note that no statistics appear for the temperature and mixing ratio above the surface because the 5-km model domain did not have supplemental upper-air measurement systems during SCOS-97 capable of taking observations for these variables more often than twice per day. Winds aloft are obtained from up to 27 radar wind profilers operated during the study period. 


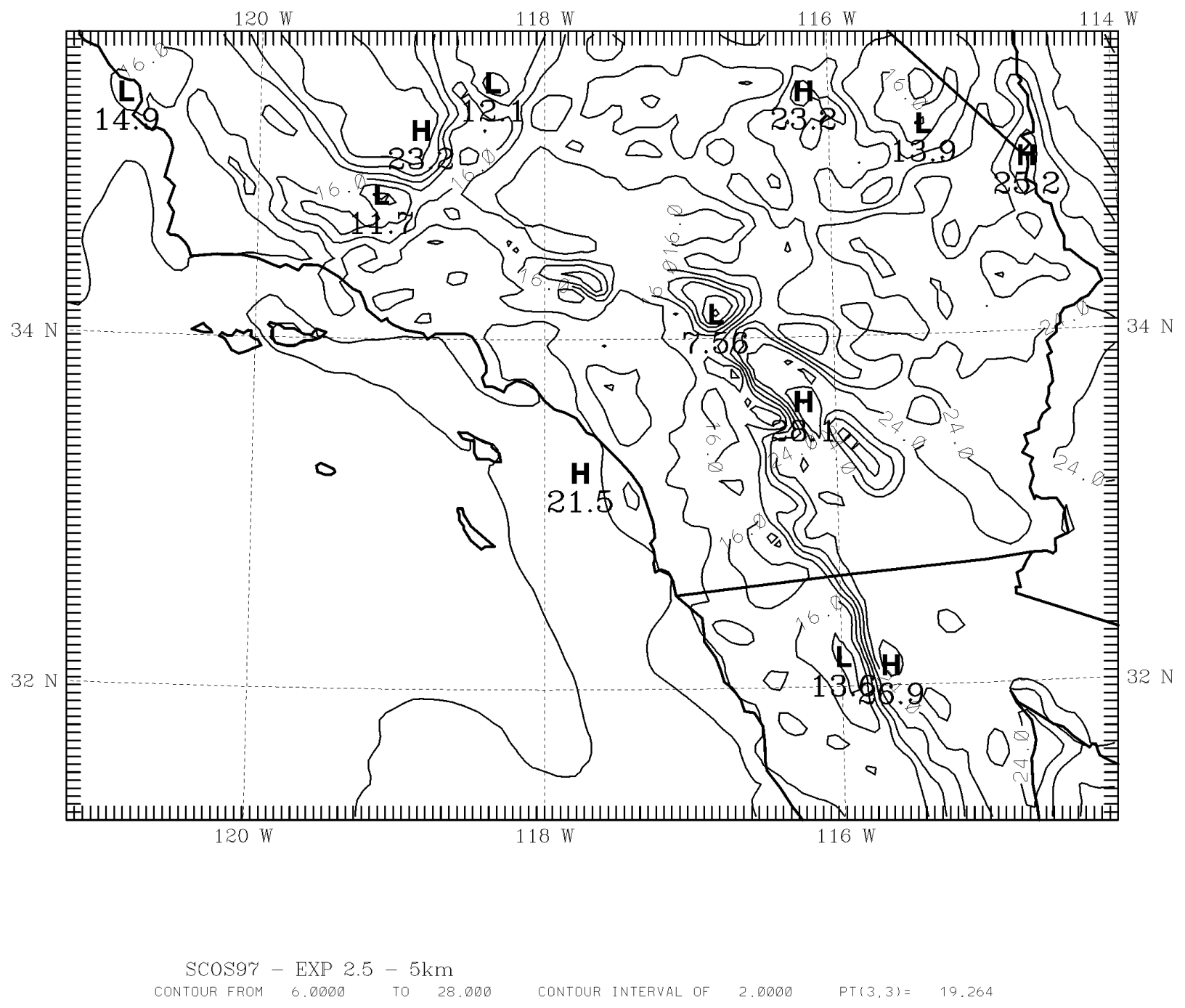

Figure 56. MM5 simulated temperatures (C) in the surface layer (12 m AGL) on the 5-km domain, valid for 1200 UTC, 21 September 1997, $(+12 \mathrm{~h})$ in Exp. 2.5. Isotherm interval is 2 C. 
$\left(X_{1}, Y_{1}\right)=(47,5) \quad\left(X_{2}, Y_{2}\right)=(47,93)$ THETA $\left(K \quad, \quad 1997-\emptyset 9-21 \_12: \varnothing \emptyset: \emptyset \emptyset \quad S M=\varnothing\right.$

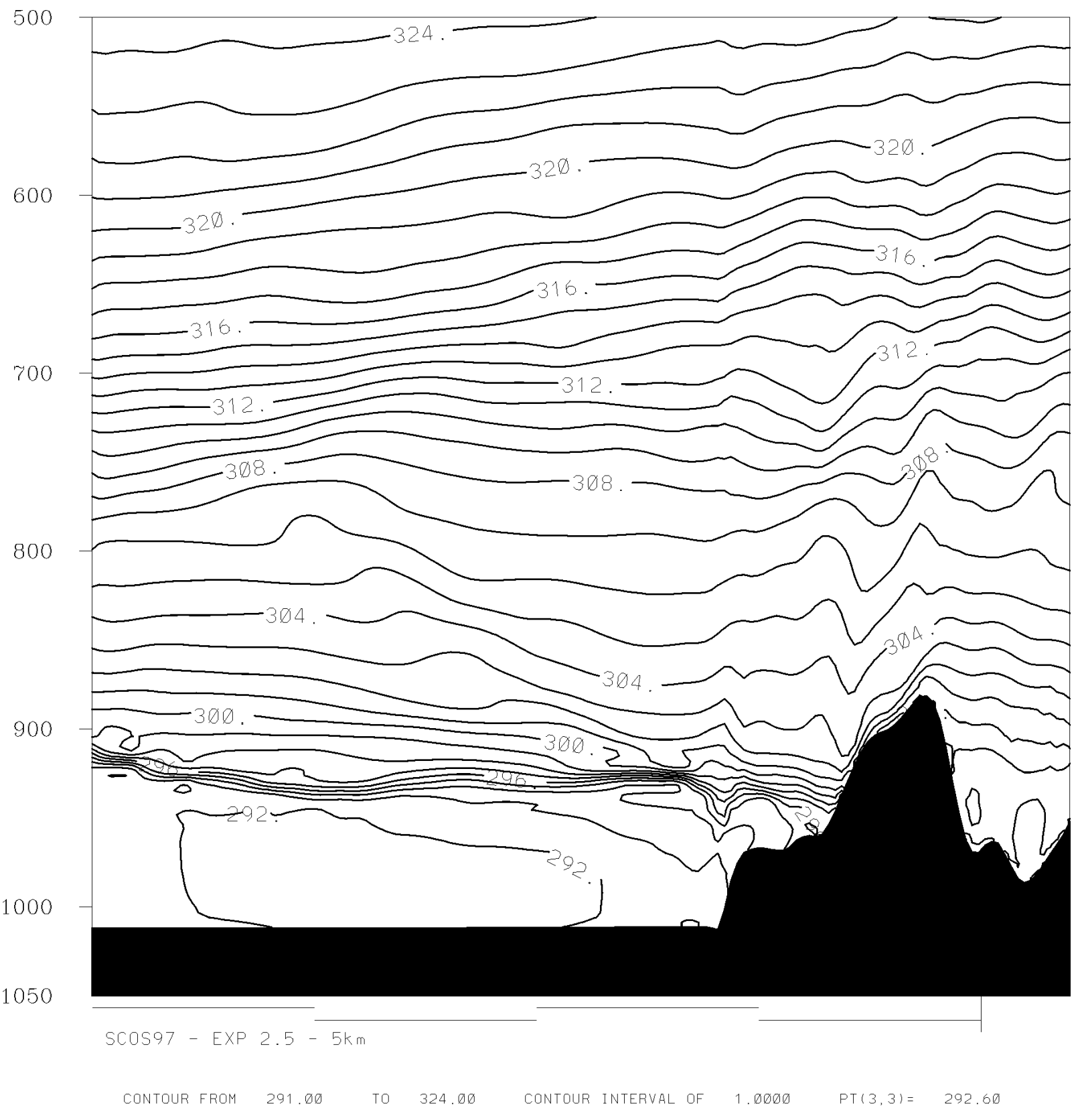

Figure 57. MM5 simulated potential temperature, $\theta(\mathrm{K})$ on the 5-km domain plotted versus pressure in the plane of the Pt. Dume north-south cross section, valid for 1200 UTC, 21 September 1997, $(+12 \mathrm{~h})$ in Exp. 2.5. Isentrope interval is $1 \mathrm{~K}$. 


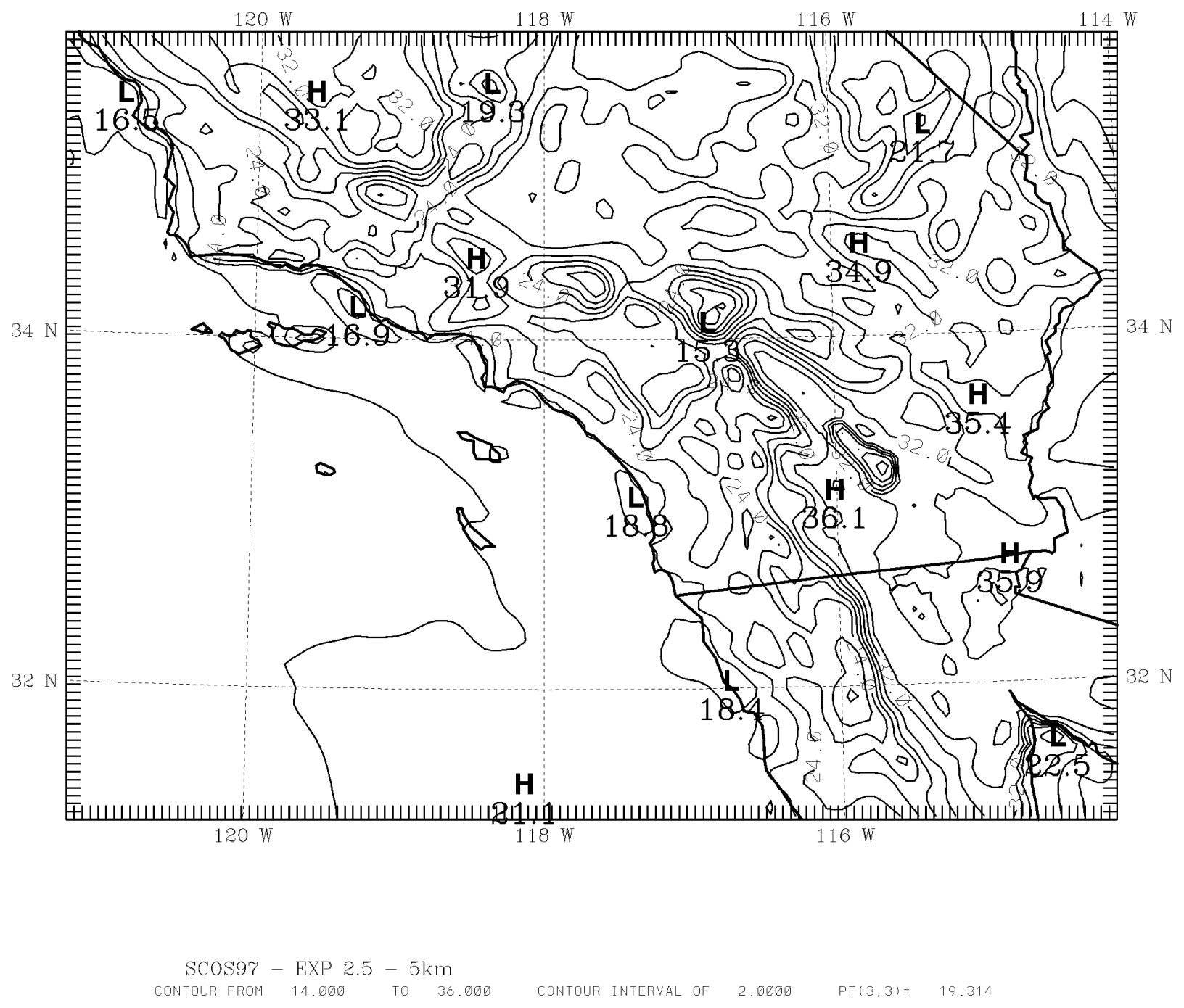

Figure 58. MM5 simulated temperatures (C) in the surface layer (12 m AGL) on the 5-km domain, valid for 0000 UTC, 22 September 1997, $(+24 \mathrm{~h})$ in Exp. 2.5. Isotherm interval is 2 C. 


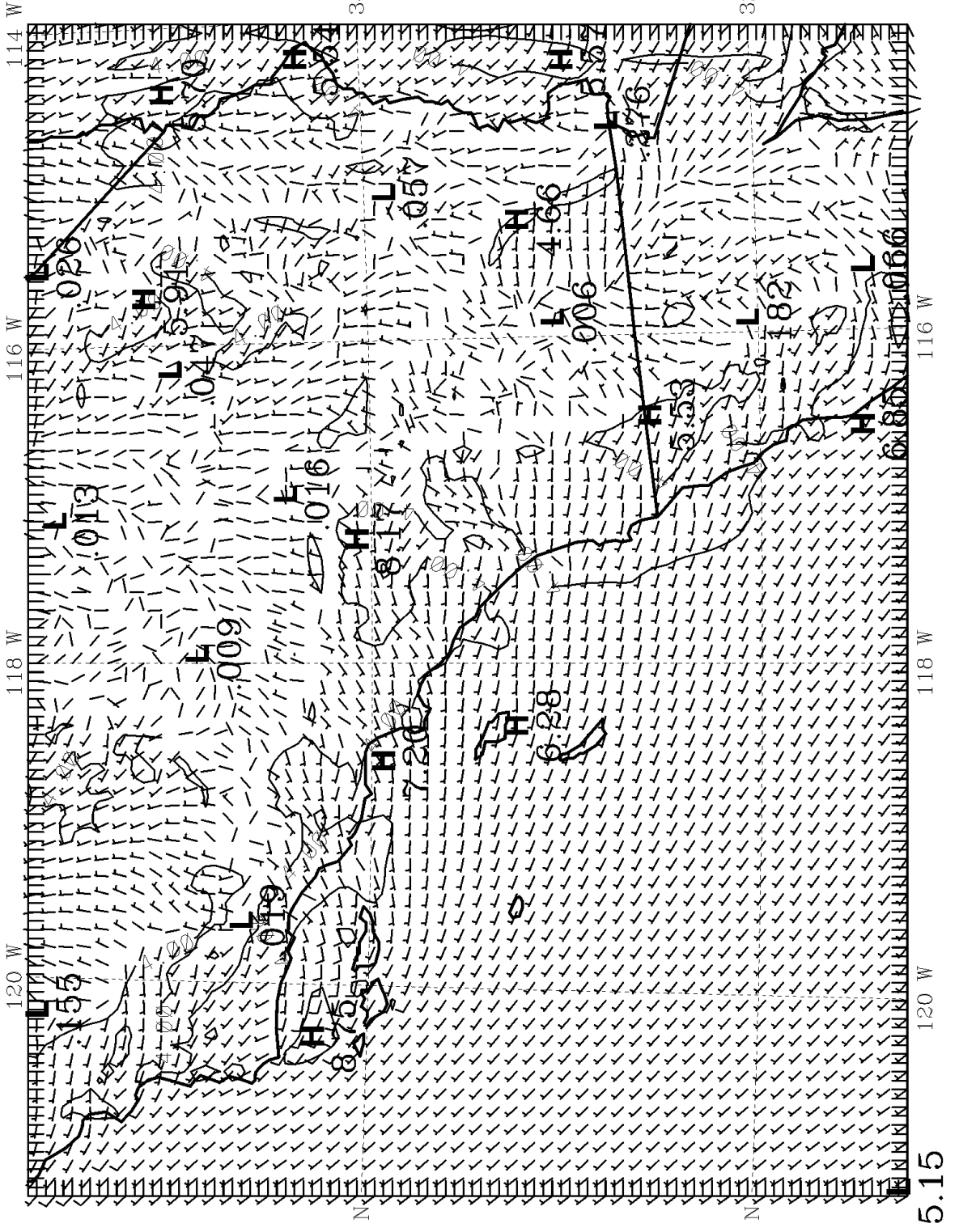




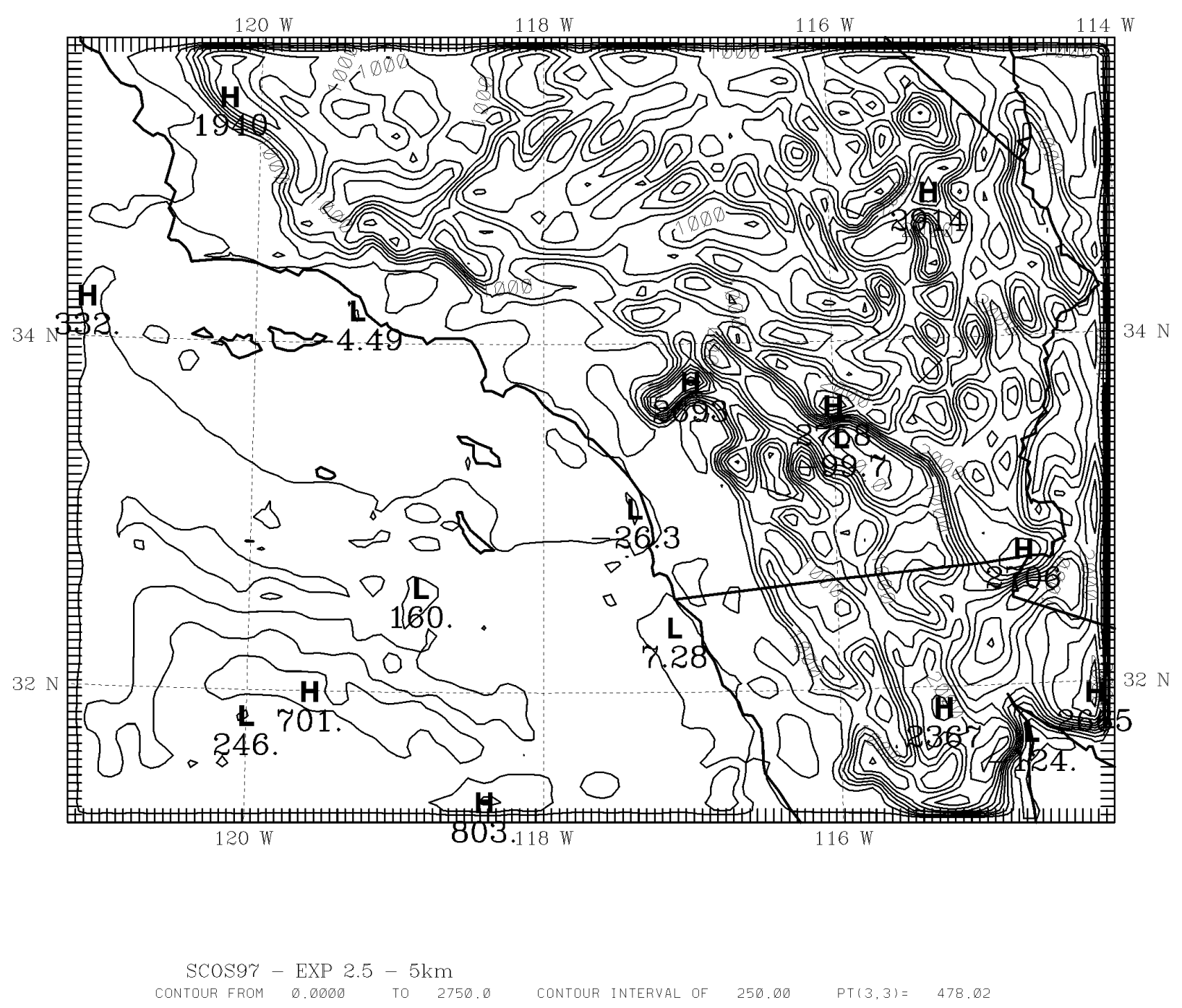

Figure 60. MM5 simulated mixed-layer depths (m) on the 5- $\mathrm{km}$ domain, valid for 0000 UTC, 22 September 1997, (+24 h) in Exp. 2.5. Contour interval is $250 \mathrm{~m}$. 


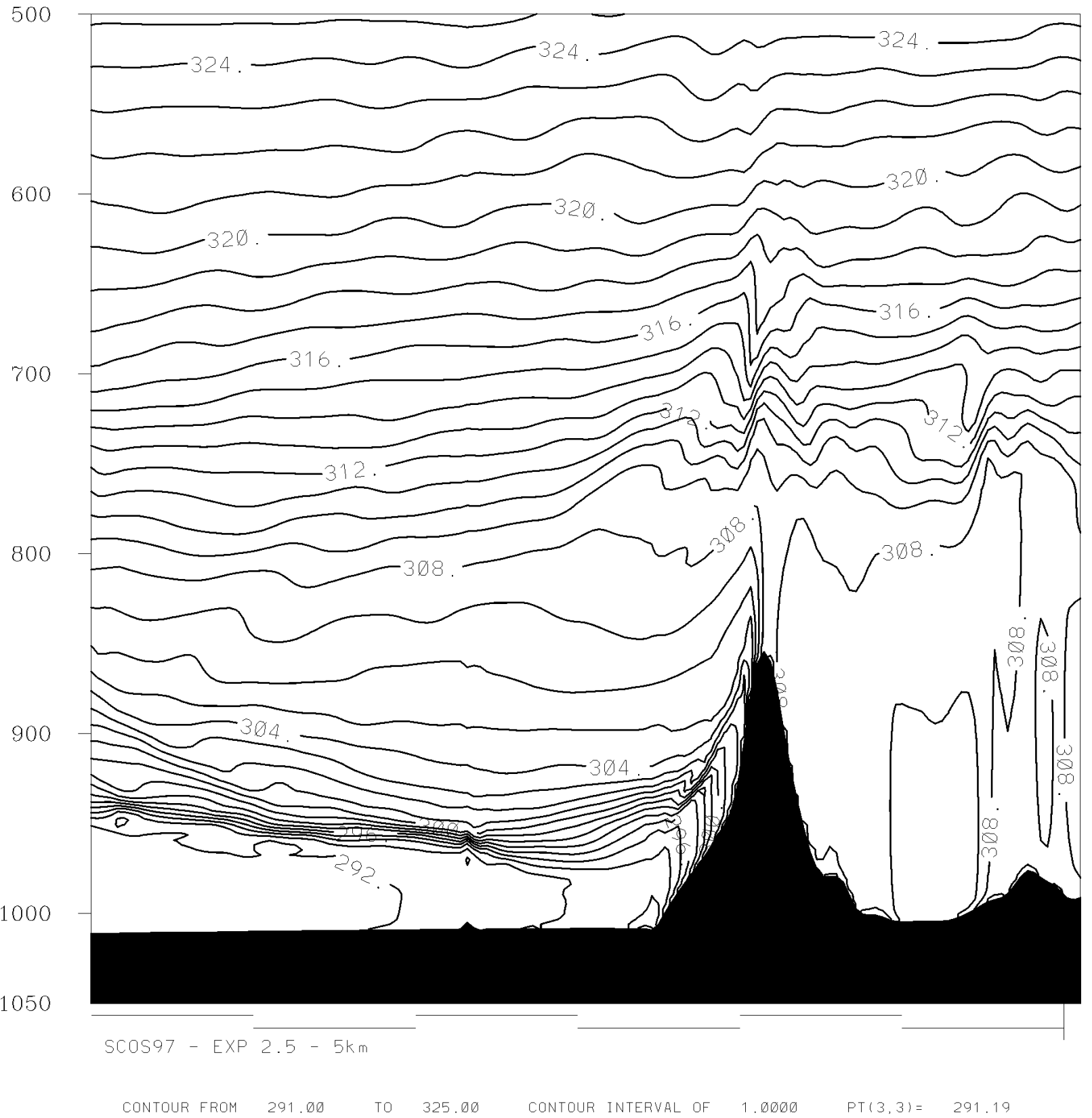

Figure 61. MM5 simulated potential temperature, $\theta(\mathrm{K})$ on the 5-km domain plotted versus pressure in the plane of the San Diego west-east cross section, valid for 0000 UTC, 22 September 1997, (+24 h) in Exp. 2.5. Isentrope interval is $1 \mathrm{~K}$. 
area. However, the much warmer marine layer from Pt. Conception to Pt. Dume causes the inversion to be weakened by half in the north (not shown). Despite the weaker marine inversion, the descending northerly winds crossing the San Rafael Mountains during the first half of the episode (not shown) do not erode the marine layer, so that the model correctly prevents hot Santa Ana winds from developing in the coastal regions.

Next, we examined the results of statistical analyses for Exp. 2.5 and compared them to those from Exp. 2. Figure 62 shows the evolution of domain-averaged surface temperatures in Exp. 2.5 versus mean hourly observed temperatures. Comparison with Figure $\mathbf{5 1}$ from Exp. 2 reveals that the daily temperature minimums are much more accurate in Exp. 2.5 as a result of the modified lower boundary conditions. The nocturnal temperatures for 21-22 September are 1-2 C too warm, but then become $\sim 1 \mathrm{C}$ too cool on 23 September. The afternoon maximums tend to be 2-3 $\mathrm{C}$ too cool in Exp. 2.5, but these errors are less than found in Exp. 2. Tables 8 and 9 indicate bias has been reduced by over $3 \mathrm{C}$, with substantial error reductions for the MAE and RMSE of temperature, as well. A negative consequence of the warmer surface temperatures, especially over the ocean, is that surface evaporation has been increased in Exp. 2.5, leading to higher surface mixing ratios. Figure 63 shows that the model has grown about $2 \mathrm{~g} \mathrm{~kg}^{-1} \mathrm{more}$ moist. Tables 8 and 9 indicate that the mixing ratio bias has grown from $+0.83 \mathrm{~g} \mathrm{~kg}^{-1}$ in Exp. 2 to $+2.96 \mathrm{~g} \mathrm{~kg}^{-1}$ in Exp. 2.5.

Of considerable note, comparison of Figures 64 and 65 (Exp. 2.5) to Figures 52 and 53 (Exp. 2) show the surface and boundary layer winds have improved somewhat due to the introduction of the warmer lower boundary conditions. This result has to occur indirectly through adjustment of the winds to changes in the mesoscale mass fields, since no change was made that directly affected the wind field. One of the more important changes in Exp. 2.5 is that the observed afternoon maximum in wind speed, when the sea breeze is strongest and downward turbulent transport of mid-level momentum should be greatest, has been intensified in the model, compared to Exp. 2. Tables 8 and 9 reveal that the episode surface-layer bias in speed has been reduced from $-0.40 \mathrm{~ms}^{-1}$ in Exp. 2 to $-0.32 \mathrm{~ms}^{-1}$ in Exp. 2.5. In the approximate boundary layer (25-1500 m AGL), the bias reduction is from $+0.44 \mathrm{~ms}^{-1}$ to $+0.24 \mathrm{~ms}^{-1}$, respectively. Similar small error reductions are found for the MAE and RMSE in Exp. 2.5. However, there is no similar reduction of statistical errors for wind direction shown in Tables 8 and 9. Apparently, the local sub-grid variability is still the dominant cause of wind direction errors near the surface. A quick glance at Figures 66 and 67 confirms that direction errors remain rather large, especially at the surface, even though the model has reproduced the main diurnal trends observed in the directions. Careful comparison between Figure 67 (Exp. 2.5) and Figure 55 (Exp. 2) shows that the model's overall wind direction evolution in the boundary layer of Exp. 2.5 is somewhat closer to the observed evolution than in Exp. 2. In particular, note that the simulated diurnal range, especially from 0000 UTC, 22 Sept., to 0600 UTC, 24 Sept., is greater and so is closer to the observed range of direction. Thus, although this clear indication of wind direction improvement is not reflected in the statistics, it would seem reasonable that the regional transport of pollutants in the SoCAB on time scales of 6-24 h must be more accurate in Exp. 2.5 as a result of the modified lower boundary conditions. 
PLOT OF TEMP (C) VS. TIME, EXPNAM= SCOS97 5KM EXP2.5 HRLYAVG

LAYER = sfc layer $(40 \mathrm{~m}) \mathrm{AGL}$, DOMAIN $=5 \mathrm{~km}$

DATE/TIME RANGE= 21 SEP 1997, 0000Z-24 SEP 1997, $2300 Z$ MODEL HOUR RANGE $=0.0-95.0 \mathrm{~h}$

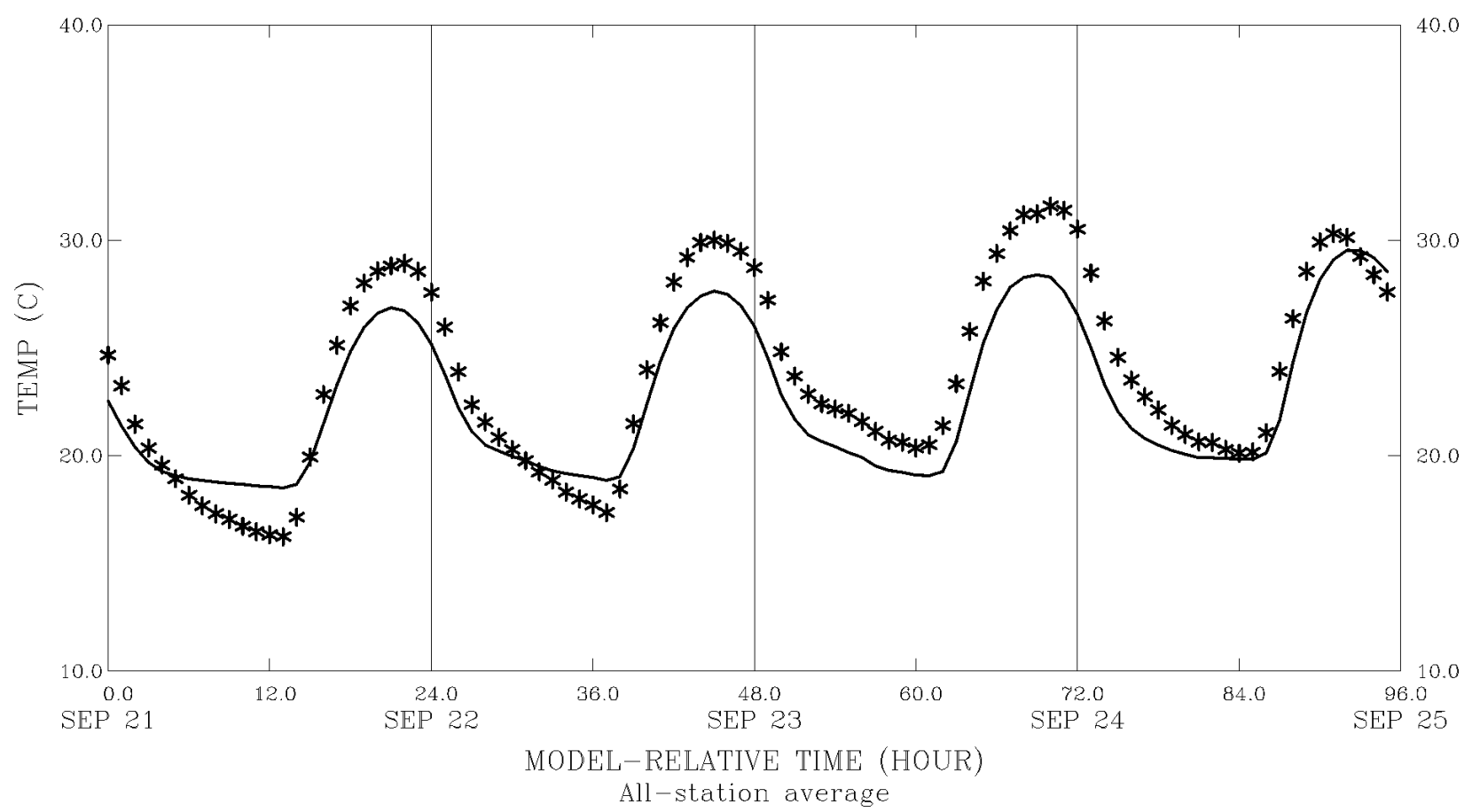

Figure 62. Evolution of domain-averaged surface-layer temperature (C) at $12 \mathrm{~m}$ AGL on the 5-km MM5 domain in the Modified Analysis Nudging Experiment (Exp. 2.5) for 21-24 September 1997. Times shown on abscissa are forecast hours from the initial time, 0000 UTC, 21 September. Solid line is model-simulated mean, asterisks are hourly observed means. 

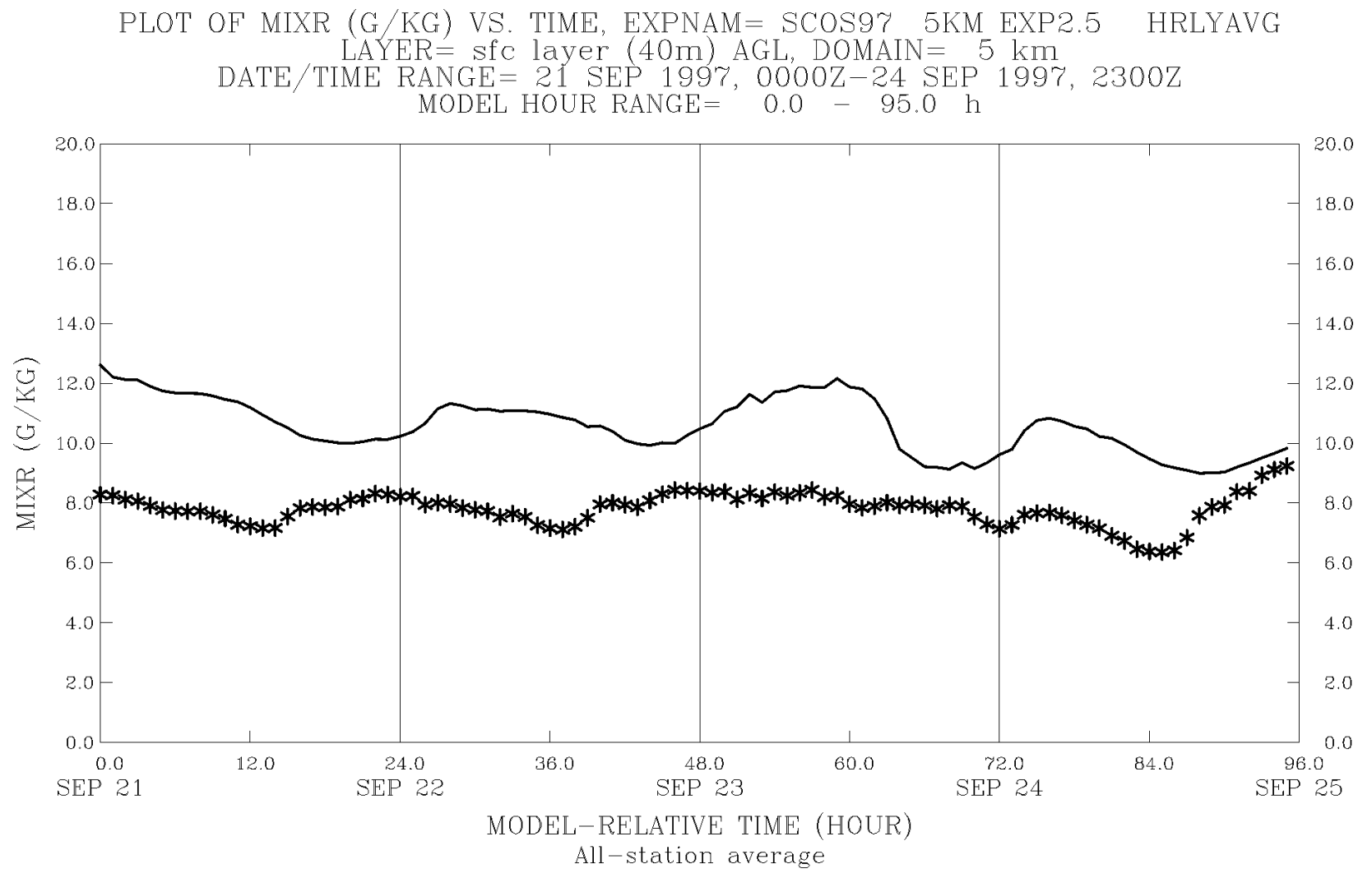

Figure 63. Evolution of domain-averaged surface-layer mixing ratio $\left(\mathrm{g} \mathrm{kg}^{-1}\right)$ at $12 \mathrm{~m} \mathrm{AGL} \mathrm{on}$ the 5-km MM5 domain in the Modified Analysis Nudging Experiment (Exp. 2.5) for 21-24 September 1997. Times shown on abscissa are forecast hours from the initial time, 0000 UTC, 21 September. Solid line is model-simulated mean; asterisks are hourly observed means. 


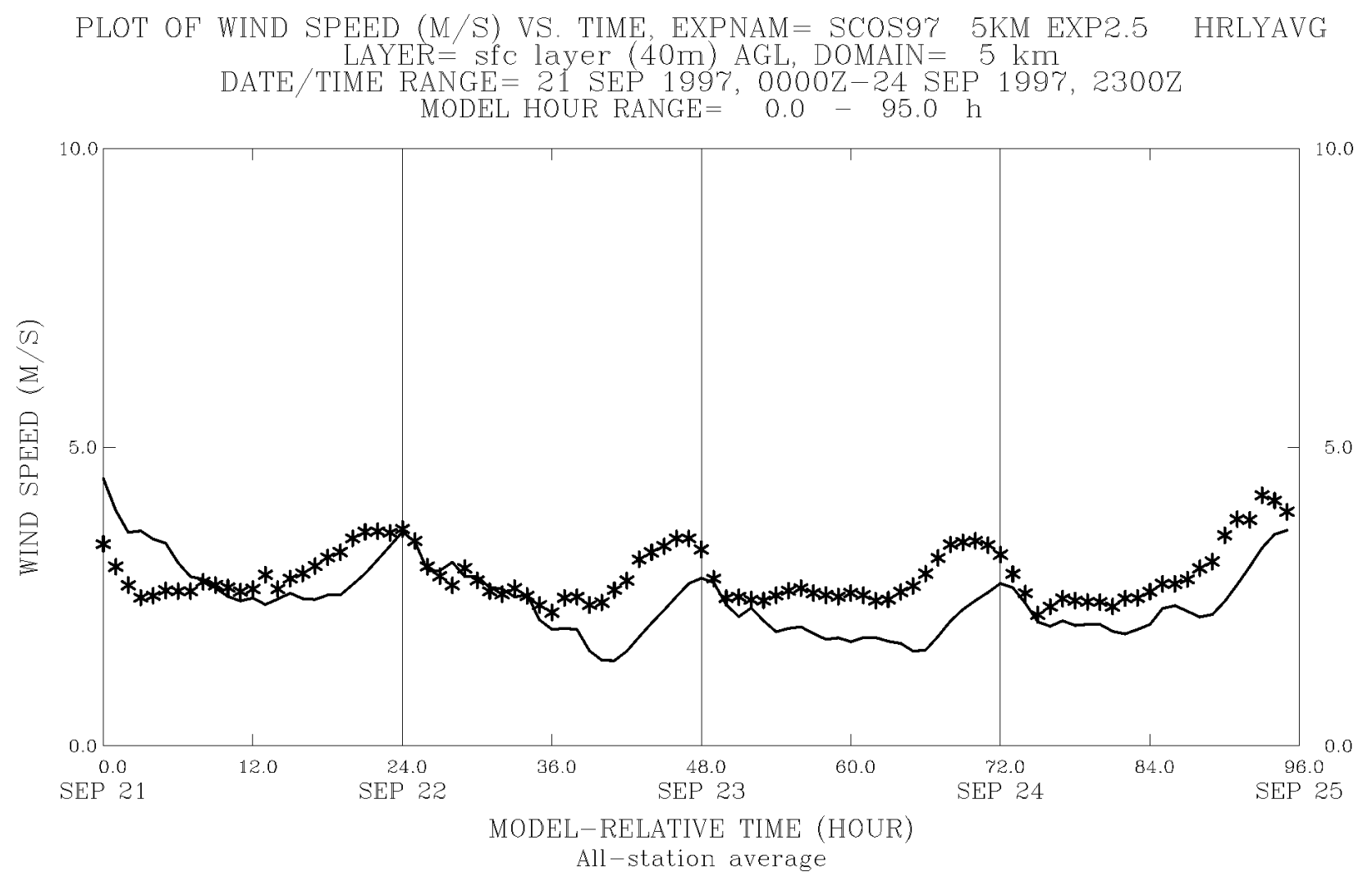

Figure 64. Evolution of domain-averaged surface-layer wind speed $\left(\mathrm{ms}^{-1}\right)$ at $12 \mathrm{~m} \mathrm{AGL}$ on the 5-km MM5 domain in the Modified Analysis Nudging Experiment (Exp. 2.5) for 21-24 September 1997. Times shown on abscissa are forecast hours from the initial time, 0000 UTC, 21 September. Solid line is model-simulated mean; asterisks are hourly observed means. 
PLOT OF WIND SPEED (M/S) VS. TIME, EXPNAM= SCOS97 $5 \mathrm{KM}$ EXP2.5 HRLYAVG $\mathrm{LAYER}=80-1500 \mathrm{~m}$ AGL, DOMAIN $=5 \mathrm{~km}$ DATE/TIME RANGE = 21 SEP 1997, 0000Z-24 SEP 1997, $2300 Z$ MODEL HOUR RANGE $=0.0-95.0 \mathrm{~h}$

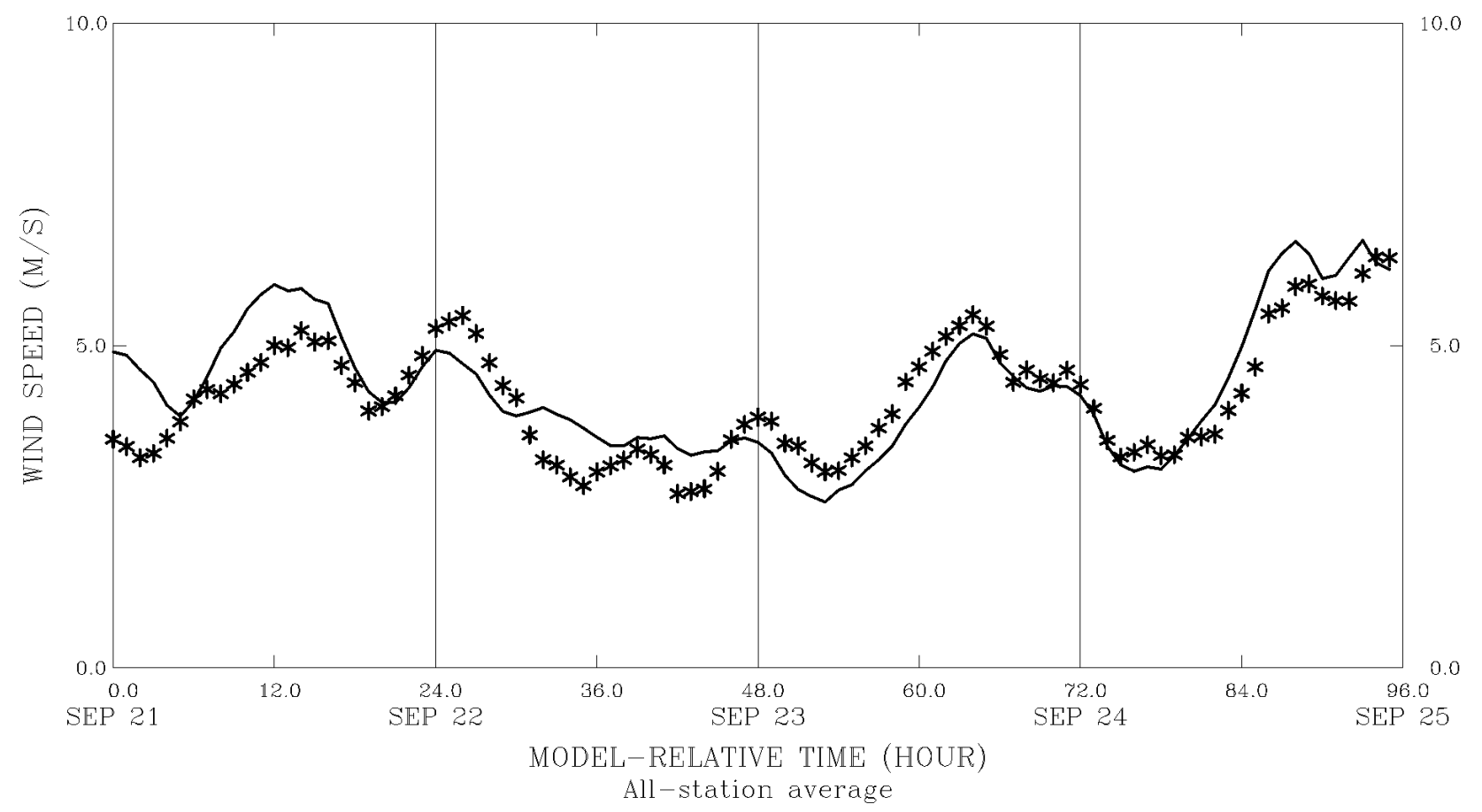

Figure 65. Evolution of domain-averaged wind speed $\left(\mathrm{ms}^{-1}\right)$ in the layers from $25-1500 \mathrm{~m}$ AGL on the 5-km MM5 domain in the Modified Analysis Nudging Experiment (Exp. 2.5) for 21-24 September 1997. Times shown on abscissa are forecast hours from the initial time, 0000 UTC, 21 September. Solid line is model-simulated mean, asterisks are hourly observed means. 
PLOT OF WIND DIRECTION (DEG) VS. TIME, EXPNAM= SCOS97 5KM EXP2.5 HRLYAVG LAYER $=$ sfc layer $(40 \mathrm{~m}) \mathrm{AGL}, \mathrm{DOMAIN}=5 \mathrm{~km}$

DATE/TIME RANGE= 21 SEP 1997, 0000Z-24 SEP 1997, 2300Z MODEL HOUR RANGE $=0.0-95.0 \mathrm{~h}$

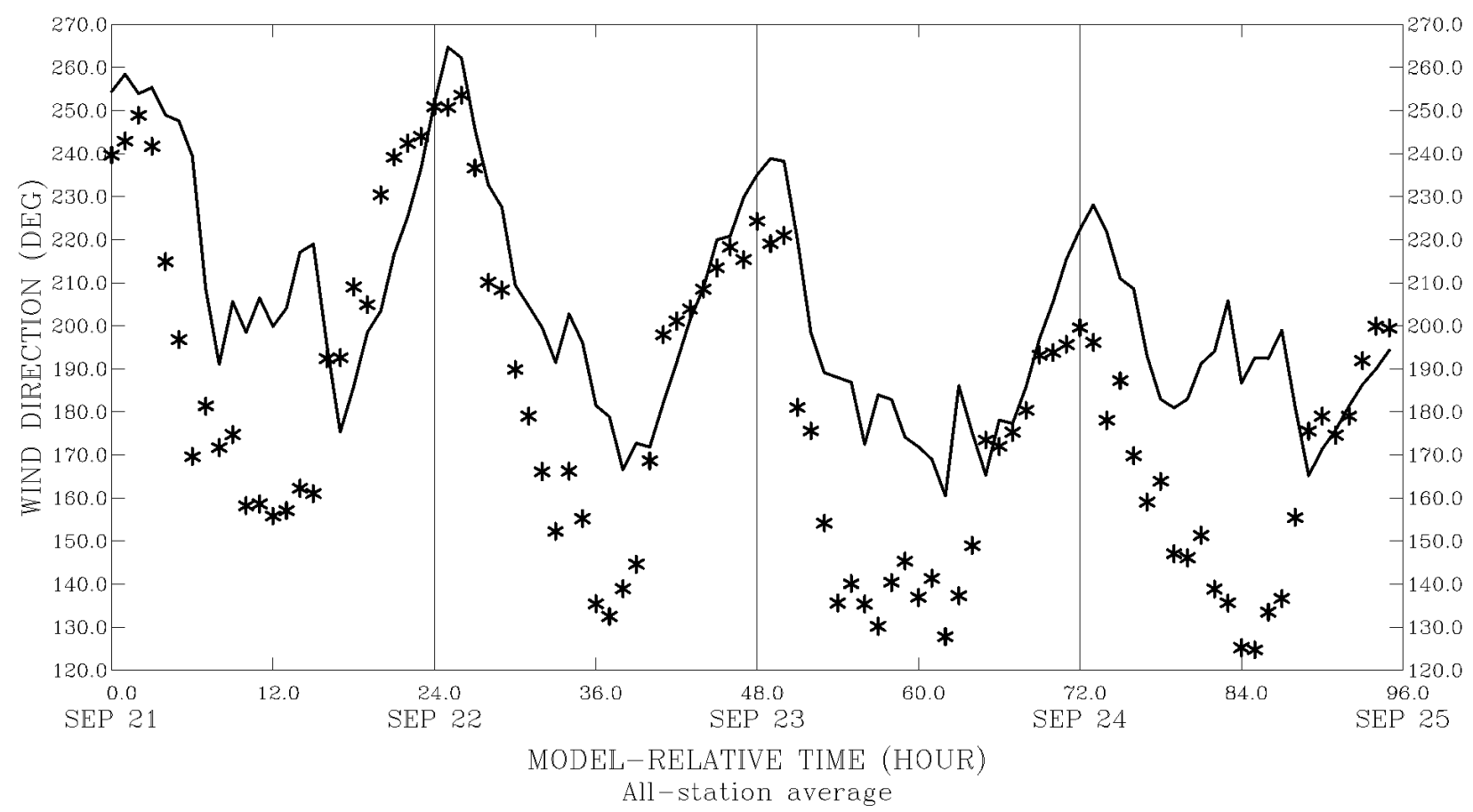

Figure 66. Evolution of domain-averaged surface-layer wind direction (deg.) at $12 \mathrm{~m}$ AGL on the 5-km MM5 domain in the Modified Analysis Nudging Experiment (Exp. 2.5) for 21-24 September 1997. Times shown on abscissa are forecast hours from the initial time, 0000 UTC, 21 September. Solid line is model-simulated mean, asterisks are hourly observed means. 
PLOT OF WIND DIRECTION (DEG) VS. TIME, EXPNAM= SCOS97 5KM EXP2.5 HRLYAVG LAYER $=80-1500 \mathrm{~m}$ AGL, DOMAIN $=5 \mathrm{~km}$

DATE/TIME RANGE= 21 SEP 1997, 0000Z-24 SEP 1997, 23007 MODEL HOUR RANGE $=0.0-95.0 \mathrm{~h}$

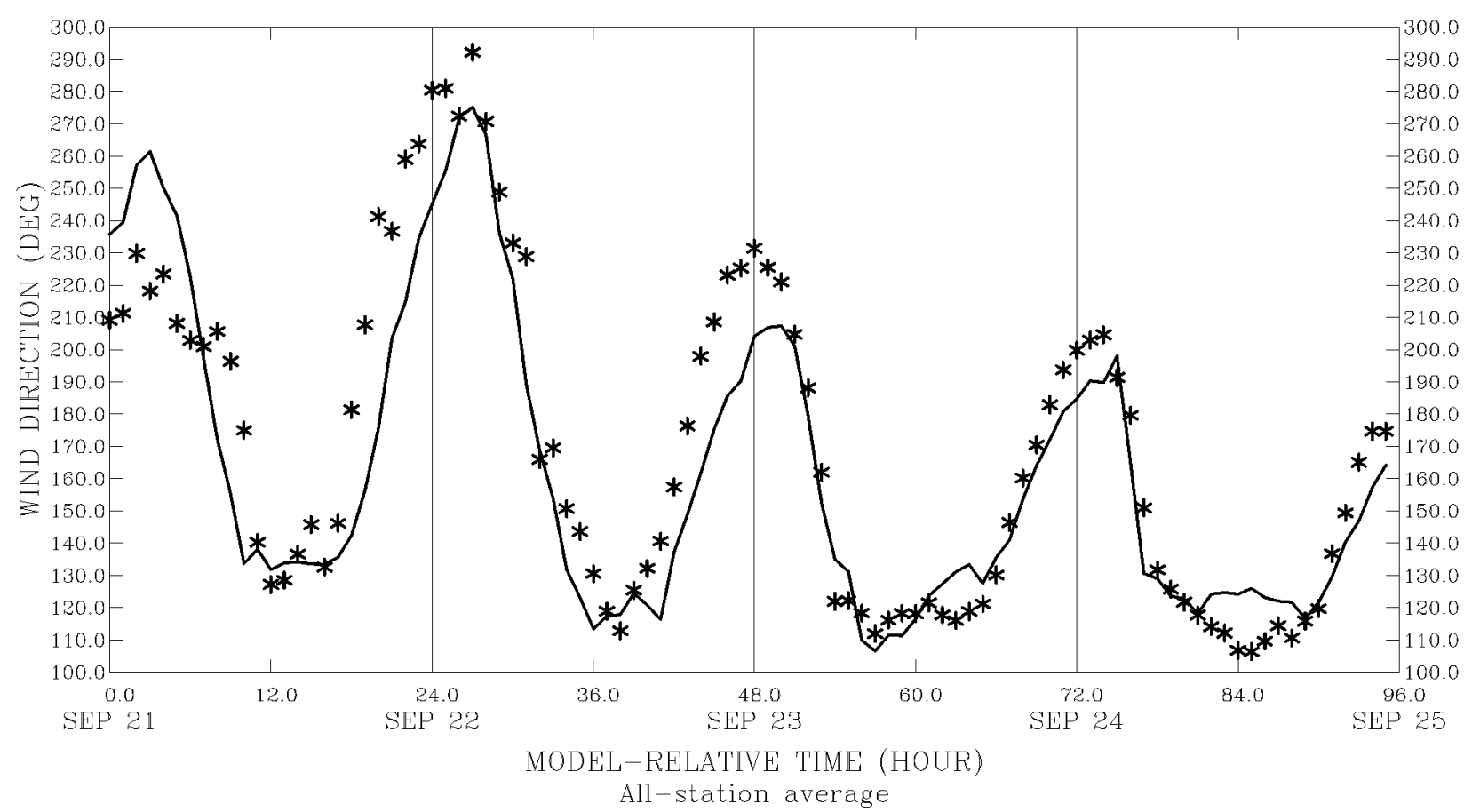

Figure 67. Evolution of domain-averaged wind direction (deg) in the layers from $25-1500 \mathrm{~m}$ AGL on the 5-km MM5 domain in the Modified Analysis Nudging Experiment (Exp. 2.5) for 21-24 September 1997. Times shown on abscissa are forecast hours from the initial time, 0000 UTC, 21 September. Solid line is model-simulated mean, asterisks are hourly observed means. 


\subsection{Experiment 3: $\quad$ Standard Observation Nudging}

Experiment 3 was run with the standard observation nudging approach, which assimilated all of the special SCOS-97 wind data discussed in Section 3.2, in addition to the analysis nudging used in Exps. 2 and 2.5. There were no special upper-air temperature and moisture soundings in the SCOS-97 database, so the observation nudging is confined to surface and upper-air (profiler) winds. Additionally, the refined sea-surface temperatures and deep-soil temperatures developed for Exp. 2.5 are repeated in Exp. 3. Results from Exp. 3 will be compared primarily with those from Exps. 2 and 2.5, plus the plotted standard and special observations. Since Exp. 3 represents the experiment design of greatest interest, as expressed by ARB in the RFP, visual examinations in this section will be the more extensive and detailed than those presented for the other experiments.

First, Figure 68 shows the surface-layer wind field at 1200 UTC, 21 September, or $+12 \mathrm{~h}$ into Exp. 3. The corresponding wind field from Exp. 2.5 was not shown, but Figure 40 from Exp. 2 can be used for comparison at this early time of the 5-km MM5 simulations. Some fairly subtle, but important differences appear upon inspection of these figures. First, Figure 68 shows that Exp. 3 did not produce a low-level cyclonic eddy in the vicinity of the Santa Barbara Channel, as simulated by Exp. 2 shown in Figure 40. The flow in the channel at this time in Exp. 3 is weak and variable. Also, the generally northwest flow prevailing in Exp. 2 from San Nicolas Is. to San Diego is replaced in Exp. 3 by weaker west and southwest flow. These changes indicate that the large-scale thermal forcing responsible for the overall northwesterly flow (hot land, cold ocean) must be weaker in the CA Bight in Exp. 3. In fact, careful examination of the winds simulated in the LA Basin and along the coastline north of San Diego in Figure 68 indicate weak downslope (cold-air drainage) winds and very light offshore land breezes at 1200 UTC. This represents a reversal of the wind direction in the nocturnal model solution found in Exp. 2 at this time. Inspection of the observed surface winds at 1200 UTC in Figure 15 reveals that the solution in Figure 68 is predominantly correct. There is no indication of a closed eddy in the vicinity of the Santa Barbara Channel, while the non-calm wind reports in the LA Basin and north of San Diego consistently indicate downslope and offshore flows. The many calm wind observations in these areas confirms that the overall flow over land is very weak and quite shallow. Thus, it appears that the combination of obs-nudging and modified lower boundary conditions in Exp. 3 have produced essentially correct early morning flow in the model simulation.

Figures 69 and 70 show the surface-layer temperature and relative humidity for Exp. 3 at the same time, 1200 UTC, 21 September $(+12 \mathrm{~h})$. Temperatures in the LA Basin are simulated to be 18-20 C, while Figure 15 indicates observations mostly in the range of 16-18 C. Comparison of Figure 69 from Exp. 3 with Figure 56 from Exp. 2.5 indicates surface layer temperatures that are virtually the same. Since surface temperature data are not assimilated by the obs-nudging scheme, this result is consistent with expectations. Much cooler temperatures are simulated at higher elevations in the mountains surrounding the LA Basin ( 8-16 C) than at low elevations in the Basin. These cool temperatures are generally corroborated by the few surface observations available at these heights. The colder air over the mountains is produced by intense surface longwave flux divergence and is responsible for the drainage winds. Nocturnal cooling at high altitudes is rapid because of low humidity (Figure 70). Also notice in Figure 69 that there is a 


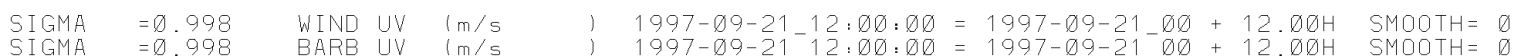

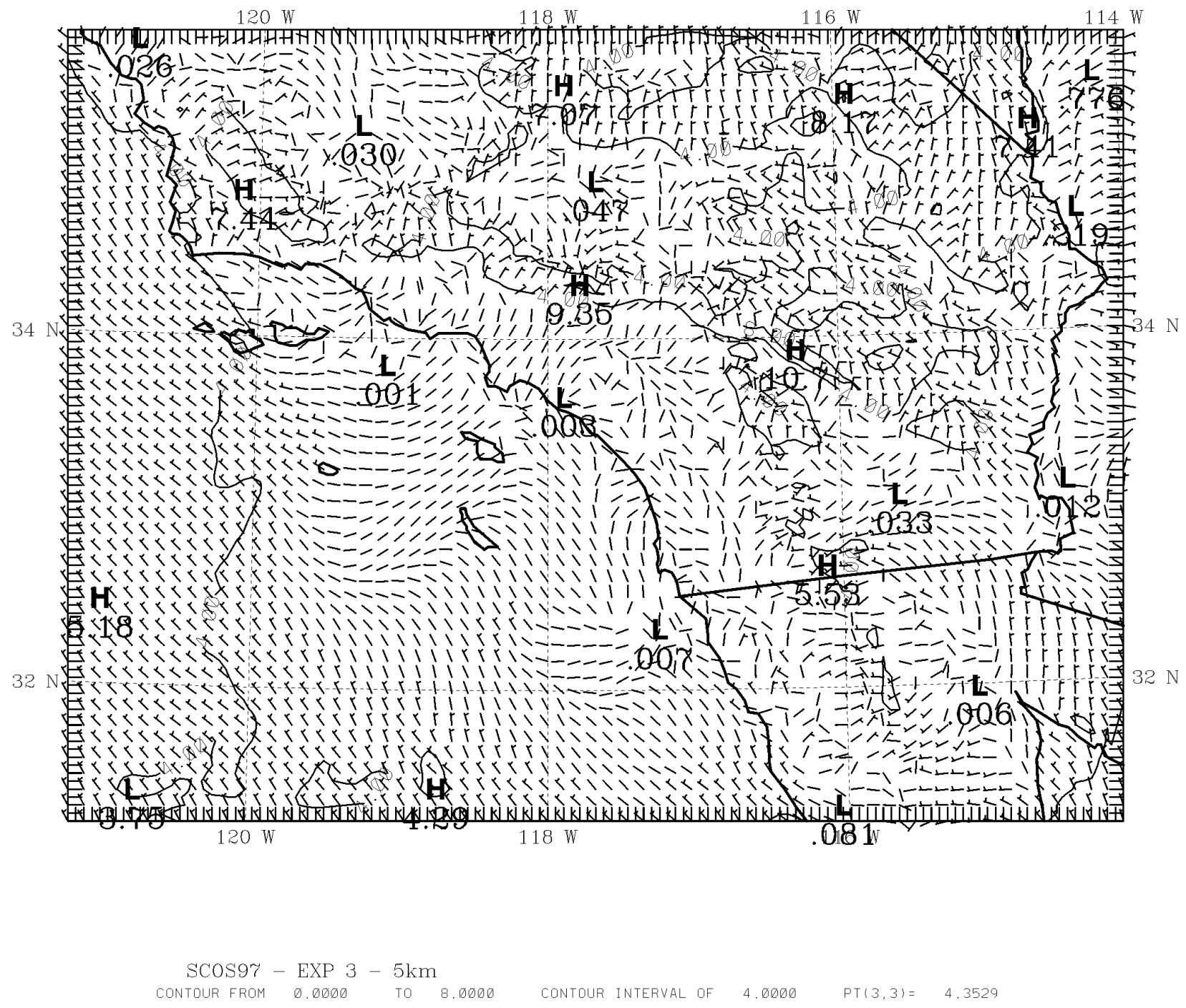

Figure 68. MM5 simulated winds $\left(\mathrm{ms}^{-1}\right)$ in the surface layer (12 $\mathrm{m}$ AGL) on the 5-km domain, valid for 1200 UTC, 21 September 1997, (+12 h) in Exp. 3. Isotach interval is $4 \mathrm{~ms}^{-1}$. 


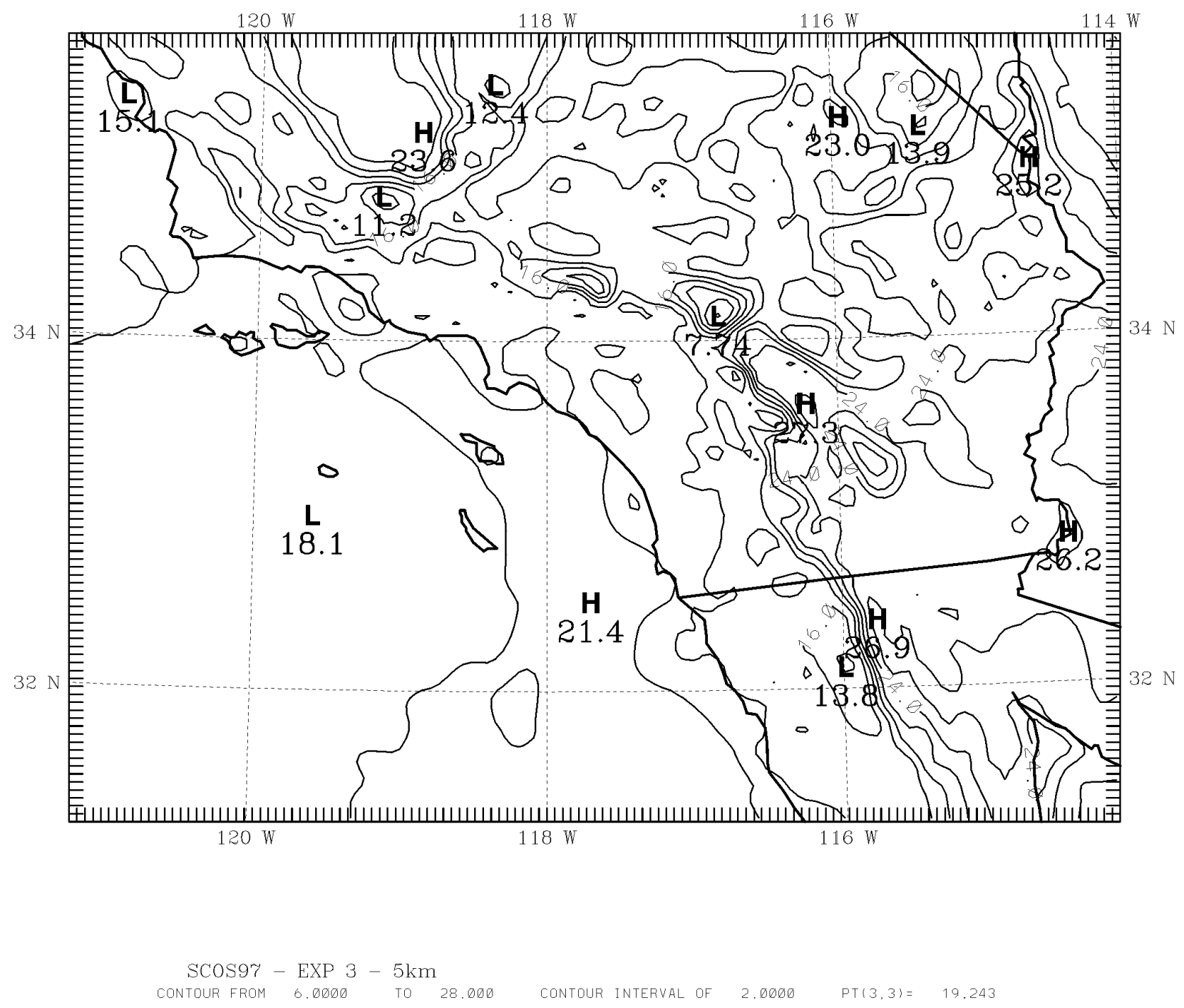

Figure 69. MM5 simulated temperatures (C) in the surface layer (12 m AGL) on the 5-km domain, valid for 1200 UTC, 21 September 1997, (+12 h) in Exp. 3. Isotherm interval is 2 C. 


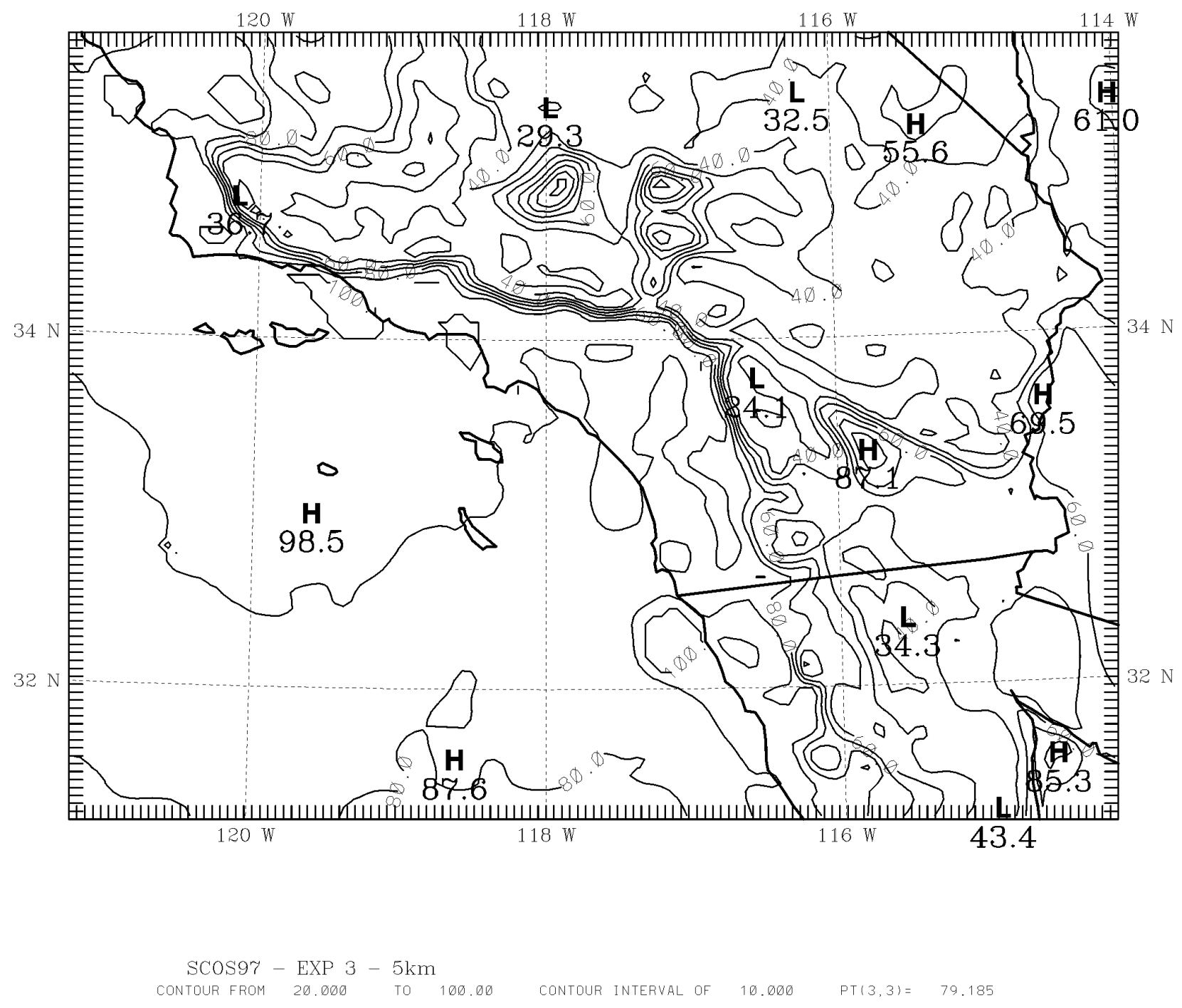

Figure 70. MM5 simulated relative humidity (\%) in the surface layer (12 m AGL) on the 5$\mathrm{km}$ domain, valid for 1200 UTC, 21 September 1997, (+12 h) in Exp. 3. Isopleth interval is 10 percent. 
local band of maximum surface air temperatures (20-21 C) just offshore from Pt. Dume southward to Baja. Since the water here is slightly warmer than the nearby land at 1200 UTC, the coastal thermal contrast and cold-air drainage from the coastal mountains combine to force the weak land breeze observed and simulated at the coast.

Continuing with the inspection of the surface simulations from Exp. 3, Figure 70 reveals that surface relative humidities greater than $90 \%$ prevail across most of the region west of the coast ranges from Santa Barbara to San Diego at 1200 UTC (+12 h), despite the predominantly offshore flow at this time. Since these humidities are considerably higher than are typical during the daytime and because humidities in the desert farther inland remain very dry, it is clear that the surface-layer air in the coastal basins is of marine origin. The explanation for this situation is that moist marine air first was advected into the coastal basins during the evening hours while the previous afternoon's sea breeze was still active, but weakening. Since the sun had already set, the surface layer quickly became thermally stable, greatly reducing vertical mixing and preventing entrainment of drier air from aloft. Thus, the basins quickly developed high humidities, which were further enhanced by radiational cooling during the night. Eventually as the night passed, the cooling in the basins led surface humidities to reach a maximum (while remaining unsaturated) and also caused the wind reversal (land breeze) when the land-sea thermal gradient reversed before sunrise. In effect, the offshore flow in the land breeze at 1200 UTC represents the return of this shallow layer of marine origin back in the direction from which it came the previous evening.

From the air pollution perspective, however, an important consequence of the offshore flow from the urbanized LA Basin could be that it may carry a considerable load of nocturnal emissions from mobile and other sources, thus creating a reservoir of ozone precursor species in a shallow marine boundary layer off the coast. Re-examination of Figure 68 from Exp. 3 shows that the convergence zone between the land breeze and the broad marine westerly and southwesterly winds over the CA Bight lies around 10-15 km offshore. Seaward advection could be even more extensive above the surface. Unfortunately, there are no observations in that offshore area to confirm or disprove the simulated location of the convergence zone. Nevertheless, the presence of coastal observations with offshore directions at a number of sites, plus the west to southerly observations at the islands southwest of Los Angeles, suggest that the actual surface flow over the Bight must be relatively close to that depicted by the model and hypothesized by the conceptual model (Sec. 4.3).

Further insight into the structure of the model-simulated atmosphere at this time can be gained by examining the key fields of potential temperature and cloud liquid water along the north-south vertical cross sections through Pt. Dume (Figures 71 and 72, respectively). The potential temperature cross section in Figure 71 can be compared to similar cross sections for Exp. 2 (Figure 43) and Exp. 2.5 (Figure 57). Note that temperatures in the marine layer of Exp. 3 are similar to those of Exp. 2.5 because they share the same SSTs. However, the depth of the marine layer near the coast northwest of Los Angeles is more shallow in Exp. 3, only $400 \mathrm{~m}$ above the sea surface, versus $\sim 600 \mathrm{~m}$ in Exp. 2.5. The simulation in Exp. 3 with obs-nudging is more consistent with the climatology of this region, even though there is no temperature sounding to verify the prediction. Figure 72 shows broken low clouds over the CA Bight south of Pt. Dume, which is approximately corroborated by satellite photographs on this day (not shown). 


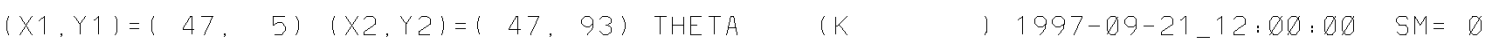

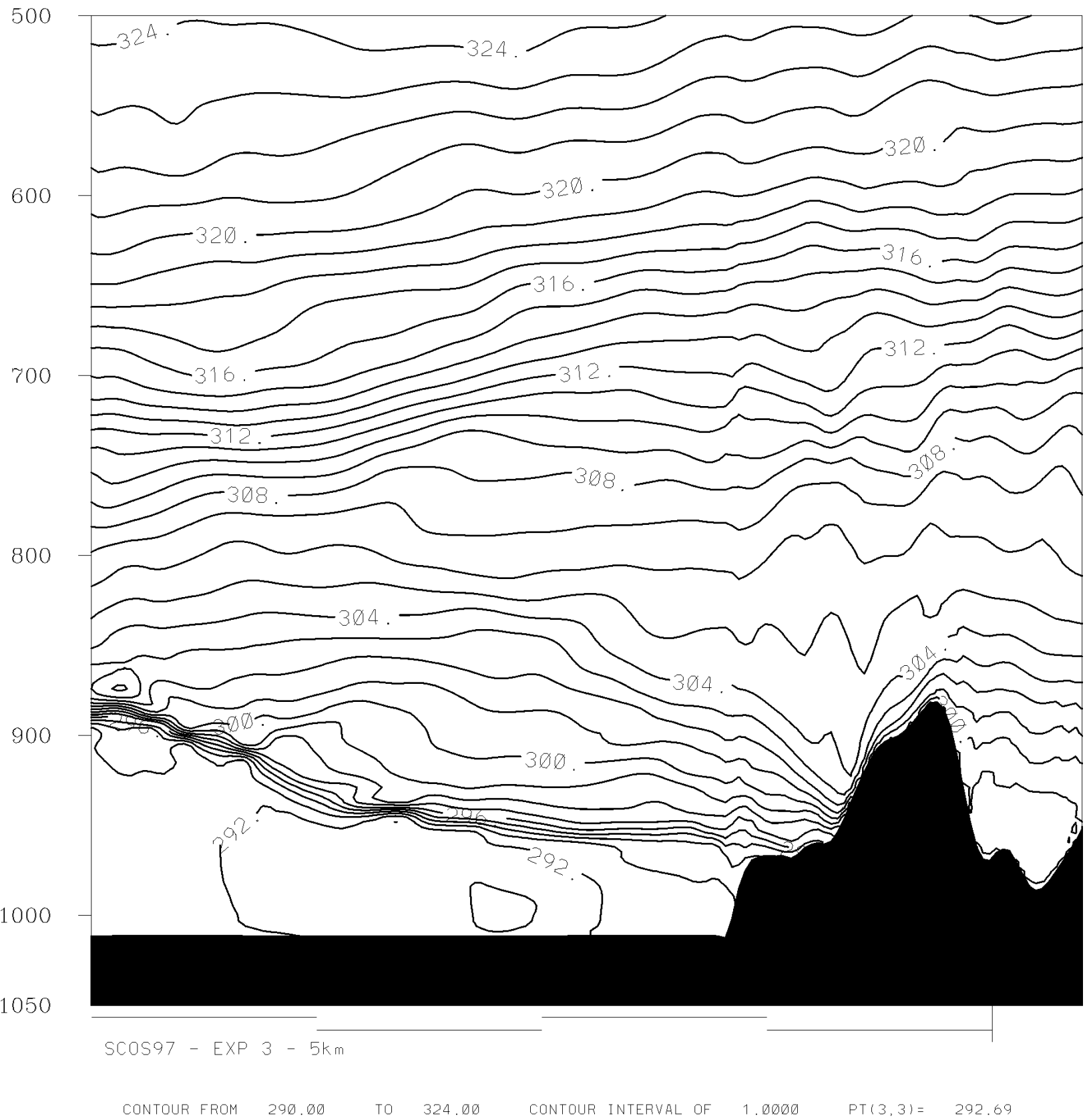

Figure 71. MM5 simulated potential temperature, $\theta(\mathrm{K})$ on the 5-km domain plotted versus pressure in the plane of the Pt. Dume north-south cross section, valid for 1200 UTC, 21 September 1997, (+12 h) in Exp. 3. Isentrope interval is $1 \mathrm{~K}$. 


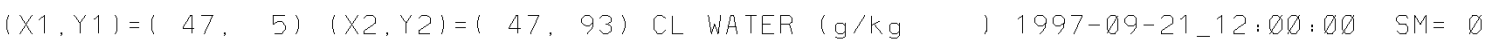

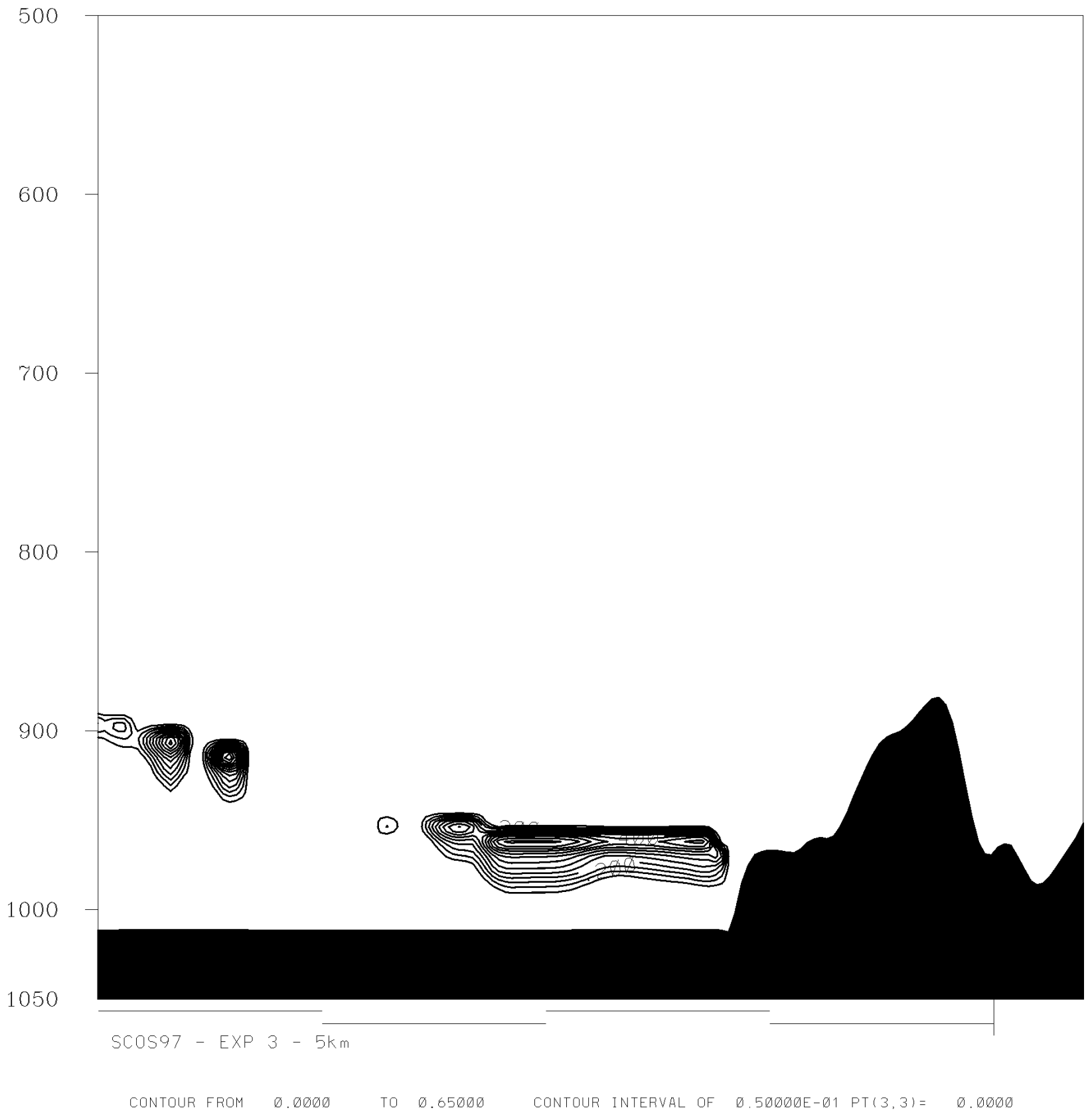

Figure 72. MM5 simulated cloud liquid water $\left(\mathrm{g} \mathrm{kg}^{-1}\right)$ on the 5-km domain plotted versus pressure in the plane of the Pt. Dume north-south cross section, valid for 1200 UTC, 21 September 1997, (+12 h) in Exp. 3. Isopleth interval is $0.05 \mathrm{~g} \mathrm{~kg}^{-1}$. 
Next, Figure 73 shows the simulated surface-layer wind field in Exp. 3 for the following afternoon at 0000 UTC, 22 September $(+24 \mathrm{~h})$. These winds can be compared to the simulated winds from Exp. 2.5 (Figure 59). As expected, both figures indicate a mature sea breeze penetrating inland through the coastal basins to the mountains. Only minor differences can be detected. For example, Figure $\mathbf{7 3}$ shows that Exp. 3 produced winds with a mostly southerly direction near the San Fernando Valley (where observed afternoon winds often shift to easterly directions, as in Figure 16), whereas Figure 59 shows that Exp. 2.5 has mostly southwesterly directions in this area. Also, Exp. 2.5 produced a broader area of winds greater than $4 \mathrm{~ms}^{-1}$ east of Oxnard than did Exp. 3. Based on past MM5 experiments in the Los Angeles region, the failure of the model to generate afternoon easterlies in the San Fernando Valley is probably due to the $5-\mathrm{km}$ mesh being too coarse to resolve the valley and its consequent terrain-driven flow. Overall, the visual inspection indicates that the data assimilation had relatively little impact on the surface flow at this time.

At the same time, 0000 UTC, 22 September, the surface-layer temperature and relative humidity simulations are shown in Figures $\mathbf{7 4}$ and 75. The temperature field can be compared to that predicted in Exp. 2.5 (Figure 58). As expected, since surface temperature observations are not assimilated, there are few differences between the two solutions. Meanwhile, comparison between the afternoon relative humidities of Exp. 3 (Figure 75) with those near sunrise at 1200 UTC in the same experiment (Figure 70) show that the strong early morning moisture gradient up against the mountains has been diffused over the entire coastal region. The more diffused humidity gradient in the afternoon is due mostly to the gradual heating of the cool marine air as it travels inland on the sea breeze. The mixed layer depth in Exp. 3, represented along the eastwest cross section through San Diego in Figure 76, is very similar to that shown in (Figure 61) from Exp. 2.5. The most significant difference between the potential temperature cross sections for these two experiments, perhaps, occurs between 800-900 mb just west of the Coast Range ridgeline. In Exp. 3, the stability in this middle layer is considerably weaker between the ridgeline and the coast than in Exp. 2.5. The winds in this cross section (Figure 77) do not reveal any easterly flow crossing the mountains from the warmer deserts. Thus, the most likely cause of the weak mid-level stability over San Diego in Exp. 3 is that mid-level subsidence has warmed that layer, while increasing the stability of the low-level coastal inversion. The midlevel subsidence is associated with the upper-level return branch of the sea breeze and valley breeze in the coastal region, which is especially strong west of the coast at this time (Figure 77). Consistent with the offshore subsidence, Figure 78 shows only a few scattered stratocumulus patches close to the coastline, but more continuous stratocumulus persist farther offshore.

At roughly 0000 UTC, 23 September (+48 h), the objective analyses (Figure 17), observations (Figure 19) and previous model solutions (e.g., Figure 62) had shown that a change of the synoptic regime was beginning well before to the arrival of the tropical storm in the vicinity of the 5-km MM5 domain. It was about this time that the upper-level ridge over the eastern Pacific propagated east over the SoCAB, causing winds aloft to shift from northwesterly to south and southwesterly (Figure 17). A brief examination of the solutions in Exp. 3 shows evidence that the model is also beginning to respond to the subtle changes underway at this time. Figure 19 


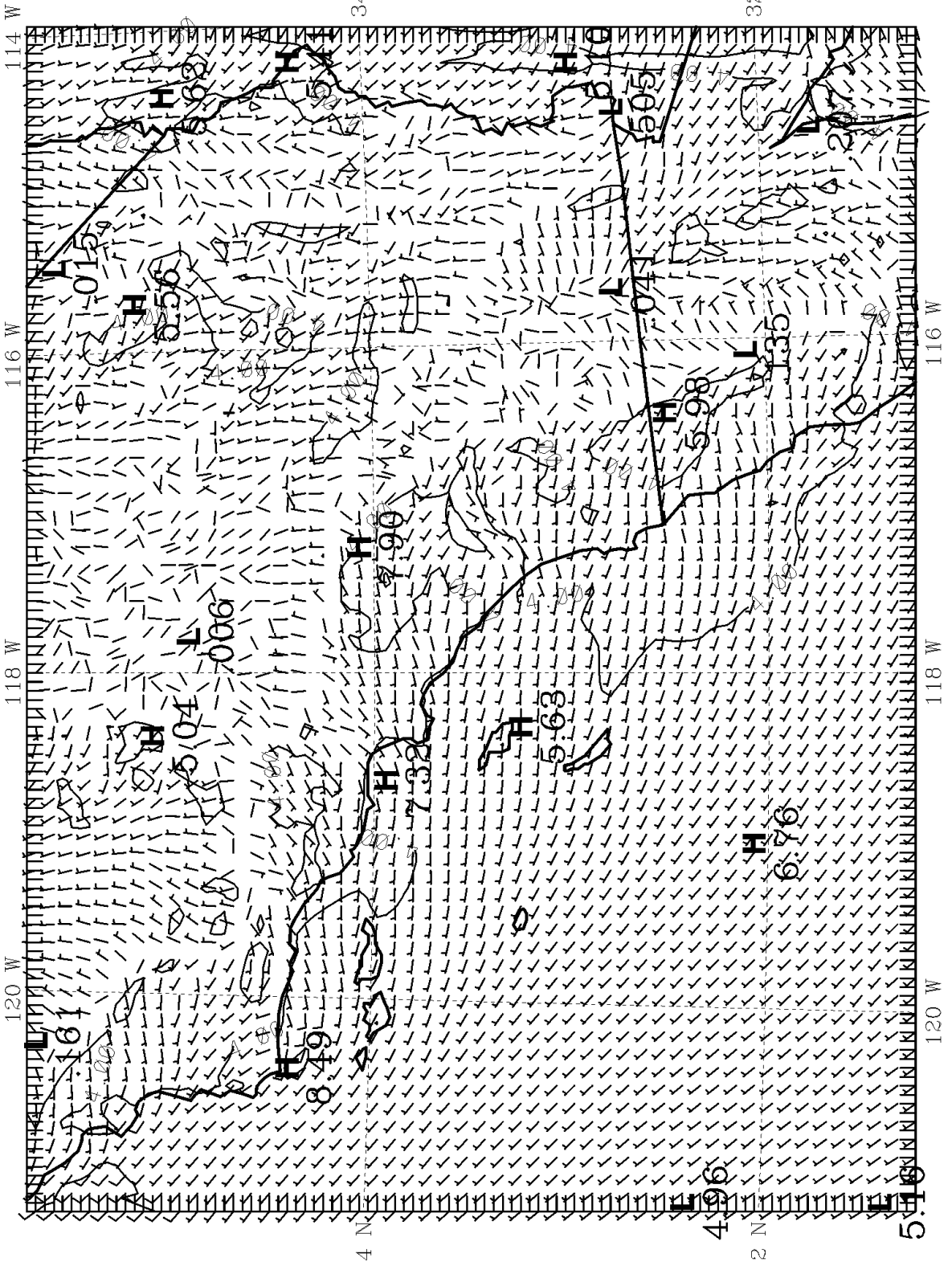

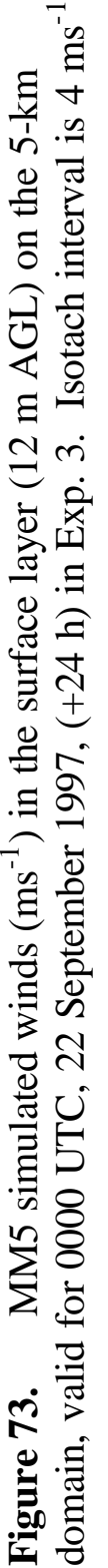




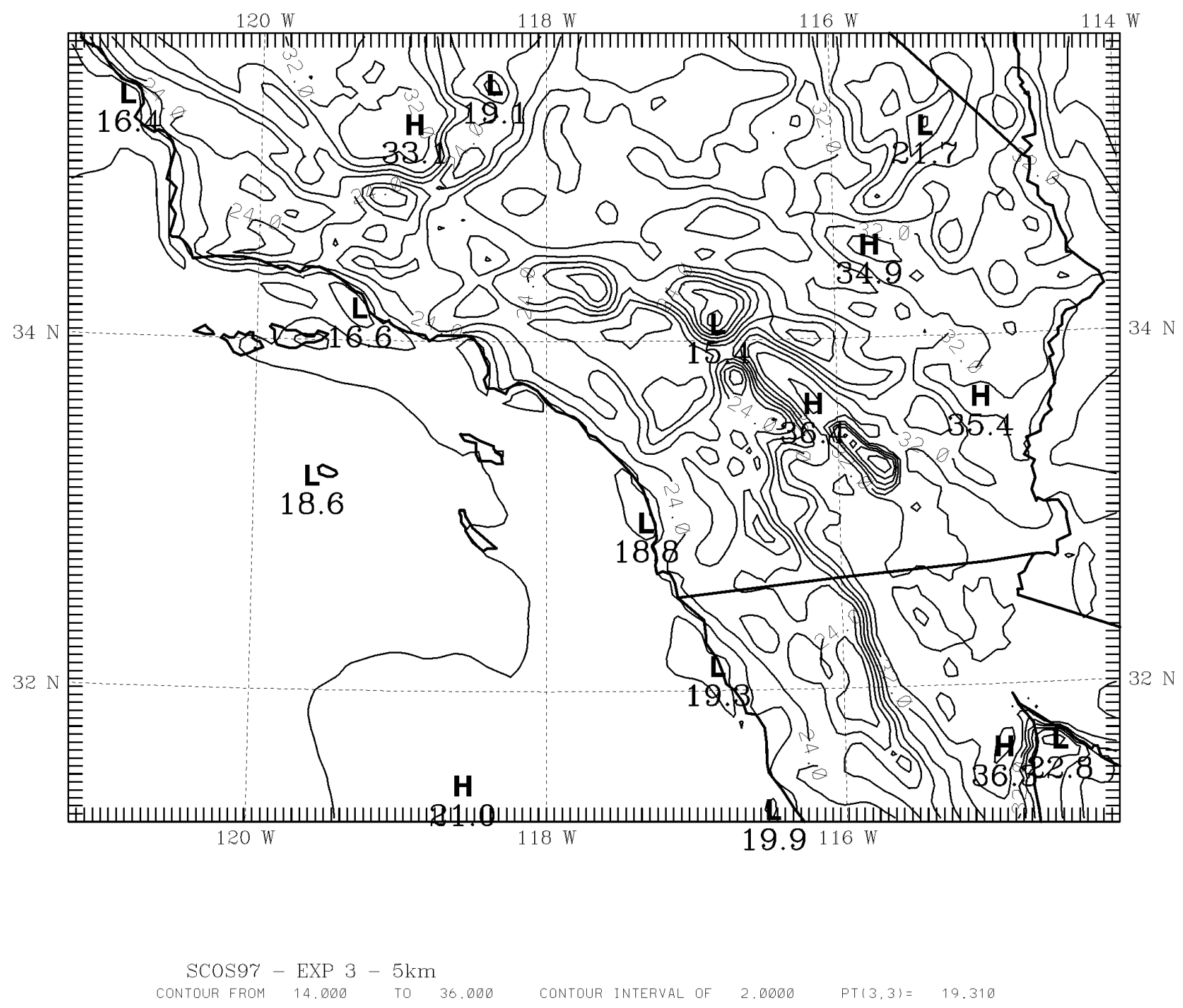

Figure 74. MM5 simulated temperatures (C) in the surface layer (12 m AGL) on the 5-km domain, valid for 0000 UTC, 22 September 1997, (+24 h) in Exp. 3. Isotherm interval is 2 C. 


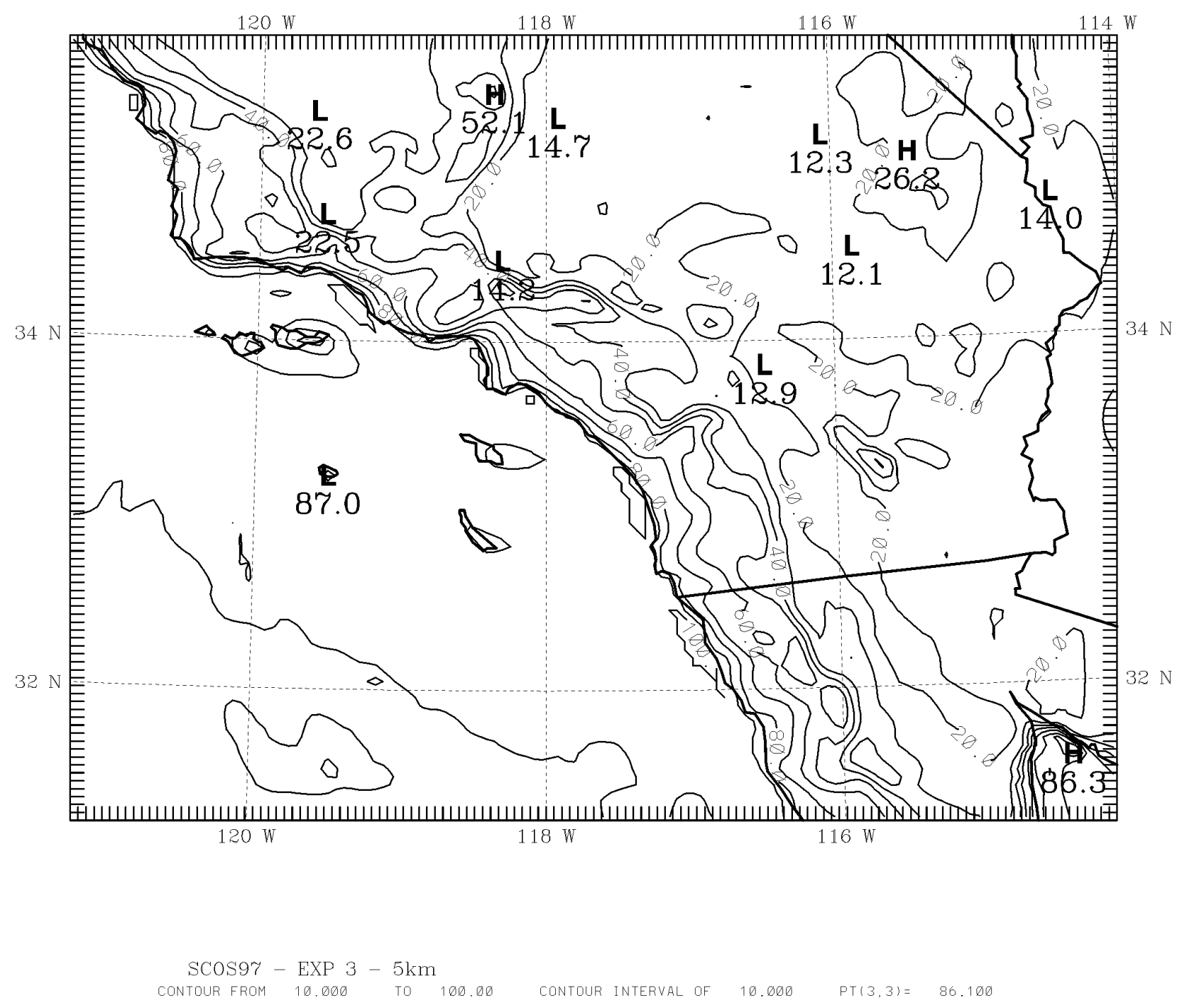

Figure 75. MM5 simulated relative humidity (\%) in the surface layer (12 m AGL) on the 5$\mathrm{km}$ domain, valid for 0000 UTC, 22 September 1997, (+24 h) in Exp. 3. Isopleth interval is 10 percent. 


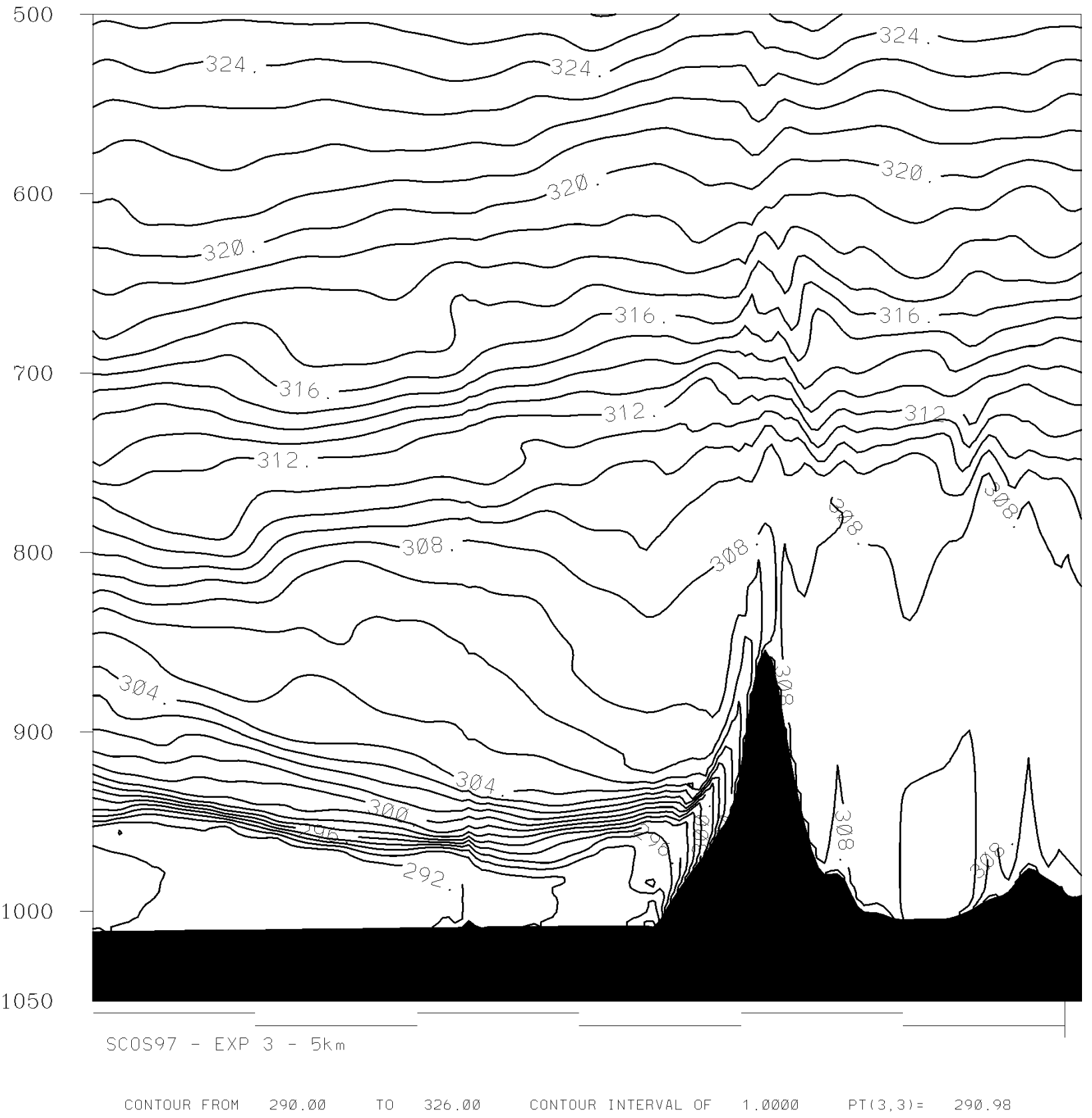

Figure 76. MM5 simulated potential temperature, $\theta(\mathrm{K})$ on the 5-km domain plotted versus pressure in the plane of the San Diego west-east cross section, valid for 0000 UTC, 22 September 1997, (+24 h) in Exp. 3. Isentrope interval is $1 \mathrm{~K}$. 


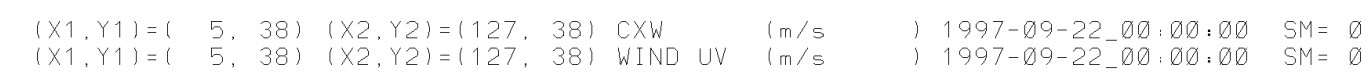

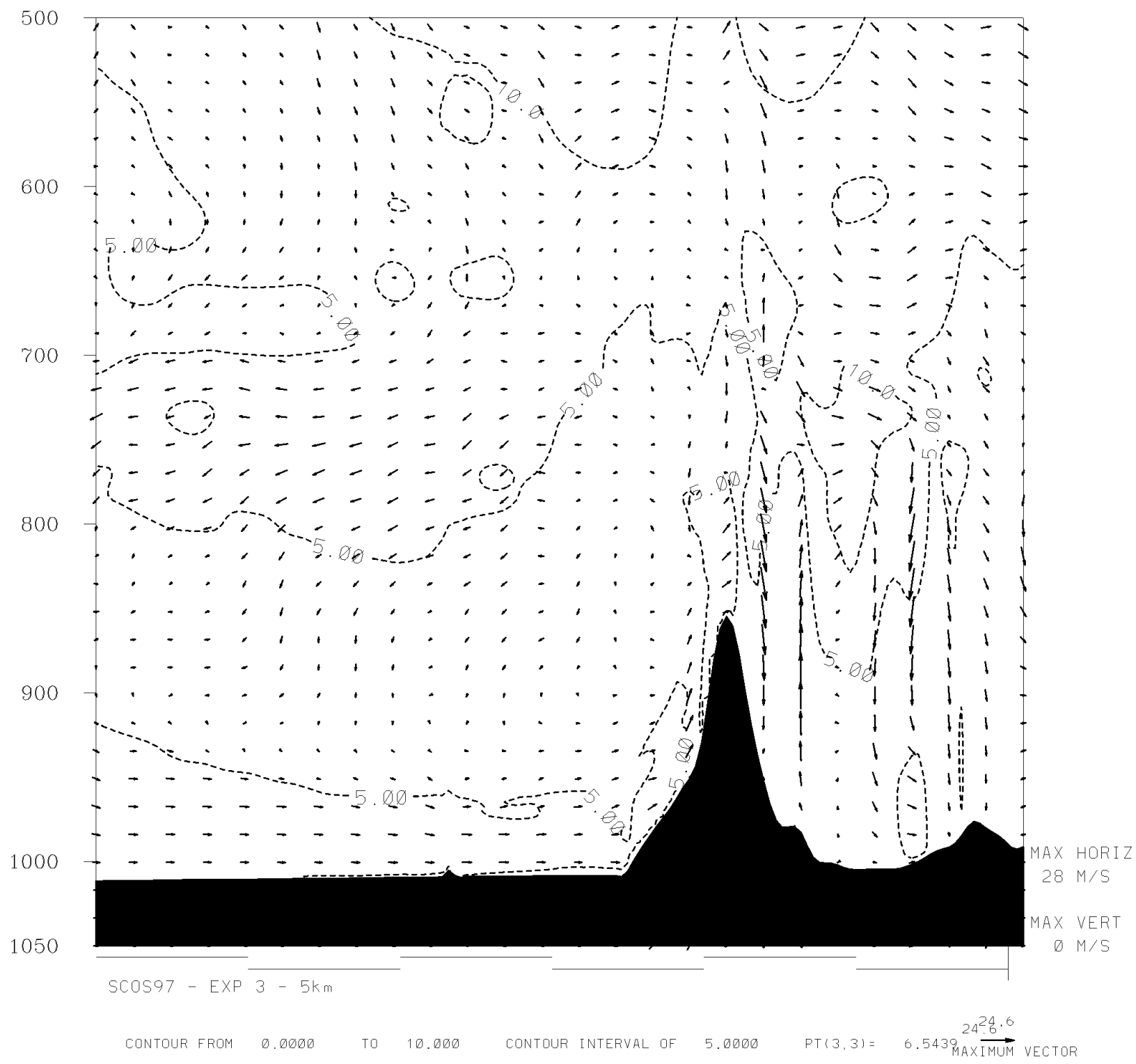

Figure 77. MM5 simulated wind $\left(\mathrm{ms}^{-1}\right)$ on the 5-km domain plotted versus pressure in the plane of the San Diego west-east cross section, valid for 0000 UTC, 22 September 1997, (+24 h) in Exp. 3. Isotach interval is $5 \mathrm{~ms}^{-1}$. 


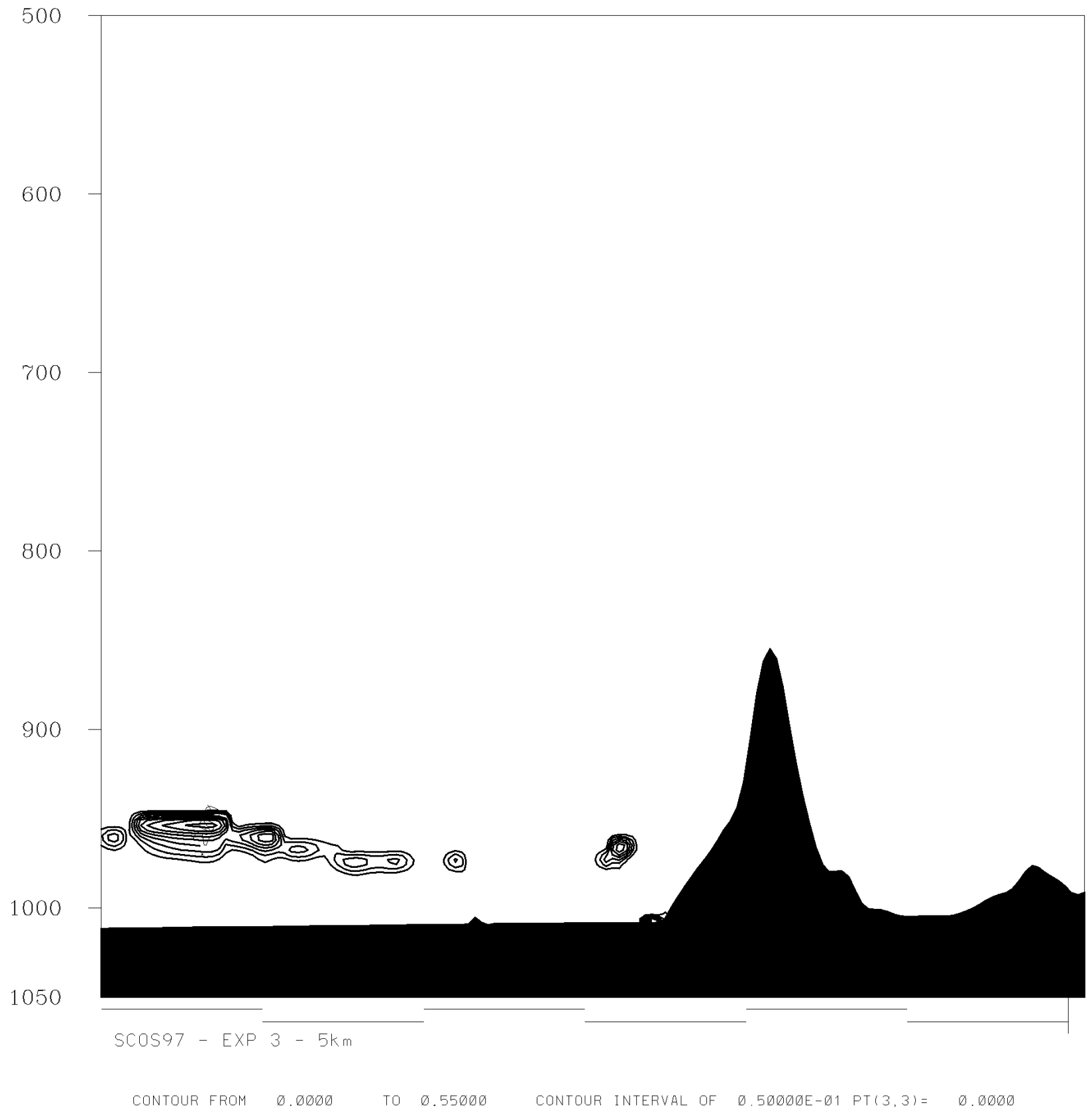

Figure 78. MM5 simulated cloud liquid water $\left(\mathrm{g} \mathrm{kg}^{-1}\right)$ on the 5-km domain plotted versus pressure in the plane of the San Diego west-east cross section, valid for 0000 UTC, 22 September 1997, (+24 h) in Exp. 3. Isopleth interval is $0.05\left(\mathrm{~g} \mathrm{~kg}^{-1}\right)$. 
showed that there were only westerly winds through the San Fernando Valley on the afternoon of 23 September, with a single southeasterly wind reported in the hills. Of course, it is not surprising that the model also simulates westerlies eastward from Oxnard (Figure 79) on this afternoon, given its inability to resolve the details of the terrain in the area. However, Figure 19 also shows more organized easterly and southeasterly wind components across southern CA in most areas lying east of the main mountain ranges in response to the passage of the ridge aloft. In Exp. 3, Figure 79 shows that the surface winds northeast of Los Angeles are beginning to respond to the passage of the upper ridge, with easterlies spreading across the Mojave Desert. Also, a plot of the surface-layer temperature at this time (not shown) indicates that simulated temperatures across the LA Basin in Exp. 3 are already about $2 \mathrm{C}$ warmer (up to $32 \mathrm{C}$ ) than on the previous afternoon. Observations in the East Basin at this time reached as high as $35 \mathrm{C}$ in a few locations. Comparison of the surface-layer winds in Exp. 3 on 22 September (Figure 73) with those on 23 September (Figure 79) shows that the sea breeze is about 1-2 $\mathrm{ms}^{-1}$ slower on the second day. Thus, the warmer temperatures in the Basin are not associated with an easterly Santa Ana wind, but are simply the result of weaker onshore westerly winds that provide more time for the air to be warmed by the surface sensible heat flux as it is advected inland.

Figure 80 shows the simulated wind at the $925 \mathrm{mb}$ level in Exp. 3 at 0000 UTC, 23 September $(+48 \mathrm{~h})$. Note that for most of the CA Bight this level is just above the sloping marine boundary layer, shown in the east-west cross section in Figure 81. However, at the western end of the cross section, the marine inversion lies near $925 \mathrm{mb}$, so that the prevailing low-level northwesterly winds extend up to this level, as shown in Figure 80. Closer to the coast and over land, the winds at $925 \mathrm{mb}$ in Figure 80 do not show a strong preferential direction, but they are veering with height, indicating warm advection has begun aloft. On the other hand, any warm advection at this time must be very weak, because comparison of the potential temperature structure at this time (Figure 81) with the structure $24 \mathrm{~h}$ earlier (Figure 76) shows very little change so far, except for warming above San Diego of $\sim 1 \mathrm{C}$ near $800 \mathrm{mb}$. This solution is consistent with the observed location of the upper-level ridge directly over the SoCAB at this time, as shown in Figure 17. Thus, Exp. 3 appears to have captured this important transition reasonably well, which helped to trigger the high-ozone event on the following day.

By the end of the third day of the model simulation in Exp. 3, the variable fields in the east-west cross section through San Diego reveal the effects of the ridge passage and the approach of the tropical storm slowly moving north up the Baja Peninsula. Figures 82-84 show the potential temperature, wind, and relative humidity in the cross section at 0000 UTC, 24 September $(+72$ h), respectively. Figure 82 shows that mid-level warm advection has continued west of the Coast Range and that weak stability now extends from $\sim 700-890 \mathrm{mb}$. Beneath this warm, weakly stable layer, the subsidence inversion is depressed so that the simulated marine layer is only about $150 \mathrm{~m}$ deep along the coast. The $850-\mathrm{mb}$ winds at this time are from the east and southeasterly directions across the entire 5-km MM5 domain (not shown), making it clear that moist, unstable subtropical air is beginning to penetrate the region. Figure 83 shows more extensive easterly wind components have developed than were present two days earlier (Figure 77), with winds becoming greater than $10 \mathrm{~ms}^{-1}$ over the Pacific Ocean. Also note Figure 83 indicates that the westerly winds of the sea breeze in the shallow marine layer have weakened by 0000 UTC, 24 September (compare to Figure 77). Finally, at this time, Figure 84 shows that 


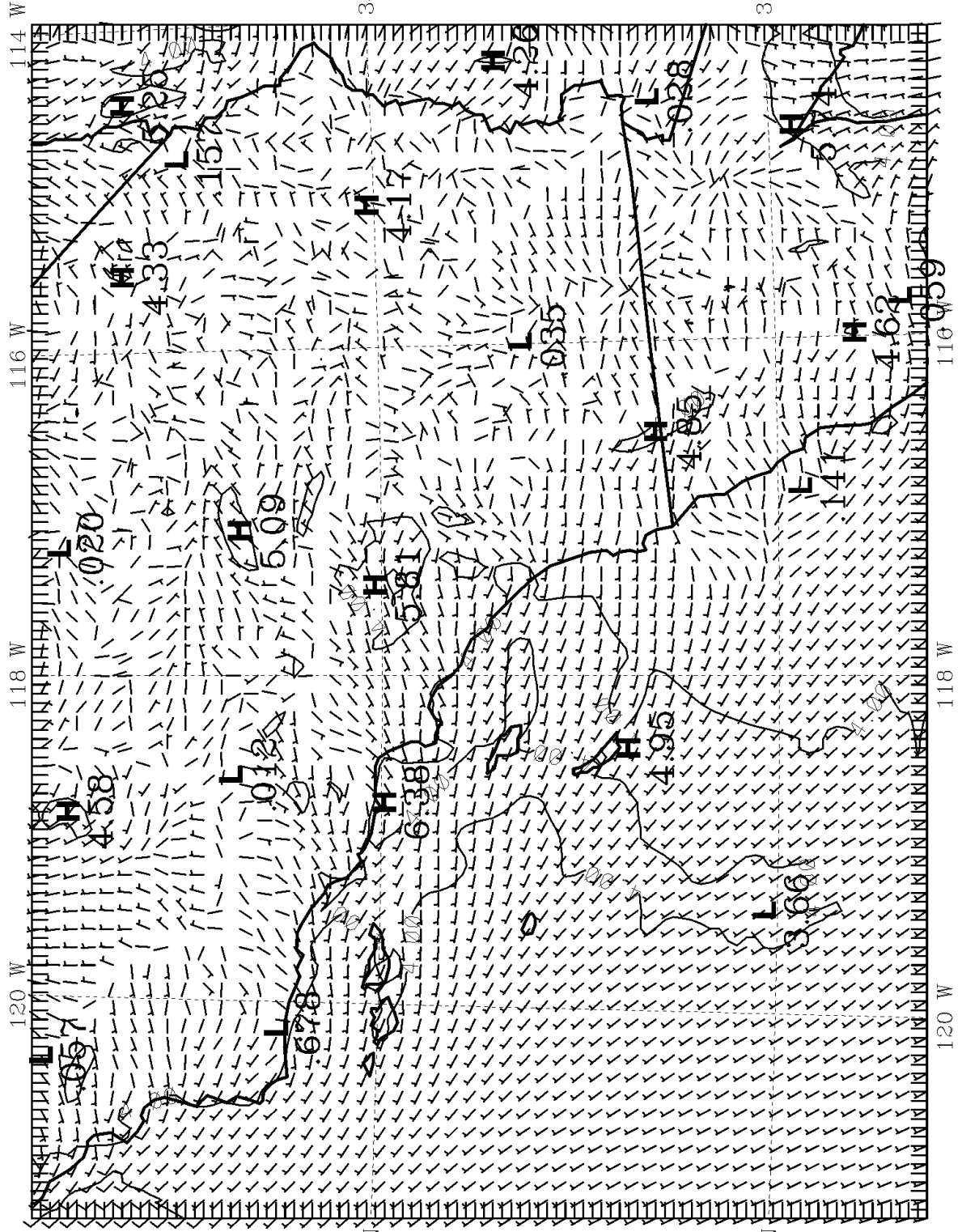

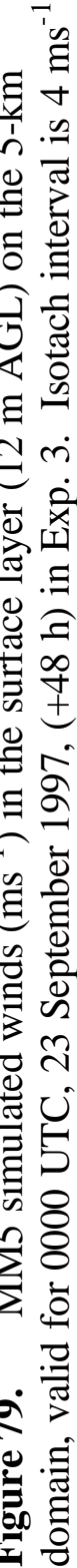




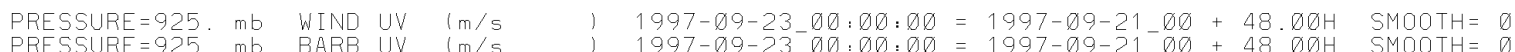

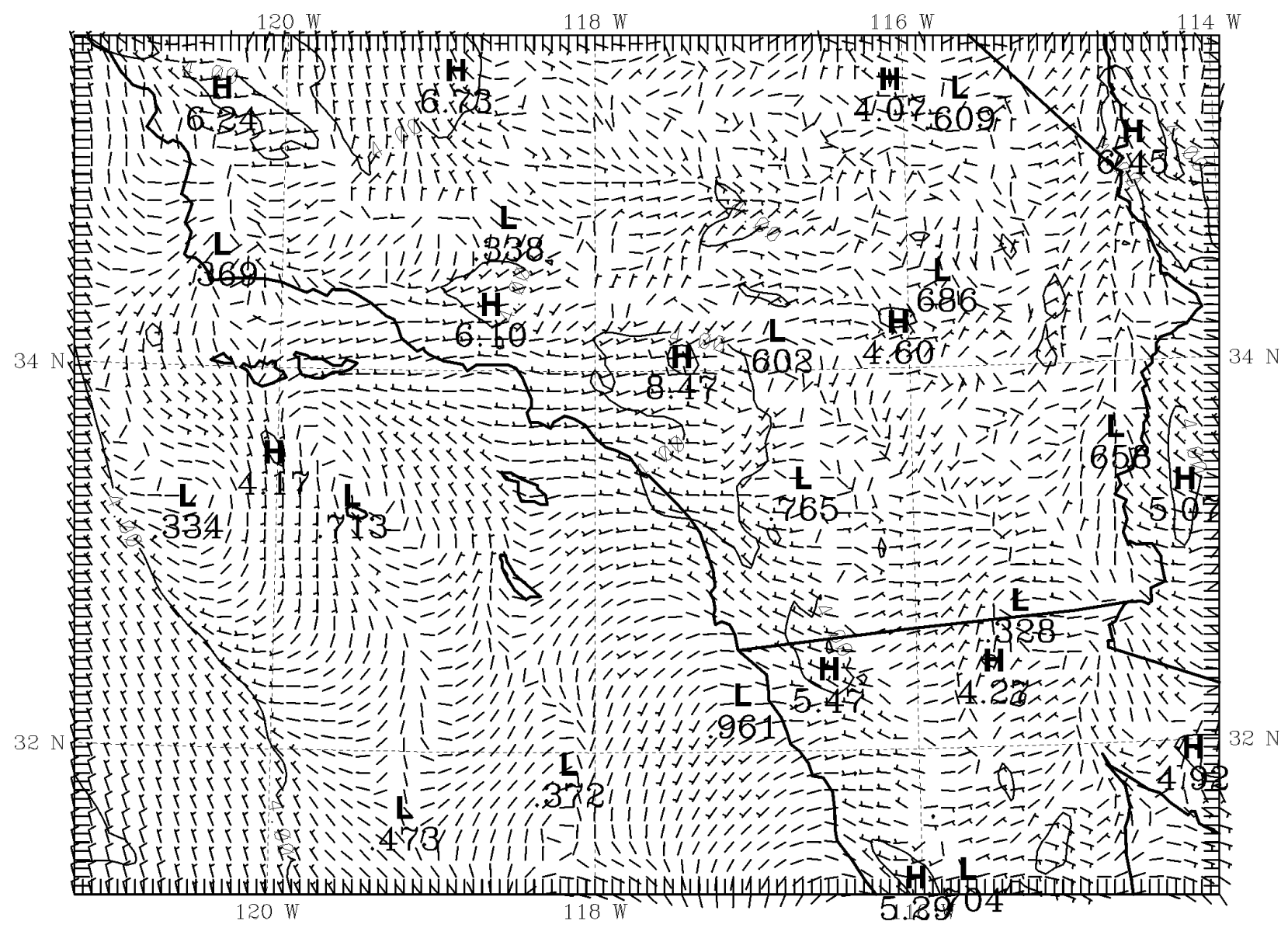

SCOS97 - EXP $3-5 \mathrm{~km}$
CONTOUR FROM 0.0000 TO $8.0000 \quad$ CONTOUR INTERVAL OF $4.0000 \quad$ PT $(3,3)=7.8947$

Figure 80. MM5 simulated winds $\left(\mathrm{ms}^{-1}\right)$ at the $925-\mathrm{mb}$ level (12 m AGL) on the 5-km domain, valid for 0000 UTC, 23 September 1997, (+48 h) in Exp. 3. Isotach interval is $4 \mathrm{~ms}^{-1}$. 


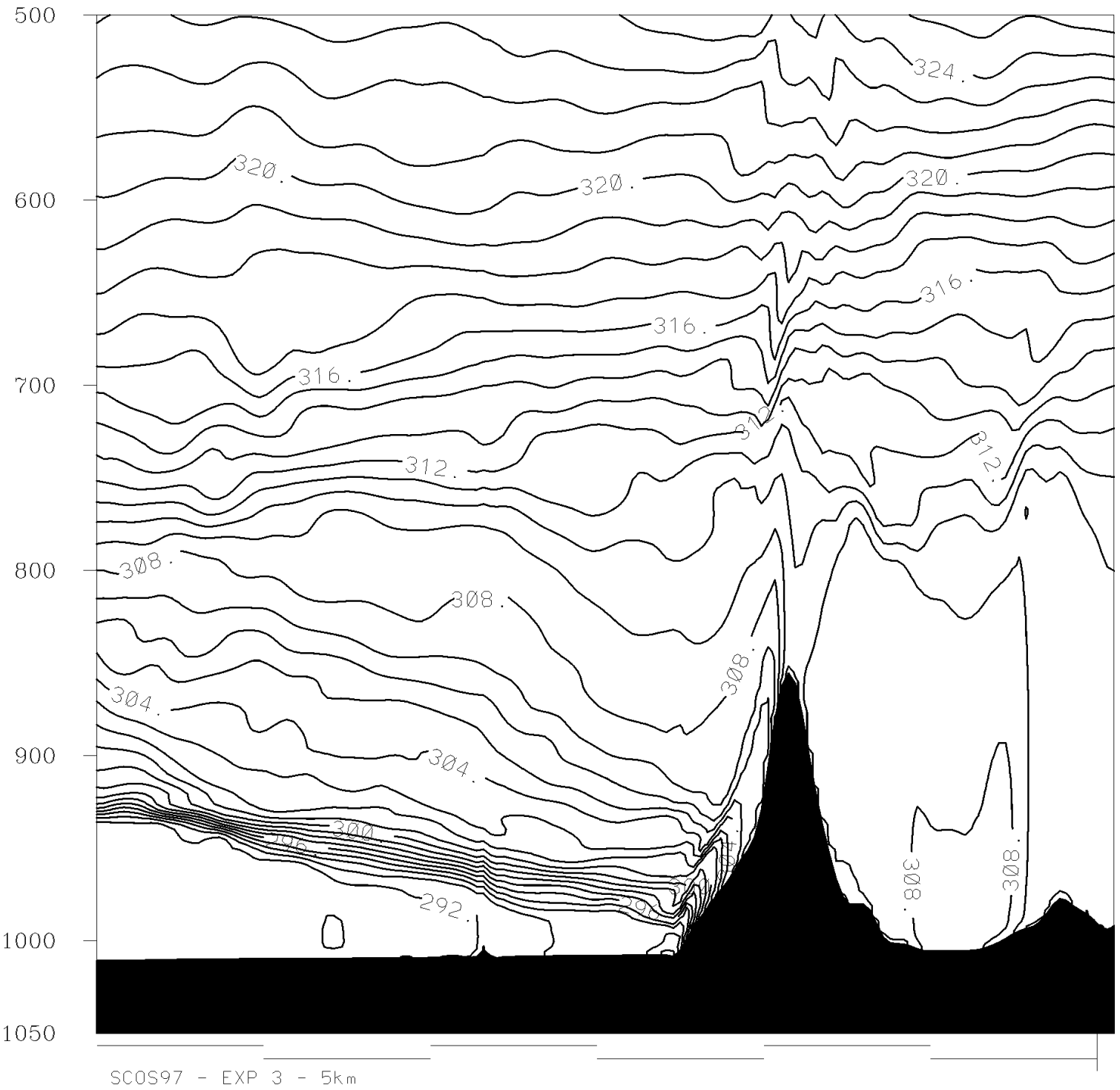

CONTOUR FROM 290.00 TO 325.00 CONTOUR INTERVAL OF $1.060 \quad$ PT $(3,3)=291.20$

Figure 81. MM5 simulated potential temperature, $\theta(\mathrm{K})$ on the 5-km domain plotted versus pressure in the plane of the San Diego west-east cross section, valid for 0000 UTC, 23 September 1997, (+48 h) in Exp. 3. Isentrope interval is $1 \mathrm{~K}$. 


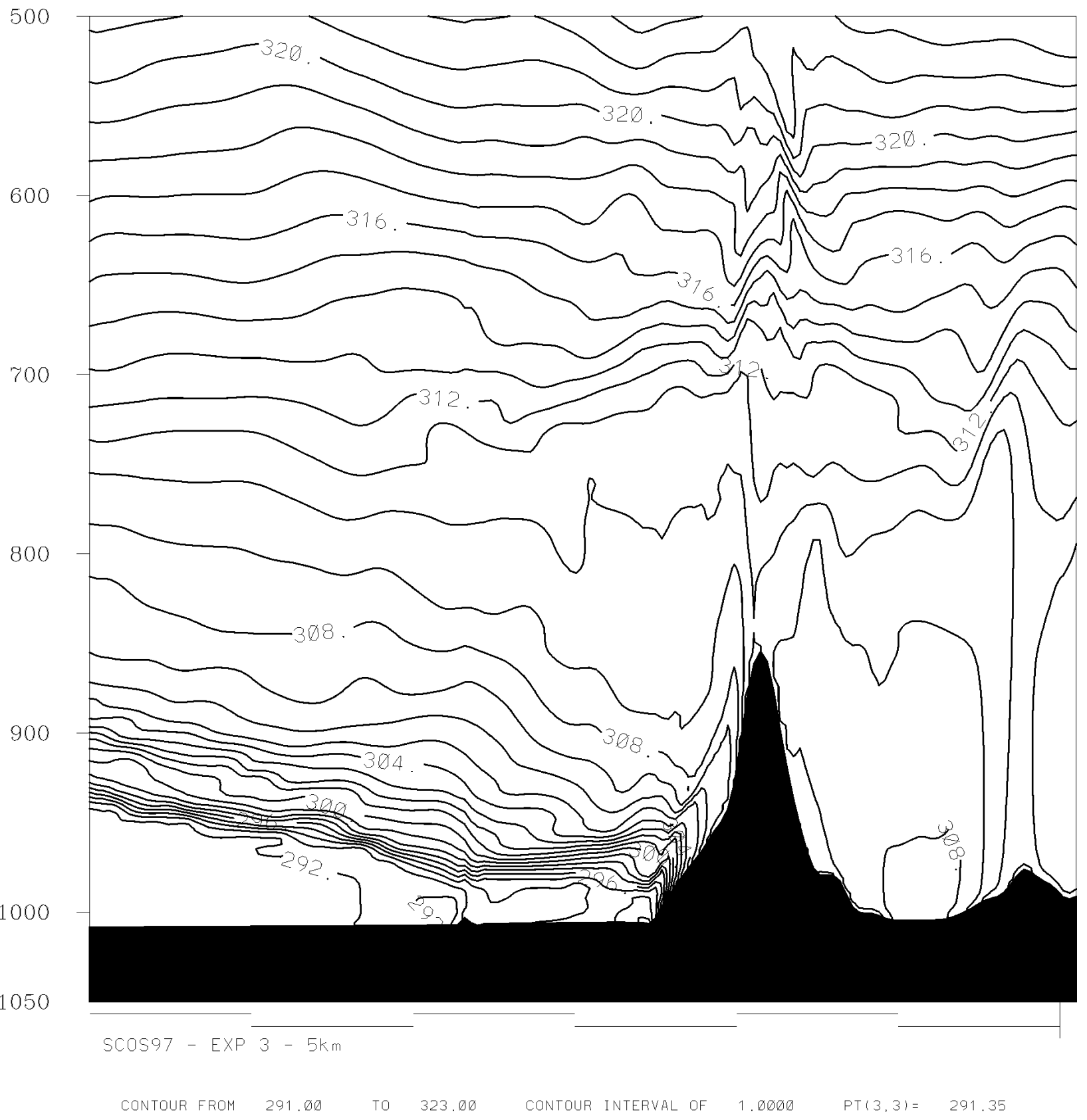

Figure 82. MM5 simulated potential temperature, $\theta(\mathrm{K})$ on the 5-km domain plotted versus pressure in the plane of the San Diego west-east cross section, valid for 0000 UTC, 24 September 1997, (+72 h) in Exp. 3. Isentrope interval is $1 \mathrm{~K}$. 


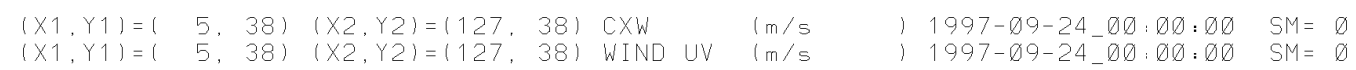

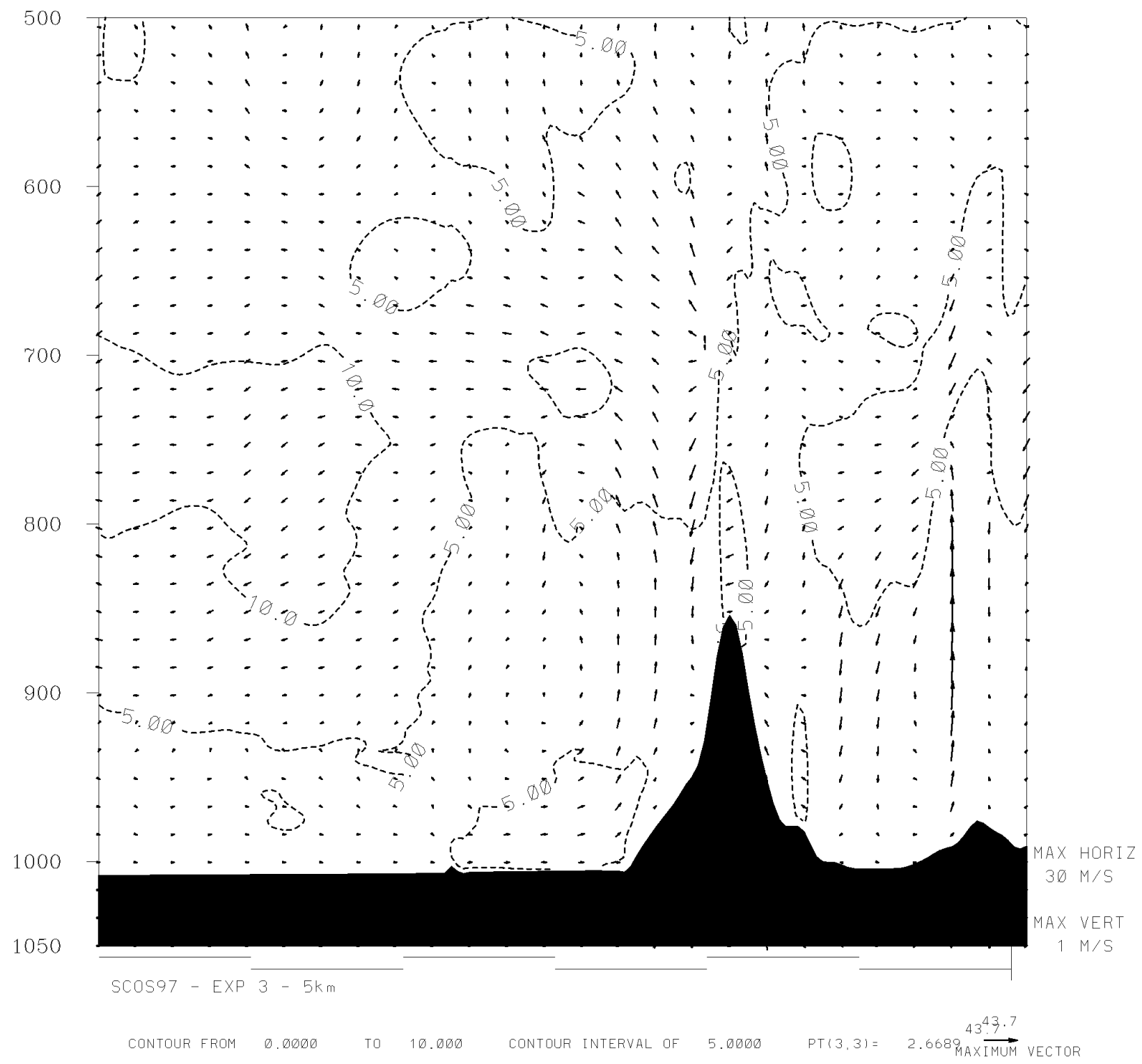

Figure 83. MM5 simulated wind $\left(\mathrm{ms}^{-1}\right)$ on the 5-km domain plotted versus pressure in the plane of the San Diego west-east cross section, valid for 0000 UTC, 24 September 1997, (+72 h) in Exp. 3. Isotach interval is $5 \mathrm{~ms}^{-1}$. 


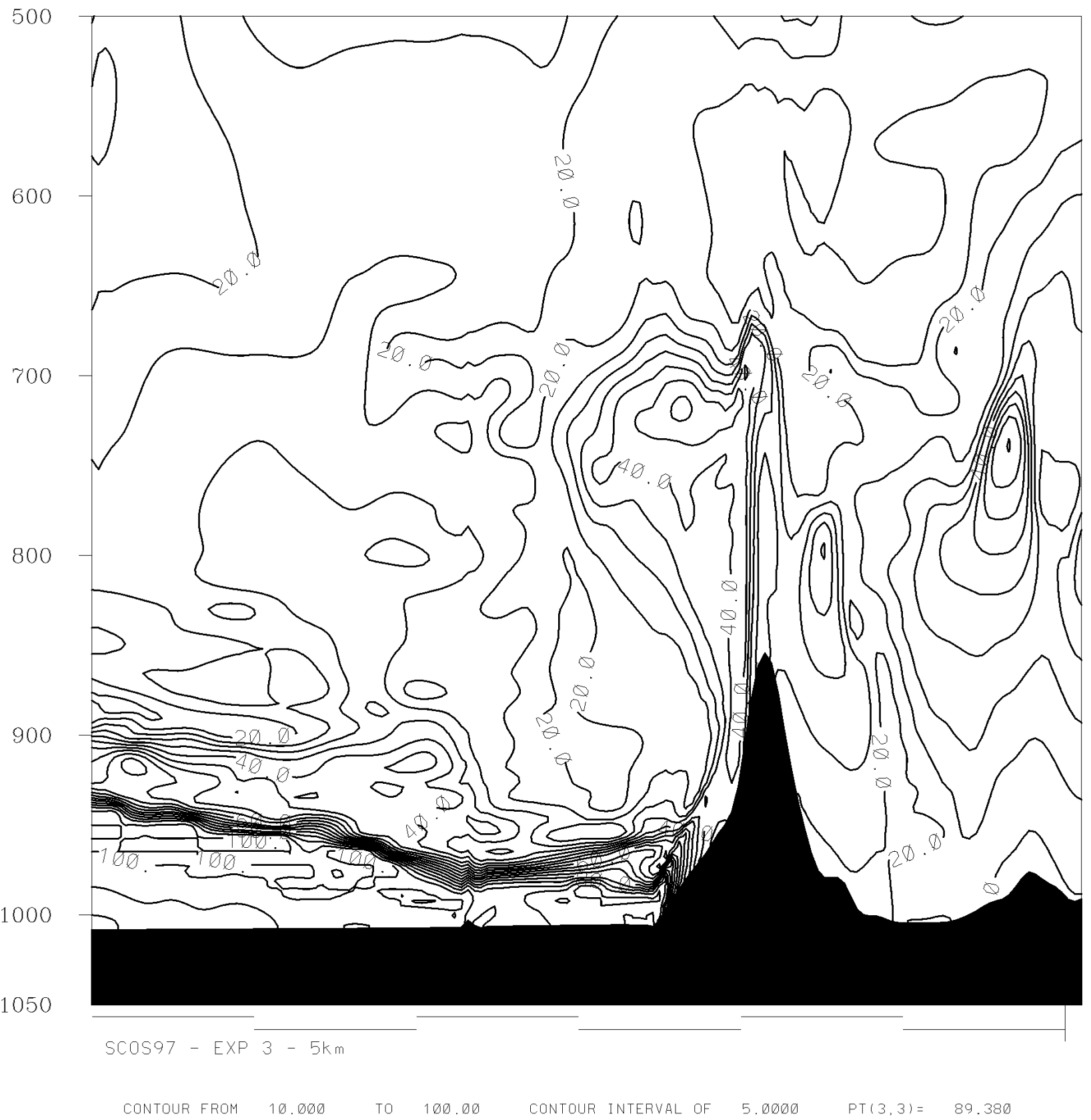

Figure 84. MM5 simulated relative humidity (\%) on the 5-km domain plotted versus pressure in the plane of the San Diego west-east cross section, valid for 0000 UTC, 24 September 1997, (+72 h) in Exp. 3. Isopleth interval is 5 percent. 
moist air is indeed penetrating aloft in bands near the 700-mb level, both along the coast and over the interior deserts. This "moist" air has humidities of only $\sim 50 \%$ so far, but it indicates the early stage of the tropical intrusion is under way. The marine layer, however, shows extensive areas west of San Clemente Island that are saturated just below the marine inversion. The GOES-9 visible images on this afternoon confirm clear skies over all of the SoCAB and coastal marine region, with extensive stratocumulus clouds beginning just west of the islands (not shown).

Taken together, several factors are seen to be contributing to poor air quality on this day (23 September 1997). First, skies are clear over the entire SoCAB. Warming in the mid-level region has strengthened and suppressed the inversion capping a very shallow mixed layer in the coastal regions. Finally, the onshore sea breeze is comparatively weaker on this day, relative to earlier days, so that advection and ventilation are reduced and surface-layer temperatures continue to rise. These factors favor strong photochemical production of ozone and weaker than average ventilation in the coastal air basins.

The nascent influence of warm, moist advection of subtropical air into the SoCAB that had begun on 23 September steadily increased on September 24 and was very strong by the end of this SCOS-97 episode at 0000 UTC, 25 September. Figure 85 presents the surface-layer winds at this time simulated in Exp. 3, showing moderate southeasterly winds across almost all of southeastern CA and northern Baja. Northwesterly winds persist in the shallow marine layer over the Pacific Ocean, but the sea breeze is very weak. The winds offshore and in the coastal air basins from Los Angeles to San Diego are mostly west to southwesterly at $\sim 1-3 \mathrm{~ms}^{-1}$. A distinct convergence zone is apparent following approximately along the peaks of the first coastal mountain range between the weak southwesterly sea breeze and the general southeasterly flow over the inland deserts. This pattern is distinctly different from the surface winds simulated earlier in the study period and is corroborated by the observations in Figure 26.

Figures 86 and 87 depict the effect of this wind regime on the surface-layer temperature and relative humidity fields simulated in Exp. 3. The modeled temperatures in the East LA Basin have risen to nearly $35 \mathrm{C}$, with maxima of over $37 \mathrm{C}$ in some of the eastern desert locations. Observed temperatures at 1800 UTC, 24 September, a few hours earlier (Figure 23) appear to agree with these rising model temperatures. However, the observed plot at 0000 UTC (Figure 26) has falling temperatures at many inland sites, which may be a sign of corrupted data. Another explanation is that the mid- and high-level cloud apparent over northern MX in the satellite image at 1800 UTC (Figure 24) may have advected rapidly over southeastern CA, allowing temperatures to fall. In either case, the model has produced high temperatures in the coastal basins on this final afternoon, which are generally correct, and Figure 86 shows the thermal gradient to lie very close to the coastline as a result of the weak sea breeze. The relative humidity gradient in Figure 87 is also very strong right along the coast for the same reason, leaving most of LA and the rest of the coastal air basins very hot and dry on this afternoon.

The model's solutions for the surface layer have their roots in the flow pattern farther aloft. Figure 88 shows the $925 \mathrm{mb}$ wind field at 0000 UTC, 25 September $(+96 \mathrm{~h}$ ), where the directions have become mostly southerly to southeasterly. The flow is much better organized and with much stronger southeasterlies than was apparent at this level two days earlier (see 


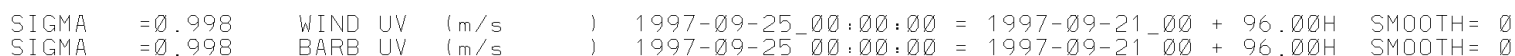

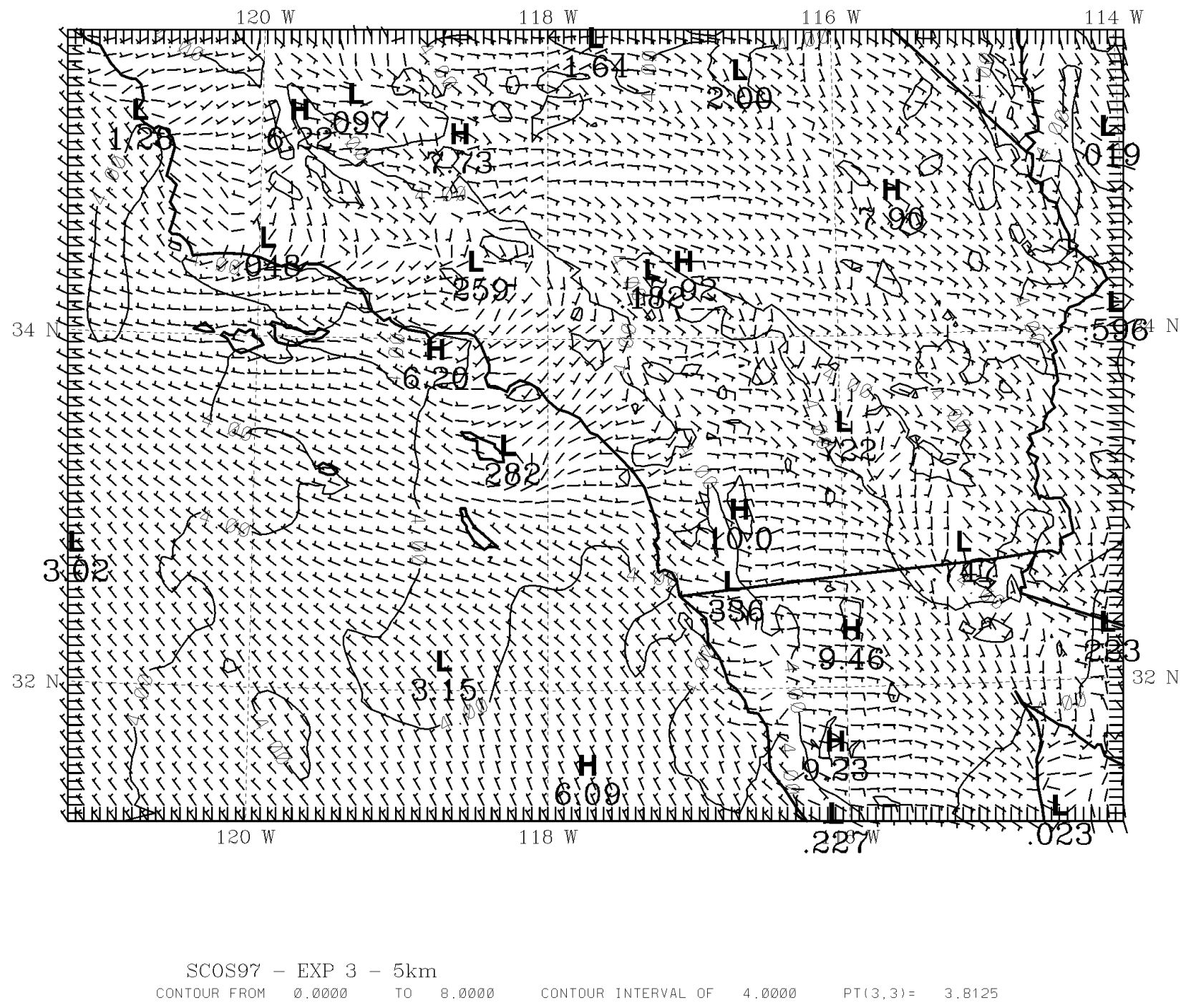

Figure 85. MM5 simulated winds $\left(\mathrm{ms}^{-1}\right)$ in the surface layer (12 $\mathrm{m} \mathrm{AGL)}$ on the 5-km domain, valid for 0000 UTC, 25 September 1997, (+96 h) in Exp. 3. Isotach interval is $4 \mathrm{~ms}^{-1}$. 


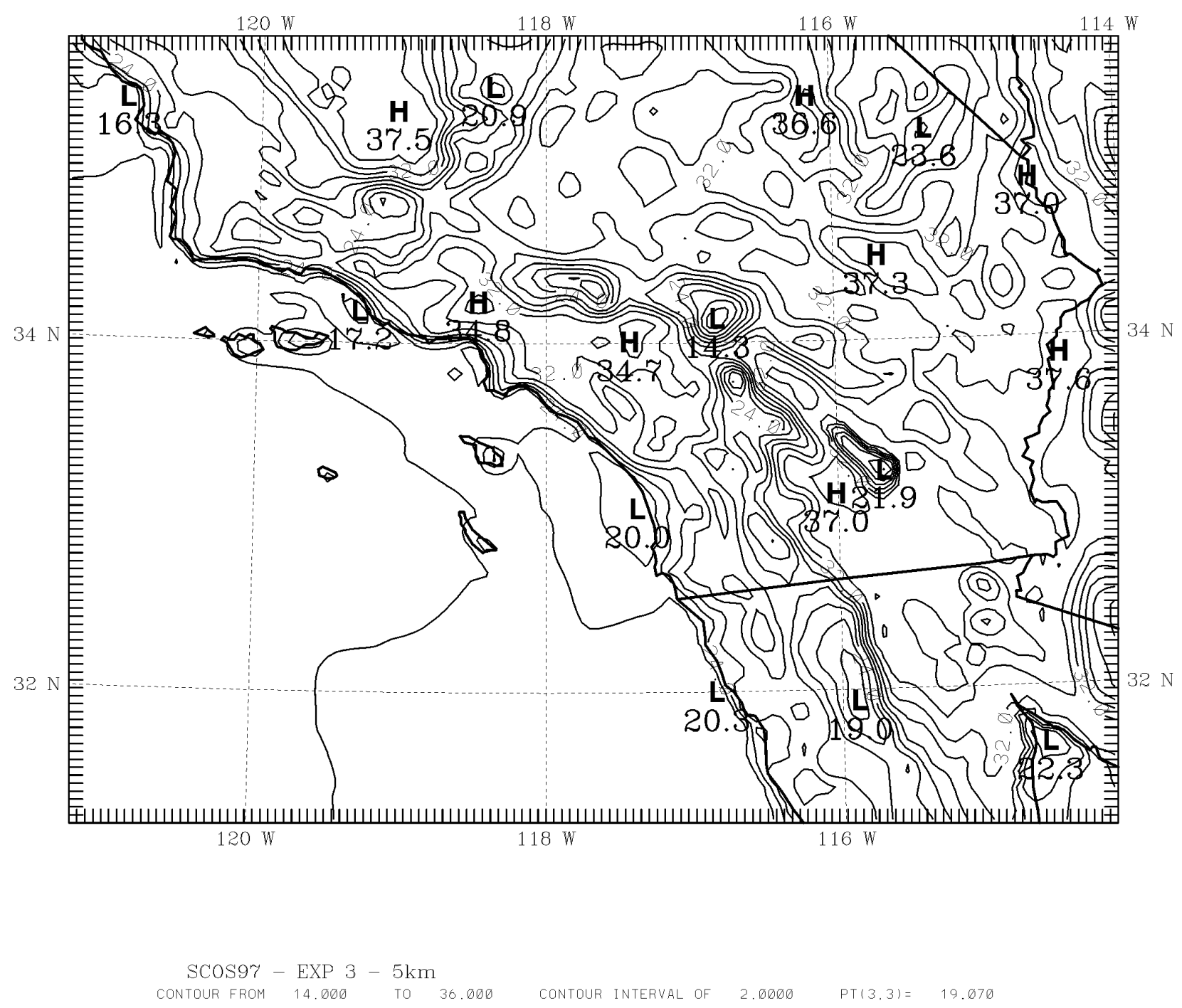

Figure 86. MM5 simulated temperatures (C) in the surface layer (12 m AGL) on the 5-km domain, valid for 0000 UTC, 25 September 1997, (+96 h) in Exp. 3. Isotherm interval is 2 C. 


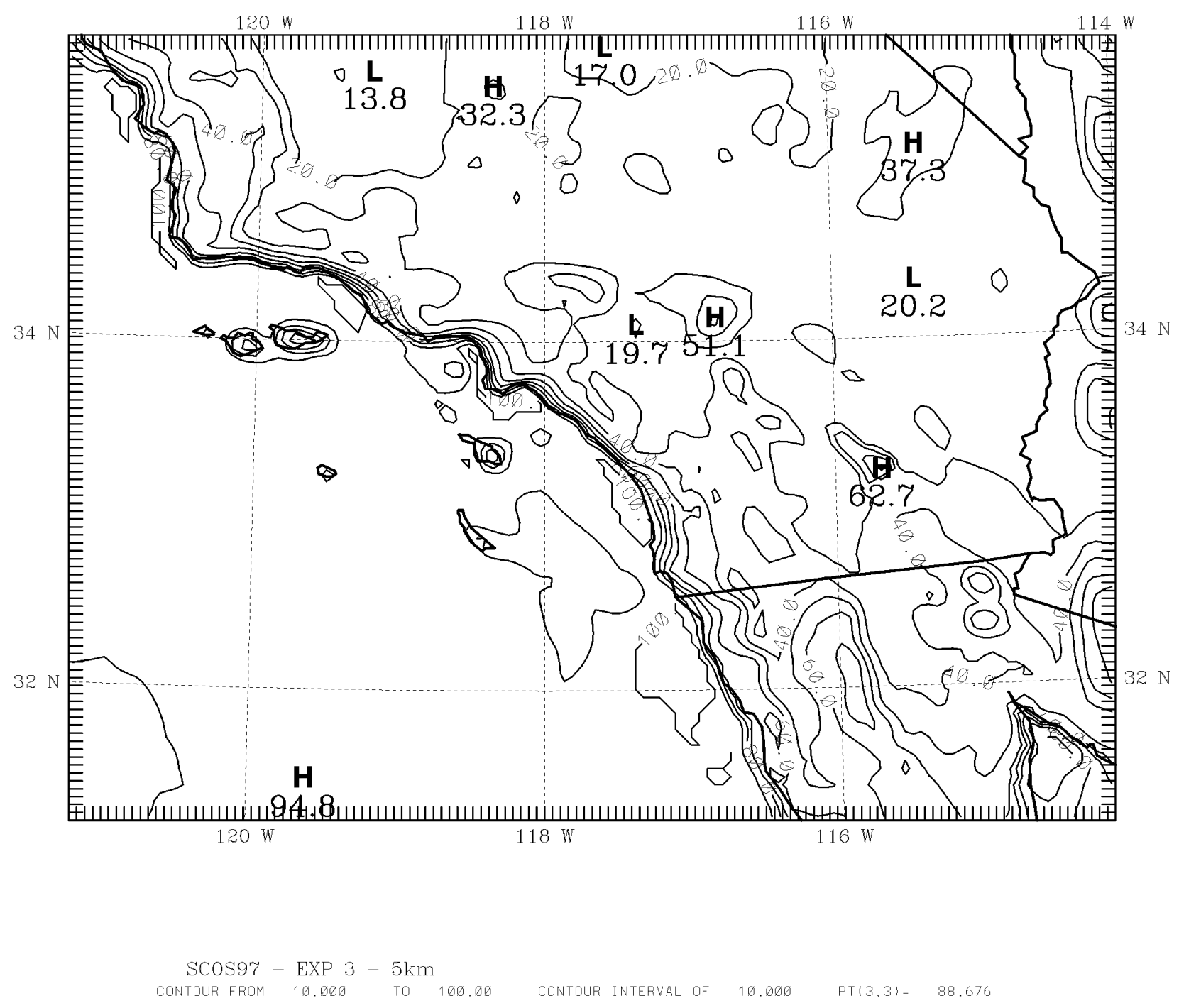

Figure 87. MM5 simulated relative humidity (\%) in the surface layer (12 m AGL) on the 5km domain, valid for 0000 UTC, 25 September 1997, (+96 h) in Exp. 3. Isopleth interval is 10 percent. 

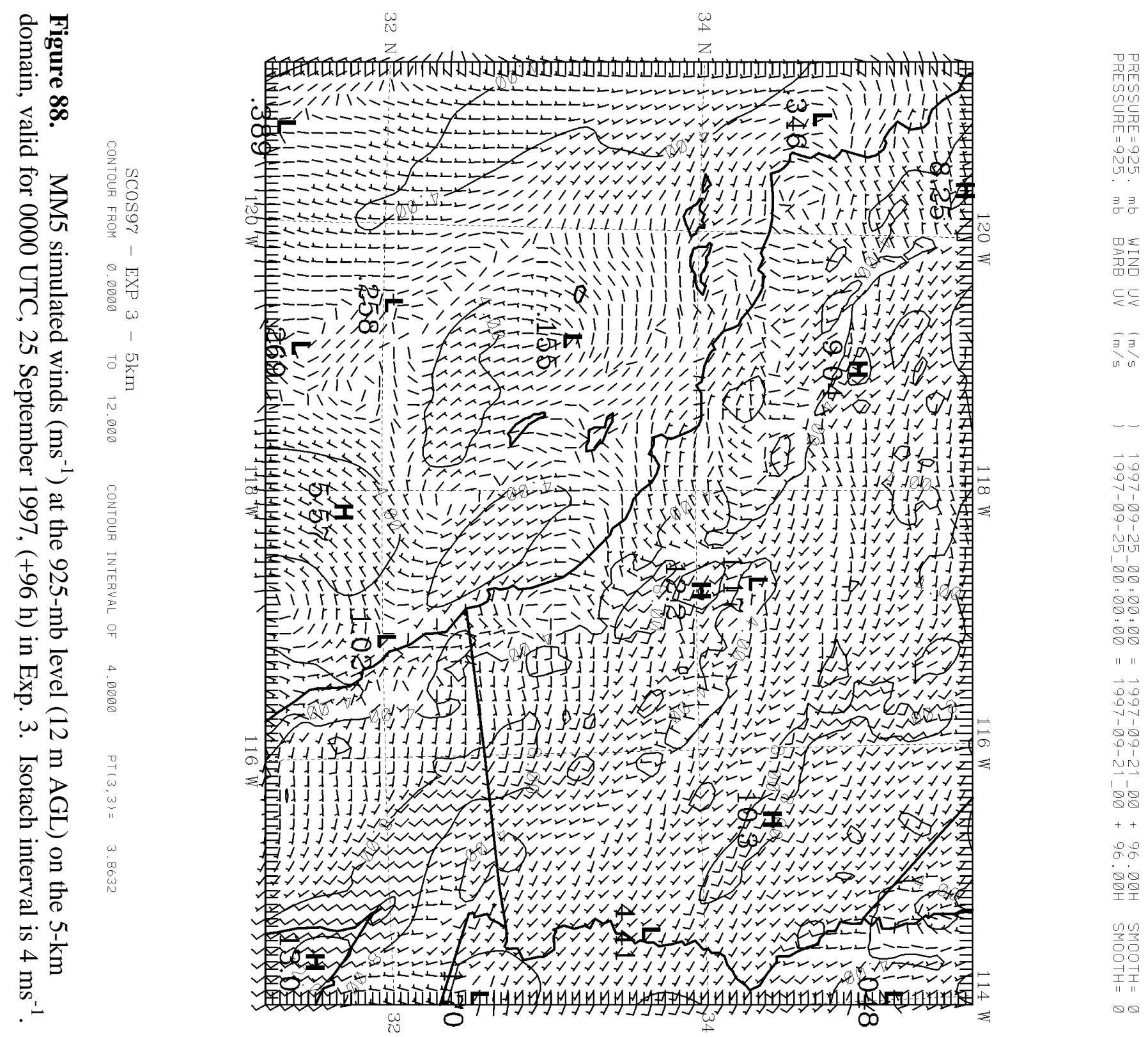
Figure 80). At $850 \mathrm{mb}$, the southeasterlies cover the entire domain, with winds up to $10-12 \mathrm{~ms}^{-1}$ (not shown). The vertical structure is apparent in the two selected vertical cross sections. Figures 89 and 90 show the potential temperature and relative humidity in the north-south cross section through Pt. Dume. Over the mountains, the unstable mixed layer extends up to $650 \mathrm{mb}$, with weak stability extending southward in the mid levels some distance over the CA Bight. The marine layer, meanwhile, is very shallow at this time with a strong capping inversion. Figure 90 indicates that the humidity is quite high (80-100\%) in the zone from 550-700 mb, revealing that moist tropical air has penetrated at high levels as far north as the Santa Barbara Channel. The GOES-9 satellite picture on this afternoon (Figure 24) confirms that clouds have appeared over the most of the CA Bight and into the mountains north and east of Los Angeles.

Figures 91-93 taken along the east-west cross section through San Diego show how the subtropical flow has drastically changed the atmospheric state by 0000 UTC, 25 September (+96 h). The comparatively weak mid-level stability shown earlier above San Diego now extends far to the west at least to San Clemente Island (Figure 91). The extensive mid-level moisture is shown between 550-700 $\mathrm{mb}$ in the relative humidity field of Figure 92, where humidities rise to 90-100\%. Elevated convection and stable rain may be occurring in these clouds, but the model would evaporate it before reaching the ground due to the drier air below $800 \mathrm{mb}$. Figure 93 shows that the easterly components of the horizontal wind are greater than $10 \mathrm{~ms}^{-1}$ almost everywhere above $850 \mathrm{mb}$, with winds more than $15 \mathrm{~ms}^{-1}$ near $700 \mathrm{mb}$. Thus, while the model has not yet produced rain in the vicinity of San Diego, the strong moist advection in the midlevels is rapidly creating the conditions where rain may occur. This solution is agrees well with observed conditions in the area near San Diego (Figures 25 and 26), which show a subtropical trough and a few scattered showers already penetrating the area.

Next, statistical analyses of Exp. 3 are presented, beginning with the evolution of the hourly domain-averaged surface temperatures in Figure 94. Comparison of these results to those from Exp. 2.5 (Figure 62) indicates no significant difference. The ME, MAE and RMSE for the same to experiments (Tables 9 and 10) confirm only slight improvement in the surface temperature simulations in Exp. 3 as a result of obs-nudging. Of course, this is expected since temperature data are not assimilated. The tables also show that there has been some moderate, but significant improvement in the statistics for domain-averaged surface-layer mixing ratio in Exp. 3. RMS errors have fallen by about $10 \%$ to $3.55 \mathrm{~g} \mathrm{~kg}^{-1}$. The ME for Exp. 2.5 is +2.68 , also a reduction of $\sim 10 \%$, indicating that most of the RMSE is due to the moist bias in the surface layer.

The model-simulated and observed domain-averaged hourly wind speeds for Exp. 3 are shown for the surface layer and the approximate boundary layer in Figures 95 and 96, respectively. These figures indicate that the model is reproducing the variability of the winds very reasonably over the entire period of the study. Not only are the main diurnal cycles simulated well, but some of the shorter-period excursions are reproduced to some extent. Comparison of the surface winds for Exp. 3 in Figure 95 to those from Exp. 2.5 in Figure 64 does not reveal much change. In fact, Tables 9 and 10 reveal that the ME in Exp. 3 has been degraded somewhat, even though the MAE and RMSE have both improved a bit in the surface layer. Surface RMSE in Exp. 3 is only $1.78 \mathrm{~ms}^{-1}$. The observed winds, of course, are assimilated in this experiment, so the mixed result in the surface layer suggests that the observations are capturing a degree of variability due to local surface irregularities that is beyond the resolution of the model to simulate. There is also 
Table 10. Statistical evaluation for Exp. 3 (Standard Observation-Nudging) for the SCOS97 episode of 21-24 September 1997. Statistics shown are mean errors (ME), mean absolute errors (MAE) and root mean square errors (RMS). Above the surface, statistics from individual MM5 calculation levels are merged into composite layers as weighted averages for the approximate boundary layer (25$1500 \mathrm{~m})$, lower troposphere $(1500-5000 \mathrm{~m})$ and upper troposphere $(5000-10500$ $\mathrm{m})^{*}$.

\begin{tabular}{|c|c|c|c|c|c|c|c|c|c|c|c|c|}
\hline \multirow[t]{2}{*}{$\begin{array}{r}\text { Verification } \\
\text { Layer (AGL) }\end{array}$} & \multicolumn{3}{|c|}{$\begin{array}{l}\text { Temperature } \\
\text { (C) }\end{array}$} & \multicolumn{3}{|c|}{$\begin{array}{c}\text { Mixing Ratio } \\
(\mathrm{g} / \mathrm{kg})\end{array}$} & \multicolumn{3}{|c|}{$\begin{array}{c}\text { Wind Speed } \\
(\mathrm{m} / \mathrm{s})\end{array}$} & \multicolumn{3}{|c|}{$\begin{array}{l}\text { Wind Direct. } \\
\text { (degrees) }\end{array}$} \\
\hline & ME & MAE & RMS & ME & MAE & RMS & ME & MAE & RMS & ME & MAE & RMS \\
\hline $5000-10500 \mathrm{~m}$ & -- & -- & -- & -- & -- & -- & -0.22 & 0.79 & 0.79 & -0.16 & 6.01 & 6.01 \\
\hline $1500-5000 \mathrm{~m}$ & -- & - & - & - & - & - & -0.30 & 1.25 & 1.54 & +0.52 & 15.0 & 19.2 \\
\hline $25-1500 \mathrm{~m}$ & - & - & -- & - & - & -- & -0.29 & 1.23 & 1.60 & -1.98 & 27.3 & 38.4 \\
\hline $12 \mathrm{~m} \mathrm{AGL}$ & -0.89 & 2.73 & 3.44 & +2.68 & 2.92 & 3.55 & -0.59 & 1.33 & 1.78 & -0.16 & 50.9 & 68.1 \\
\hline
\end{tabular}

* Note that no statistics appear for the temperature and mixing ratio above the surface because the 5-km model domain did not have supplemental upper-air measurement systems during SCOS-97 capable of taking observations for these variables more often than twice per day. Winds aloft are obtained from up to 27 radar wind profilers operated during the study period. 


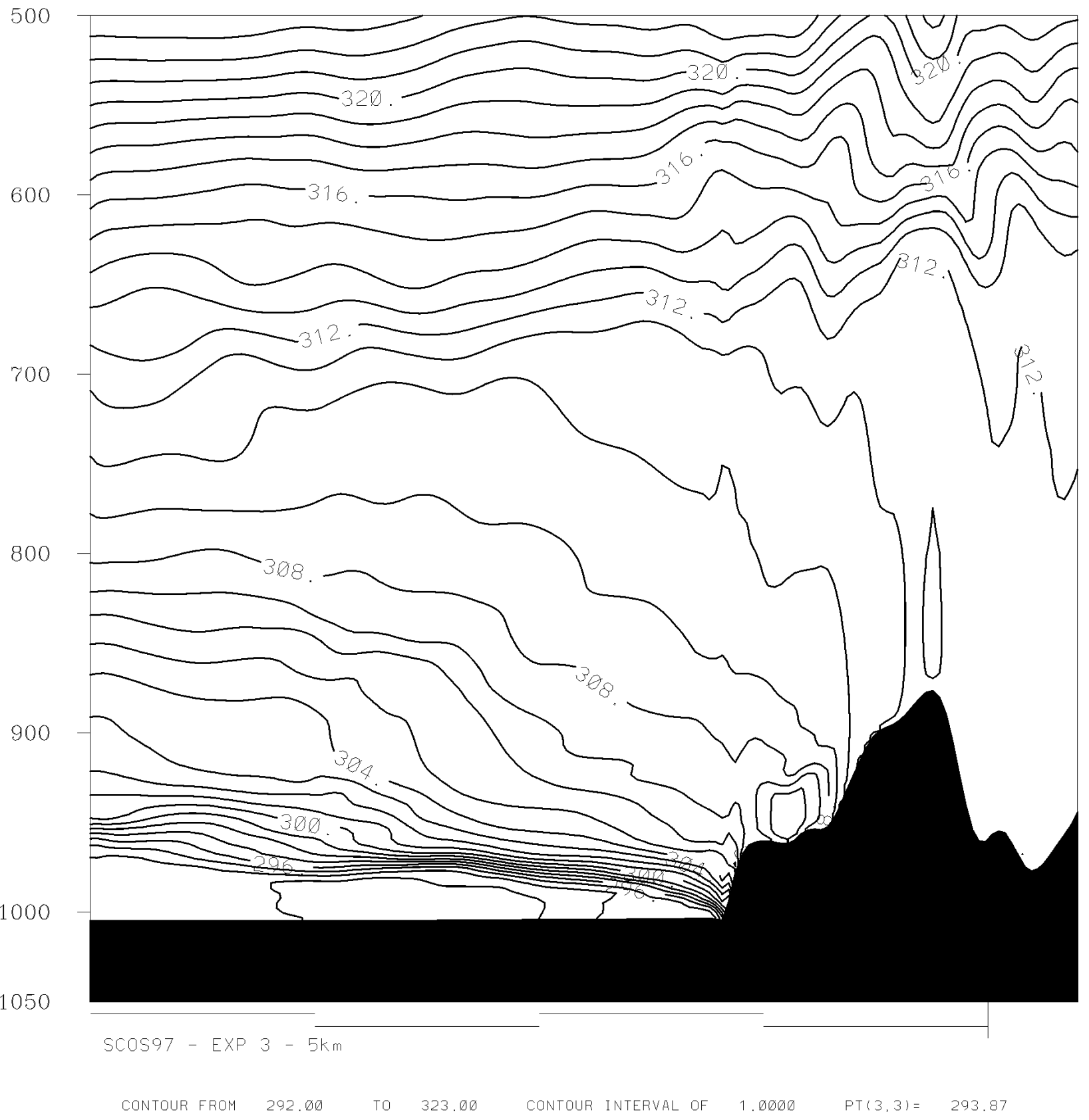

Figure 89. MM5 simulated potential temperature, $\theta(\mathrm{K})$ on the 5-km domain plotted versus pressure in the plane of the Pt. Dume north-south cross section, valid for 1200 UTC, 25 September 1997, (+96 h) in Exp. 3. Isentrope interval is $1 \mathrm{~K}$. 


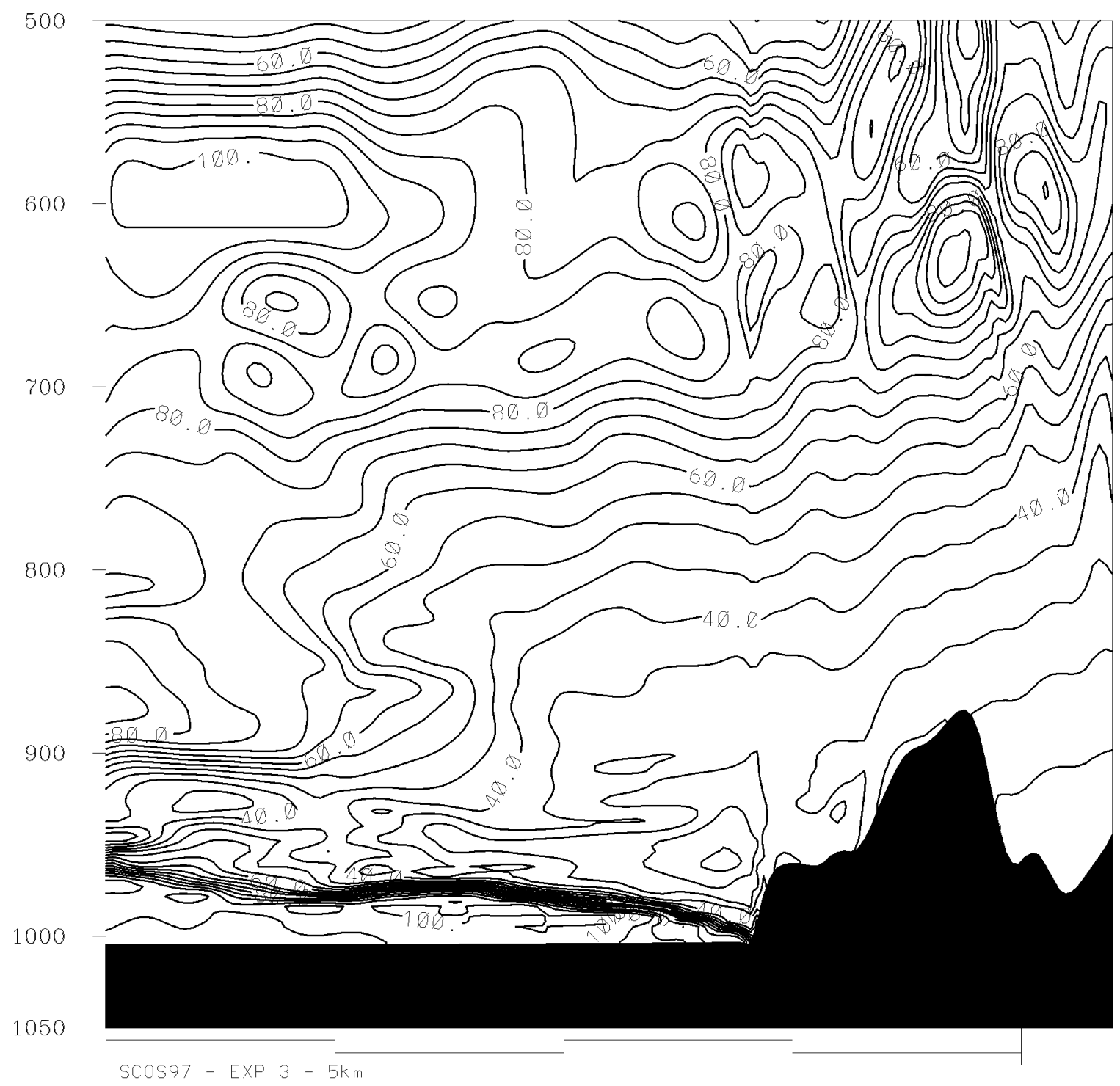

CONTOUR FROM 15.000 TO 100.00 CONTOUR INTERVAL OF $5.0000 \quad$ PT(3,3)= 92.875

Figure 90. MM5 simulated relative humidity (\%) on the 5-km domain plotted versus pressure in the plane of the Pt. Dume north-south cross section, valid for 0000 UTC, 25 September 1997, (+96 h) in Exp. 3. Isopleth interval is $0.05 \mathrm{~g} \mathrm{~kg}^{-1}$. 


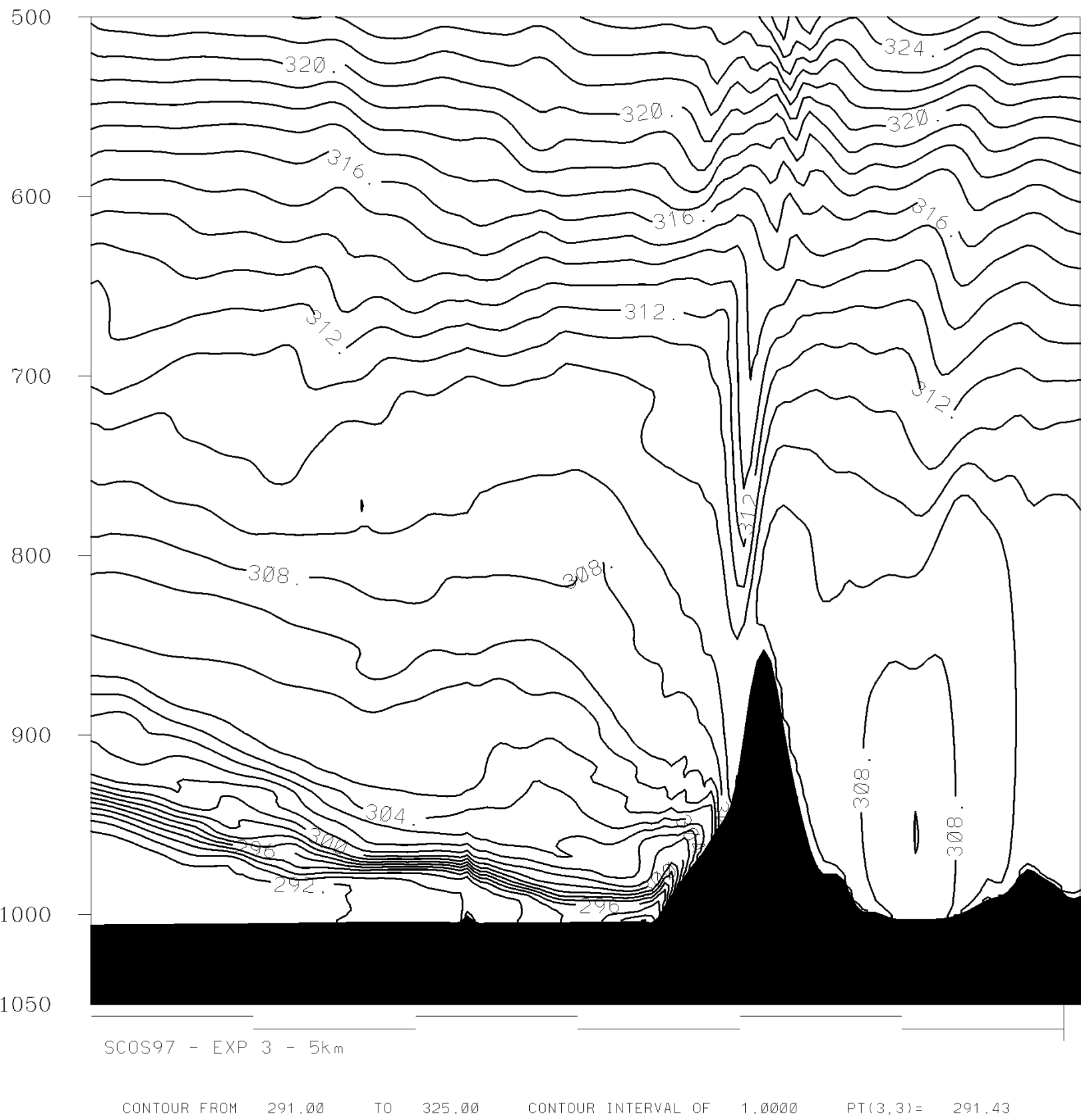

Figure 91. MM5 simulated potential temperature, $\theta(\mathrm{K})$ on the 5-km domain plotted versus pressure in the plane of the San Diego west-east cross section, valid for 0000 UTC, 25 September 1997, (+96 h) in Exp. 3. Isentrope interval is $1 \mathrm{~K}$. 


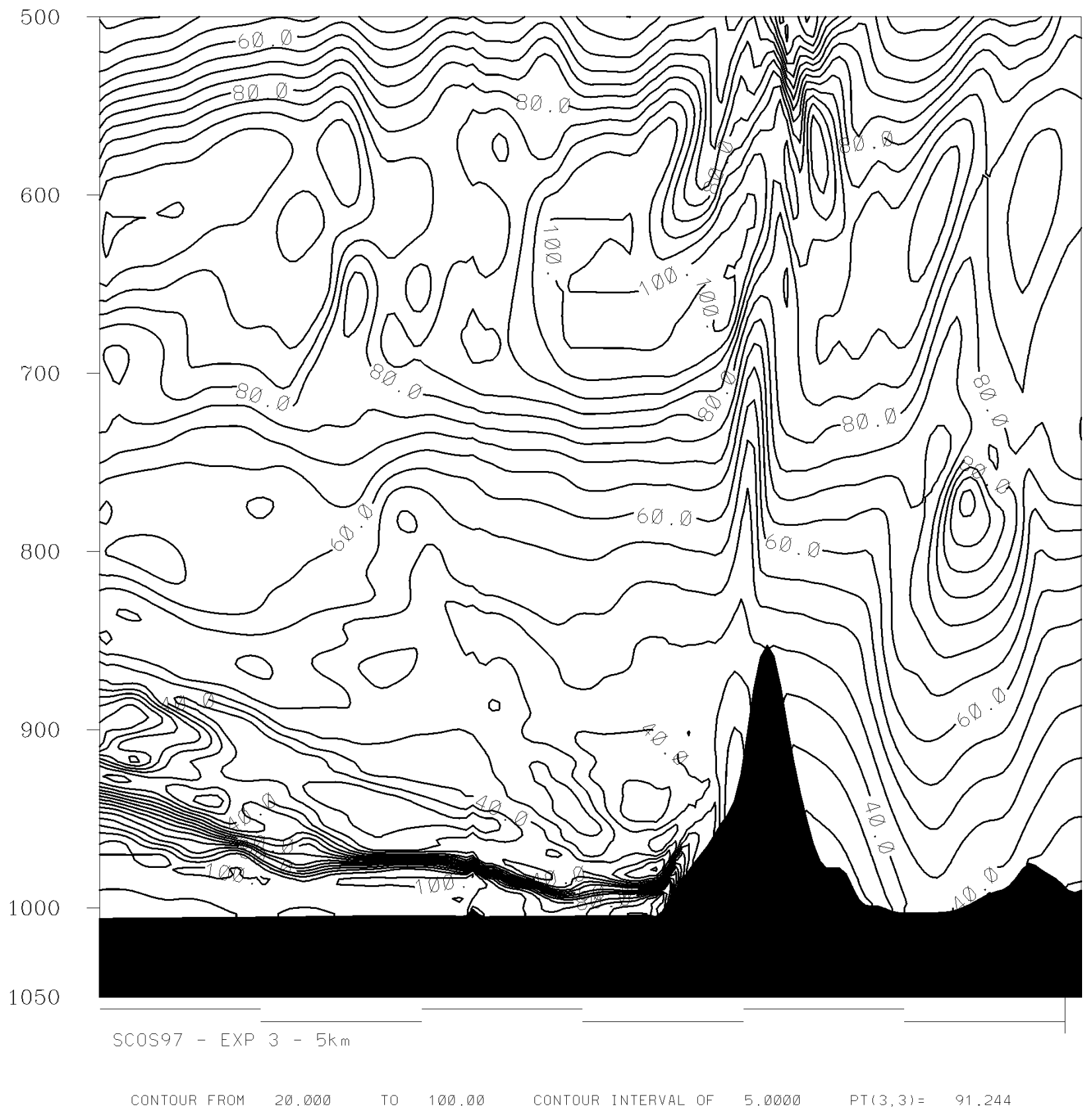

Figure 92. MM5 simulated relative humidity (\%) on the 5-km domain plotted versus pressure in the plane of the San Diego west-east cross section, valid for 0000 UTC, 25 September 1997, (+96 h) in Exp. 3. Isopleth interval is 5 percent. 

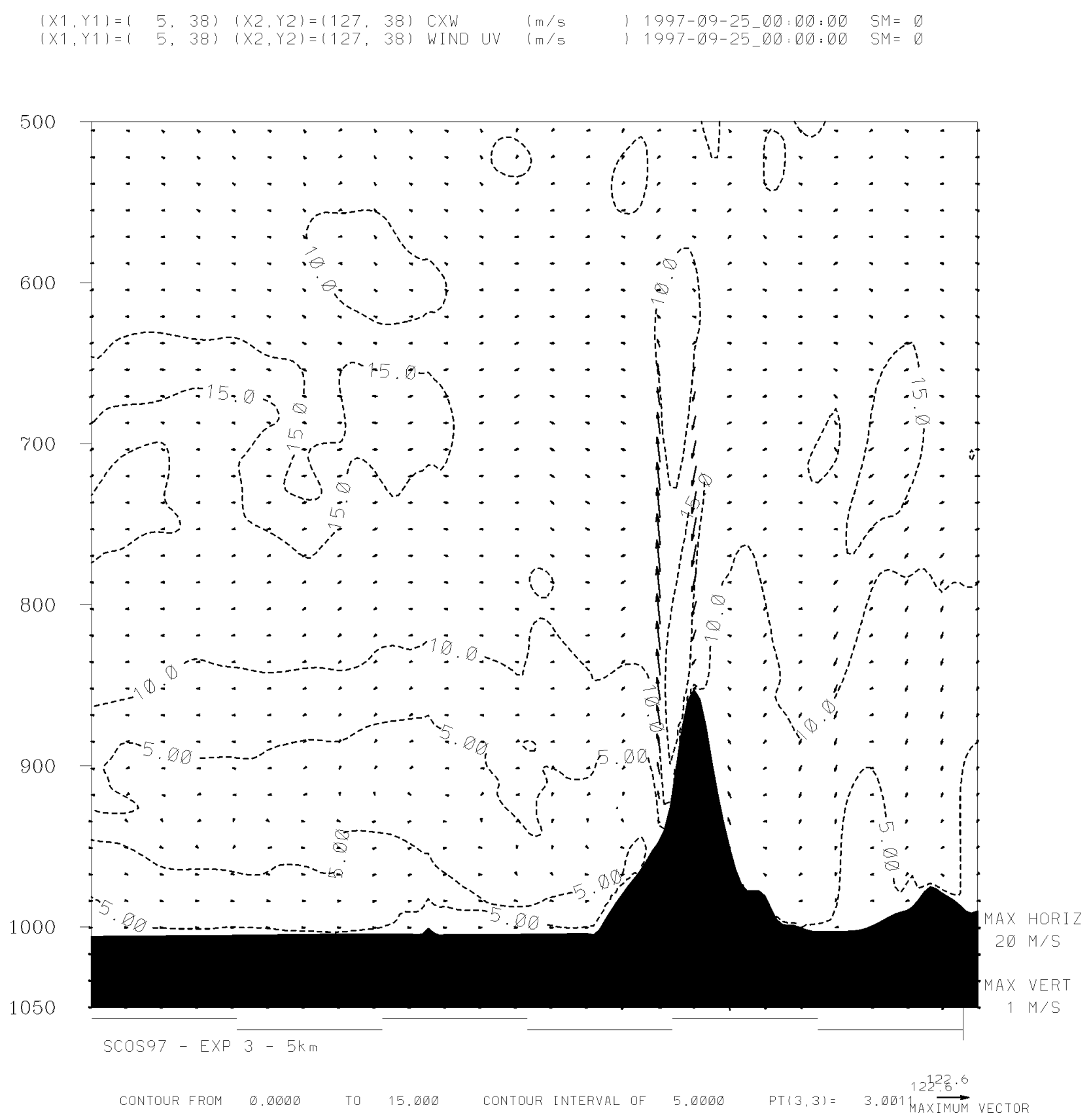

Figure 93. MM5 simulated wind $\left(\mathrm{ms}^{-1}\right)$ on the 5-km domain plotted versus pressure in the plane of the San Diego west-east cross section, valid for 0000 UTC, 25 September 1997, (+96 h) in Exp. 3. Isotach interval is $5 \mathrm{~ms}^{-1}$. 
PLOT OF TEMP (C) VS. TIME, EXPNAM= SCOS97 5KM EXP3 HRLYAVG

LAYER = sfc layer $(40 \mathrm{~m}) \mathrm{AGL}$, DOMAIN $=5 \mathrm{~km}$

DATE/TIME RANGE = 21 SEP 1997, 0000Z-24 SEP 1997, 23007 MODEL HOUR RANGE $=0.0-95.0 \mathrm{~h}$

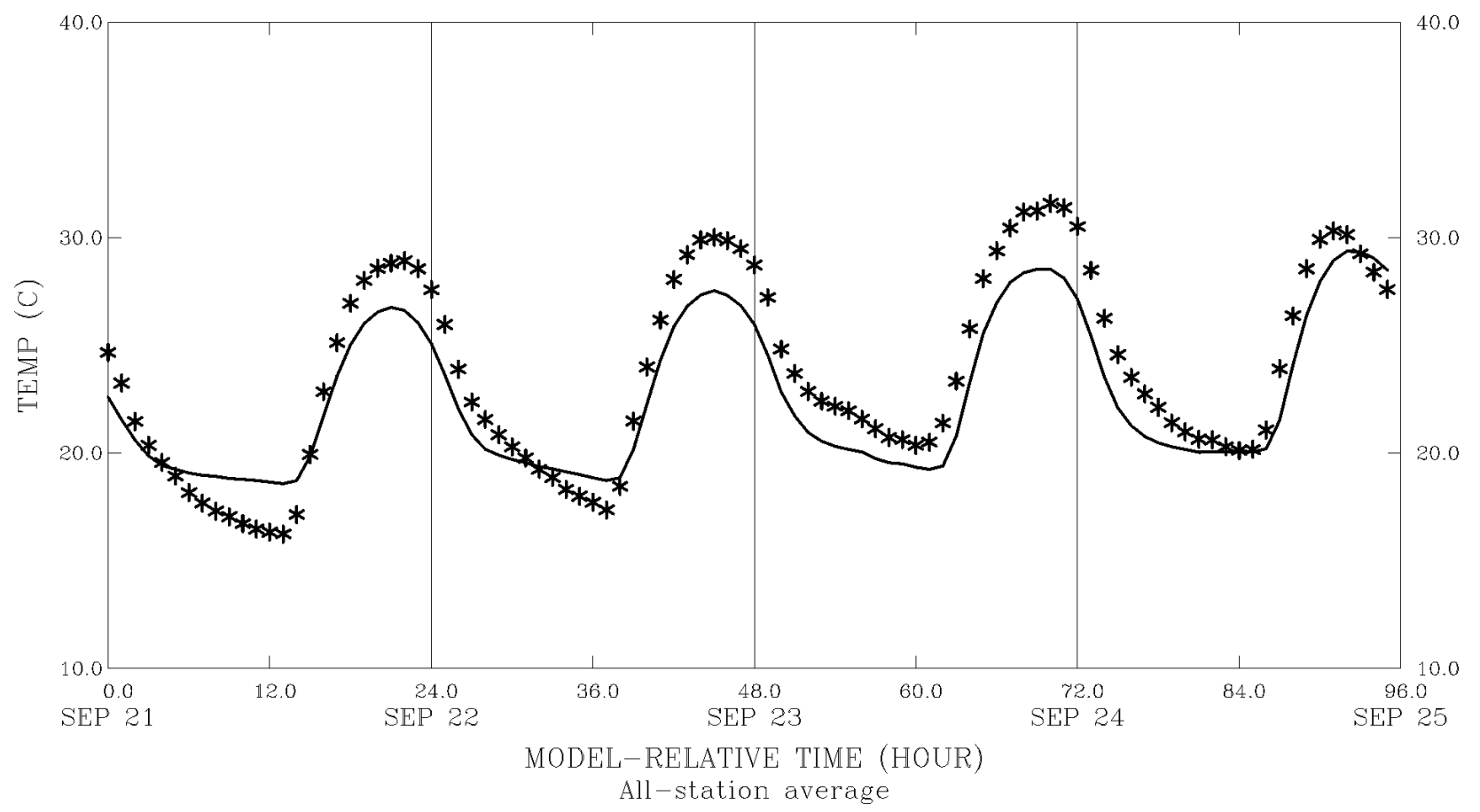

Figure 94. Evolution of domain-averaged surface-layer temperature (C) at $12 \mathrm{~m}$ AGL on the 5-km MM5 domain in the Standard Observation Nudging Experiment (Exp. 3) for 21-24 September 1997. Times shown on abscissa are forecast hours from the initial time, 0000 UTC, 21 September. Solid line is model-simulated mean, asterisks are hourly observed means. 
PLOT OF WIND SPEED (M/S) VS. TIME, EXPNAM= SCOS97 5KM EXP3 HRLYAVG

LAYER = sfc layer $(40 \mathrm{~m}) \mathrm{AGL}$, DOMAIN $=5 \mathrm{~km}$

DATE/TIME RANGE = 21 SEP 1997, 0000Z-24 SEP 1997, $2300 Z$ MODEL HOUR RANGE $=0.0-95.0 \mathrm{~h}$

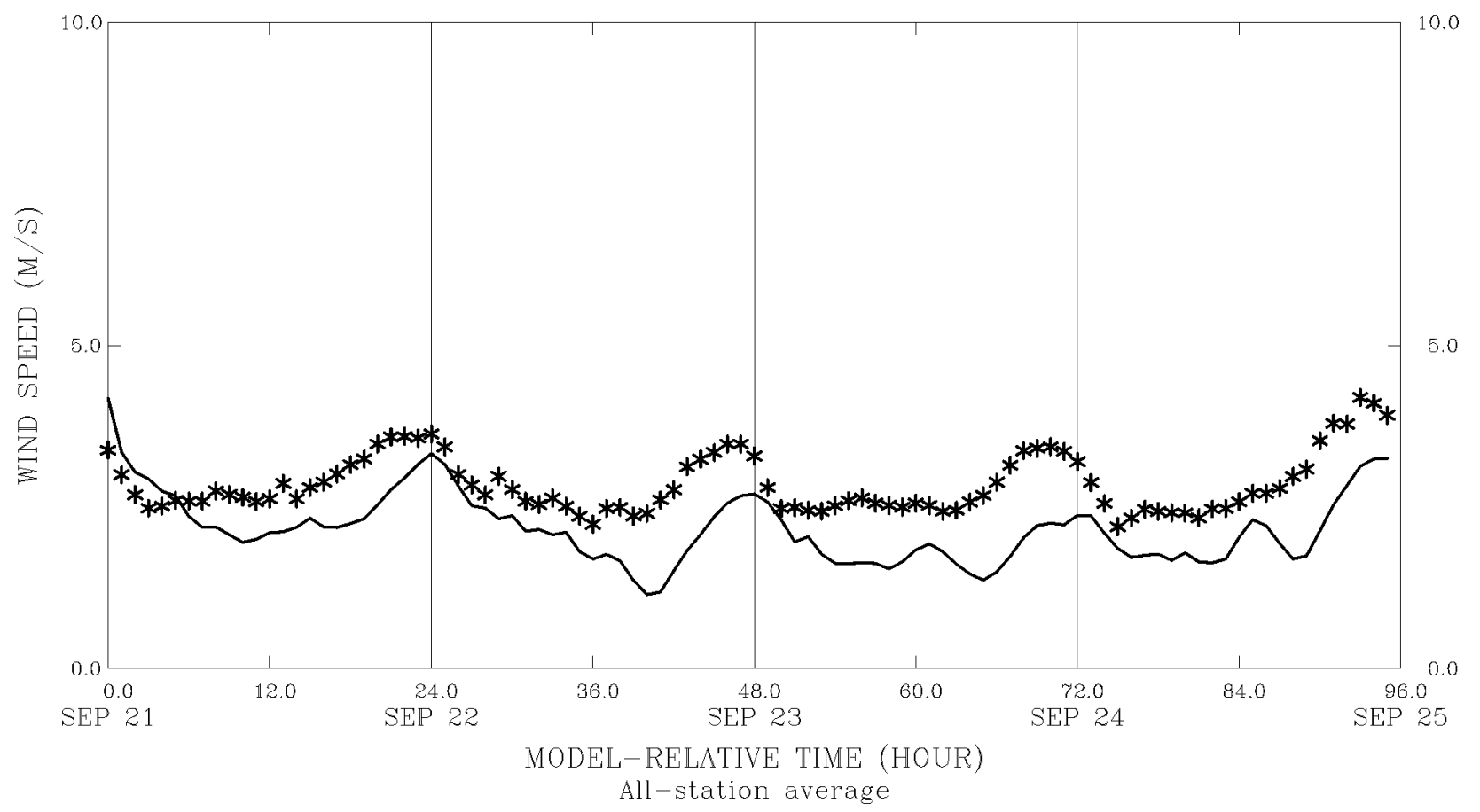

Figure 95. Evolution of domain-averaged surface-layer wind speed $\left(\mathrm{ms}^{-1}\right)$ at $12 \mathrm{~m}$ AGL on the 5-km MM5 domain in the Standard Observation Nudging Experiment (Exp. 3) for 21-24 September 1997. Times shown on abscissa are forecast hours from the initial time, 0000 UTC, 21 September. Solid line is model-simulated mean; asterisks are hourly observed means. 
PLOT OF WIND SPEED (M/S) VS. TIME, EXPNAM= SCOS97 5KM EXP3 HRLYAVG $\mathrm{LAYER}=80-1500 \mathrm{~m}$ AGL, DOMAIN $=5 \mathrm{~km}$

DATE/TIME RANGE = 21 SEP 1997, 0000Z-24 SEP 1997, $2300 Z$ MODEL HOUR RANGE $=0.0-95.0 \mathrm{~h}$

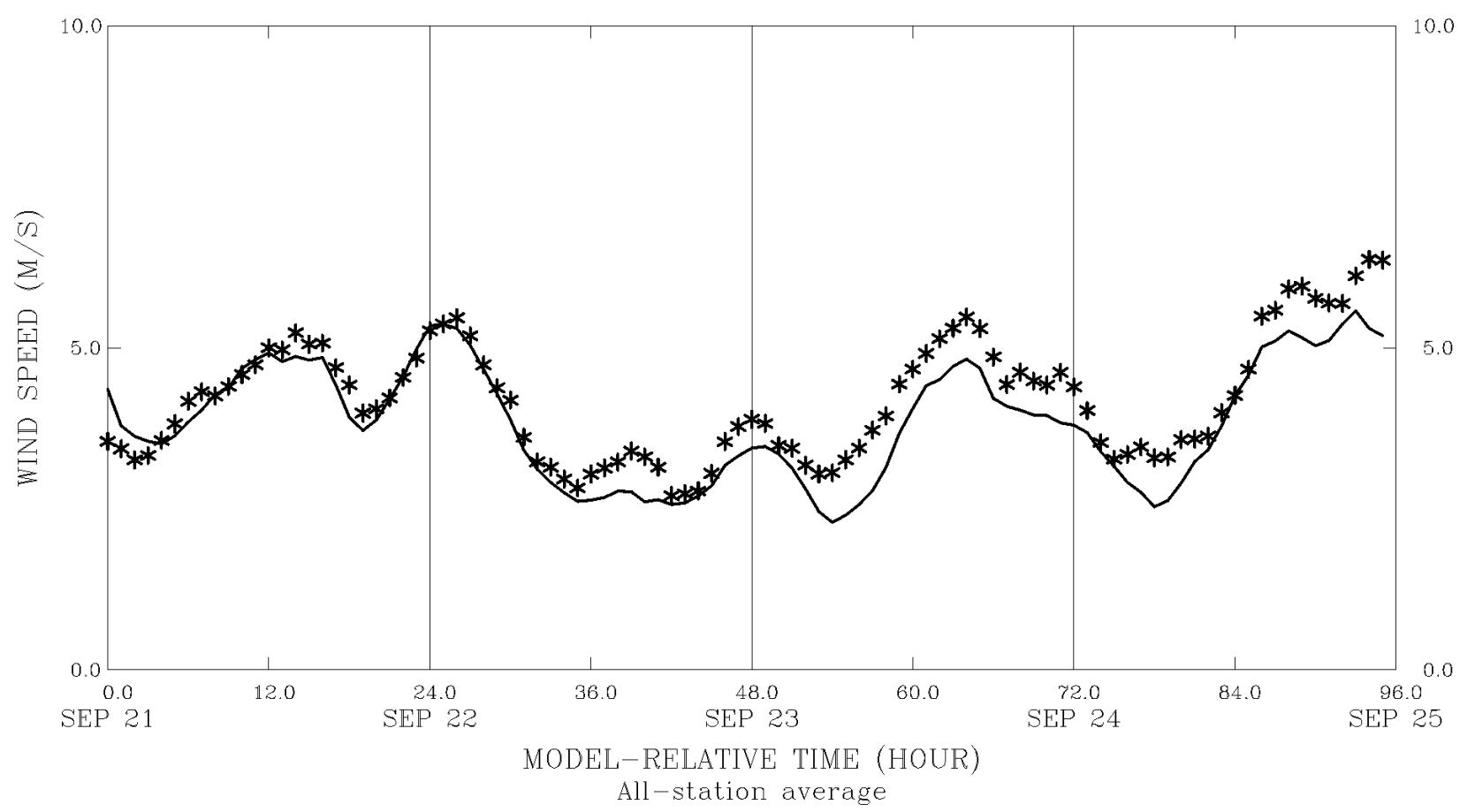

Figure 96. Evolution of domain-averaged for wind speed $\left(\mathrm{ms}^{-1}\right)$ in the layers from $25-1500 \mathrm{~m}$ AGL on the 5-km MM5 domain in the Standard Observation Nudging Experiment (Exp. 3) for 21-24 September 1997. Times shown on abscissa are forecast hours from the initial time, 0000 UTC, 21 September. Solid line is model-simulated mean, asterisks are hourly observed means. 
a slow bias in the surface layer winds on the order of $1 \mathrm{~ms}^{-1}$ on the second and third days of the period. The wind simulations in the approximate boundary layer from 25-1500 m AGL (Figure 96) is a zone where the profiler winds were assimilated. Here the model tracks the observed wind evolution very well, so that the MAE is only $1.23 \mathrm{~ms}^{-1}$ and the RMS error falls to $1.60 \mathrm{~ms}^{-1}$. in Exp. 3, versus $2.27 \mathrm{~ms}^{-1}$ in Exp. 2.5. These statistical results place the model solution within the target goal for RMS error of $2.0 \mathrm{~ms}^{-1}$ often expected for meteorological datasets intended for air-quality applications. Even allowing for some effect due to the absence of an independent dataset for wind that can be used to validate this experiment, the true error is almost certainly less than $2.0 \mathrm{~ms}^{-1}$ for these important layers. That assessment is justified from previous studies in CA for which independent wind data was available for assessing obs-nudging impact that showed $50-75 \%$ of the apparent error reduction is real, while the rest is due to the loss of independence in the verifying data. Comparison between the RMSEs in these layers calculated for Exps. 2.5 and 3 (Tables 9 and 10) indicate the "true" RMSEs are safely less than the criterion. Thus, the advection represented by the model winds is expected to be reasonably accurate. Table 10 shows that the errors in the mid and upper troposphere are even smaller.

Some further analysis on the wind errors is appropriate for Exp. 3, since it is the primary experiment intended for use by ARB in subsequent air-quality modeling studies. Figures 97 and 98 show how well the model solutions match the observed evolution of the domainaveraged east-west $(\mathrm{u})$ component of the winds in the surface layer and the 25-1500 m layer. The u-components clearly reveal the diurnal cycle of the sea-breeze and valley breeze. It is evident that the model has captured this variability very well, including the tendency through the final two days of the period for the predominantly westerly flow to become mostly easterly. This tendency is most clearly evident above the surface (Figure 98). The north-south (v) components for same two same two layers are shown for Exp. 3 in Figures 99 and 100. Figure 99 reveals that the domain-averaged $\mathrm{v}$ components are very small in the surface layer through the entire period (even though they may become important on certain sub-regions of the domain). However, above the surface in the $25-1500 \mathrm{~m}$ zone, the v-components are much easier to understand. In this layer, where most of the actual pollutant transport takes place, it is clear from Figure 100 that the first $36 \mathrm{~h}$ of the study period were dominated by a northerly component. This regime prevailed while the upper-level ridge position was west of the SoCAB, but the vcomponent virtually disappeared by +48 h (0000 UTC, 23 September), when the upper-level ridge crossed over the SoCAB. Thereafter, Figure 100 indicates that southerly components became dominant, resulting in the advection of warm, moist subtropical air northward from the tropical storm. As for the u-components, the model has replicated these trends very well.

Finally, Figures 101 and 102 depict the evolution of the domain-averaged hourly wind directions in Exp. 3 versus the observations. On the basis of the wind-component plots shown in Figures 97-100, one would expect the wind direction errors in Exp. 3 to be much smaller than in prior experiments. However, comparison with the same figures from Exp. 2.5 (Figures 66 and 67) suggests no obvious difference in the surface layer and perhaps only small improvements in the 25-1500 m layer. Further comparison of the ME, MAE and RMSE for these two experiments in Tables 9 and $\mathbf{1 0}$ confirms that while moderate improvements were found in all layers, the model cannot reproduce all of the fine structure in the winds, especially in the surface layer. The $\mathrm{ME}$ is small at all levels (less than 2 degrees), but surface RMSE remains 68 degrees, falling to 38 degrees in the 25-1000 m layer. 
PLOT OF U (M/S) VS. TIME, EXPNAM= SCOS97 5KM EXP3 HRLYAVG

LAYER = sfc layer $(40 \mathrm{~m}) \mathrm{AGL}$, DOMAIN $=5 \mathrm{~km}$

DATE/TIME RANGE= 21 SEP 1997, 0000Z-24 SEP 1997, 23007 MODEL HOUR RANGE $=0.0-95.0 \mathrm{~h}$

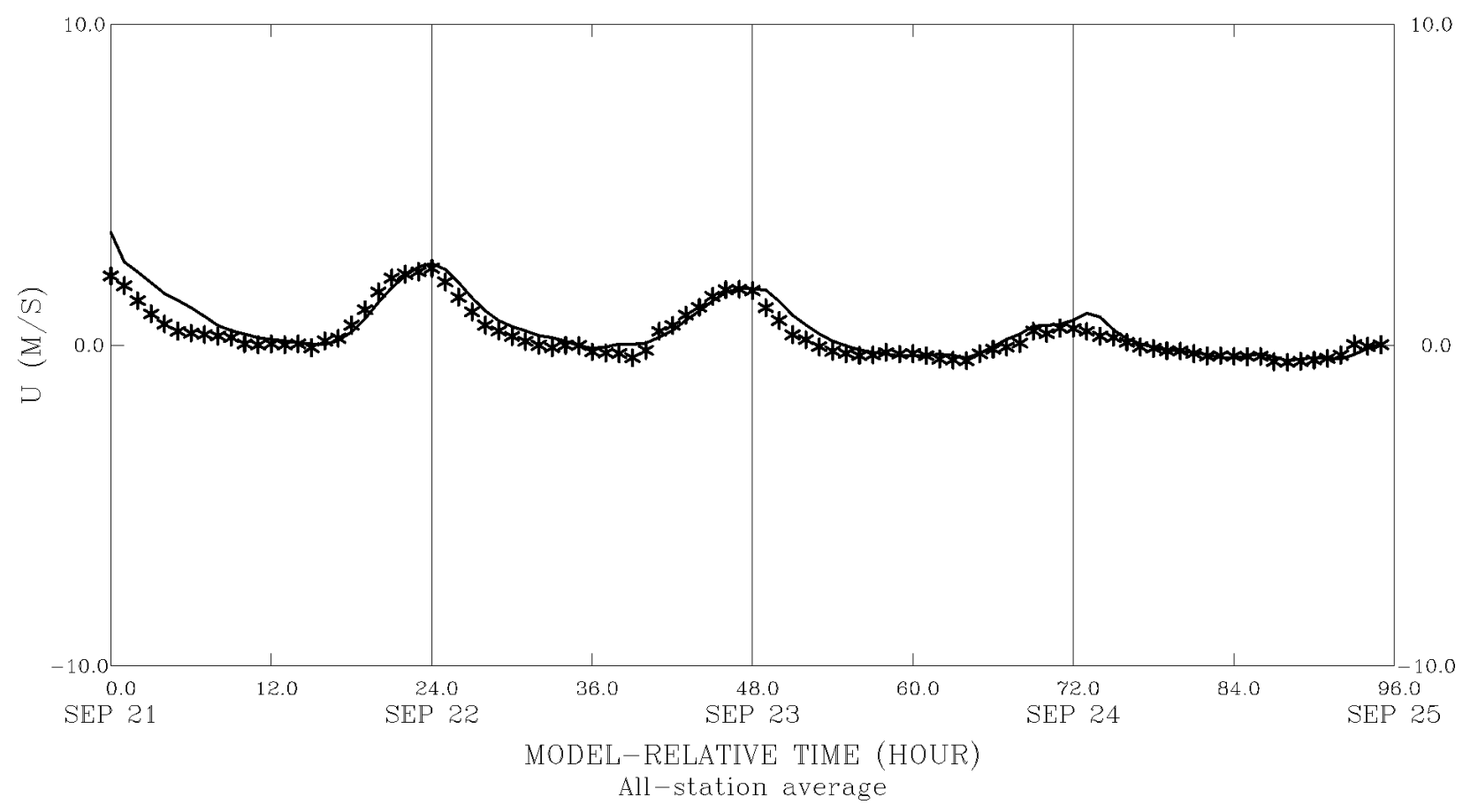

Figure 97. Evolution of domain-averaged surface-layer u-component of wind speed $\left(\mathrm{ms}^{-1}\right)$ at $12 \mathrm{~m}$ AGL on the 5-km MM5 domain in the Standard Observation Nudging Experiment (Exp. 3) for 21-24 September 1997. Times shown on abscissa are forecast hours from the initial time, 0000 UTC, 21 September. Solid line is model-simulated mean; asterisks are hourly observed means. 


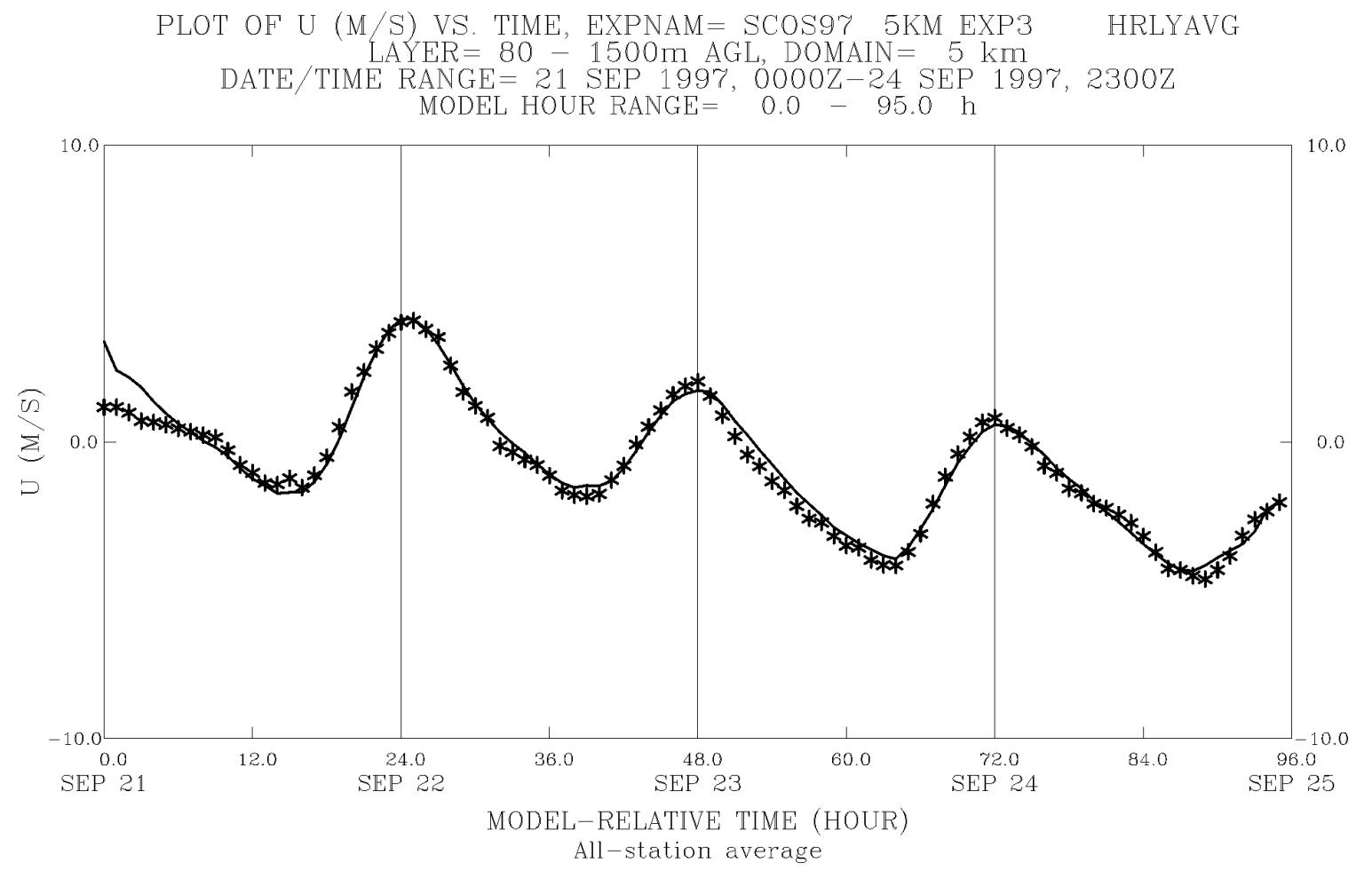

Figure 98. Evolution of domain-averaged u-component of wind speed $\left(\mathrm{ms}^{-1}\right)$ in the layers from 25-1500 m AGL on the 5-km MM5 domain in the Standard Observation Nudging Experiment (Exp. 3) for 21-24 September 1997. Times shown on abscissa are forecast hours from the initial time, 0000 UTC, 21 September. Solid line is model-simulated mean; asterisks are hourly observed means. 


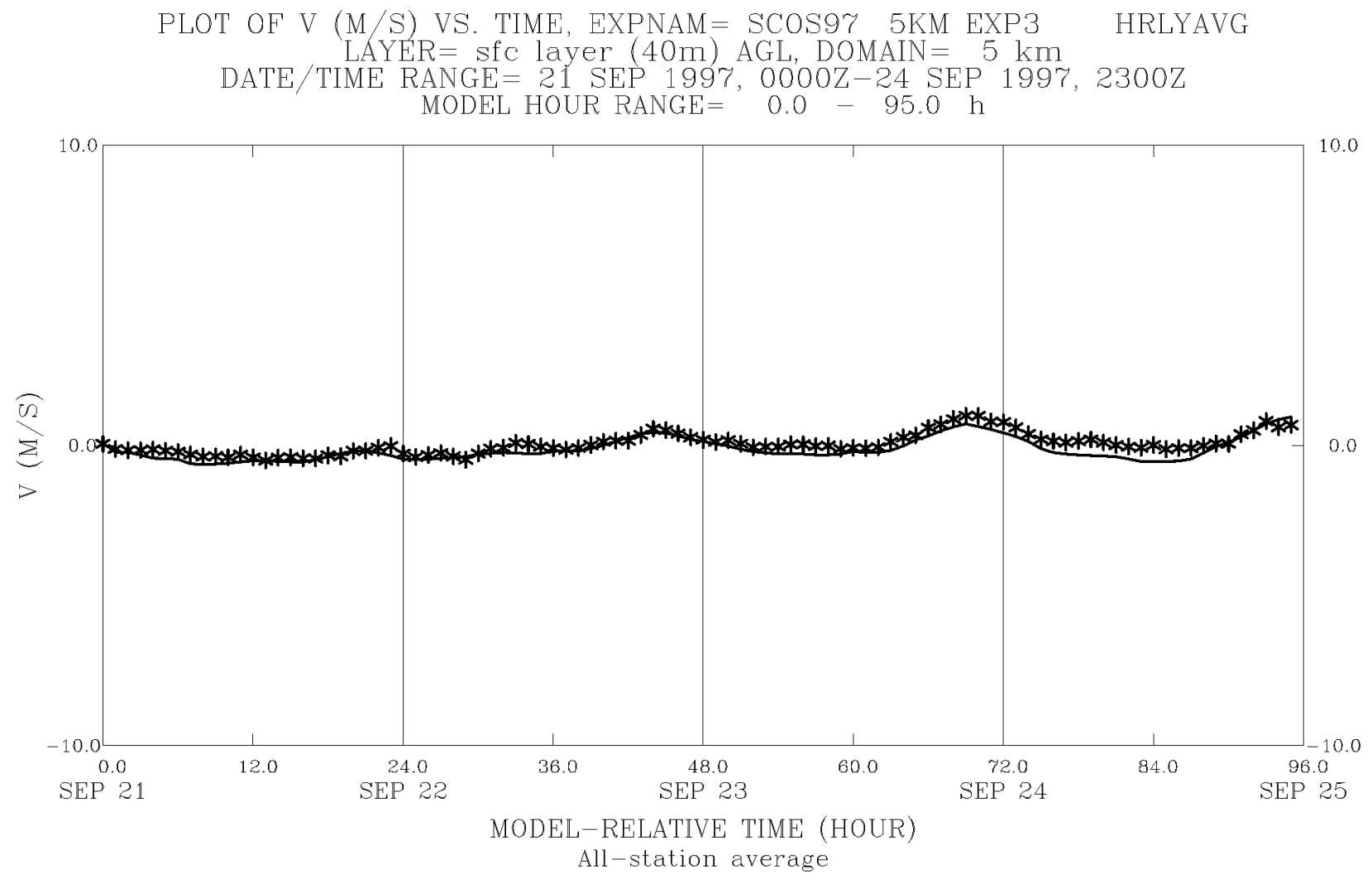

Figure 99. Evolution of domain-averaged surface-layer v-component of wind speed $\left(\mathrm{ms}^{-1}\right)$ at $12 \mathrm{~m}$ AGL on the 5-km MM5 domain in the Standard Observation Nudging Experiment (Exp. 3) for 21-24 September 1997. Times shown on abscissa are forecast hours from the initial time, 0000 UTC, 21 September. Solid line is model-simulated mean; asterisks are hourly observed means. 


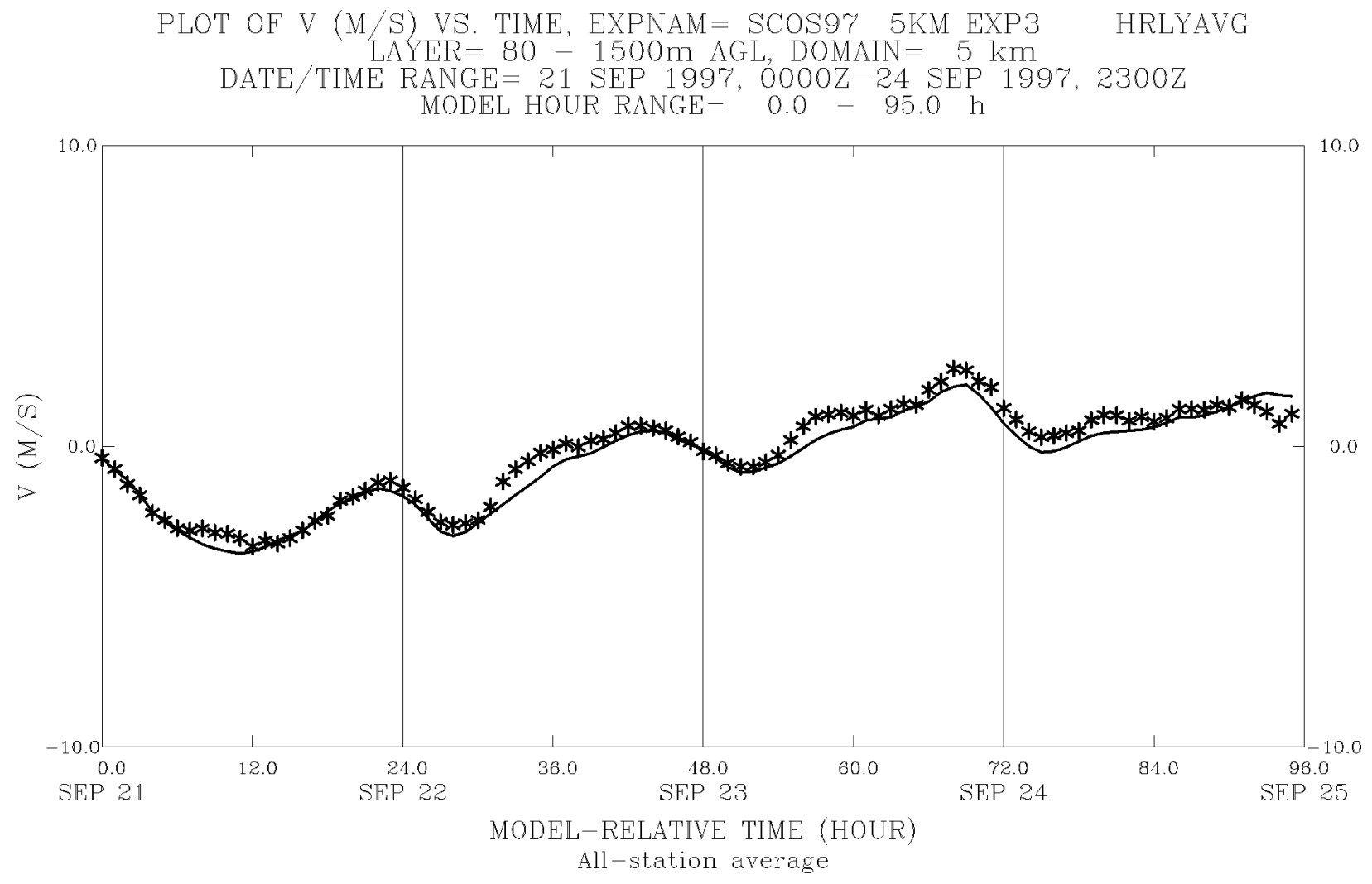

Figure 100. Evolution of domain-averaged v-component of wind speed $\left(\mathrm{ms}^{-1}\right)$ in the layers from 25-1500 m AGL on the 5-km MM5 domain in the Standard Observation Nudging Experiment (Exp. 3) for 21-24 September 1997. Times shown on abscissa are forecast hours from the initial time, 0000 UTC, 21 September. Solid line is model-simulated mean; asterisks are hourly observed means. 
PLOT OF WIND DIRECTION (DEG) VS. TIME, EXPNAM = SCOS97 5KM EXP3 HRLYAVG LAYER $=$ sfc layer $(40 \mathrm{~m})$ AGL, DOMAIN $=5 \mathrm{~km}$

DATE/TIME RANGE = 21 SEP 1997, 0000Z-24 SEP 1997, 23007 MODEL HOUR RANGE $=0.0-95.0 \mathrm{~h}$

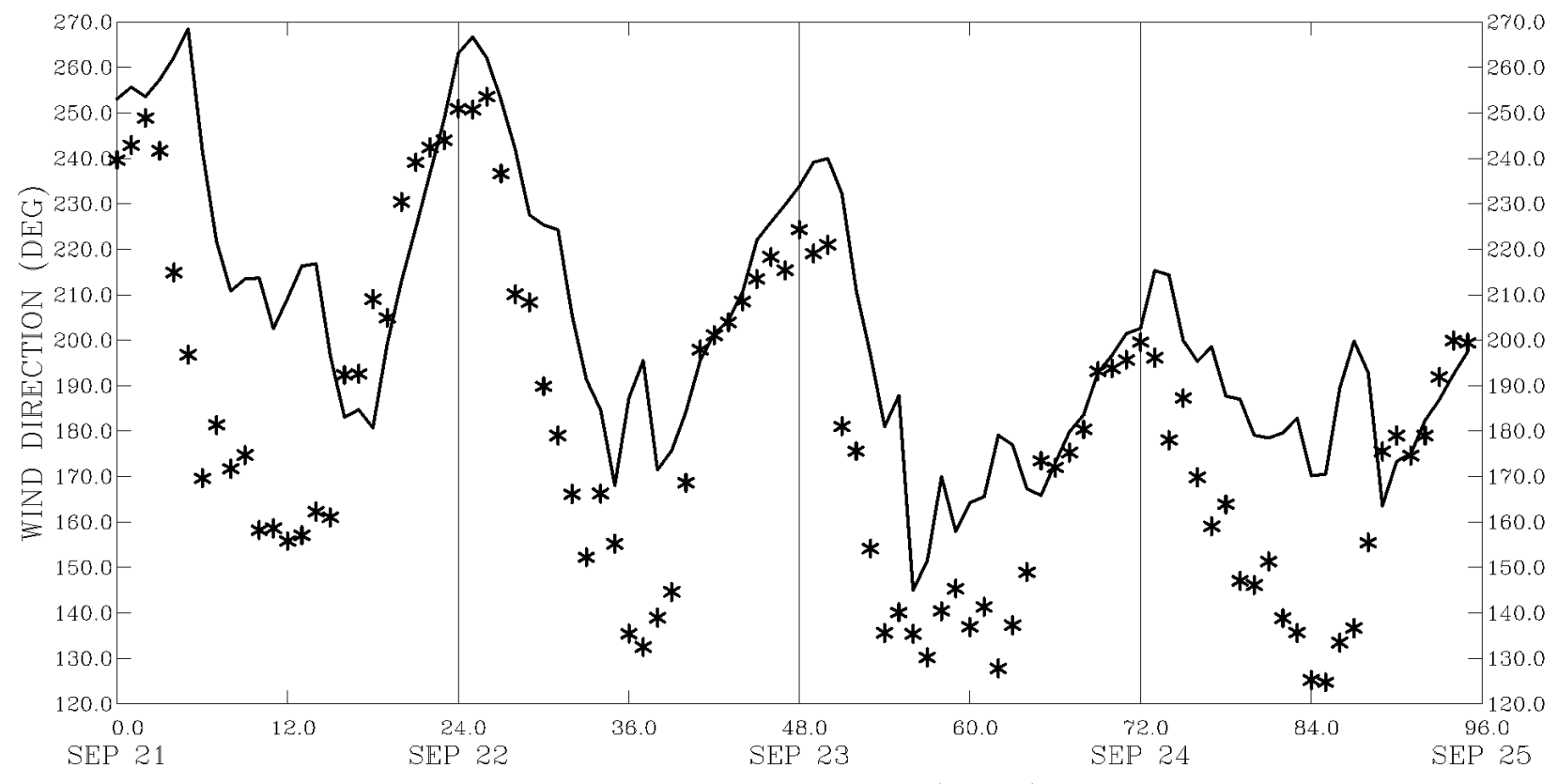

MODEL-RELATIVE TIME (HOUR)

All-station average

Figure 101. Evolution of domain-averaged surface-layer wind direction (deg.) at $12 \mathrm{~m} \mathrm{AGL}$ on the 5-km MM5 domain in the Standard Observation Nudging Experiment (Exp. 3) for 21-24 September 1997. Times shown on abscissa are forecast hours from the initial time, 0000 UTC, 21 September. Solid line is model-simulated mean, asterisks are hourly observed means. 
PLOT OF WIND DIRECTION (DEG) VS. TIME, EXPNAM= SCOS97 5KM EXP3 HRLYAVG LAYER $=80-1500 \mathrm{~m} \mathrm{AGL}$, DOMAIN $=5 \mathrm{~km}$

DATE/TIME RANGE = 21 SEP 1997, 0000Z-24 SEP 1997, 23007 MODEL HOUR RANGE $=0.0-95.0 \mathrm{~h}$

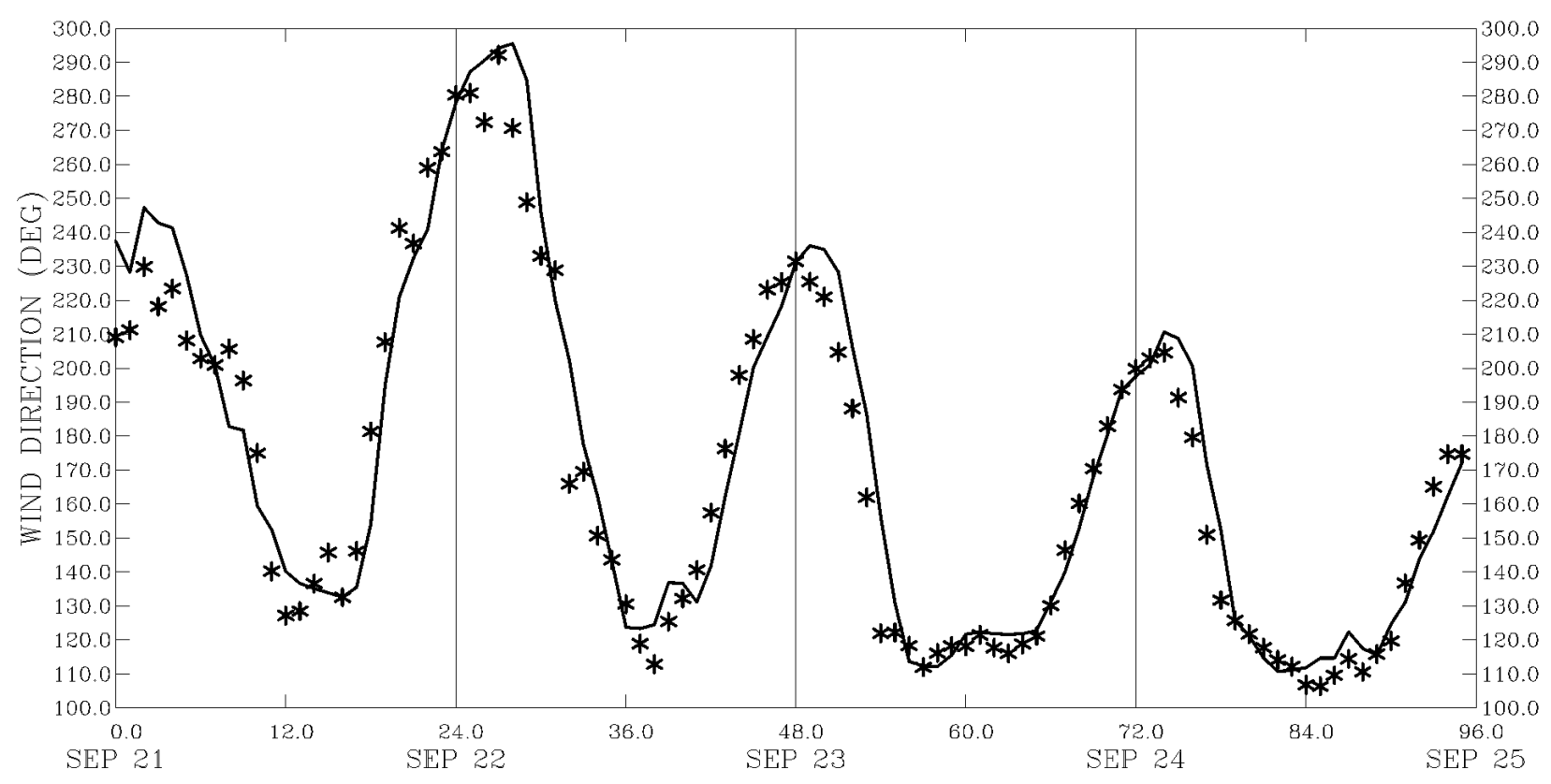

MODEL-RELATIVE TIME (HOUR)

All-station average

Figure 102. Evolution of domain-averaged wind direction (deg) in the layers from $25-1500 \mathrm{~m}$ AGL on the 5-km MM5 domain in the Standard Observation Nudging Experiment (Exp. 3) for 21-24 September 1997. Times shown on abscissa are forecast hours from the initial time, 0000 UTC, 21 September. Solid line is model-simulated mean, asterisks are hourly observed means. 
The interpretation of this result is best understood in view of the wind component plots (Figures 97-100) versus the density of the surface observations. That is, the dense observations are able to capture not only the mesoscale character of the winds, but they also contain local forcing by sub-grid scale terrain, trees, buildings, etc., that cannot possibly be represented by the model. In some grid boxes there can even be more than one surface observation and the winds at those stations can have very different directions due to these sub-grid effects. The mesoscale flow over regions the size of the airsheds, however, is simulated more accurately, as supported by the results shown in Figures 97-100. This interpretation is confirmed by the rapid reduction of direction errors in the layer from 25-1500 m AGL, compared to the surface layer. This zone is well within the region that can be influenced by the major ridges and mountains, which exceed $3000 \mathrm{~m}$ in some places. Despite these influences, the direction errors are reduced to about half the size of those at the surface. Therefore, the overall impact of the direction errors for air quality applications may not be very adverse.

\subsubsection{Additional Evaluation Details}

As noted previously, Exp. 3 represents the experiment design of greatest interest, as expressed by $\mathrm{ARB}$ in the RFP, and therefore the evaluations are more extensive and detailed than those presented for the other experiments. In addition to the standard analyses already presented, subregional performance statistics, spatial comparison plots, time-series plots, and wind profile plots were prepared. Many of these analyses are suitable for a use in a technical support document if the meteorological fields from this experiment are used for regulatory air quality modeling. While only a couple of examples are provided here, the complete set of analyses are available on the Analysis CD-ROM provided with this report.

Subregional Statistics - As requested in the RFP, subregional statistics were prepared for three areas: the Border (San Diego and Imperial counties), the Coast (Orange, Los Angeles, Ventura, and Santa Barbara counties), and the Desert (Riverside and San Bernardino counties). Table 11 includes sub-regional peak (values, times, lags, and ratios), mean error or bias (ME), error or mean absolute error (MAE), and correlation ( $\mathrm{R}$ and $\mathrm{R}^{2}$ ) statistics by day for level 1 wind speeds (WSPD), X and Y components of the wind (WINDX and WINDY), air temperatures (ATEMP), and mixing ratio (MRATIO). While there variations between variables, particularly on a normalized basis, the variations between sub-regions for any given variable are small. In general, the performance is best for temperatures and worst for winds. However, it should be noted that the observed winds during this episode are generally low and the normalized statistics exaggerate what otherwise might be considered poor performance. For example, the MAE for wind speed at border sites on 23 September is $1.2 \mathrm{~m} / \mathrm{s}$, which becomes $97 \%$ when normalized to observed wind speeds. 
Table 11. Sub-regional statistics for portions of the 5-km domain.

\begin{tabular}{|c|c|c|c|c|c|c|c|c|c|c|c|c|c|c|c|c|c|c|}
\hline \multirow[b]{2}{*}{ Variable } & \multirow[b]{2}{*}{ Units } & \multirow[b]{2}{*}{ YYYY } & \multirow[b]{2}{*}{ MM } & \multirow[b]{2}{*}{ DD } & \multirow[b]{2}{*}{ Region } & \multirow[b]{2}{*}{$\mathbf{N}$} & \multicolumn{2}{|c|}{\begin{tabular}{c|} 
Peak \\
Observed
\end{tabular}} & \multicolumn{2}{|c|}{$\begin{array}{c}\text { Peak } \\
\text { Predicted }\end{array}$} & \multirow[b]{2}{*}{$\mid \begin{array}{r}\text { Time } \\
\text { Lag }\end{array}$} & \multirow[b]{2}{*}{$\begin{array}{l}\text { Peak } \\
\text { Ratio }\end{array}$} & \multicolumn{6}{|c|}{ Comparisons with Observations } \\
\hline & & & & & & & Value & Time & Value & Time & & & ME & MAE & $\begin{array}{c}\text { Normalized } \\
\text { ME }\end{array}$ & $\begin{array}{c}\text { Normalized } \\
\text { MAE }\end{array}$ & $\mathbf{R}$ & $\mathbf{R}^{2}$ \\
\hline WSPD & $\mathrm{m} / \mathrm{s}$ & 1997 & 9 & 21 & BORD & 713 & 7.2 & 14 & 4.8 & 21 & -7 & \begin{tabular}{|l|}
0.67 \\
\end{tabular} & 0.0 & 1.0 & $21 \%$ & $64 \%$ & \begin{tabular}{|c|}
0.48 \\
\end{tabular} & 0.23 \\
\hline WSPD & $\mathrm{m} / \mathrm{s}$ & 1997 & 9 & 22 & BORD & 698 & 7.4 & 17 & 5.1 & 15 & 2 & 0.69 & -0.2 & 1.1 & $10 \%$ & $69 \%$ & 0.42 & 0.18 \\
\hline WSPD & $\mathrm{m} / \mathrm{s}$ & 1997 & 9 & 23 & BORD & 719 & 7.8 & 6 & 5.9 & 6 & 0 & 0.76 & -0.1 & 1.2 & $40 \%$ & $97 \%$ & 0.37 & 0.14 \\
\hline WSPD & $\mathrm{m} / \mathrm{s}$ & 1997 & 9 & 24 & BORD & 546 & 8.6 & 12 & 7.9 & 12 & 0 & 0.92 & -0.2 & 1.7 & $34 \%$ & $90 \%$ & 0.42 & 0.18 \\
\hline WSPD & $\mathrm{m} / \mathrm{s}$ & 1997 & 9 & 21 & DSRT & 617 & 10.8 & 10 & 8.3 & 7 & 3 & 0.77 & -0.2 & 1.8 & $49 \%$ & $99 \%$ & 0.22 & 0.05 \\
\hline WSPD & $\mathrm{m} / \mathrm{s}$ & 1997 & 9 & 22 & DSRT & 594 & 7.7 & 11 & 4.7 & 1 & 10 & 0.60 & \begin{tabular}{l|}
-0.3 \\
\end{tabular} & 1.6 & $30 \%$ & $88 \%$ & 0.03 & 0.00 \\
\hline WSPD & $\mathrm{m} / \mathrm{s}$ & 1997 & 9 & 23 & DSRT & 616 & 9.3 & 19 & 5.6 & 12 & 7 & 0.60 & -0.5 & 1.7 & $29 \%$ & $83 \%$ & 0.23 & 0.05 \\
\hline WSPD & $\mathrm{m} / \mathrm{s}$ & 1997 & 9 & 24 & DSRT & 467 & 18.5 & 17 & 8.2 & 17 & 0 & 0.44 & -0.5 & 2.0 & $38 \%$ & $89 \%$ & 0.38 & 0.14 \\
\hline WSPD & $\mathrm{m} / \mathrm{s}$ & 1997 & 9 & 21 & CSTL & 2069 & 14.9 & 23 & 10.0 & 9 & 14 & 0.67 & 0.0 & 1.6 & $48 \%$ & $93 \%$ & 0.39 & 0.15 \\
\hline WSPD & $\mathrm{m} / \mathrm{s}$ & 1997 & 9 & 22 & CSTL & 2013 & 14.5 & 0 & 8.7 & 2 & -2 & 0.60 & -0.1 & 1.5 & $41 \%$ & $90 \%$ & 0.31 & 0.10 \\
\hline WSPD & $\mathrm{m} / \mathrm{s}$ & 1997 & 9 & 23 & \begin{tabular}{|l|l|} 
CSTL \\
\end{tabular} & 2068 & 10.0 & 14 & 6.9 & 9 & 5 & 0.69 & -0.4 & 1.4 & $16 \%$ & $81 \%$ & 0.20 & 0.04 \\
\hline WSPD & $\mathrm{m} / \mathrm{s}$ & 1997 & 9 & 24 & 4 CSTL & 1556 & 12.4 & 10 & $\begin{array}{l}7.3 \\
\end{array}$ & 7 & 3 & (0.59 & -0.4 & 1.4 & $16 \%$ & $76 \%$ & 0.29 & 0.08 \\
\hline WINDX & $\mathrm{m} / \mathrm{s}$ & 1997 & 9 & 21 & BORD & 713 & 7.1 & 14 & 4.6 & 16 & -2 & 0.65 & 0.7 & 1.1 & $83 \%$ & $125 \%$ & 0.71 & 0.50 \\
\hline WINDX & $\mathrm{m} / \mathrm{s}$ & 1997 & 9 & 22 & BORD & 698 & 6.6 & 16 & 5.0 & 15 & 1 & 0.76 & 0.5 & 1.2 & $57 \%$ & $127 \%$ & 0.64 & 0.41 \\
\hline WINDX & $\mathrm{m} / \mathrm{s}$ & 1997 & 9 & 23 & BORD & 719 & 5.4 & 15 & 5.0 & 17 & -2 & \begin{tabular}{l|l}
0.93 \\
\end{tabular} & 0.4 & 1.3 & $34 \%$ & $132 \%$ & 0.62 & 0.38 \\
\hline WINDX & $\mathrm{m} / \mathrm{s}$ & 1997 & 9 & 24 & BORD & 546 & 7.1 & 14 & 5.4 & 14 & 0 & 0.76 & 0.8 & 1.9 & $31 \%$ & $246 \%$ & $\begin{array}{l}0.57 \\
\end{array}$ & 0.32 \\
\hline WINDX & $\mathrm{m} / \mathrm{s}$ & 1997 & 9 & 21 & DSRT & 617 & 6.0 & 6 & 4.6 & 17 & -11 & 0.77 & \begin{tabular}{|c|}
-0.3 \\
\end{tabular} & 1.5 & $-58 \%$ & $172 \%$ & 0.45 & 0.20 \\
\hline WINDX & $\mathrm{m} / \mathrm{s}$ & 1997 & 9 & 22 & DSRT & 594 & 6.4 & 17 & 3.9 & 1 & 16 & 0.61 & \begin{tabular}{l|}
0.3 \\
\end{tabular} & 1.5 & $-73 \%$ & $208 \%$ & 0.55 & 0.30 \\
\hline WINDX & $\mathrm{m} / \mathrm{s}$ & 1997 & 9 & 23 & DSRT & 616 & 5.4 & 14 & 3.7 & 6 & 8 & 0.69 & 0.5 & 1.8 & $-28 \%$ & $231 \%$ & 0.59 & 0.35 \\
\hline WINDX & $\mathrm{m} / \mathrm{s}$ & 1997 & 9 & 24 & DSRT & 467 & 5.4 & 13 & 4.0 & 6 & 7 & 0.74 & 0.5 & 2.2 & $-176 \%$ & $329 \%$ & 0.53 & 0.28 \\
\hline WINDX & $\mathrm{m} / \mathrm{s}$ & 1997 & 9 & 21 & CSTL & 2069 & 10.3 & 18 & 7.3 & 21 & -3 & 0.71 & 0.4 & 1.6 & $29 \%$ & $172 \%$ & 0.58 & 0.34 \\
\hline WINDX & $\mathrm{m} / \mathrm{s}$ & 1997 & 9 & 22 & CSTL & 2013 & 10.2 & 16 & 7.2 & 0 & 16 & 0.71 & 0.4 & 1.5 & $32 \%$ & $170 \%$ & 0.54 & 0.29 \\
\hline WINDX & $\mathrm{m} / \mathrm{s}$ & 1997 & 9 & 23 & $\begin{array}{ll}\text { CSTL } \\
\end{array}$ & 2068 & 9.3 & 19 & 4.5 & 18 & 1 & \begin{tabular}{l|l}
0.48 \\
\end{tabular} & 0.5 & 1.5 & $-11 \%$ & $158 \%$ & 0.45 & 0.20 \\
\hline WINDX & $\mathrm{m} / \mathrm{s}$ & 1997 & 9 & 24 & CSTL & 1556 & 11.8 & 13 & 4.8 & 15 & -2 & 0.41 & 0.1 & 1.6 & $-63 \%$ & $160 \%$ & 0.51 & 0.26 \\
\hline WINDY & $\mathrm{m} / \mathrm{s}$ & 1997 & 9 & 21 & BORD & 713 & 4.5 & 0 & 3.9 & 18 & -18 & 0.87 & 0.1 & 0.9 & $-126 \%$ & $200 \%$ & 0.41 & 0.17 \\
\hline WINDY & $\mathrm{m} / \mathrm{s}$ & 1997 & 9 & 22 & BORD & 698 & 4.1 & 18 & 3.7 & 19 & -1 & 0.90 & 0.3 & 1.0 & $-111 \%$ & $169 \%$ & 0.31 & 0.10 \\
\hline WINDY & $\mathrm{m} / \mathrm{s}$ & 1997 & 9 & 23 & BORD & 719 & 6.6 & 12 & 3.9 & 19 & -7 & 0.59 & 0.1 & 1.2 & $-69 \%$ & $178 \%$ & 0.26 & 0.07 \\
\hline WINDY & $\mathrm{m} / \mathrm{s}$ & 1997 & 9 & 24 & BORD & 546 & 6.2 & 17 & 3.2 & 16 & 1 & 0.52 & -0.2 & 1.3 & $-128 \%$ & $177 \%$ & 0.44 & 0.19 \\
\hline WINDY & $\mathrm{m} / \mathrm{s}$ & 1997 & 9 & 21 & DSRT & 617 & 7.2 & 15 & 3.5 & 23 & -8 & 0.49 & -0.1 & 1.9 & $-165 \%$ & $277 \%$ & 0.49 & 0.24 \\
\hline WINDY & $\mathrm{m} / \mathrm{s}$ & 1997 & 9 & 22 & DSRT & 594 & 6.0 & 22 & \begin{tabular}{l|}
4.1 \\
\end{tabular} & 23 & -1 & \begin{tabular}{l|l}
0.68 \\
\end{tabular} & \begin{tabular}{l|}
-0.3 \\
\end{tabular} & 1.5 & $-58 \%$ & $182 \%$ & 0.40 & 0.16 \\
\hline WINDY & $\mathrm{m} / \mathrm{s}$ & 1997 & 9 & 23 & \begin{tabular}{|l|l|} 
DSRT \\
\end{tabular} & 616 & 6.9 & 12 & 4.2 & 0 & 12 & 0.61 & \begin{tabular}{l|}
-0.2 \\
\end{tabular} & 1.7 & $-67 \%$ & $218 \%$ & 0.51 & 0.26 \\
\hline
\end{tabular}




\begin{tabular}{|c|c|c|c|c|c|c|c|c|c|c|c|c|c|c|c|c|c|c|}
\hline \multirow[b]{2}{*}{ Variable } & \multirow[b]{2}{*}{ Units } & \multirow[b]{2}{*}{ YYYY } & \multirow[b]{2}{*}{ MM } & \multirow[b]{2}{*}{ DD } & \multirow[b]{2}{*}{ Region } & \multirow[b]{2}{*}{$\mathbf{N}$} & \multicolumn{2}{|c|}{$\begin{array}{c}\text { Peak } \\
\text { Observed }\end{array}$} & \multicolumn{2}{|c|}{$\begin{array}{c}\text { Peak } \\
\text { Predicted }\end{array}$} & \multirow[b]{2}{*}{$\begin{array}{c}\text { Time } \\
\text { Lag }\end{array}$} & \multirow[b]{2}{*}{$\begin{array}{l}\text { Peak } \\
\text { Ratio }\end{array}$} & \multicolumn{6}{|c|}{ Comparisons with Observations } \\
\hline & & & & & & & Value & Time & Value & Time & & & ME & MAE & $\begin{array}{c}\text { Normalized } \\
\mathrm{ME}\end{array}$ & $\underset{\text { MAE }}{\text { Normalized }}$ & $\mathbf{R}$ & $\mathbf{R}^{2}$ \\
\hline WINDY & $\mathrm{m} / \mathrm{s}$ & 1997 & 9 & 24 & DSRT & 467 & 11.2 & 17 & 4.1 & 1 & 16 & $\begin{array}{l}0.37 \\
\end{array}$ & -0.2 & 1.7 & $-25 \%$ & $252 \%$ & 0.56 & 0.31 \\
\hline WINDY & $\mathrm{m} / \mathrm{s}$ & 1997 & 9 & 21 & CSTL & 2069 & 7.3 & 17 & 3.8 & 7 & 10 & $\begin{array}{l}0.52 \\
\end{array}$ & 0.0 & 1.7 & $-58 \%$ & $215 \%$ & 0.44 & 0.19 \\
\hline WINDY & $\mathrm{m} / \mathrm{s}$ & 1997 & 9 & 22 & CSTL & 2013 & 8.3 & 1 & 3.7 & 15 & -14 & \begin{tabular}{|l|}
0.45 \\
\end{tabular} & -0.1 & 1.5 & $-68 \%$ & $187 \%$ & 0.44 & 0.19 \\
\hline WINDY & $\mathrm{m} / \mathrm{s}$ & 1997 & 9 & 23 & CSTL & 2068 & \begin{tabular}{|l|}
10.0 \\
\end{tabular} & 14 & 5.0 & 20 & -6 & \begin{tabular}{|l|}
0.50 \\
\end{tabular} & -0.1 & 1.4 & $-49 \%$ & $166 \%$ & 0.35 & 0.12 \\
\hline WINDY & $\mathrm{m} / \mathrm{s}$ & 1997 & 9 & 24 & CSTL & 1556 & 9.2 & 16 & 4.3 & 16 & 0 & 0.47 & 0.0 & 1.4 & $-62 \%$ & $190 \%$ & 0.26 & 0.07 \\
\hline ATEMP & DegC & 1997 & 9 & 21 & BORD & 737 & 36.7 & 15 & 35.0 & 16 & -1 & 0.95 & 0.2 & 2.3 & $5 \%$ & $13 \%$ & 0.92 & 0.85 \\
\hline ATEMP & DegC & 1997 & 9 & 22 & BORD & 722 & 37.4 & 15 & 36.5 & 15 & 0 & 0.98 & -1.1 & 3.0 & $0 \%$ & $14 \%$ & 0.87 & 0.76 \\
\hline ATEMP & DegC & 1997 & 9 & 23 & BORD & 743 & 37.5 & 14 & 36.7 & 15 & -1 & 0.98 & -2.0 & 3.3 & $-5 \%$ & $14 \%$ & 0.85 & 0.72 \\
\hline ATEMP & DegC & 1997 & 9 & 24 & BORD & 563 & 38.5 & 11 & 37.0 & 14 & -3 & 0.96 & -0.6 & 3.5 & $0 \%$ & $14 \%$ & 0.68 & 0.46 \\
\hline ATEMP & DegC & 1997 & 9 & 21 & DSRT & 657 & 35.0 & 13 & 32.8 & 15 & -2 & $\begin{array}{l}0.94 \\
\end{array}$ & -0.3 & 2.5 & $2 \%$ & $14 \%$ & 0.86 & 0.74 \\
\hline ATEMP & DegC & 1997 & 9 & 22 & DSRT & 642 & 38.8 & 16 & 34.4 & 15 & 1 & 0.89 & -0.7 & 3.0 & $4 \%$ & $18 \%$ & 0.86 & 0.74 \\
\hline ATEMP & DegC & 1997 & 9 & 23 & DSRT & 664 & 38.8 & 14 & 35.7 & 16 & -2 & 0.92 & -1.2 & 2.9 & $-1 \%$ & $15 \%$ & 0.84 & 0.71 \\
\hline ATEMP & DegC & 1997 & 9 & 24 & DSRT & 503 & \begin{tabular}{|r|}
40.5 \\
\end{tabular} & 11 & 37.1 & 15 & -4 & 0.92 & -0.6 & 3.0 & $1 \%$ & $15 \%$ & 0.80 & 0.64 \\
\hline ATEMP & DegC & 1997 & 9 & 21 & CSTL & 2106 & \begin{tabular}{|l|}
36.1 \\
\end{tabular} & 14 & 33.5 & 16 & -2 & 0.93 & -0.9 & 3.1 & $1 \%$ & $16 \%$ & 0.77 & 0.59 \\
\hline ATEMP & DegC & 1997 & 9 & 22 & CSTL & 2057 & 38.3 & 13 & 33.4 & 15 & -2 & 0.87 & -1.4 & 3.2 & $-1 \%$ & $16 \%$ & 0.77 & 0.59 \\
\hline ATEMP & DegC & 1997 & 9 & 23 & CSTL & 2083 & \begin{tabular}{|l|}
40.0 \\
\end{tabular} & 13 & 37.3 & 16 & -3 & 0.93 & -2.1 & 3.6 & $-5 \%$ & $16 \%$ & 0.78 & 0.61 \\
\hline ATEMP & DegC & 1997 & 9 & 24 & CSTL & 1568 & \begin{tabular}{|l|}
39.0 \\
\end{tabular} & 14 & 37.8 & 15 & -1 & 0.97 & -1.4 & 3.3 & $-4 \%$ & $14 \%$ & 0.74 & 0.55 \\
\hline MRATIO & $\mathrm{g} / \mathrm{Kg}$ & 1997 & 9 & 21 & BORD & 449 & \begin{tabular}{|r|}
13.2 \\
\end{tabular} & 17 & 14.9 & 19 & -2 & 1.13 & 3.4 & 3.5 & $55 \%$ & $55 \%$ & 0.64 & 0.41 \\
\hline MRATIO & $\mathrm{g} / \mathrm{Kg}$ & 1997 & 9 & 22 & BORD & 435 & \begin{tabular}{|l|}
14.1 \\
\end{tabular} & 22 & 15.8 & 19 & 3 & 1.12 & 3.3 & 3.5 & $60 \%$ & $62 \%$ & 0.65 & 0.42 \\
\hline MRATIO & $g / \mathrm{Kg}$ & 1997 & 9 & 23 & BORD & 445 & 14.8 & 8 & 16.4 & 20 & -12 & \begin{tabular}{|l|}
1.11 \\
\end{tabular} & 3.4 & 3.5 & $64 \%$ & $66 \%$ & 0.63 & 0.40 \\
\hline MRATIO & $g / \mathrm{Kg}$ & 1997 & 9 & 24 & BORD & 332 & 24.4 & 9 & 15.4 & 0 & 9 & \begin{tabular}{|l|}
0.63 \\
\end{tabular} & 1.6 & 3.8 & $45 \%$ & $60 \%$ & 0.18 & 0.03 \\
\hline MRATIO & $\mathrm{g} / \mathrm{Kg}$ & 1997 & 9 & 21 & DSRT & 569 & 13.0 & 19 & 14.8 & 21 & -2 & \begin{tabular}{|l|}
1.14 \\
\end{tabular} & 2.4 & 2.5 & $57 \%$ & $59 \%$ & 0.70 & 0.49 \\
\hline MRATIO & $\mathrm{g} / \mathrm{Kg}$ & 1997 & 9 & 22 & DSRT & 546 & 9.6 & 0 & 15.3 & 21 & -21 & 1.59 & 2.0 & 2.2 & $49 \%$ & $53 \%$ & 0.60 & 0.36 \\
\hline MRATIO & $\mathrm{g} / \mathrm{Kg}$ & 1997 & 9 & 23 & DSRT & 568 & 10.2 & 11 & 16.1 & 22 & -11 & 1.58 & 1.5 & 1.8 & $37 \%$ & $41 \%$ & 0.46 & 0.21 \\
\hline MRATIO & $\mathrm{g} / \mathrm{Kg}$ & 1997 & 9 & 24 & DSRT & 431 & 10.9 & 17 & 13.7 & 0 & 17 & 1.26 & 1.5 & 1.8 & $37 \%$ & $41 \%$ & 0.40 & 0.16 \\
\hline MRATIO & $g / \mathrm{Kg}$ & 1997 & 9 & 21 & CSTL & 1239 & \begin{tabular}{|l|}
15.1 \\
\end{tabular} & 12 & 14.8 & 0 & 12 & $\begin{array}{l}0.98 \\
\end{array}$ & 3.7 & 3.8 & $65 \%$ & $66 \%$ & 0.54 & 0.29 \\
\hline MRATIO & $\mathrm{g} / \mathrm{Kg}$ & 1997 & 9 & 22 & CSTL & 1193 & \begin{tabular}{|r|}
15.6 \\
\end{tabular} & 14 & 14.6 & 22 & -8 & $\begin{array}{l}0.94 \\
\end{array}$ & 3.6 & 3.8 & $65 \%$ & $66 \%$ & 0.60 & 0.36 \\
\hline MRATIO & $\mathrm{g} / \mathrm{Kg}$ & 1997 & 9 & 23 & CSTL & 1227 & 16.6 & 17 & 14.8 & 20 & -3 & \begin{tabular}{|l|}
0.89 \\
\end{tabular} & 3.4 & 3.7 & $65 \%$ & $67 \%$ & 0.57 & 0.32 \\
\hline MRATIO & $g / \mathrm{Kg}$ & 1997 & 9 & 24 & CSTL & 923 & 15.5 & 9 & 15.4 & 17 & -8 & 0.99 & 2.8 & 3.1 & $54 \%$ & $57 \%$ & 0.52 & 0.27 \\
\hline
\end{tabular}


Spatial Comparisons - Spatial plots of winds, temperature, mixing ratio, and PBL height were prepared at three hour intervals. The MM5 results were plotted as vectors for winds and contours for scalar variables. Where available the observed values were over-plotted on the analysis at the observation site's location. Figure $\mathbf{1 0 3}$ shows an example spatial plot with the MM5 wind vectors plotted in blue and the observed winds plotted in red.

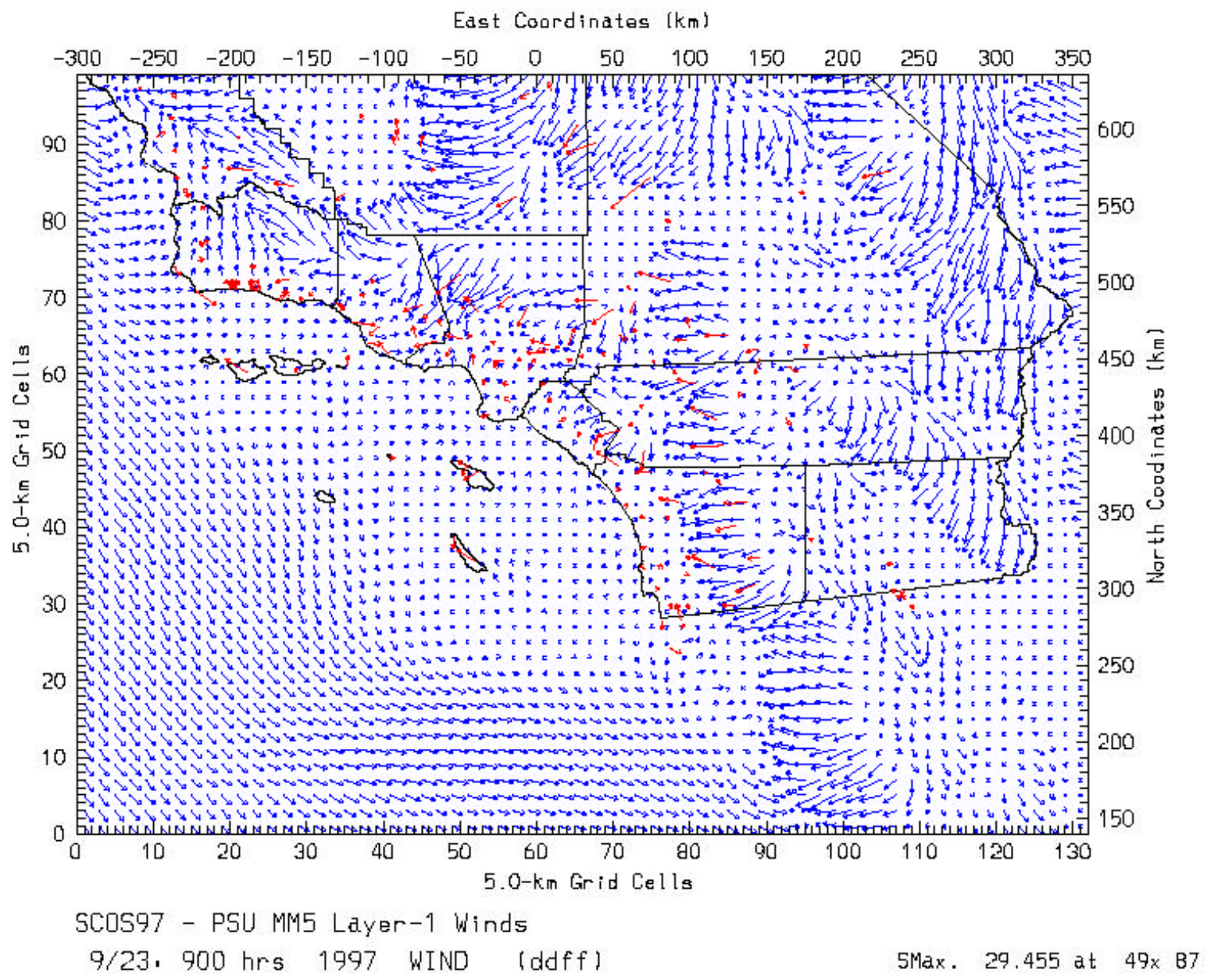

Figure 103. Example of spatial comparison plot, 0900 UTC, 23 September 1997.

Time series comparisons - Time series comparing observed values of mixing ratio, air temperature, wind speed, and wind direction, with the predictions from MM5 experiments 2, 2.5, and 3 were prepared for 155 observation sites. While continuous observed PBL heights were not available, predicted PBL heights were plotted for 26 RWP sites. Figure 104 is an example timeseries plot comparing observed and predicted meteorology at the University of Baja CaliforniaMexicali. 

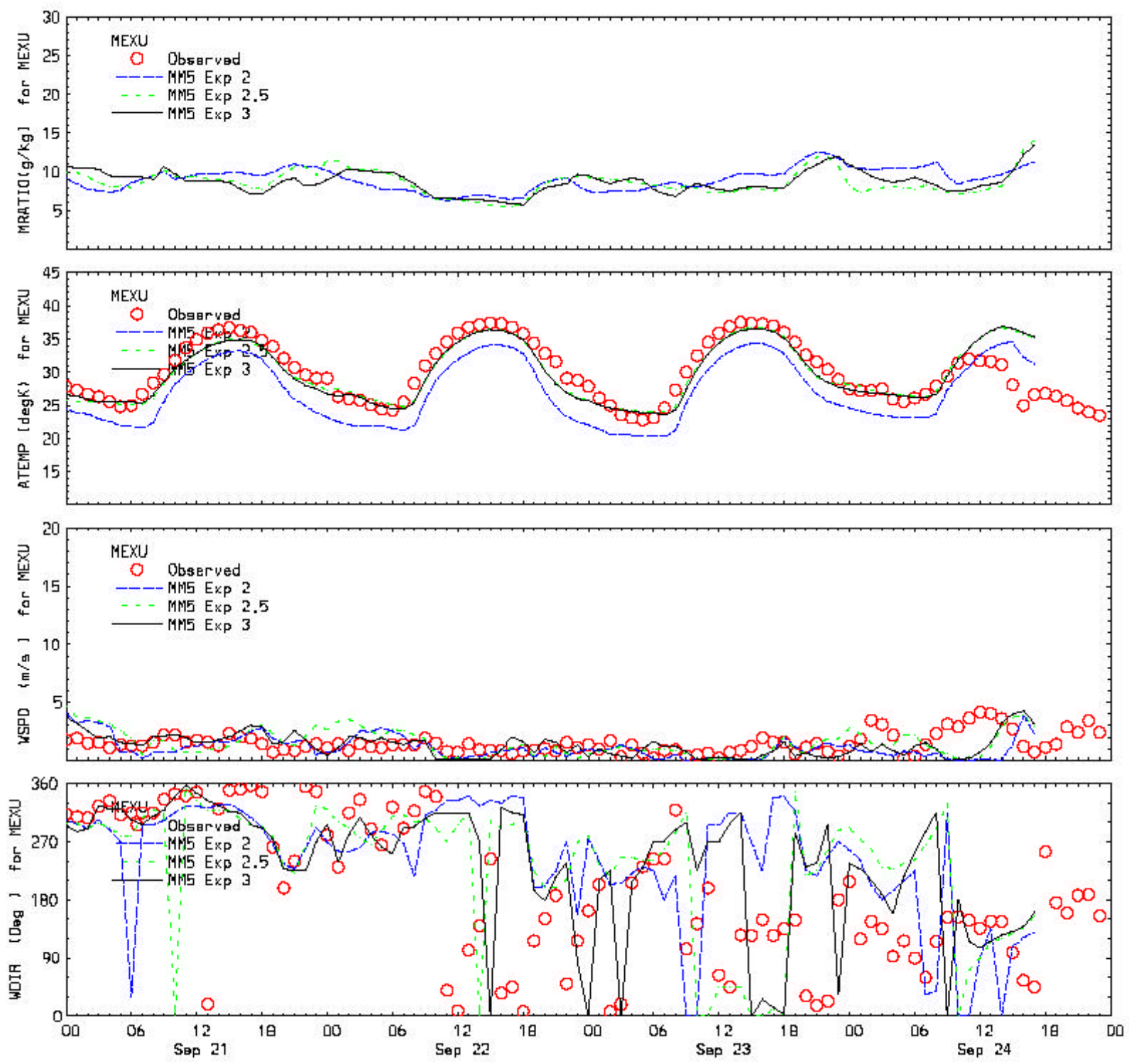

Figure 104. Example time-series plot comparing observed and predicted meteorology at the University of Baja California-Mexicali.

Wind Profile Comparisons - As a part of the data validation, wind profile plots of RWP data were prepared. As for the meteorological model evaluation, wind profiles for seven RWP sites were extracted from the MM5 results and plotted. Figures 105 and 106 are provided as examples of the observed and predicted wind profiles. These plots are typical of those reviewed in that the RWP and MM5 wind profiles match very well, which is to be expected since the RWP data were assimilated in this experiment. 


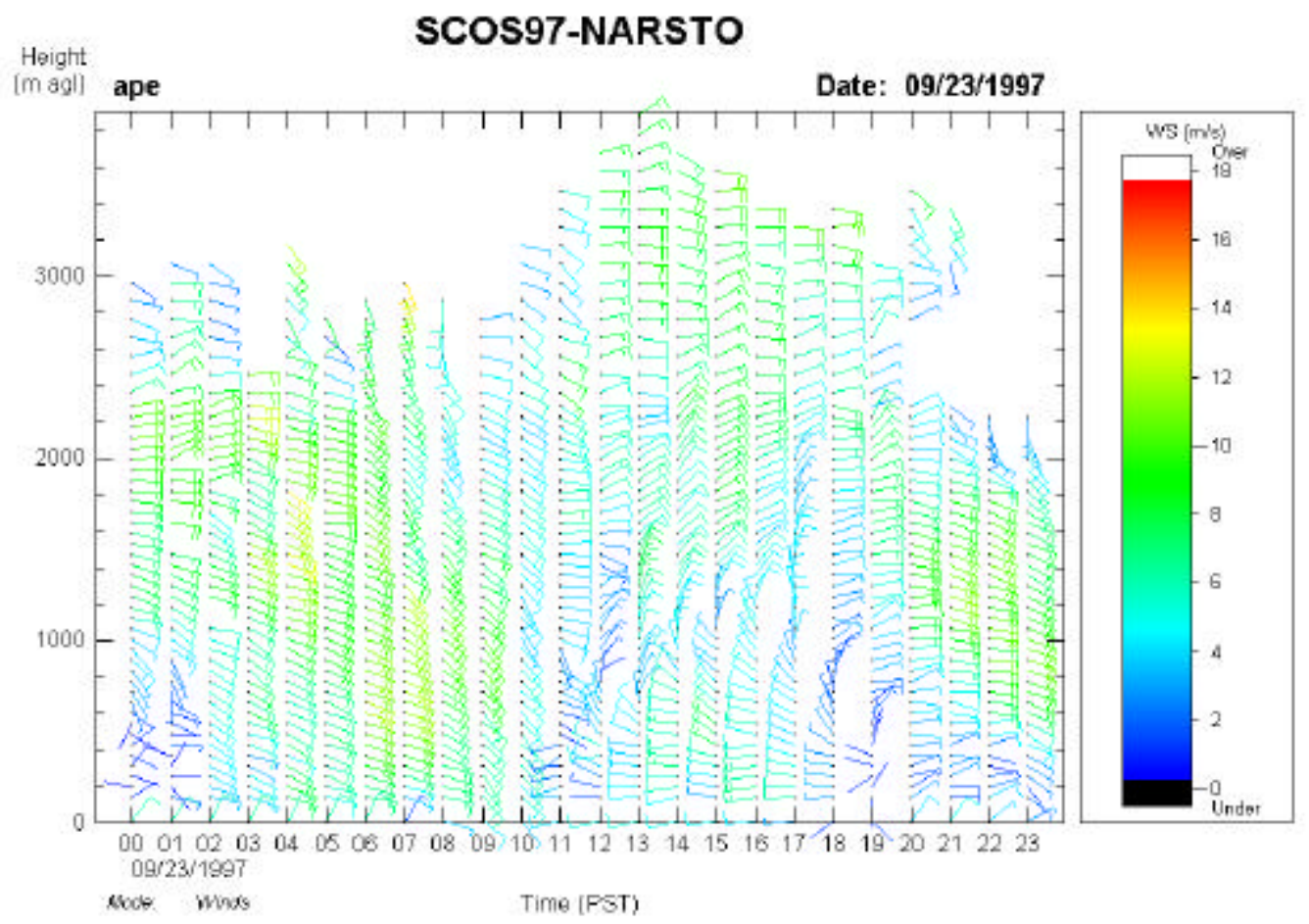

Figure 105. Observed wind profiles at the Alpine RWP site for 23 September 1997.

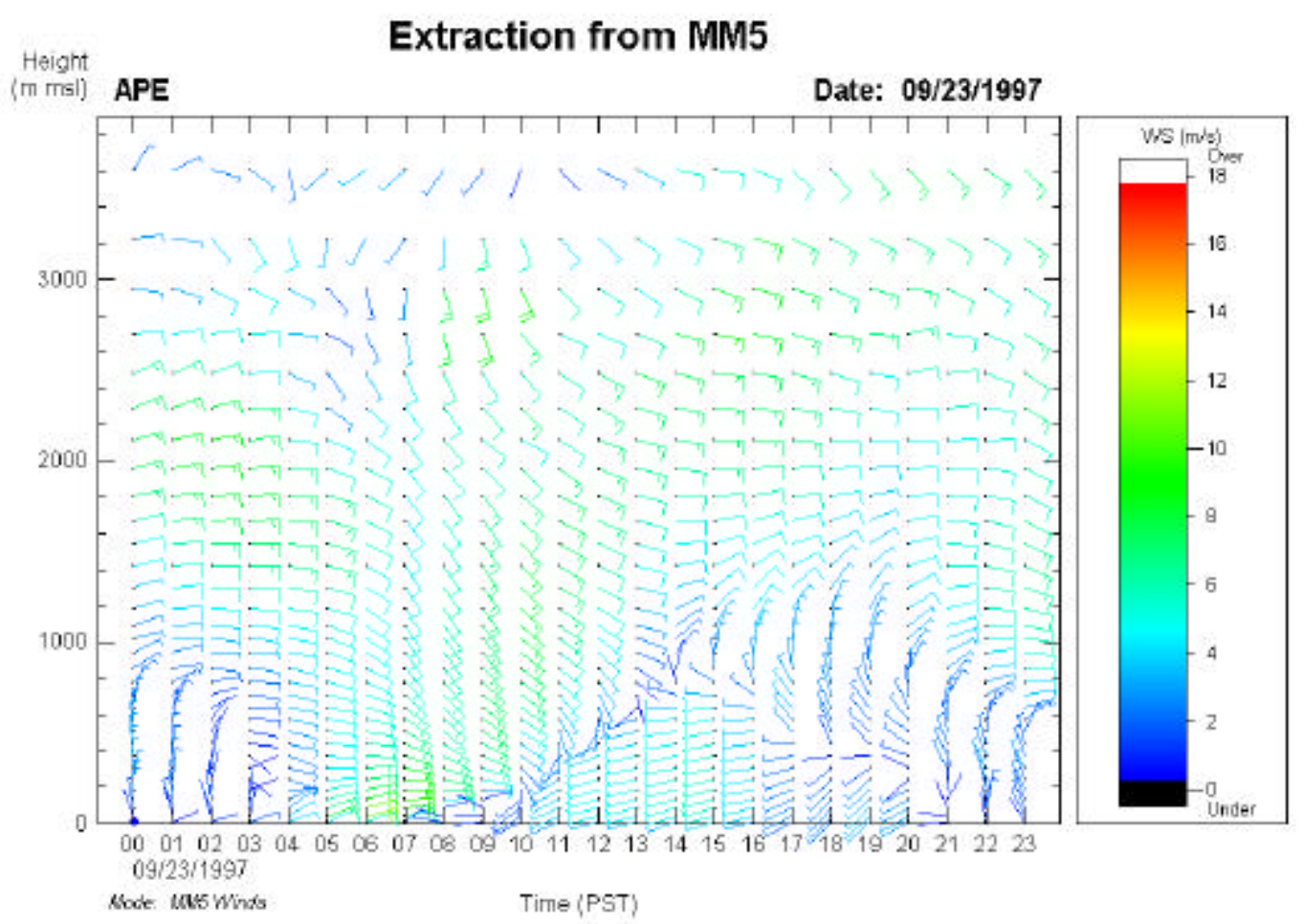

Figure 106. Predicted wind profiles at the Alpine RWP site for 23 September 1997 from MM5 Exp3. 


\subsection{Experiment 4: Observation Nudging Plus Surface Thermodynamic FDDA}

In the final experiment (Exp. 4) a recently developed approach (Alapaty et al. 2001) was used that allowed assimilation of surface temperature and moisture observations. This method has the potential for reducing the biases found in the surface-layer simulations of the thermodynamic variables discussed in earlier sections.

Generally, the impact of this modification on the observation nudging approach was confined to the surface layer, with only very small changes in the MM5 solutions aloft. Most of the changes occurred in the coastal air basins where the surface observations were most plentiful. However, since the changes were quite modest, even in the surface layer, we will forego presentation of any spatial plots of individual variable fields. Instead we will concentrate in this section on the statistical evaluations.

Figure 107 presents the hourly evolution of domain-averaged surface temperatures for the MM5 in Exp. 4 versus the observations. This figure can be compared to the similar evolution of domain-averaged temperatures in Exp. 3 (Figure 94). At first, these figures look very similar. However, careful examination of the periods close to the early morning minimums for the first two days shows that the surface nudging has resulted in somewhat smaller temperature errors in Exp. 4. Also, the somewhat warmer evening period on 24 September is simulated more accurately in Exp. 4. Contrary to these modest positive impacts, Exp. 4 produces no obvious improvement in the simulation of daytime temperature maximums. These results are reflected in Tables 10 and 12, which show the surface-layer temperature bias (ME) decreasing from $-0.89 \mathrm{C}$ in Exp. 3 to $-0.78 \mathrm{C}$ in Exp. 4. While the case-average bias reduction is not large, Figures 94 and 107 show that the domain-averaged errors decreased by as much as $1 \mathrm{C}$ at some particular times. This is a hopeful result, although certainly not dramatic. Meanwhile the reduction in RMS error in Exp. 4, relative to Exp. 3, is $0.20 \mathrm{C}$, or about $6 \%$ averaged over the entire period. Again, an hour-by-hour examination would show much greater reductions at certain times as noted above. 

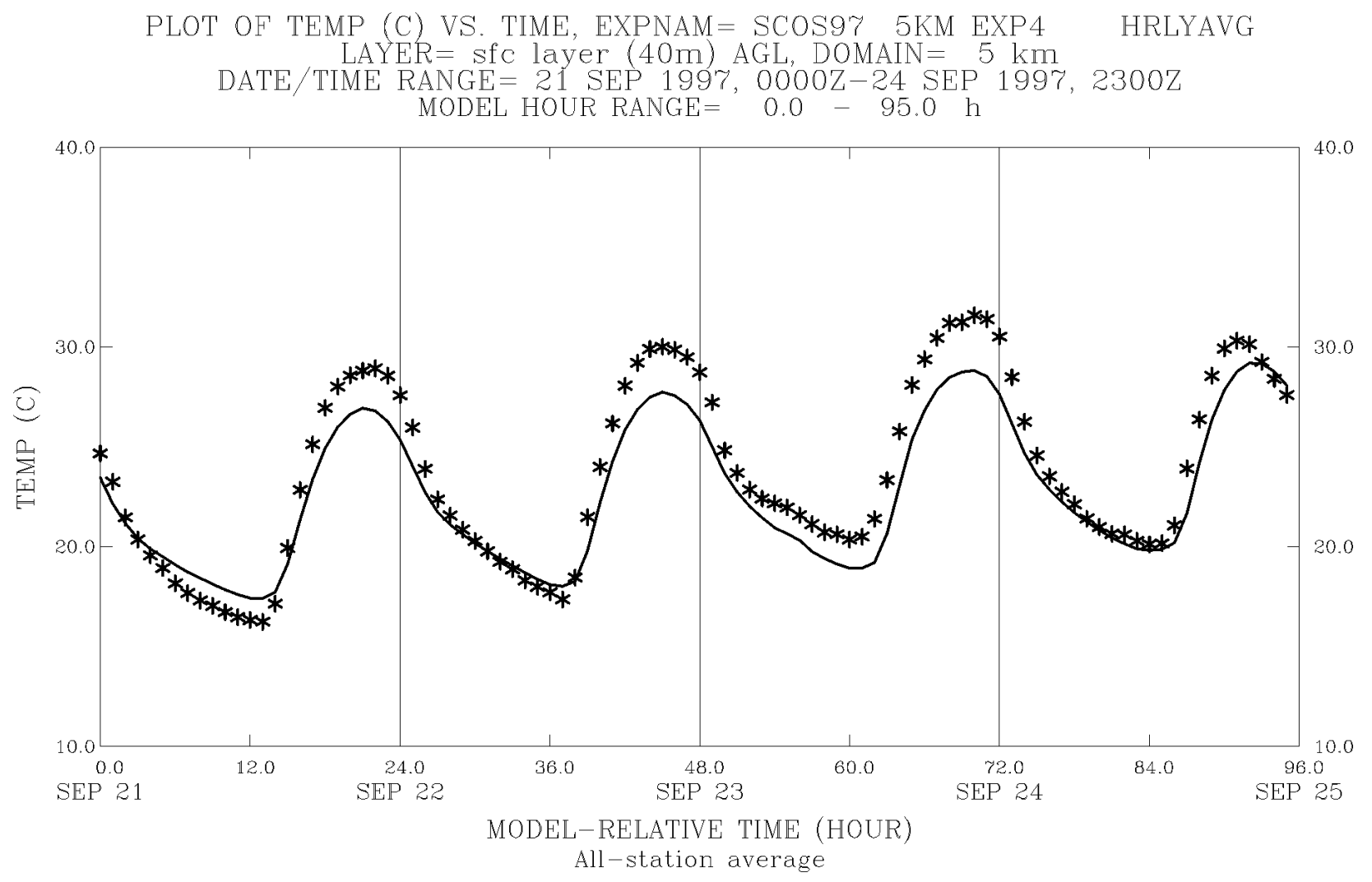

Figure 107. Evolution of domain-averaged surface-layer temperature (C) at $12 \mathrm{~m}$ AGL on the 5-km MM5 domain in the Observation Nudging Experiment Plus Surface Thermodynamic FDDA (Exp. 4) for 21-24 September 1997. Times shown on abscissa are forecast hours from the initial time, 0000 UTC, 21 September. Solid line is model-simulated mean; asterisks are hourly observed means. 
Next, Figure 108 shows the hourly evolution of the domain-averaged surface-layer mixing ratio for the model in Exp. 4 versus the observations. For comparison, Figure $\mathbf{6 3}$ shows the mixing ratio evolving hourly through the study period, as simulated in Exp. 2.5 (which produced moisture fields almost identical to those in Exp. 3). Unlike the temperature trends, comparison of Figures 108 and 63 reveals a large decrease in the mixing ratio errors. The error reduction is quite significant on all days and at all times. Tables 10 and 12 confirm that the mixing ratio bias has fallen from +2.68 in Exp. 3 to +1.83 in Exp. 4, or $32 \%$. Similar error reductions are evident in the RMS error.

Finally, Figures 109 and 110 depict the evolution of modeled and observed domain-averaged wind speed and direction, respectively, in the surface layer for Exp. 4. The same fields for Exp. 3 are shown in Figures 95 and 101. Recall that the surface wind observations were assimilated by the standard observation nudging method in both Exps. 3 and 4 . Therefore, as expected, the trends shown in these figures for speed and direction show no dramatic changes. More careful examination, however, suggests that at some hours there has been a non-trivial change. For example at $+12 \mathrm{~h}$, The domain-averaged wind direction in Exp. 4 (Figure 110) is about southerly (which is close to being correct), while it is southwesterly in Exp. 3 (Figure 101). But for many hours there is virtually no difference discernable in the two solutions for either speed or direction. Tables 10 and 12 reflect this generally benign response in the surface wind field, with very small case-averaged changes in either speed or direction. Above the surface, the impact on winds due to the assimilation of surface thermodynamic observations is negligible, as expected.

Interestingly, the change in wind direction near daybreak on the first day (mentioned above) can be explained, at least in part. It is at this time of day that the mean wind speeds in the coastal air basins typically approach their daily minimums. With land and sea temperatures being rather similar at this time, even small changes in the model's temperature predictions due to the surface thermal data assimilation can have a disproportionately large impact on the direction and strength of the comparatively weak early-morning thermal gradient vector along the coast. (By contrast, the thermal gradient vector in the afternoon is normally very large and is directed offshore, consistent with the strong afternoon sea breeze.) So, it is the direction of this thermal gradient vector that determines whether the coast experiences a land breeze or not. When the magnitude of the thermal gradient vector is weak, changes in its direction can be large and rapid. Thus, small changes in the temperature field at daybreak can have a more dramatic impact on the thermally driven wind direction compared to other times of day, as noted in Figures 101 and 110. 
Table 12. Statistical evaluation for Exp. 4 (Standard Observation-Nudging) for the SCOS97 episode of 21-24 September 1997. Statistics shown are mean errors (ME), mean absolute errors (MAE) and root mean square errors (RMS). Above the surface, statistics from individual MM5 calculation levels are merged into composite layers as weighted averages for the approximate boundary layer (25$1500 \mathrm{~m})$, lower troposphere $(1500-5000 \mathrm{~m})$ and upper troposphere $(5000-10500$ $\mathrm{m})^{*}$.

\begin{tabular}{|c|c|c|c|c|c|c|c|c|c|c|c|c|}
\hline \multirow[t]{2}{*}{$\begin{array}{c}\text { Verification } \\
\text { Layer (AGL) }\end{array}$} & \multicolumn{3}{|c|}{$\begin{array}{l}\text { Temperature } \\
\text { (C) }\end{array}$} & \multicolumn{3}{|c|}{$\begin{array}{c}\text { Mixing Ratio } \\
(\mathrm{g} / \mathrm{kg})\end{array}$} & \multicolumn{3}{|c|}{$\begin{array}{c}\text { Wind Speed } \\
(\mathrm{m} / \mathrm{s})\end{array}$} & \multicolumn{3}{|c|}{$\begin{array}{c}\text { Wind Direct. } \\
\text { (degrees) }\end{array}$} \\
\hline & $\overline{M E}$ & MAE & RMS & ME & MAE & RMS & ME & MAE & RMS & $\mathbf{M E}$ & MAE & RMS \\
\hline $5000-10500 \mathrm{~m}$ & -- & -- & -- & -- & -- & -- & -0.21 & 0.78 & 0.78 & -0.26 & 6.02 & 6.02 \\
\hline $1500-5000 \mathrm{~m}$ & -- & - & - & -- & - & -- & -0.29 & 1.26 & 1.55 & +0.65 & 15.0 & 19.2 \\
\hline $25-1500 \mathrm{~m}$ & -- & - & -- & - & -- & - & -0.28 & 1.22 & 1.58 & -2.50 & 27.0 & 38.0 \\
\hline $12 \mathrm{~m} \mathrm{AGL}$ & -0.78 & 2.53 & 3.24 & +1.83 & 2.15 & 2.79 & -0.61 & 1.35 & 1.80 & -1.02 & 48.9 & 65.8 \\
\hline
\end{tabular}

* Note that no statistics appear for the temperature and mixing ratio above the surface because the 5-km model domain did not have supplemental upper-air measurement systems during SCOS-97 capable of taking observations for these variables more often than twice per day. Winds aloft are obtained from up to 27 radar wind profilers operated during the study period. 

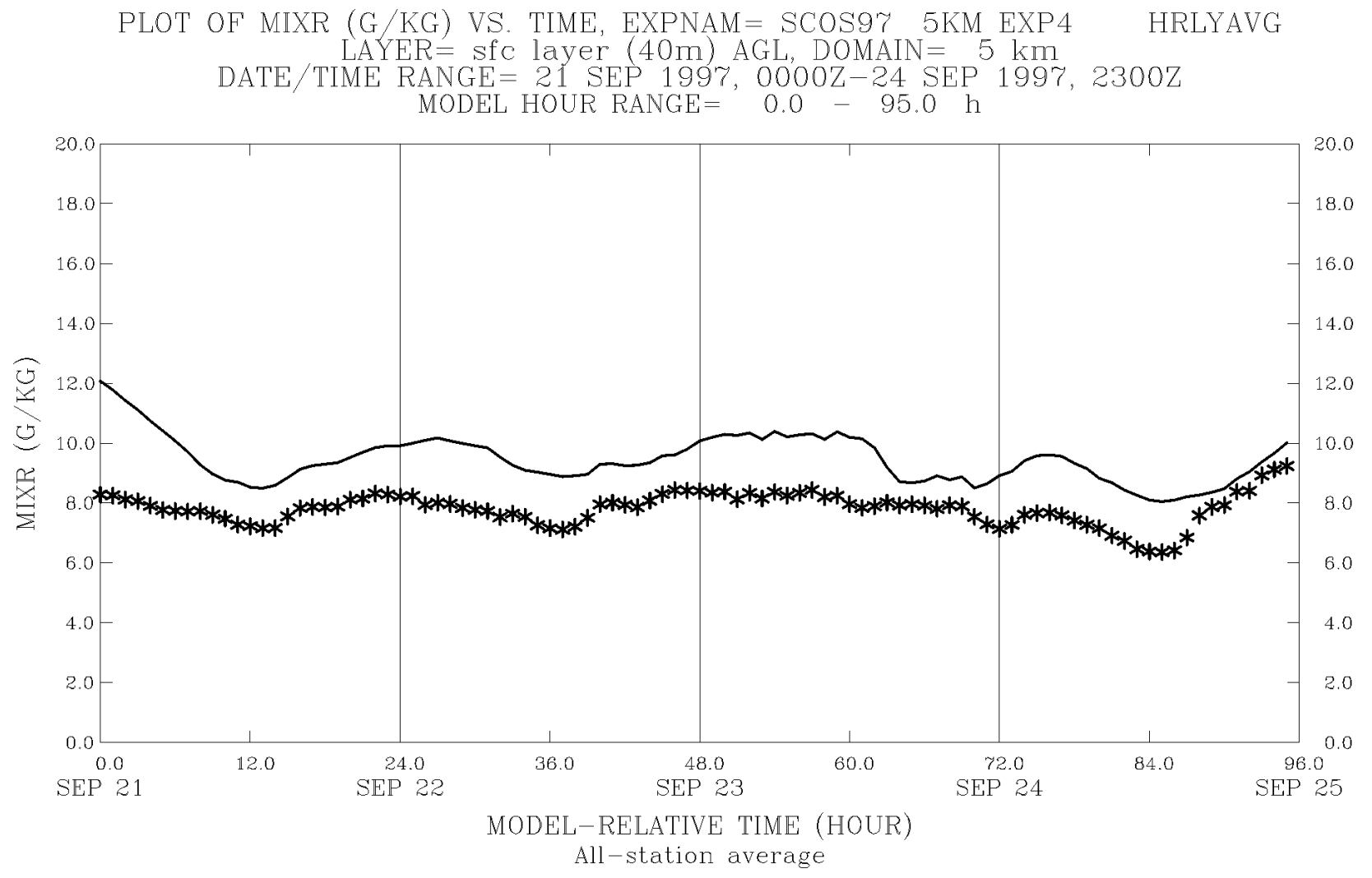

Figure 108. Evolution of domain-averaged surface-layer mixing ratio $\left(\mathrm{g} \mathrm{kg}^{-1}\right)$ at $12 \mathrm{~m}$ AGL on the 5-km MM5 domain in the Observation Nudging Experiment Plus Surface Thermodynamic FDDA (Exp. 4) for 21-24 September 1997. Times shown on abscissa are forecast hours from the initial time, 0000 UTC, 21 September. Solid line is model-simulated mean; asterisks are hourly observed means. 
PLOT OF WIND SPEED (M/S) VS. TIME, EXPNAM= SCOS97 5KM EXP4 HRLYAVG

LAYER = sfe layer (40m) AGL, DOMAIN $=5 \mathrm{~km}$

DATE/TIME RANGE= 21 SEP 1997, 0000Z-24 SEP 1997, $2300 Z$

MODEL HOUR RANGE $=0.0-95.0 \mathrm{~h}$

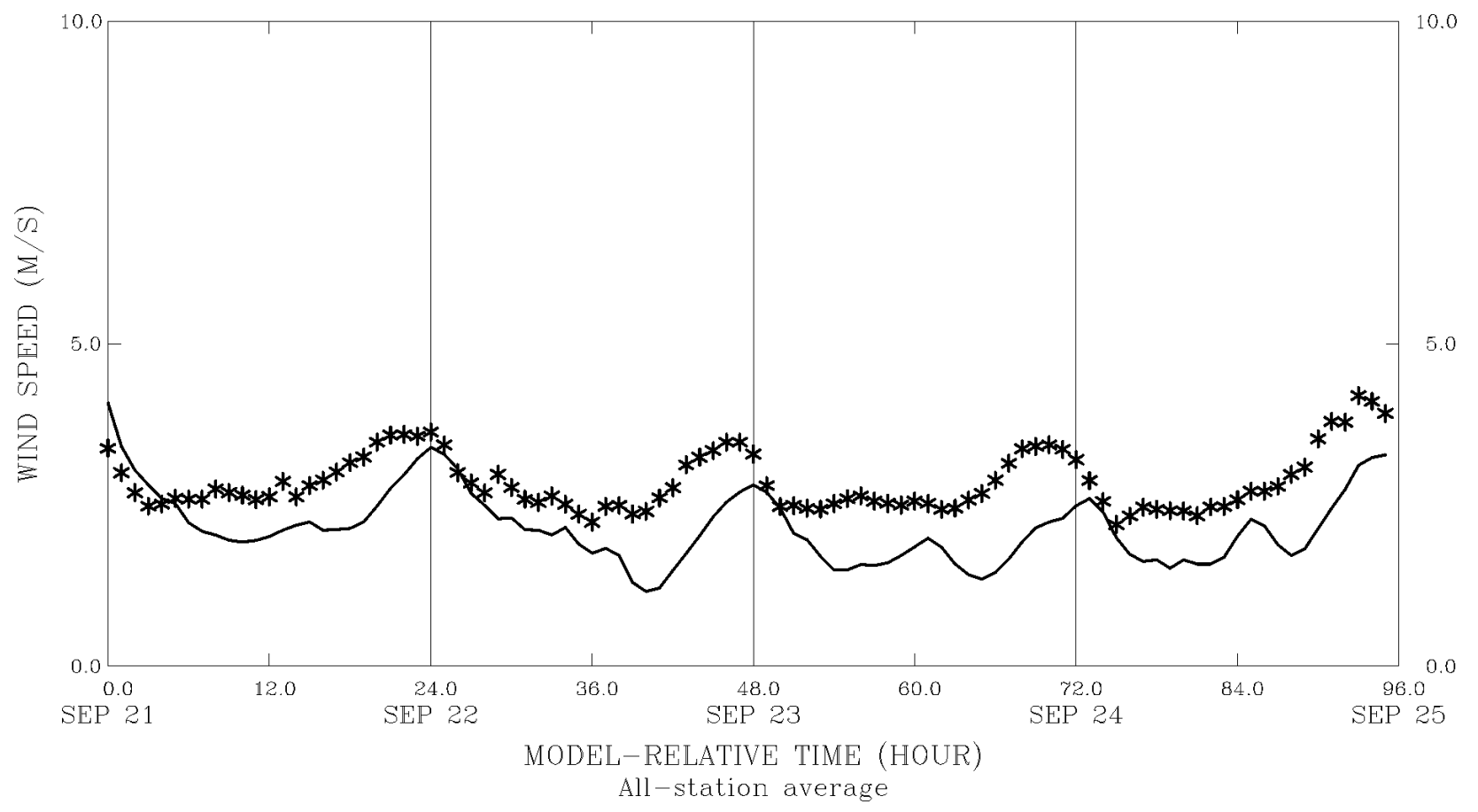

Figure 109. Evolution of domain-averaged surface-layer wind speed $\left(\mathrm{ms}^{-1}\right)$ at $12 \mathrm{~m} \mathrm{AGL} \mathrm{on}$ the 5-km MM5 domain in the Observation Nudging Experiment Plus Surface Thermodynamic FDDA (Exp. 4) for 21-24 September 1997. Times shown on abscissa are forecast hours from the initial time, 0000 UTC, 21 September. Solid line is model-simulated mean; asterisks are hourly observed means. 
PLOT OF WIND DIRECTION (DEG) VS. TIME, EXPNAM= SCOS97 5KM EXP4 HRLYAVG

LAYER $=$ sfc layer $(40 \mathrm{~m})$ AGL, DOMAIN $=5 \mathrm{~km}$

DATE/TIME RANGE= 21 SEP 1997, 0000Z-24 SEP 1997, 2300Z MODEL HOUR RANGE $=0.0-95.0 \mathrm{~h}$

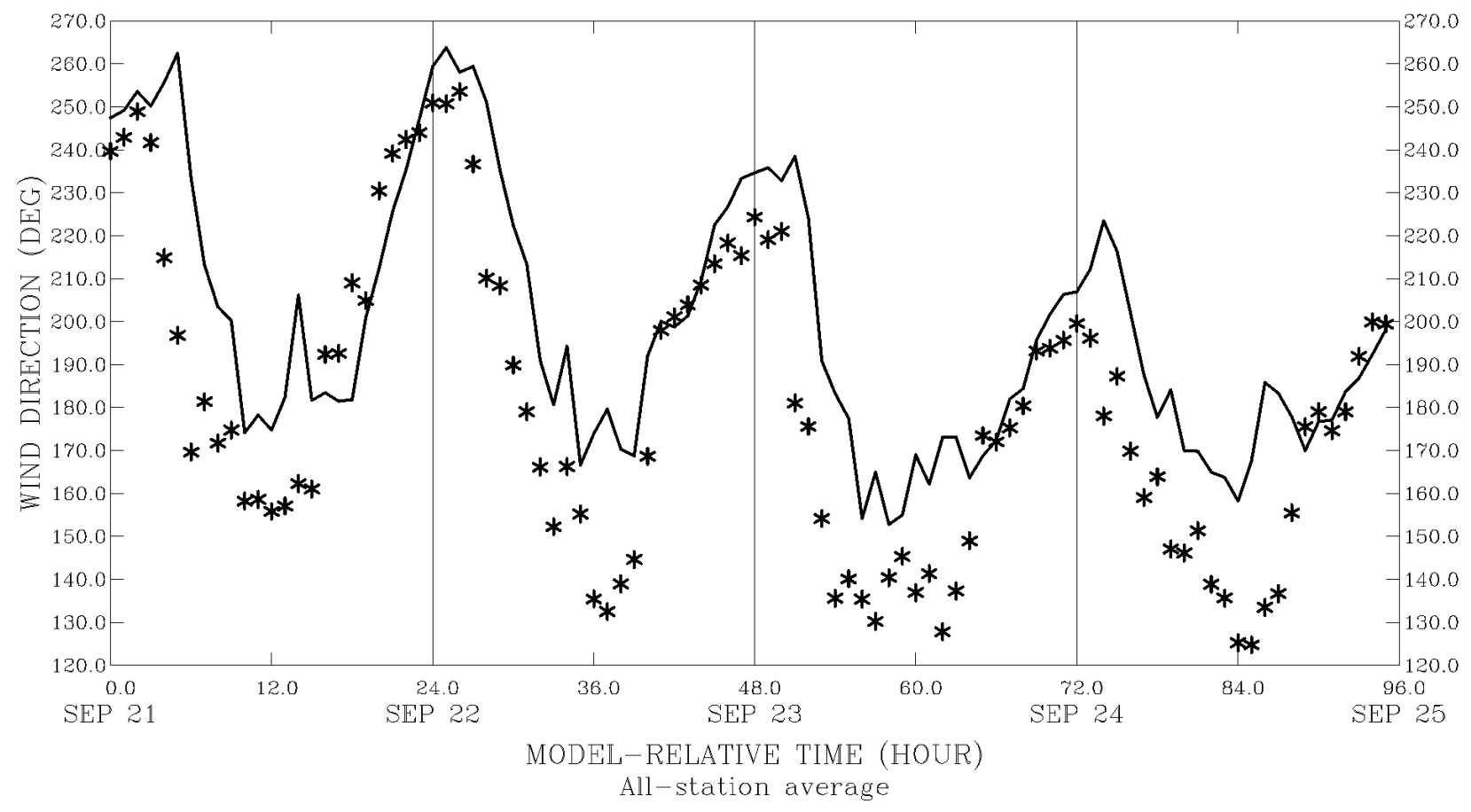

Figure 110. Evolution of domain-averaged surface-layer wind direction (deg.) at $12 \mathrm{~m}$ AGL on the 5-km MM5 domain in the Observation Nudging Experiment Plus Surface Thermodynamic FDDA (Exp. 4) for 21-24 September 1997. Times shown on abscissa are forecast hours from the initial time, 0000 UTC, 21 September. Solid line is model-simulated mean, asterisks are hourly observed means. 


\section{SUMMARY}

\subsection{Main Conclusions of the Study}

- The SCOS-97 September 21-25 air-quality episode was dominated by the passage of an upper-level ridge on 22-23 September that caused mid-level winds to shift from northwesterly to southeasterly over the SoCAB and the border areas near Mexico. As a result of the ridge passage, northwesterly boundary-layer winds from the Pacific Ocean were weakened and airflow in the SoCAB stagnated, leading to elevated levels of ozone. The southeasterly winds became slightly stronger on 23 September, which caused heavily polluted air to be transported west-northwest from Los Angeles to Ventura and Santa Barbara counties. At the same time temperatures rose several degrees $\mathrm{C}$ in the coastal basins due to reduced onshore advection of cool marine air, plus the westward advection of warm air from the southeastern CA deserts. During the second half of the episode a tropical storm that had been slowly progressing northward from the southern tip of the Baja Peninsula began to affect the SoCAB and border areas. The tropical storm caused southeasterly winds to intensify and by 24 September, subtropical moist air penetrated into the SoCAB. The increasing winds and clouds prevented active photochemistry and caused airborne chemical species to be advected rapidly out of the region, so that ozone levels dropped dramatically, bringing the episode to an end on 24 September.

- The Control Experiment 1 for the SCOS-97 September 21-25 episode was successful inasmuch as no large systematic errors developed in the winds that would suggest serious imbalances in the dynamical forcing of the MM5 model. However, there were serious cold biases on the order of $4 \mathrm{C}$ in the model solutions that did affect adversely the intensity of the sea breeze circulation and precluded the development of nocturnal land breezes. Thus, the model's thermodynamic errors along the coast could have moderately negative impacts on the advection of pollutants in and from the coastal air basins during the early and middle parts of the episode, before the influence of the tropical storm began to dominate the SoCAB.

- Using only standard analysis nudging Experiment 2 significantly reduced errors in the wind speed, but did not have much impact on the temperature or wind direction errors. Temperatures on average remained too cool by about $4 \mathrm{C}$. The cause of the cool temperatures was diagnosed to be due to a combination of two factors. First, NASA 9-km resolution sea-surface temperature images indicated that the NCEP seasurface temperature analysis was too cool by 2-6 C over much of the CA Bight. Second, default values for the MM5's deep-soil temperatures were quite likely too cool for this late-September episode, which falls around the time of maximum deepsoil temperatures expected near the end of summer. 
- Experiment 2.5 tested the hypothesis that erroneously cool land and sea-surface temperature specifications caused MM5's air-temperature simulations to average $4 \mathrm{C}$ too cold in Experiments 1 and 2. The deep soil temperature was raised to $4 \mathrm{C}$ above the climatological average and NCEP sea-surface temperatures were replaced by NASA sea temperatures observed at 9-km resolution. This experiment included the analysis nudging used in Exp. 2. Results showed dramatic improvement in the MM5simulated temperature field, with MAE dropping from $4.4 \mathrm{C}$ to $2.8 \mathrm{C}$. However, because of the warmer ocean temperatures, mixing ratio also rose, introducing a lowlevel moist bias of $\sim 3 \mathrm{gkg}^{-1}$. More important from an air-quality perspective, the changes made to the lower boundary conditions allowed the model to simulate a weak offshore-directed land breeze during the hours near sunrise. This change in the winds was confirmed by a number of 1200 UTC observations on the morning of 22 September.

- Experiment 3 used the modified lower boundary conditions, plus both obs-nudging and analysis nudging. The resulting model solutions had domain-averaged RMS errors for surface-layer wind speed of $1.78 \mathrm{~ms}^{-1}$. Because the average wind speed was very slow in the coastal air basins, where most of the observation sites are located, the MAE for surface-layer wind-direction error in Exp. 3 was 51 degrees. However, these direction errors appear to be more related mostly to the influence of surface irregularities (trees, buildings, hills, etc.) in light-wind conditions than to serious systematic model errors. Also, the very light mean winds caused the normalized wind speed errors to appear relatively large. In the layer from 25-1500 m AGL, where small surface irregularities have less effect, the MAE for direction dropped to 27 degrees, with an RMS error of wind speed $=1.60 \mathrm{~ms}^{-1}$. On the other hand, despite the improvement of the lower-boundary conditions, the MAE for surface temperature remained somewhat larger than desired, $\mathrm{MAE}_{\mathrm{T}}=2.73 \mathrm{C}$. Overall, this experiment produced the best match to observations of the standard FDDA approaches. Moreover, Experiment 3 did fairly well in capturing the shift of wind directions that occurred as the upper-level ridge passed over the SoCAB and the acceleration of southeast winds on 24 September due to the approach of the tropical storm from the south.

- Experiment 4 extended Exp. 3 by adding the method developed by Alapaty et al. (2001) for assimilating surface temperature and mixing ratio data. This experiment was only moderately successful. The MAE for surface temperature on the $5-\mathrm{km}$ domain was decreased further to $2.53 \mathrm{C}$ (larger corrections occurred at times of the day when model errors had been greatest) and mixing ratio errors were lower (MAE = $2.15 \mathrm{~g} \mathrm{~kg}^{-1}$ ). The wind statistics were virtually unchanged relative to Exp. 3. Thus, results of Exp. 4 were also quite successful, producing the best low-level temperature and moisture solutions, and therefore should be suitable for air-quality modeling applications. 


\subsection{Recommendations for Future Research}

The 21-25 September 1997 episode revealed that the methods for defining the lower boundary conditions in the MM5 over southern CA should be re-evaluated. The default method for estimating deep-soil temperatures and soil moisture tends to have significant biases. A more physically realistic land-surface model might be a valuable addition to the representation of the thermal and moisture processes in the MM5. Work on this topic has been underway in the MM5 community for some time. NCAR has installed a new five-layer land surface scheme that allows soil moisture content to vary with time. At the time that the present SCOS-97 modeling study was begun, the methodology for initializing soil moisture for the new land surface scheme was not yet mature enough to ensure accurate results, especially for the complex conditions in the LA Basin and its surroundings. However, recent advancements have introduced an upgraded version of the scheme that can be initialized with improved estimates of soil temperature and moisture produced by a similar land-surface model (LSM) run by NCEP. It is recommended that this new community land-surface model (called $\mathrm{NOAH}$ ) should be tested and evaluated specifically for the SoCAB environment. It is possible that this LSM, in combination with improved satellitemeasured sea-surface temperatures as used in the present study, could provide significant improvements for simulating the thermodynamics of the SoCAB.

During the project kick-off meeting in Sacramento, Penn State had agreed to consider an optional 1.667-km inner domain over the LA Basin and Santa Barbara Channel. This very-high resolution domain would be run for one experiment (most likely the base-case simulation, Exp. 3 ), only if time and resources allowed, and if model evaluations indicated that the 5-km domain was not resolving the flow in the September 21-24, 1997, episode.

It is possible that a $1.667-\mathrm{km}$ inner domain might have provided some additional details of flow between the coastline of the Santa Barbara Channel and the ridges and valleys lying to its north. Table 11 indicates that some local areas of the $5-\mathrm{km}$ domain do have larger errors than others, although there are no specific results for the Santa Barbara - San Fernando Valley region. However, time and resources were exhausted by the completion of the first five experiments. Nevertheless, it could be worth running the higher-resolution domain envisioned by ARB. That step should be undertaken only after further evaluation of the observed and simulated winds in the particular area that would be covered by a $1.667-\mathrm{km}$ mesh domain. 


\section{REFERENCES}

Alapaty, K., N.L. Seaman, D.S. Niyogi, and A.F. Hanna, 2001 Assimilating Surface Data to Improve the Accuracy of Atmospheric Boundary Layer Simulations. In press, J. Appl. Meteor., 40, $32 \mathrm{pp}$.

Benjamin, S.G., and N.L. Seaman, 1985: A simple scheme for objective analysis in curved flow. Mon. Wea. Rev., 113, 1184-1198.

Bornstein, R.D., D. Boucouvala, J. Wilkinson, A. Yadav, N.L. Seaman, D.R. Stauffer, G.K. Hunter, and D. Miller, 2001: Improvement and evaluation of the mesoscale meteorological model MM5 for air-quality applications in southern California and the San Joaquin Valley. Final Report to CA Air Resource Board, Contract No. 97-310. [Available from ARB, 2020 L St., P.O. Box 2815, Sacramento, CA, 95812]

Byun, D.W. and Ching, J.K.S., 1999: Science Algorithms of the EPA Models-3 Community Multiscale Air Quality (CMAQ) Modeling System, EPA/660R-99/030, U.S. Environmental Protection Agency, ORD, Research Triangle Park, NC, March 1999.

Chang, J.S., R.A. Brost, I.S.A. Isaksen, S. Madronich, P. Middleton, W.R. Stockwell, and C.J. Walcek, 1987: A three-dimensional Eulerian acid deposition model. Physical concepts and formulation. J. Geophys. Res., 92, 14681-14700.

Dudhia, J., 1989: Numerical study of convection observed during the winter monsoon experiment using a mesoscale two-dimensional model. J. Atmos. Sci., 46, 3077-3107.

Dudhia, J., 1993: A nonhydrostatic version of the Penn State-NCAR mesoscale model: Validation tests and simulation of an Atlantic cyclone and cold front. Mon. Wea. Rev., 121, 1493-1513.

ENVIRON, 2000: User's Guide - Comprehensive Air Quality Model with Extensions (CAMx) Version 3.00, ENVIRON International Corporation, Novato, CA, December 2000.

Gayno, G.A., N.L. Seaman, A.M. Lario and D.R. Stauffer, 1994: Forecasting Visibility Using a 1.5-Order Closure Boundary Layer Scheme in a 12-km Non-Hydrostatic Model. 10th AMS Conference on Numerical Weather Prediction, July 18-22, Portland, Oregon, 18-20.

Grell, G.A., 1993: Prognostic evaluation of assumptions used by cumulus parameterizations. Mon. Wea. Rev., 121, 764-787.

Kain, J. S., and J. M. Fritsch, 1990: A one dimensional entraining/detraining plume model and its application to convective parameterization. J. Atmos. Sci., 47, 2784-2802.

Mellor, G.L. and T. Yamada, 1974: A Hierarchy of Turbulence Closure Models for Planetary Boundary-Layers. J. Atmos. Sci., 31, 1791-1806. 
Michelson, S.A. and N.L. Seaman, 2000: Assimilation of NEXRAD-VAD Winds in Meteorological Simulations over the Northeast U.S., J. Appl. Meteor., 39, 367-383.

Mueller P.K. and Watson J.G., 1982: Eastern regional air quality measurements. Vol. 1, Section 7. Report prepared by Electric Power Research Institute, Palo Alto, CA, Report No. EA1914.

Pleim, J.E., J.S. Chang, and K. Zhang, 1991: "A nested grid mesoscale atmospheric chemistry model". J. Geophys. Research, 96, 3065-3084.

Seaman, N.L., 2000: Meteorological Modeling for Air-Quality Assessments. Atmospheric Environment, 34, 2231-2259.

Seaman, N.L. and S.A. Michelson, 2000: Mesoscale Meteorological Structure of a High-Ozone Episode during the 1995 NARSTO-Northeast Study. J. Appl. Meteor., 39, 384-398.

Seaman, N.L., D.R. Stauffer and A.M. Lario-Gibbs, 1995: A Multi-Scale Four-Dimensional Data Assimilation System Applied in the San Joaquin Valley During SARMAP: Part I: Modeling Design and Basic Performance Characteristics. J. Appl. Meteor., 34, 17391761.

Shafran, P.C., N.L. Seaman and G.A. Gayno, 2000: Evaluation of Numerical Predictions of Boundary-Layer Structure during the Lake Michigan Ozone Study (LMOS). J. Appl. Meteor., 39, 412-426.

Stauffer, D. R. and N. L. Seaman, 1990: Use of four-dimensional data assimilation in a limitedarea mesoscale model. Part I: Experiments with synoptic-scale data. Mon. Wea. Rev., $118,1250-1277$.

Stauffer, D.R. and N.L. Seaman, 1994: On Multi-Scale Four-Dimensional Data Assimilation. $J$. Appl. Meteor., 33, 416-434.

Stauffer, D.R., and N.L. Seaman, 1999: Intercomparison of turbulence parameterizations for simulating coastal-zone marine boundary layer structure. Preprints, Third Conference on Coastal Atmospheric and Oceanic Prediction Processes, New Orleans, Amer. Meteor. Soc., 7-12.

Stauffer, D.R., N.L. Seaman and F.S. Binkowski, 1991: Use of Four-Dimensional Data Assimilation in a Limited-Area Mesoscale Model. Part II: Effects of Data Assimilation Within the Planetary Boundary Layer. Mon. Wea. Rev., 119, 734-754.

Stauffer, D.R., R.C. Munoz and N.L. Seaman, 1999: In-cloud turbulence and explicit microphysics in the MM5. Preprints, Ninth PSU/NCAR MM5 Modeling System Users' Workshop, Boulder, Colorado, June 23-24, 177-180. 
Stauffer, D.R., N.L. Seaman, G.K. Hunter, S.M. Leidner, A.M. Lario-Gibbs and S. Tanrikulu, 2000: A field-coherence technique for meteorological field-program design for airquality studies. Part I: Description and interpretation. J. Appl. Meteor., 39, 297-316.

Tanrikulu, S., D.R. Stauffer, N.L. Seaman, and A.J. Ranzieri, 2000: A field-coherence technique for meteorological field-program design for air-quality studies. Part II: Evaluation in the San Joaquin Valley. J. Appl. Meteor., 39, 317-334.

Tesche, T.W., D.E. McNally, N.L. Seaman and D.R. Stauffer, 1997: The use of the San Joaquin Valley Meteorological Model in Preparation of a Field Program in the South Coast Air Basin and Surrounding Regions of Southern California. Vol. I: Final MM5 Evaluation for the 3-6 August 1990 SARMAP Episode. Final Report, ARB Contract 94-730, Available from Technical Support Division, ARB, Sacramento, CA,

USEPA, 1999: Draft Guidance on the Use of Models and Other Analyses in Attainment Demonstrations for the 8-Hour Ozone NAAQS, EPA-454/R-99-004, U.S. Environmental Protection Agency, OAQPS, Research Triangle Park, NC, May 1999.

Watson J.G., Lioy P.J., and Mueller P.K., 1989: The measurement process: precision, accuracy, and validity. In Air Sampling Instruments for Evaluation of Atmospheric Contaminants, 7th Edition, Hering S.V., ed., American Conference of Governmental Industrial Hygienists, Cincinnati, OH, pp. 51-57.

Zhang, D.-L. and R.A. Anthes, 1982: A high-resolution model of the planetary boundary layer - Sensitivity tests and comparisons with SESAME-79 data. J. Appl. Meteor., 21, 1594-1609. 